\title{
Instrumented, Shielded Test Canister System for Evaluation of Spent Nuclear Fuel in Dry Storage
}

by

R. L. Sindelar

Westinghouse Savannah River Company

Savannah River Site

Aiken, South Carolina 29808

D. J. Pak

P. J. French

R. F. Eakle

W. S. Large

K. Chen

\author{
RECEIVED
}

NOV 151999

OSTI

DOE Contract No. DE-AC09-96SR18500

This paper was prepared in connection with work done under the above contract number with the U. S.

Department of Energy. By acceptance of this paper, the publisher and/or recipient acknowledges the U.S.

Government's right to retain a nonexclusive, royalty-free license in and to any copyright covering this paper, along with the right to reproduce and to authorize others to reproduce all or part of the copyrighted paper. 


\section{Instrumented, Shielded Test Canister System} $\therefore$ for Evaluation of Spent Nucleár Fuel

\section{in Dry :Storage (U)-}

R. L. Sindelar, D. J. Pak, P. J. French, R. F. Eakle, W. S. Large, and K. Chen

Savannah River Technology Center and

Spent Fuel-Storage Division

Publication Date: September 1997

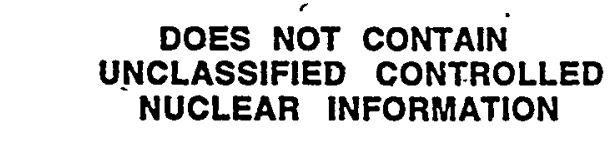

ADC \&

Reviewing Official:

$\bar{Y}$

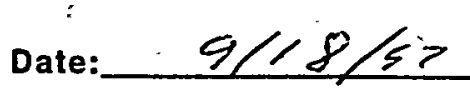

Westinghouse Savannah River Company Savannah River Site Aiken, SC 29808

This document was prepared in connection with work done under Contract No. DE-AC09-96SR18500 with the U. S. Department of Energy 


\section{DISCLAIMER}

This report was prepared as an account of work sponsored by an agency of the United States Government. Neither the United States Government nor any agency thereof, nor any of their employees, makes any warranty, express or implied, or assumes any legal liability or responsibility for the accuracy, completeness, or usefulness of any information, apparatus, product, or process disclosed, or represents that its use would not infringe privately owned rights. Reference herein to any specific commercial product, process, or service by trade name, trademark, manufacturer, or otherwise does not necessarily constitute or imply its endorsement, recommendation, or favoring by the United States Government or any agency thereof. The views and opinions of authors expressed herein do not necessarily state or reflect those of the United States Government or any agency thereof.

This report has been reproduced directly from the best available copy.

Available to DOE and DOE contractors from the Office of Scientific and Technical Information, P.O. Box 62, Oak Ridge, TN 37831; prices available from (615) 576-8401.

Available to the public from the National Technical Information Service, U.S. Department of Commerce; 5285 Port Royal Road, Springfield, VA 22161. 


\section{DISCLAIMER}

Portions of this document may be illegible in electronic image products. Images are produced from the best available original document. 
DOCUMENT:

TITLE:

TASK:

\section{APPROVALS}

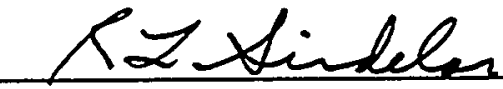

Date: $\quad 9-16-97$

R.L. Sindelar, Editor and Author

SRTC/Strategic Materials Technology Department/Materials Technology Section

D. T. Pak, Author

SRTC/Engineered Equipment \& Systems Department/Remote \& Specialty Equipment Systems

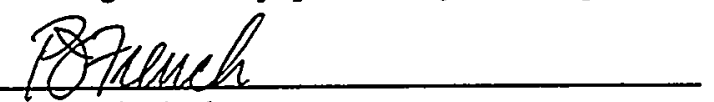

Date: $9 / 16 / 97$

P. J. French, Author

SRTC/Engineered Equipment \& Systems Department/Remote \& Specialty Equipment Systems
RF Kakle

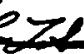
Date: $9-16-97$

R.. F. Eakle, Author

SRTC/Engineered Equipment \& Systems Department/Instrumentation \& Examination
W. \&. Large, Author
Date: $9 / 16 / 97$
SPENT FUEL STORAGE DIVISION/Reactor Engineering Department
Bouper CO
Date: $9 / 16 / 97$
K. Chen, Author
SRTCAM Aeasurements Technology Department

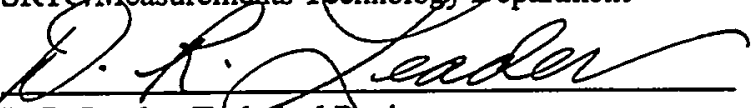
D. R. Leader, Teenthical Rkviewer

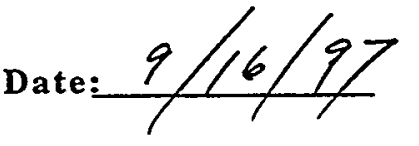

SRTC/Strategic Materials Technology Department/Materials Technology Section

$$
\text { inat } \frac{1}{2}
$$

Date: $9 / 18 / 97$

N. C. Tyer, SRTC-Spent Nuluear Fuel Manager

Manager, Materials Applications \& Corrosion Technology Group

SRTC/Strategic Materials Technology Department/Materials Technology Section

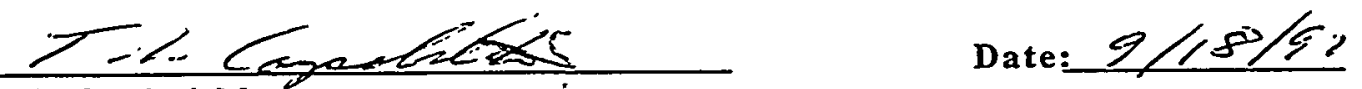

T. L. Capeletti, Manager

SRTC/Strategic Materials Technology Department/Materials Technology Section

J. R. Murphy

Date: $9 / 16 / 97$

SPENT FUEL STORAGE DIVISION 


\section{(Blank Page)}




\section{EXECUTIVE SUMMARY}

This document describes the development of an instrumented, shielded test canister system to store and monitor aluminum-based spent nuclear fuel (Al SNF) under dry storage conditions. The document is organized into the following three parts:

Part I: $\quad$ Objectives for Tests Using Instrumented Canisters

Part II: $\quad$ Design and Fabrication of the Instrumented, Shielded Test Canister System

Part III: $\quad$ Vacuum Drying of Al SNF for Canister Storage

The primary test objectives using the instrumented canisters are to:

- $\quad$ validate drying and storage criteria for road-ready storage;

- $\quad$ validate corrosion models;

- $\quad$ validate gas release models;

- validate heat transfer analysis methodology; and

- $\quad$ provide lead-assembly-surveillance for a dry storage system.

These objectives will be achieved following.the loading of Materials Test Reactor type (MTR) fuel assembly into the canister and the analysis of data collected under the test environmental conditions of storage.

An instrumented, shielded test canister system has been designed and fabricated (see photograph below). The canister can house an MTR assembly in a sealed dry storage configuration and is instrumented to measure and record the following parameters during storage to characterize the environment internal to the canister and the fuel materials response:

- fuel clad and air space temperatures

- $\quad$ gas species (released from fuel; corrosion reaction products)

- pressure

- relative humidity

- fuel material visual condition

The canister is capable of being dried to any desired level. Tests to demonstrate unheated vacuum drying of the test canister containing a mock Materials Test Reactor fuel assembly and water have been performed. The results show that free water can be removed to a minimal vapor. A vacuum of less than 5 torr at room temperature is readily achievable, meeting the site-established criteria for road-ready storage. Drying of a representative Foreign Research Reactor/Domestic Research Reactor (FRR/DRR) MTR assembly using the unheated vacuum drying technique will be performed as part of the validation testing.

The instrumented test canister system design is one-of-a-kind in capability to monitor the storage environmental conditions and the response of nuclear fuel in a dry storage system. In calendar year 1998, two canisters will be loaded with FRR MTR assemblies; dried using unheated vacuum drying; backfilled with air and a finite level of water corresponding to the environmental limit prescribed for dry storage; sealed; and staged in the SRS L-

disassembly dry cave. These actions will be performed following preparation of the area and documentation of safety reviews. Data will be accessible at the staged location, and also remotely via computer network. The response of the SNF to varying environmental conditions will be monitored to validate the storage criteria. 


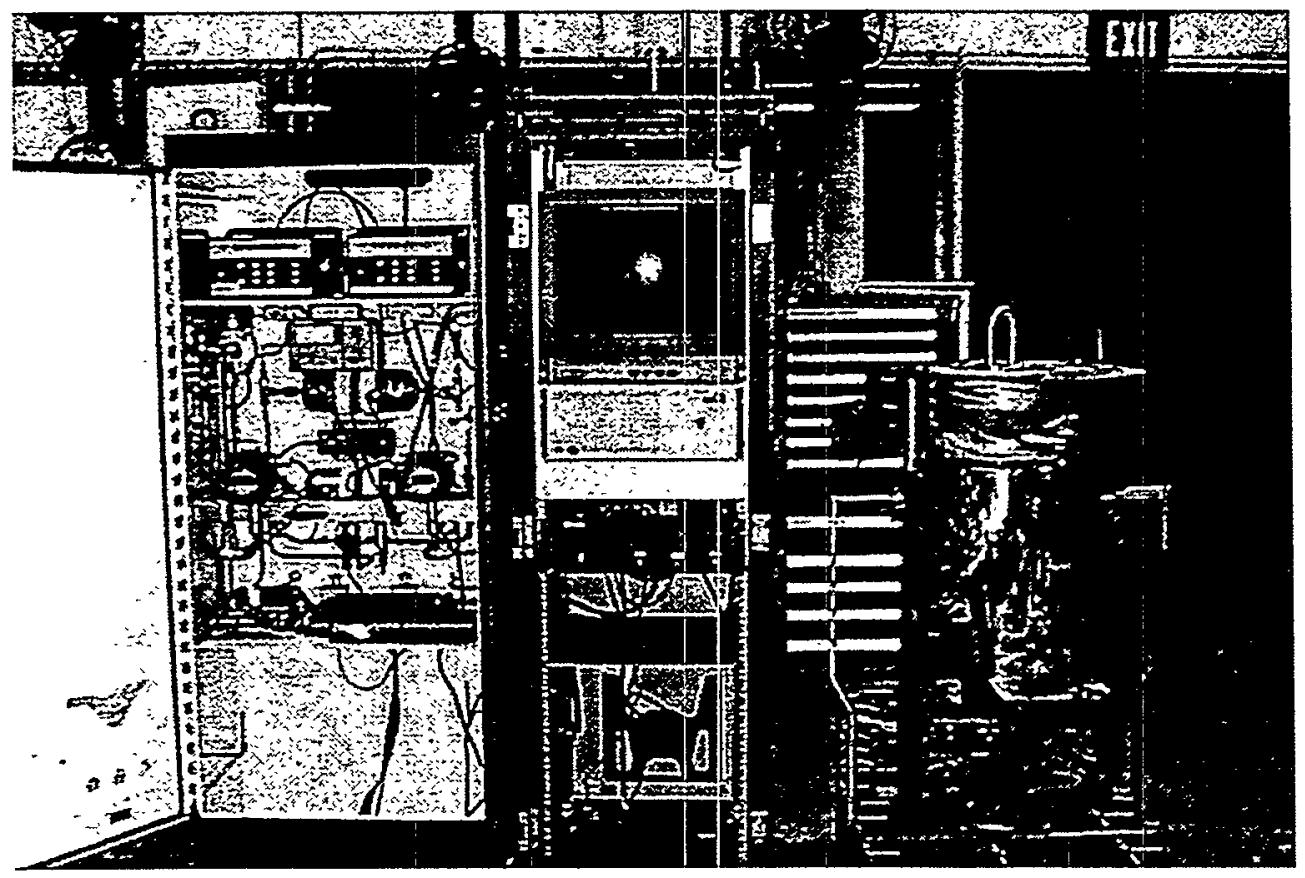

Instrumented, Shielded Test Canister System for Dry Storage of Al SNF. The Test System includes the Fuel/Canister Monitoring System, the Data Acquisition System, and the Canister with Shielding. 


\section{WSRC-TR-97-00269, Part I \\ Objectives for Tests Using Instrumented Canisters \\ by R. L. Sindelar}

\section{Background}

A total inventory of up to approximately 24 metric tons or approximately 32,000 aluminum-based spent nuclear fuel (AI SNF) assemblies are expected to be shipped to SRS over the next several decades. These fuels will be shipped from foreign research reactors (FRR), domestic research reactors (DRR), and the Idaho National Environmental Engineering Laboratory (INEEL) to the Savannah River Site (SRS). Some assemblies have already been received at SRS and are being temporarily stored in the L-Basin and the Receiving Basin for Off-site Fuels (RBOF) [1].

An Alternative Treatment Technology Program is currently evaluating options for the disposition of this SNF in a geologic repository. A pre-conceptual design of a facility for Transfer and Storage Services (TSS) has been completed [2] in support of this program. Under one alternative, namely direct/co-disposal, fuels would be removed from basin storage and prepared for placement in sealed canisters for interim dry storage at SRS while the repository is undergoing licensing and final site preparation. The desired service life of the facility is 40 years.

Nuclear fuel from commercial and research reactors has been in dry storage systems throughout the world [3]. Australia, Japan, Canada, [4] and Brazil [5] have been dry storing Al SNF for several years. The dry storage systems were designed with good engineering judgment but without specific criteria tied to long-term performance to maintain structural integrity over many decades. Degradation has been observed when water and air have inadvertently entered into the storage environments.

Site criteria have been established for interim dry storage conditions for Al SNF to avoid excessive degradation during the handling, processing, and interim storage prior to repository disposition $[6,7]$. To demonstrate that the fuel condition is maintained within expectations and that the environment is within criteria when drying to the specified level, a test apparatus is needed for validations. In addition, such apparatus could be used as lead surveillance for an interim dry storage system. This report outlines the design and development of an instrumented canister system that could be used to monitor Al SNF performance in dry storage.

\section{Objectives for Tests Using the Instrumented, Shielded Test Canister System}

The test canister system described in part $\Pi$ of this report is designed to be an apparatus for tests of Materials Test Reactor type (MTR) fuel assemblies in dry storage although other fuel, fuel segments, and waste forms could be accommodated. The storage environments can be set by water injection and gas back fill. Self-heating of the waste form is the heat source in the canister.

The primary test objectives in using the canister are:

- validate drying and storage criteria for road-ready storage;

- validate corrosion model; 
- validate gas release model;

- validate heat transfer analysis methodology; and

- provide lead-assembly-surveillance for dry storage system.

The drying and storage criteria governing the handling, processing, and interim dry storage of Al SNF, originally developed and reported in reference 6, have been adopted as technical functional performance requirements for a dry storage system in reference 7. A summary of these technical functional performance requirements follows.

$\begin{array}{ll}\text { Fuel Temperature Limit: } & 200^{\circ} \mathrm{C} \\ \text { Canister Storage System: } & \text { Sealed } \\ \text { Free Water Limit in Canister: } & \text { Limit } \mathrm{H}_{2} \text { Build-up to 4\% } \\ \text { Fuel/Clad Consumption Limit: } & 0.003^{\prime \prime} \\ \text { Canister Cover Gas: } & \text { Helium }\end{array}$

The preliminary intended storage condition of FRR/DRR MTR fuel assemblies in the canisters will be to store in an initial air/water vapor environment such that limited corrosion would occur. Based on a level of free water injected into the system, hydrogen could be generated up to the limit.

The response of the fuel to the storage is predicted using analytical models of the materials' response which have been developed for interim dry storage conditions. A brief summary of the models and expected fuel response to the storage environment is provided in the next section. The actual response of the fuel will be compared to its predicted response following the loading of the MTR assemblies and the analysis of data collected under the test environmental conditions of storage in calendar year 1998.

\section{Fuel Materials' Response to Environments of Dry Storage}

The spent nuclear fuel to be stored at the Savannah River Site is aluminum-based. The fuel core for these fuels is characterized as an aluminum matrix in which particles (dispersoids) of either $\mathrm{UAl}_{\mathrm{x}}, \mathrm{U}_{3} \mathrm{Si}_{2}$, or $\mathrm{U}_{3} \mathrm{O}_{8}$ oxide particles are embedded. The core is protected by a cladding of aluminum alloy which is metallurgically bonded to the core. The fuel response in a dry storage system is dependent on the environment and period of storage. The environment includes the surrounding gas, relative humidity, and temperature of the fuel. Site criteria have been established to limit the amount of degradation that occurs during the handling, processing, and storage periods of the spent fuel $[6,7]$.

Thermal Analysis Model- The temperature of the fuel is dependent on the canister design, heat loading within the canister, and the heat removal from the canister. Previously, analyses were performed to identify the appropriate heat transfer code and develop the appropriate analytical methods to model heat removal from a system with low differential temperatures and low convective flow within the canister and outside the canisters [8]. This methodology will be applied in analyzing the temperature data from the tests.

Corrosion Model- General corrosion of the fuel is the primary degradation mode and would occur by vapor corrosion in a dry storage system in the presence of corrodant species. A extensive testing program is in progress, and test results have been used to benchmark a semi-empirical model for the corrosion the cladding alloys [9]. As a consequence of the corrosion reaction, hydrogen gas is generated, and the amount based on initial free water in 
a closed system can be calculated [9]. An Arrhenius relation is used to describe the temperature and time dependence of the weight gain, $\mathrm{W}$, or the consumption of the metal:

$$
\mathrm{W}=\mathrm{A} \cdot \operatorname{EXP}\left(-\mathrm{Q}_{1} \mathrm{n} / \mathrm{RT}\right) \cdot \mathrm{t}^{\mathrm{n}},
$$

where $A$ is an coefficient which in general is a function of material, relative humidity, corrodant species, etc., $\mathrm{Q}_{1}$ is related to the diffusion of oxygen in the oxide film or activation energy for diffusion in Boehmite, $R$ is the universal gas constant, $T$ is the absolute temperature in Kelvin. No direct measure of weight gain will be performed in the test; however two means to assess the corrosion response will be available. The direct visual examination of the fuel plate surface including the crevice region at the fuel plate/end plate intersection will be performed to check for evidence of additional corrosion during storage. The second means to assess corrosion is the build-up of hydrogen through the corrosion reactions. The following two reactions are considered to be the predominant reactions of aluminum corrosion at the expected storage temperatures

Gibbsite Reaction -

$$
2 \mathrm{Al}+6 \mathrm{H}_{2} \mathrm{O} \rightarrow \mathrm{Al}_{2} \mathrm{O}_{3} \cdot 3 \mathrm{H}_{2} \mathrm{O}+3 \mathrm{H}_{2}
$$

Boehmite Reaction -

$$
2 \mathrm{Al}+4 \mathrm{H}_{2} \mathrm{O} \rightarrow \mathrm{Al}_{2} \mathrm{O}_{3} \cdot \mathrm{H}_{2} \mathrm{O}+3 \mathrm{H}_{2}
$$

Measurement of the amount of hydrogen generated during the test and comparison to the amount that would be generated based on the available free water will be performed.

Creep Model- Under extended periods of storage and at high storage temperatures [10] deformation of the fuel under self-weight loading will occur. The deformation mechanism for this is based on a phenomenological model of creep considering grain boundary sliding. The creep law is given by:

$$
\dot{\varepsilon}_{C_{o}}^{c r}=A_{C o} D_{0(g b)} \exp \left(\frac{-Q_{g b}}{R T}\right)\left(\frac{G b}{k T}\right)\left(\frac{b}{d}\right)^{3}\left(\frac{\sigma}{G}\right)
$$

for pure aluminum, where

$A_{c o}=$ dimensionless Coble creep constant $=66.8$,

$D_{o}(g b)=$ grain boundary frequency factor $=1.86 \mathrm{~cm}^{2} \mathrm{sec}^{-1}=1.86 \mathrm{E}-04 \mathrm{~m}^{2} \mathrm{sec}^{-1}$,

$R=$ gas constant $=8.31441 \mathrm{~J} \mathrm{~mol}^{-1} \mathrm{~K}^{-1}$,

$k=$ Boltzmann's constant $=1.38 \mathrm{E}-23 \mathrm{~J} \mathrm{~K}^{-1}$,

$Q_{g b}=$ grain boundary diffusion activation energy $=86.04 \mathrm{~kJ} \mathrm{~mol}^{-1}$,

$G=$ shear modulus at temperature $T=G_{O}-D G T=3.022 E+04 \mathrm{MPa}-\left(16.0 \mathrm{MPa} \mathrm{K}^{-1}\right) T$,

$b_{B}=$ Burger's vector $=2.86 \mathrm{E}-08 \mathrm{~cm}=2.86 \mathrm{E}-10 \mathrm{~m}$.

$d=$ average grain size $(\mathrm{cm})$

$\sigma=$ von Mises equivalence stress (Mpa or psi)

$T=$ absolute temperature $(\mathrm{K})$ 
The deformation response of the plates of an MTR assembly have been analyzed [10]. Up to $200^{\circ} \mathrm{C}$, and even after several decades of storage, no significant deformation would be expected. Visual information will be available in the instrumented canister to verify no creep deformation of fuel occurs.

Gas Release Model- A simple model for the release rate from breached fuel at low temperatures is based on the consideration of binary diffusion of volatile species [11] in aluminum either through the cladding or directly from exposed fuel meat since no copious cracking of the fuel microstructure is created during irradiation. The fission products that have the highest diffusion and/or highest vapor pressures are $\mathrm{Cs}, \mathrm{Xe}$, and $\mathrm{Kr}$ [11].

The model for gas release is being refined and additional laboratory testing is in progress. It is anticipated that very little if any release would occur over years of storage. Measurement of the concentration of species in the canister gas will verify this.

\section{Preliminary Selection of MTR Assemblies and Conditions for Storage in Test Canister}

An estimate of $10 \%$ of the fuel assemblies have corrosion or mechanical damage that has resulted in minor penetrations (breaches) of the aluminum cladding and exposure of the fuel core to the ambient environment. Fuels with minor breaches are acceptable for direct placement in the dry storage canisters [7]. The basis for this acceptance is that the materials and structure of the Al SNF provides a measure of confinement of the radionuclides. The corrosion of any exposed fuel material is expected to be on the same order as the cladding [9]. In addition, significant diffusion and release of species through the fuel matrix and cladding is not expected at low temperature $\left(<200^{\circ} \mathrm{C}\right)$, short term $(<50$ years) storage [11]. The canister test will verify that the release of volatile products from exposed fuel is low.

The MTR assembly placed in the canisters during the tests will be based on availability, existing degraded condition, and fission product inventory which affects heat generation and radiation field. Preliminary selection of two fuels have been tentatively selected, fuel with exposed meat from the SAPHIR and fuel with exposed meat from the R2 reactor. Figure I- 1 below shows fuel plate 243 from the SAPHIR assembly SESO2 with an apparent exposure of fuel meat. 


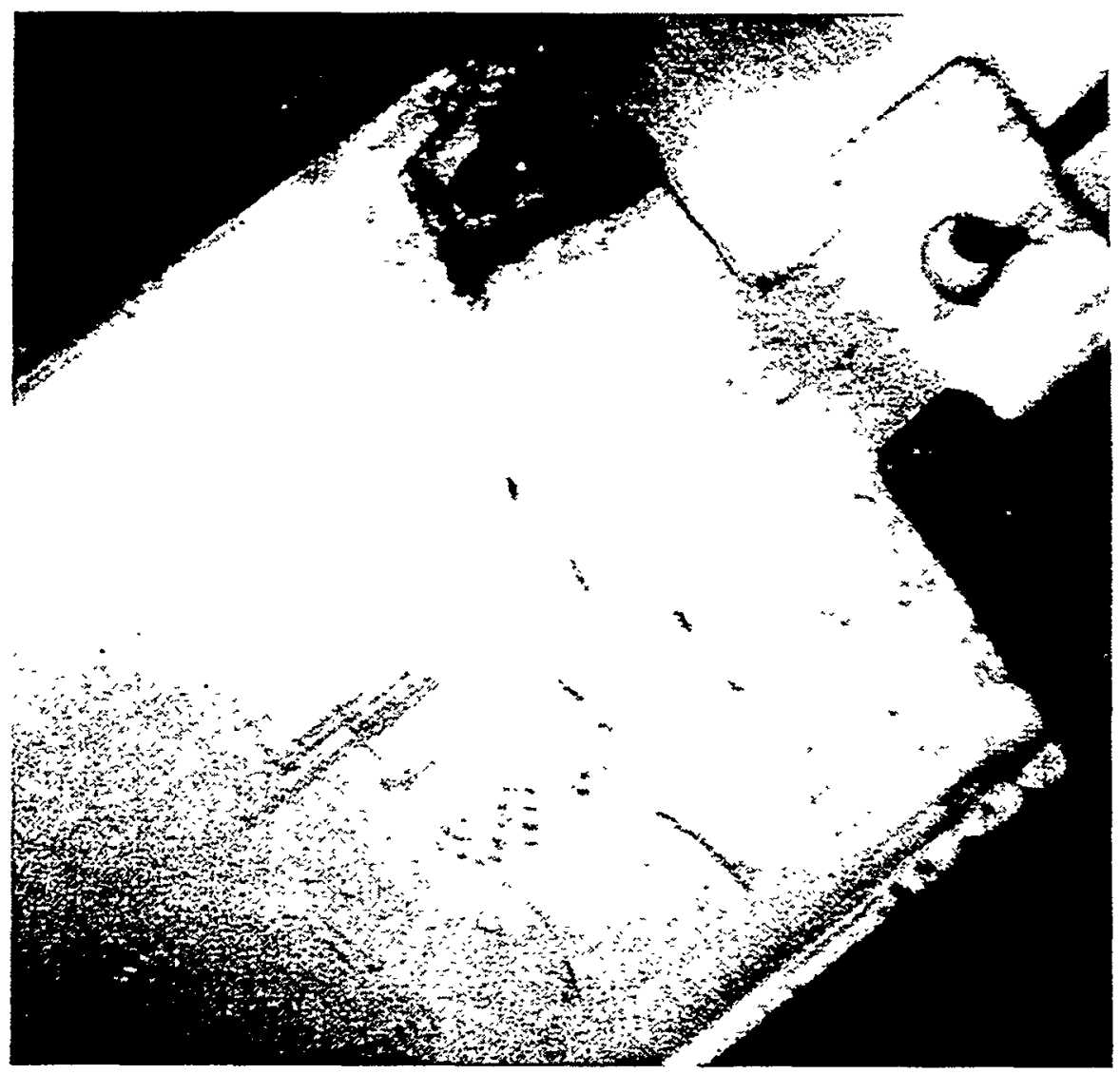

Figure I-1 Saphir fuel plate \#243 Saphir with Cladding Breach

In fiscal year 1998, L-Dry Cave will be prepared to stage the canister system [12]. Safety documentation and a fuel/canister handling procedure will be issued. The fuels will then be transferred from RBOF to L-disassembly basin. The fuels will be loaded underwater into the shielded canisters. The canister will be vacuum dried, then vented to air and injected with a controlled amount of water. The system will be sealed and staged in the L-area dry caves and the collection of data will begin.

\section{References for Part I}

1. Savannah River Site EIS (1997 draft)

2. G-CDP-00002, Rev. A, "SRS SNF TSS Pre-Conceptual Design," dated June 23, 1997.

3. K. J. Schneider, S. J. Mitchell, and A. B. Johnson, Jr., "International Status on Dry Storage of Spent Fuels," in Proceedings of High Level Radioactive Waste Management Conference, Las Vegas, 12-16 April 1992, pp. 1159-1165, American Nuclear Society 1992. 
4. M. R. Duignan, "Experiences in the Dry Storage of Aluminum-Clad Spent Nuclear Fuels," in the proceedings of the Topical Meeting on DOE Spent Nuclear Fuel Challenges and Initiatives, p. 67, December 1994, published by the American Nuclear Society, ANS Order No. 700214.

5. SRT-MTS-962041, "TRIP REPORT: Characterization of IEA-R1 Spent Nuclear Fuels at the IPEN, São Paulo, Brazil, July 22 - July 31, 1996 (U)," R. L. Sindelar, H. B. Peacock, Jr., J. P. Howell, S. D. Burke, and A. S. Busby, Westinghouse Savannah River Company, Savannah River Technology Center.

6. WSRC-TR-95-0347, "Acceptance Criteria for Interim Dry Storage of AluminumAlloy Clad Spent Nuclear Fuel (U)," R. L. Sindelar, H. B. Peacock, Jr., P. S. Lam, N. C. Iyer, and M. R. Louthan, Jr., Westinghouse Savannah River Co. report, March 1996.

7. WSRC-TR-97-00262, "SRS Transfer and Storage Services Technical Functional Performance Requirements for Dry Storage of Al-Based SNF (U)," R. L. Sindelar and J. N. Baysden, Westinghouse Savannah River Co. report, September 1997.

8. S. Y. Lee, "Three-Dimensional Computational Fluid Dynamics (CFD) Modeling of Dry Spent Nuclear Fuel Storage Canisters", Presented at the 1997 AIChE National Meeting at Houston, TX, March 9 - 13, 1997.

9. WSRC-TR-97-0120, "Vapor Corrosion of Aluminum Cladding Alloys and Aluminum-Uranium Fuel Materials in Storage Environments (U)," P. S. Lam, R. L. Sindelar, and H. B. Peacock, Jr., Westinghouse Savannah River Co. report, April 1997.

10. WSRC-TR-95-0121, "Creep Analysis for Materials Test Reactor (MTR) Fuel Assemblies in Dry Storage (U)," R. F. Miller and R. L. Sindelar, Westinghouse Savannah River Co. report, April 1995.

11. WSRC-TR-93-502, "Material Issues in Interim Storage and Direct Disposal of Aluminum Clad Spent Nuclear Fuel," G. R. Caskey, Westinghouse Savannah River Co. report, September 1993.

12. SFS-SNF-970089, "Plan for Instrumented Dry Storage of SNF," W. S. Large and D. G. Blanchard, September 9, 1997. 


\section{Design Considerations}

The instrumented test canister system is to store a single MTR Aluminum SNF assembly in a canister in closed environment and to collect data on fuel conditions and storage environment for some period of time. Initially the fuel will be monitored as a test case, then should long term dry storage prove to be a desirable option, the canisters will be used as a lead case for long term stored fuel monitoring. To meet the objectives of this task, the canister system requires to be equipped to monitor following key parameters.

- Temperatures: fuel surface, canister, ambient, circulating air

- Gas generation: Hydrogen, Oxygen, NOx

- Gas release from fuel: Cesium, Xenon, Krypton

- Internal pressure

- Relative humidity

- Circulating air flow rate

- Visual inspection on fuel surface

All monitoring and data collecting operations shall be done remotely and automatically. The canister monitoring loop also must be designed to prevent any accidental release of fission products from the stored SNF assembly.

The system also requires to allow remote fuel loading to minimize radiation exposure to the operating personnel. In addition, due to the high radiation level of the fuel assembly, the canister must have adequate shielding to protect personnel during the monitoring period.

\section{Deliverable Items}

Two complete independent systems to store and monitor two Al SNF assemblies under test conditions were designed and fabricated. These include two canisters, two shields, two camera brackets, two air monitoring loops with instrumentation, and one data acquisition system with uninterrupted power supply to manage and record data on environmental conditions inside the two test canisters.

All engineering documents generated for the design and fabrication of the test canister system are filed in EES Job No. 22585 folder.

\section{System Designs and Features}

The instrumented test canister system consists of an instrumented canister, shield, fuel monitoring system and data acquisition system. Designs and features of each component are described in the following.

\section{Instrumented Canister}

The instrumented canister (Figure II-1 photograph) provides sealed containment for a Materials Test Reactor (MTR) fuel assembly which is approximately 3-inches square and just over two feet long. The fuel assembly is supported by an aluminum sensor rack to center it and to allow positioning of thermocouple tips on the fuel surface. The canister body is made from a section of 6" outside diameter Type 304 stainless steel tubing with a 
wall thickness of $1 / 8$ ". The top of the body is welded to a commercial 8 " vacuum flange. A blank flange, which is welded to the shield lid, bolts to twenty threaded holes in the flange of the canister and gives the vacuum tight enclosure. The bottom of the canister tube is seal welded to a flat $1 / 8$-inch thick 304 stainless steel plate.

Three stainless steel tubes, $1 / 2$ " o.d. with .050 " wall tubing, are welded to the canister. One lower tube and one upper tube serve as air inlet and outlet ports, respectively, to mate with the air circulation loop for air sampling. For air sampling during the test, air enters the canister through the bottom tube, passes the fuel assembly and exits one of the top tubes. All thermocouple wires exit through the third port which serves as a conduit. The canister is housed within a lead shield (see Figures $\Pi 1-2,3$, and 4 schematics from Reference Drawing number EES-22585-R1-001) to reduce the radiation exposure to allow limited access to the L-area dry cave where the canister will be staged. It also has a 4 inch diameter sealed quartz viewing window to allow direct visual inspection of the fuel surface approximately 8 inches from the bottom. This observation will be done with the aid of a video camera that can be seen in the cross section plan view, in Figure II-4. The camera is mounted around a $90^{\circ}$ corner and views the assembly through a front surface mirror mounted in the viewing tunnel to avoid the high direct radiation field directly in front of the assembly.

\section{Shield}

The shield (Figure $\Pi-5$ photograph) is needed due to the high radiation field expected from a spent fuel assembly. A shielding analysis was performed to determine shielding requirements (Appendix 1 to this report).

The shield consists of a 1/8 inch-thick stainless steel shell construction filled with molten lead. Based on the analysis, the shield has 4.25" of lead shielding to keep the dose rate on the shield surface for one High Flux Beam Reactor assembly below $100 \mathrm{mR} / \mathrm{hr}$. The approximate weight of the shield with the canister is 6,640 pounds.

\section{Design Calculations for Instrumented Canister}

Maximum Pressure in Canister: The canister will be initially at atmospheric pressure at room temperature when vented to air following vacuum drying after fuel loading. A finite level of water will then be injected to simulate incomplete drying as an initial condition of the stored fuel and the system will remain sealed throughout the test. This environment is expected to cause limited, predictable corrosion. Two chemical reactions of the aluminum with water are considered:

Gibbsite Reaction -

$$
2 \mathrm{Al}+6 \mathrm{H}_{2} \mathrm{O} \rightarrow \mathrm{Al}_{2} \mathrm{O}_{3} \cdot 3 \mathrm{H}_{2} \mathrm{O}+3 \mathrm{H}_{2}
$$

Boehmite Reaction -

$$
2 \mathrm{Al}+4 \mathrm{H}_{2} \mathrm{O} \longrightarrow \mathrm{Al}_{2} \mathrm{O}_{3} \cdot \mathrm{H}_{2} \mathrm{O}+3 \mathrm{H}_{2}
$$

If the canister temperature is raised sufficiently before corrosion takes place, all water will evaporate. In this case, the initial partial pressure due to water vapor will be greater than 
the final partial pressure from hydrogen generated after the corrosion reaction. Using gibbsite reaction to estimate the total pressure of the canister at high temperature is conservative.

Assume that the final pressure of the hydrogen generated as a result of corrosion is $\mathrm{P}_{\mathrm{H}}$. The initial vapor pressure $\left(\mathrm{P}_{\text {water }}\right)$ is thus

$$
\begin{array}{ll}
\text { Gibbsite: } & \mathrm{P}_{\text {water }}=2 \mathrm{P}_{\mathrm{H}} \\
\text { Boehmite: } & \mathrm{P}_{\text {water }}=(4 / 3) \mathrm{P}_{\mathrm{H}}
\end{array}
$$

The total pressure of the canister (P) has two major contributions: 1) The air trapped in the canister $\left(\mathrm{P}_{\text {air }}\right)$ when it is sealed (initial pressure is 1 atm at room temperature); 2 ) Water vapor pressure $\left(\mathrm{P}_{\text {water }}\right)$ in the beginning of the test or the hydrogen pressure $\left(\mathrm{P}_{\mathrm{H}}\right)$ when all water is consumed by corrosion. As stated earlier, the initial water vapor pressure is higher than the final hydrogen pressure and will be used in the calculation. That is,

$$
\mathrm{P}=\mathrm{P}_{\text {air }}+\mathrm{P}_{\text {water }}
$$

(1) Calculation of $\mathrm{P}_{\mathrm{air}}$

Let $\mathrm{P}_{\mathrm{T}}$ be the air pressure at temperature $\mathrm{T}$ (Kelvin) and $\mathrm{T}_{\mathrm{rm}}$ is the room temperature in Kelvin, using the ideal gas law:

$$
\mathrm{P}_{\mathrm{T}}=(1 \mathrm{~atm}) \cdot \mathrm{T} / \mathrm{T}_{\mathrm{rm}}
$$

(2) Calculation of $P_{\text {water }}$

Assume that the volume fraction of the final hydrogen buildup is $\mathrm{X}$. Let the free volume of the canister be $V$. The number of moles of hydrogen is therefore $X V / M$, where $V$ is in cubic meters and $M$ is the molar volume of hydrogen $\left(24789.2 \times 10^{-6} \mathrm{~m}^{3}\right)$. As a result, the number of moles of water corresponding to that amount of hydrogen in the gibbsite reaction is $2 X V / M$. Using ideal gas law, the initial vapor pressure at temperature $T$ is

$$
\mathrm{P}_{\text {water }}=(2 \mathrm{XV} / \mathrm{M}) \mathrm{RT} / \mathrm{V}=2 \mathrm{XRT} / \mathrm{M} \text {, }
$$

where $R$ is the universal gas constant $\left(8.205 \times 10^{-2} \mathrm{~m}^{3} \cdot a t \mathrm{~m} / \mathrm{kmol} \bullet \mathrm{K}\right)$.

(3) The total pressure in the canister is

$$
\mathrm{P}=(1 \mathrm{~atm}) \cdot \mathrm{T} / \mathrm{T}_{\mathrm{rm}}+2 \mathrm{XRT} / \mathrm{M}
$$

With $\mathrm{T}_{\mathrm{rm}}=300 \mathrm{~K}$ and $\mathrm{T}=473.15 \mathrm{~K}$ (or $200^{\circ} \mathrm{C}$, the temperature limit),

$$
\mathrm{P}=(1 \mathrm{~atm}) \cdot 473.15 / 300+2 \cdot \mathrm{X} \cdot\left(8.205 \times 10^{-2} / 1000\right) \cdot 473.15 / 24789.2 \times 10^{-6}
$$

Therefore

$$
\begin{gathered}
\mathrm{P}(\text { in atm })=1.577+3.132 \mathrm{X} \\
\text { or } \quad \mathrm{P}(\text { in psia })=23.176+46.028 \mathrm{X}
\end{gathered}
$$


or

$$
\mathrm{P}(\text { in psig })=\mathrm{P}(\text { in psia })-14.696=8.480+46.028 \mathrm{X}
$$

(4) Assume that a conservative estimate of hydrogen production is $10 \%$ of the free volume $(\mathrm{X}=0.1)$. The total gauge pressure in the canister is $13.1 \mathrm{psig}$ which is less than the allowable internal pressure for the window (15 psig). The safety margin will increase when the temperature is lowered (from $200^{\circ} \mathrm{C}$ ). Figure II- 6 shows the canister pressure as a function of hydrogen concentration and temperature. For the test, the amount of free water will be limited to a lead to a nominal hydrogen pressure of $4 \%$. In addition, the expected temperature in the canister will be well below $100^{\circ} \mathrm{C}$.

Capacity of Canister against Buckling: This calculation is performed to check that vacuum drying does not collapse the canister. The calculation is performed using ASME code, Section VIII, paragraph UG-28 criteria. The canister is a cylinder length, L, of 27 5/8", the inside diameter, $D_{0}$, is $6^{\prime \prime}$, and the nominal thickness, $t$, is $1 / 8^{\prime \prime}$.

$$
\begin{aligned}
& L / D_{0}=27.625 / 6=4.604 \\
& D_{o} / t=6 /(1 / 8)=48
\end{aligned}
$$

A maximum canister temperature of $200^{\circ} \mathrm{C}$ (approximately $400^{\circ} \mathrm{F}$ ) is considered which corresponds to the fuel temperature limit for dry storage. The canister temperature expected in the tests will be nominally elevated above room temperature due to the low heat output of the fuel ( $<10$ watts). Young modulus for $304 \mathrm{SS}$ at $400^{\circ} \mathrm{F}$ is $26.5 \mathrm{E} 6 \mathrm{psi}$.

Using Appendix 5 of the ASME code, Chart 5-UGO-28.0, for $\mathrm{L}_{\mathrm{o}} / \mathrm{D}_{\mathrm{o}}=4.604$ and $\mathrm{D}_{\mathrm{o}} / \mathrm{t}=$ 48 , the factor $A$ is $7.5 \mathrm{E}-4$.

Using Figure 5-UHA-28.1 of Appendix 5, for $304 \mathrm{SS}$ at $400^{\circ} \mathrm{F}$, using interpolation, the factor $B$ is 6643 . The allowable external pressure $P_{a}$ is

$$
\mathrm{P}_{\mathrm{a}}=4 \mathrm{~B} /\left(3\left(\mathrm{D}_{\mathrm{o}} / \mathrm{t}\right)\right)=4 \times 6643 /(3 \times 48)=184.5 \mathrm{psi} \text {. }
$$

With a complete vacuum inside the canister, the safety margin against collapse is 184.5/14.7. The window welded to the vessel does not weaken the vessel if there is no external mechanical loading.

Capacity of Lifting Bails: The weight of the shielded canister is 6640 lbs. The lifting bail/bar design is such that it minimizes the moment loading at the $1 / 8$ " shell. This is due to the fact that moment loading is deflection limited. The deflection is negligible since bars $\left(3^{\prime \prime} \times 3 / 8^{\prime \prime}\right)$ on the 2 " diameter lifting bails limit the deflection. The moment loading at the shell is also negligibly small.

The stress on the bail section is:

$$
\begin{aligned}
& \sigma=(7000 / 2) /(3 / 8 * 1)=9333 \mathrm{psi} \\
& F_{y}=\text { yield stress }=30,000 \text { psi (per ASME BPV code, section II, part D) }
\end{aligned}
$$

The allowable stress is $0.6 \mathrm{~F}_{\mathrm{y}}=18,000 \mathrm{psi}$ (per AISC manual) 
Approximate deflection is $\sigma / \mathrm{E}^{*}$ length $=9333^{*} 1.5 /\left(28.3 \times 10^{6}\right)=0.0005^{\prime \prime}$ which is negligible

Now the lifting pin is attached to the shell by a 5 " diameter piece and a $3 / 16^{\prime \prime}$ fillet weld around the circumference.

The weld length $=5 \mathrm{PI}=15.71^{\prime \prime}$

The weld strength in shear (per AISC manual) $=0.3 * 0.707 * 3 / 16^{*} 15.71 * \mathrm{~F}_{\mathrm{u}}$ where $F_{u}$ is the minimum tensile strength of the weld material. For SS304 plate, $F_{u}=$ 75,000 psi.

Therefore, the weld strength is $0.3 * 0.707 * 3 / 16^{*} 15.71 * 75000=46851 \mathrm{lbs}$.

The total weld strength for both ends is $2 * 46851=93702 \mathrm{lbs}$.

The safety factor is $93702 / 7000=13.39$.

The shear stress in the shell is $(7000 / 2) /(15.71 * 0707 * 3 / 16)=1681 \mathrm{psi}$.

The shear allowable is $0.4 \mathrm{~F}_{\mathrm{y}}=0.4 \times 30,000=12,000 \mathrm{psi}$.

Therefore the shell will not be damaged.

\section{Fuel Monitoring System}

The fuel monitoring system consists of a cabinet containing one complete instrumentation loop for each canister (Figure II-7 schematic). Each loop has two primary components; a gas chromatograph (GC) and an instrument manifold. The gas chromatograph takes a one microliter sample of air from the canister once per day. This sample is combined with a carrier gas in the instrument and is analyzed for hydrogen, nitrous oxides, and oxygen content. The carrier gas is ultra high purity argon which is contained in a cylinder just outside the cabinet. A calibration gas system is programmed to periodically confirm the GC output and automatically purges itself to prevent dilution of subsequent samples. Calibration gas bottles containing a mixture of hydrogen, nitrogen, and oxygen are located in the bottom of the cabinet.

The instrument manifold houses a temperature/relative humidity sensor and a pressure transducer. A radiation monitor is included between the instrumentation manifolds monitoring the loops for both canisters simultaneously. The radiation monitor senses the presence of gamma radiation indicating that radioactive material has been released from the fuel element and is circulating within one or both instrument loops. This material is retained by the system such that no radioactive panicles are admitted to the atmosphere. Further analysis to determine the exact source and constituents of the radiation will be required upon detection. Each loop is also equipped with a circulating pump, a flow meter, and line for introducing outside air in the event that pressure falls off over time. Solenoid valves are controlled by the data acquisition computer. These valves are used to direct air flow to the gas chromatograph during sampling and calibration procedures. Signals to and from all instrumentation are linked to the data acquisition system in an adjacent cabinet. 


\section{Data Acquisition System}

A computer based data acquisition system has been developed to monitor environmental parameters associated with two identical shielded test canisters. The system consists of a central computer cabinet, instrumented process cabinet and two instrumented canisters (Figure II-8 schematic). The computer provides real-time display of data, data storage, and remote data access via network/internet connection. Sensors in the process cabinet allow monitoring of air temperature, air flow, canister gas composition, pressure, relative humidity, radiation. Sensors in the canister measure surface temperatures of the fuel, canister wall and temperatures of inlet and outlet air.. Circulating pumps located in the instrument cabinet (Figure II-6 photo) ensure continuous circulation of system air past all sensors. The visual appearance of stored fuel is monitored by a video camera mounted on each canister.

Data acquisition, storage and display are accomplished in four basic levels: sensor output, signal conditioning, communication and computer translation. All process sensors, except gas composition, video, and radiation, provide voltage or current level analog outputs proportional to the measured parameter. Each analog signal is converted to digital form by a dedicated signal conditioning module located in close proximity to the sensor. The signal conditioning modules reside in backplanes which convert the digital information to a robust serial format which ultimately enters the computer through a standard serial (RS232) communication port. Gas composition information is conditioned and transmitted directly from one of two gas chromatographs to a dedicated serial port on the computer. Video information is provided by one camera mounted on each of the canisters. Standard (NTSC) video signals are transmitted directly to the computer and received through one of two ports on a video capture board. Radiation detection is accomplished with a single dedicated sensor and meter. At a predetermined level the meter generates a contact closure. The contact closure is detected by a signal conditioning module where it is transmitted along with other signal data. The computer translates all received signals to tabular and/or graphical form for storage and display. Video from observation cameras can be displayed exclusively or concurrent with parameter information on the computer display.

Computer System: The computer system is the central component of the data acquisition system. The basic configuration consists of a CPU chassis, keyboard, mouse and color display. The chassis is a Texas Micro Systems (TMS) passive backplane with nine ISA, three PCI type slots and a 300W power supply. One slot of the chassis is occupied by a TMS single board CPU. The CPU is Pentium/133MHz based with 32 Megabyte of RAM. Two serial, one parallel, SCSI and IDE interfaces are included on the CPU board. An SVGA video display driver board with 2 megabytes of RAM is located in a PCI slot next to the CPU board. Other slots contain interface boards for video capture and two additional communication ports. Removable media is accommodated by a $3.5 ", 1.44 \mathrm{Mb}$ high density floppy drive and 4X CD ROM drive. Operator inputs are entered into an IBMTM AT compatible, sealed, industrial grade keyboard. Cursor movements are input through a serial communication port by a sealed track ball mouse located in the keyboard housing.

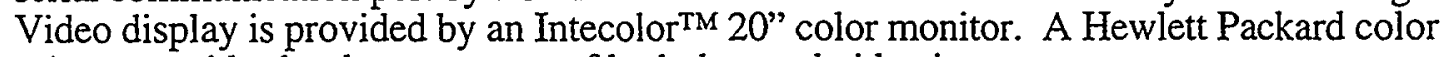
printer provides hard copy output of both data and video images.

Temperature Sensing: Temperature sensing is performed within the process cabinet and each canister. In the process cabinet measurement is performed at three locations: canister 1 air plenum, canister 2 air plenum, and ambient air. The sensors used are $\mathrm{HyCal}$ model CT-839-A-R-(30/130F)-(0/100\%) humidity/temperature transmitters configured with a model EL-705 platinum temperature element. Each transmitter provides an industry 
standard $4-20 \mathrm{~mA}$ output proportional to temperature over the range 30 to 130 degrees $\mathrm{F}$. Specified accuracy is $+/-0.3 \mathrm{C}$ at $25 \mathrm{C}$ or $+/-0.8 \%$ of span. Mounting of canister air sensors is accomplished by insertion into the plenum air stream and sealing with swage type fitting. Within the each canister temperature measurements are made at five fuel surface locations, one canister surface and at the air inlet and air outlet. Canister sensors are Omega Engineering model KMQSS-040U-72 thermocouples. Each thermocouple is $\mathrm{K}$ type, ungrounded, and sealed in a .040" x 72" long 304 stainless steel sheath. Combined with the signal conditioning module $\mathrm{K}$ type thermocouples have a range of 0 to $1000^{\circ} \mathrm{C}$ and a maximum error of $+1-0.75^{\circ} \mathrm{C}$.

Humidity: Relative humidity measurements are performed in the process cabinet at three locations: canister 1 air, canister 2 air, and ambient air. The sensors used in each location are HyCal model CT-839-A-R(30/130)-(0/100\%) humidity/temperature transmitters configured with a model $\mathrm{HH}-3602$-A humidity sensing element. Each transmitter provides an industry standard $4-20 \mathrm{~mA}$ output proportional to humidity over the range of 0 to $100 \%$ relative humidity. Specified accuracy is $+1-2 \%$ for $0-90 \% \mathrm{RH}$ at $25 \mathrm{C}$ and $+1-3 \%$ over $15 \mathrm{C}$ to $50 \mathrm{C}$. Mounting of canister air sensors is accomplished by insertion into the plenum air stream and sealing with swage type fitting.

Pressure: Pressure is measured at five locations in the process cabinet: canister 1 air, canister 2 air, ambient, gas chromatograph 1(GC1), and gas chromatograph 2 (GC2). Canister and ambient pressure sensors are Lucas model P4183-0005-030PA digitally compensated transducers. Combined accuracy is $+/-2 \%$ over the range of 0 to $30 \mathrm{psi}$ absolute. Output is an industry standard $4-20 \mathrm{~mA}$ over the operating range. Each transducer is contained in a NEMA 4316 SS housing and all exposed process surfaces are 316SS. Canister transducers are connected to canister air plenums by a NPT female port. GC1 and GC2 pressure sensors are Druck model 960 transducers with 0 - 50 psig operating range. Output is 0 to $100 \mathrm{mV}$ over the specified range.

Flow Rate: Circulating air flow is measured within the process cabinet for canister 1 and canister 2. Each air stream is measured with an Eldridge Products model 8659-SSS-103BDC24-AIR thermal mass flowmeter. Specified accuracy is $+1-2 \%$ over the operating range of 0 to 3 SCFM with a one second response time. The signal output is an industry standard 4-20mA output over the specified operating range.

Gas Chromatographs: Canister 1 and canister 2 air streams are each sampled by a dedicated gas chromatograph (GC). The GC units are MTI Analytical Instruments model M200 configured with a 5 angstrom 4 meter molecular sieve. The units will be calibrated for $\mathrm{O} 2, \mathrm{H} 2$ and NOx gases, however the $\mathrm{GC}$ can respond to a spectrum of gases allowing the detection of unanticipated gas species. The resulting serial data output provides a spectral distribution based on molecular size or gas species.

Video Observation: Canister 1 and canister 2 are each equipped with a video camera and light source for fuel observation. The camera and light assembly are aligned with the quartz window view port on each canister. The NTSC color video signal from each camera is connected to independent input on the video capture board located in the computer chassis. The video capture board is a Creative Labs model SE1000. Video capture allows viewing and storage of either canister observations and is operable in either a Windows or DOS software system.

Radiation Detection: A single radiation monitor is employed to detect the unlikely buildup of contaminants from fuel anomalies. The system consists of an Eberline RM-14SA count 
rate meter coupled with an Eberline SPA-9, 2", NaI scintillation probe. The count rate meter has selectable ranges from 0-50 to 5 million counts per minute full scale. An adjustable alarm set point generates an alarm output to the data acquisition system if the set point is exceeded. The probe is mounted equidistant between canister 1 and canister 2 air plenums within the process cabinet. Should contaminants be detected a multichannel analyzer can be used to identify specific species.

Signal Conditioning: Analog and digital signals from sensors are conditioned and communicated to the computer through a system of intelligent modules and backplanes. Each analog signal is connected to an Omega Engineering OM6-TC module where the specific signal type is converted to digital form for transmission to the computer. Each module is configured prior to installation so that it has a unique digital address and the appropriate method of conversion for the incoming signal. Analog modules are mounted in Omega Engineering, sixteen position, model OM6-BP16-485 or OM6-BP16-232 backplanes. Digital modules are manufactured as either input or output and for specific voltage ranges. Configuration of the module consists only of assigning a unique address. Digital modules have four channels and are installed in an Omega Engineering model OM6DIO-1, six position backplane. When installed in a backplane modules become part of an RS-485 communication network and can be queried as needed.

Backplanes and modules reside in three locations: one analog (BP1) and one digital backplane (BP2) in the process cabinet, one analog backplane (BP3) on canister 1 and one analog backplane (BP4) on canister 2. BP1 is an Omega model OM6-BP16-232 which provides an RS232 interface between the computer and all modules in the system. The additional backplanes are connected in series to BP1 through a serial RS-485 network. Use of the RS-485 and remotely located backplanes ensures reliable communication and minimizes cabling.

\section{Fuel Loading and Canister Handling}

The SNF loading operation is to be done in the 105-L Transfer Bay and the loaded canister system will be stored in the 105-L Disassembly Area Dry Cave for monitoring [1].

To provide the adequate shielding during the loading operation, the SNF will be loaded into the shielded canister in the Transfer Bay pit pool using water as a shield. The shield assembly is designed to be submersible for this reason. Initially the bottom shield assembly with the canister and the thermocouple sensor rack will be lowered into the pool. Then the specific SNF will be loaded into the canister. After the fuel is loaded, the canister lid will be put on top of the bottom shield. Before the shielded canister assembly leaves the Transfer Bay pit, two bolts will be put on to secure the lid and the assembly will be rinsed with clean water while it is over the Transfer Bay pit. The assembly will then be lowered onto the Transfer Bay floor near the northeast corner and it will be surveyed for any surface contamination and adequacy of shielding. Once it clears the Radiation Control survey, a pump will be used to remove the bulk of water from the canister via the half inch tubing which serves as the air circulation system. The canister lid is then completely closed using $5 / 16-24 \times 13$ " long bolts.

At this point, the vacuum pump will be connected to the canister for drying of the canister assembly by drawing a vacuum until the vacuum gage reaches below approximately five Torr on the system. 
Once the drying operation is complete, the canister system will be transported to the $105-\mathrm{L}$ Disassembly Basin Dry Cave which is its designated long term storage location [1]. The canister will be vented to atmosphere and a limited volume of water will be injected into the system. Data collection cycle and monitoring operation plan will be determined by the Spent Fuel Storage Division and SRTC personnel.

\section{Acknowledgments}

The following individuals contributed to the success of this work: Juan Hill for drafting support; 717-A, 749-A, \& Construction Shop personnel; G. Reeves for DAS development; N. K. Gupta and P. S. Lam for the canister design calculations; C. S. Stripling for photographs; and Si-Young Lee for T/C placement

\section{References for Part II}

1. SFS-SNF-970089, "Plan for Instrumented Dry Storage of SNF," W. S. Large and D. G. Blanchard, September 9, 1997. 


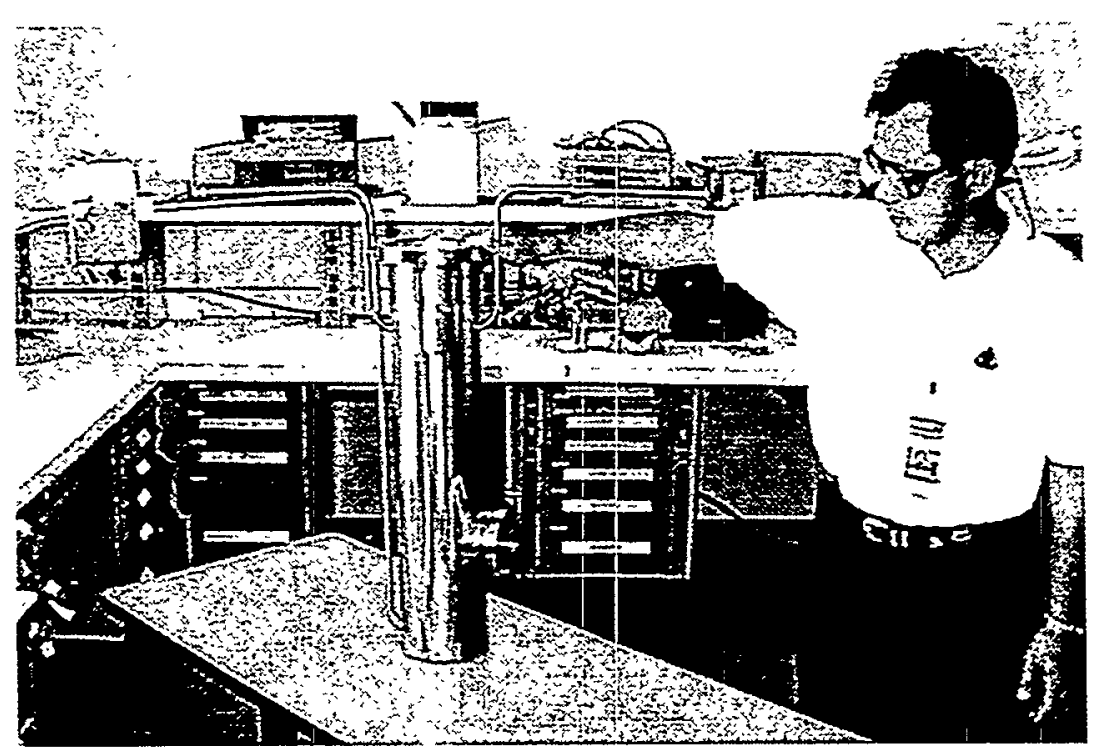

Figure II-1 Photograph of Test Canister for Housing an MTR Fuel Assembly. The visible features are the quartz viewing window, the thermo-couple feed-through line, and the circulation inlet and outlet lines.

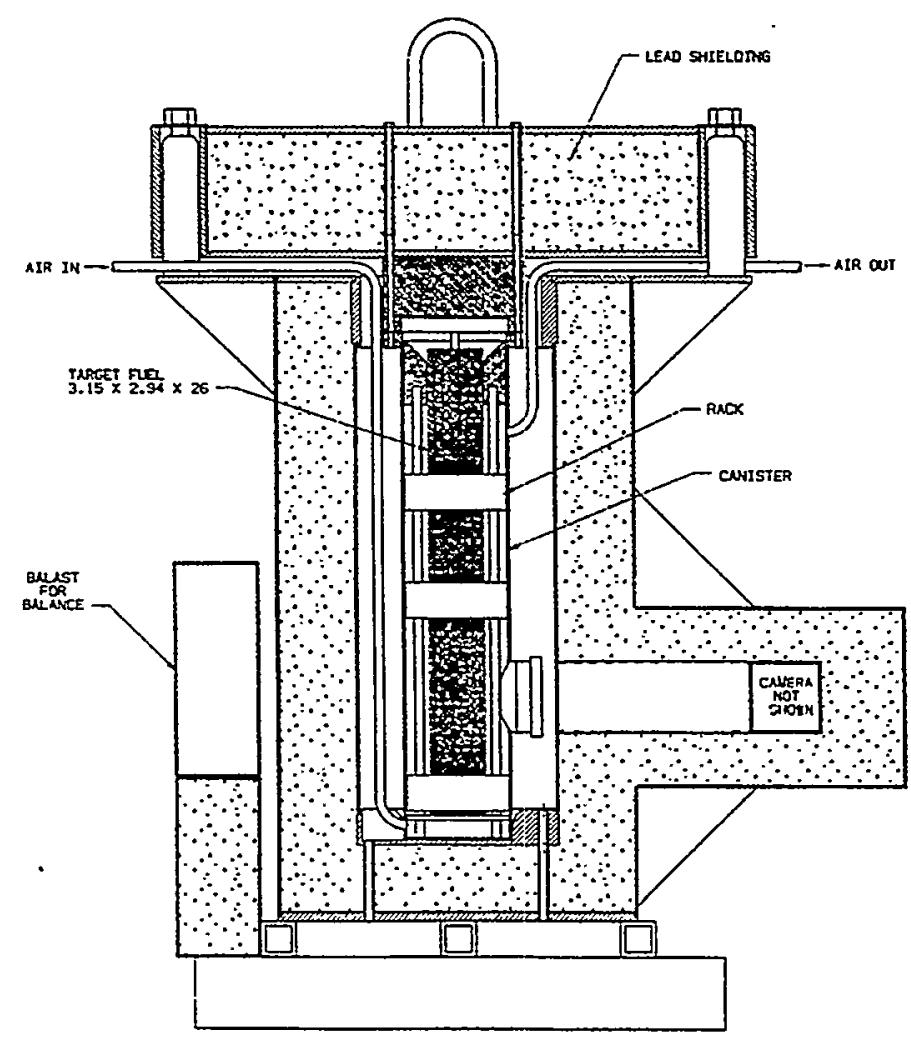

Figure II-2 Schematic of Side View 1 of Test Canister within Lead Shield for Containing an MTR Fuel Assembly. 


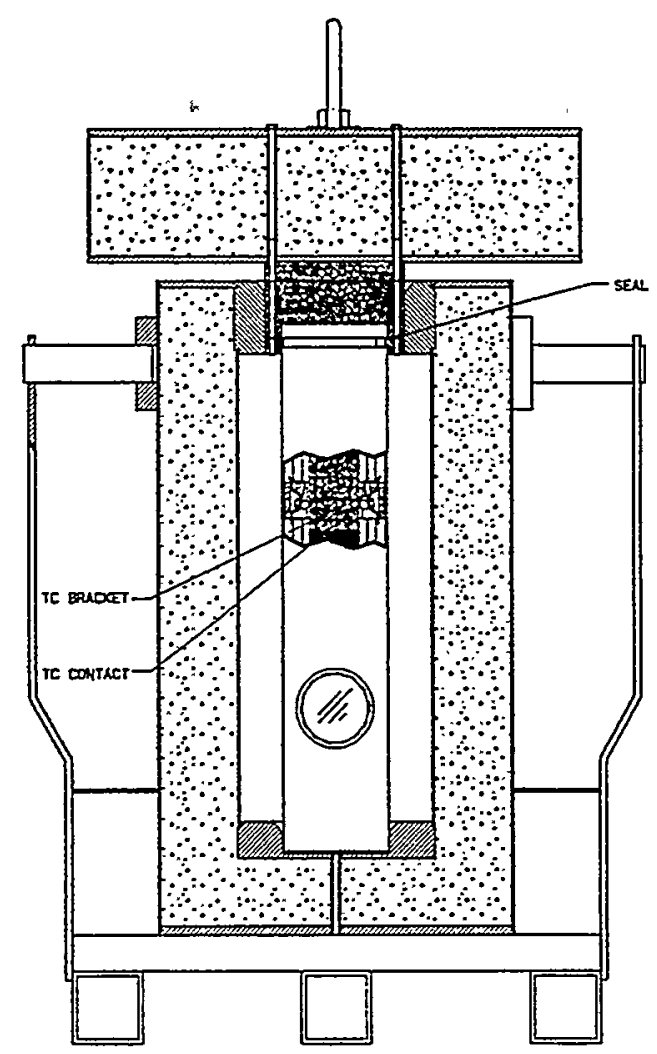

Figure II-3 Schematic of Side View 2 of Test Canister within Lead Shield for Containing an MTR Fuel Assembly. Note the lifting bails for the shield/canister assembly.

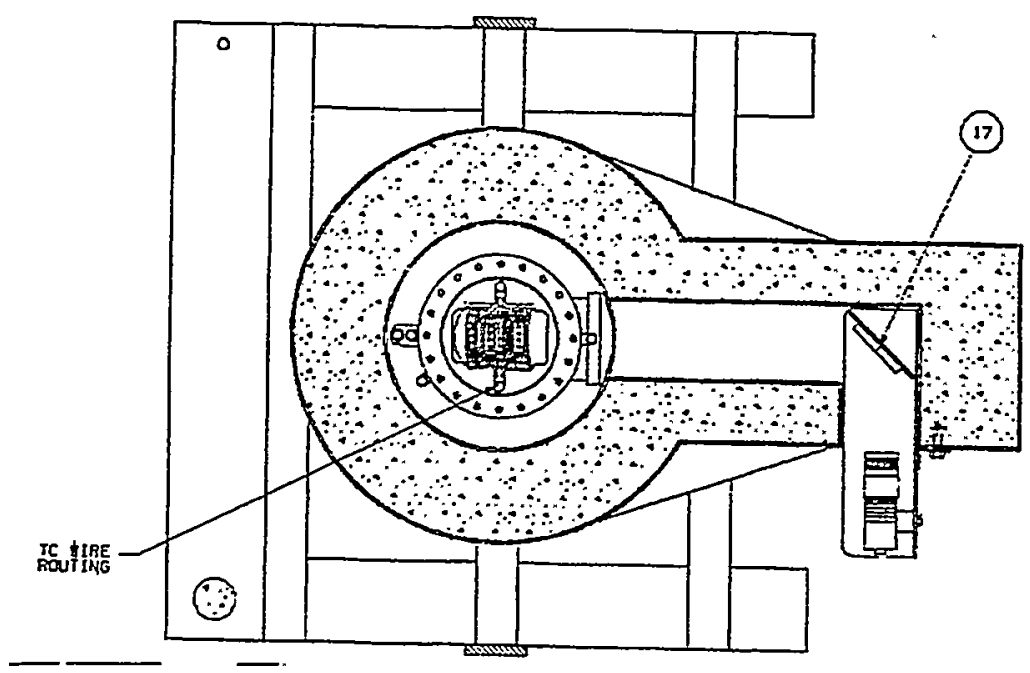

Figure II-4 Schematic of Top View of Test Canister within Lead Shield for Containing an MTR Fuel Assembly. Note the camera mounted around a $90^{\circ}$ corner to view the assembly through a front surface mirror (item 17) mounted in the viewing tunnel to avoid the high direct radiation field directly in front of the assembly. 


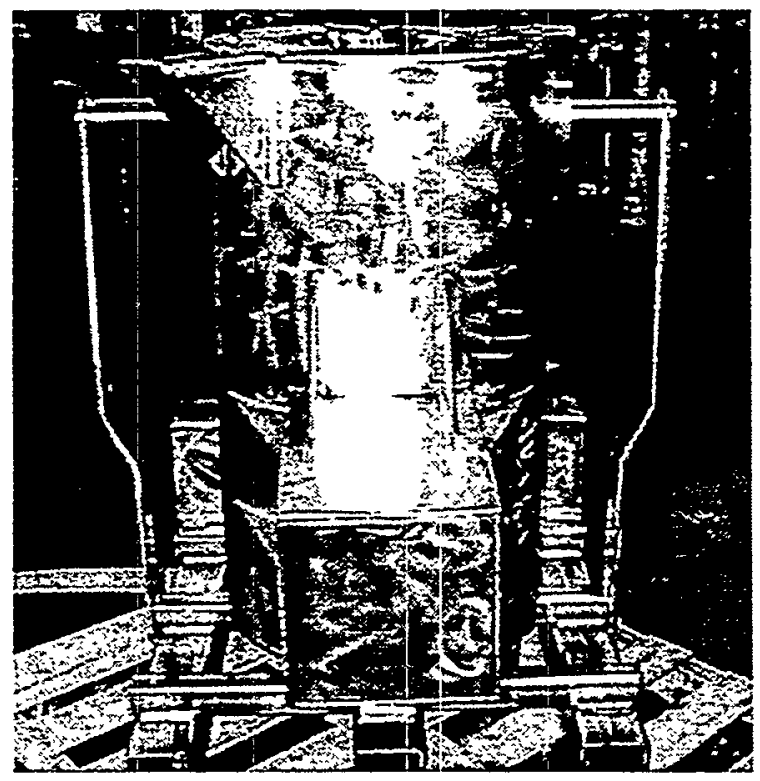

Figure II-5 Photograph of Shield for Test Canister. Note the lifting bails and skid mounting of the shield.

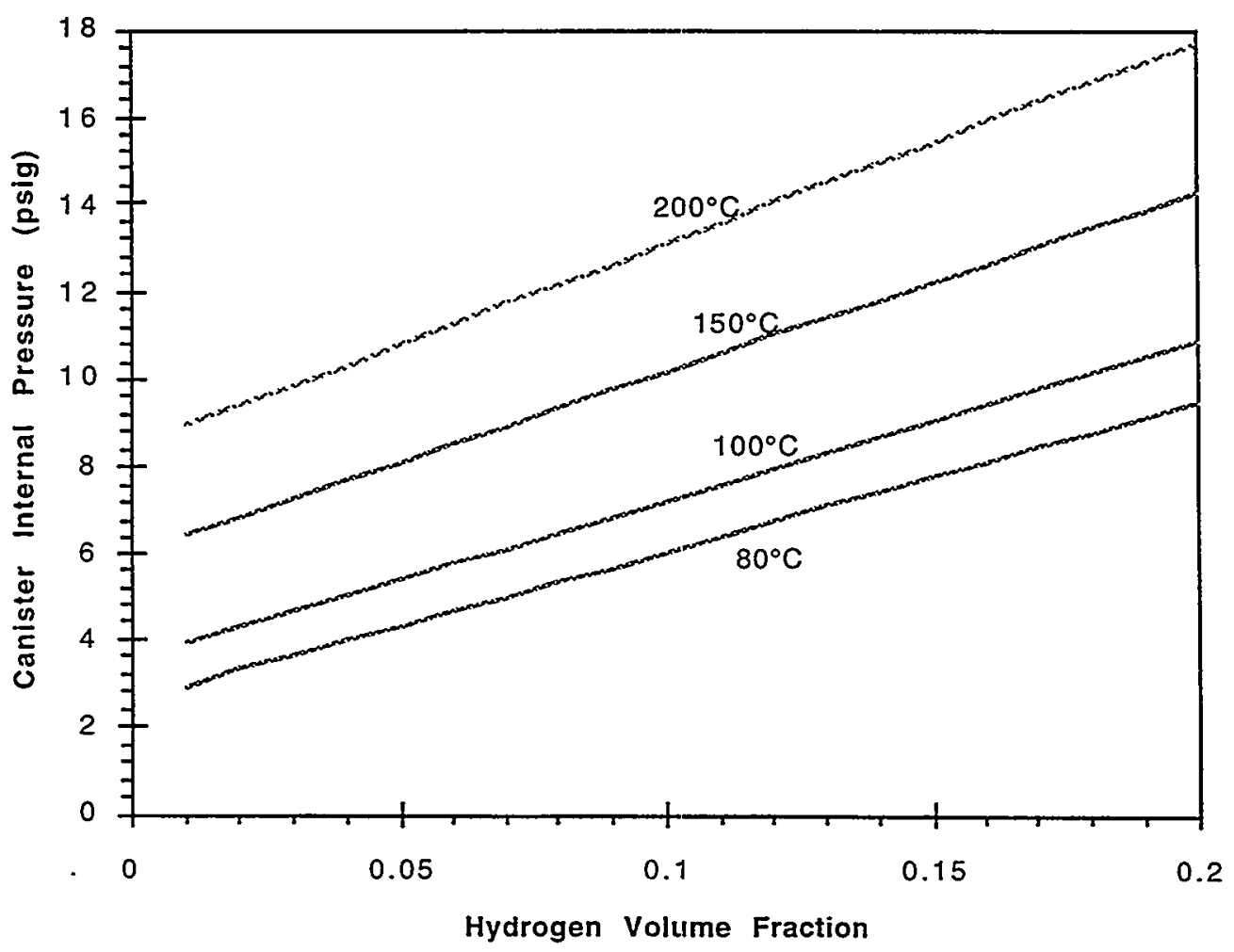

Figure II-6 Predicted Pressure from $\mathrm{H}_{2}$ Build-up as a Function of Canister Internal Temperature. Free water will be limited to avoid significant $\mathrm{H}_{2}$ build-up. 


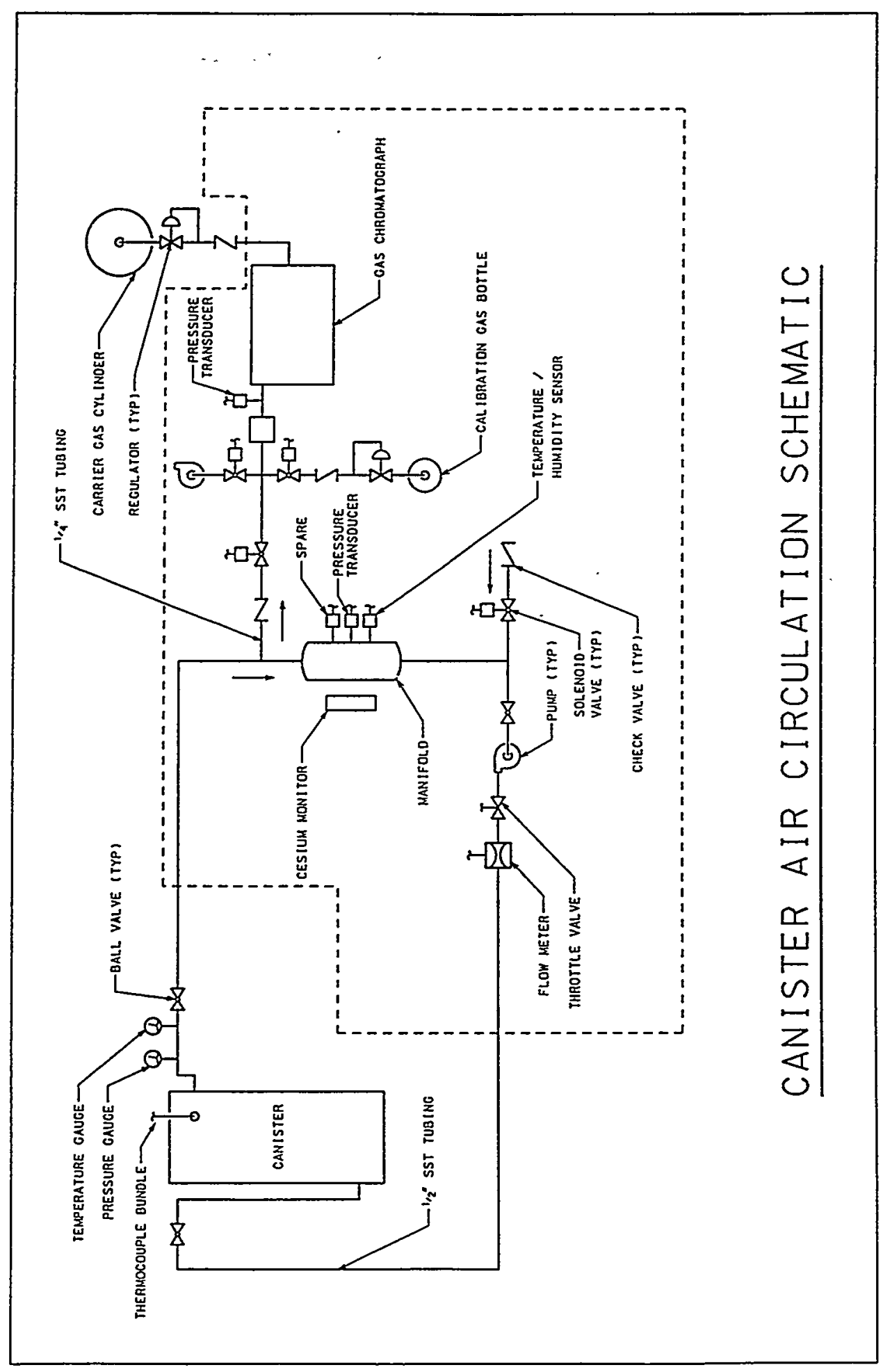

Figure II-7 Fuel Monitoring Instrumentation Schematic 

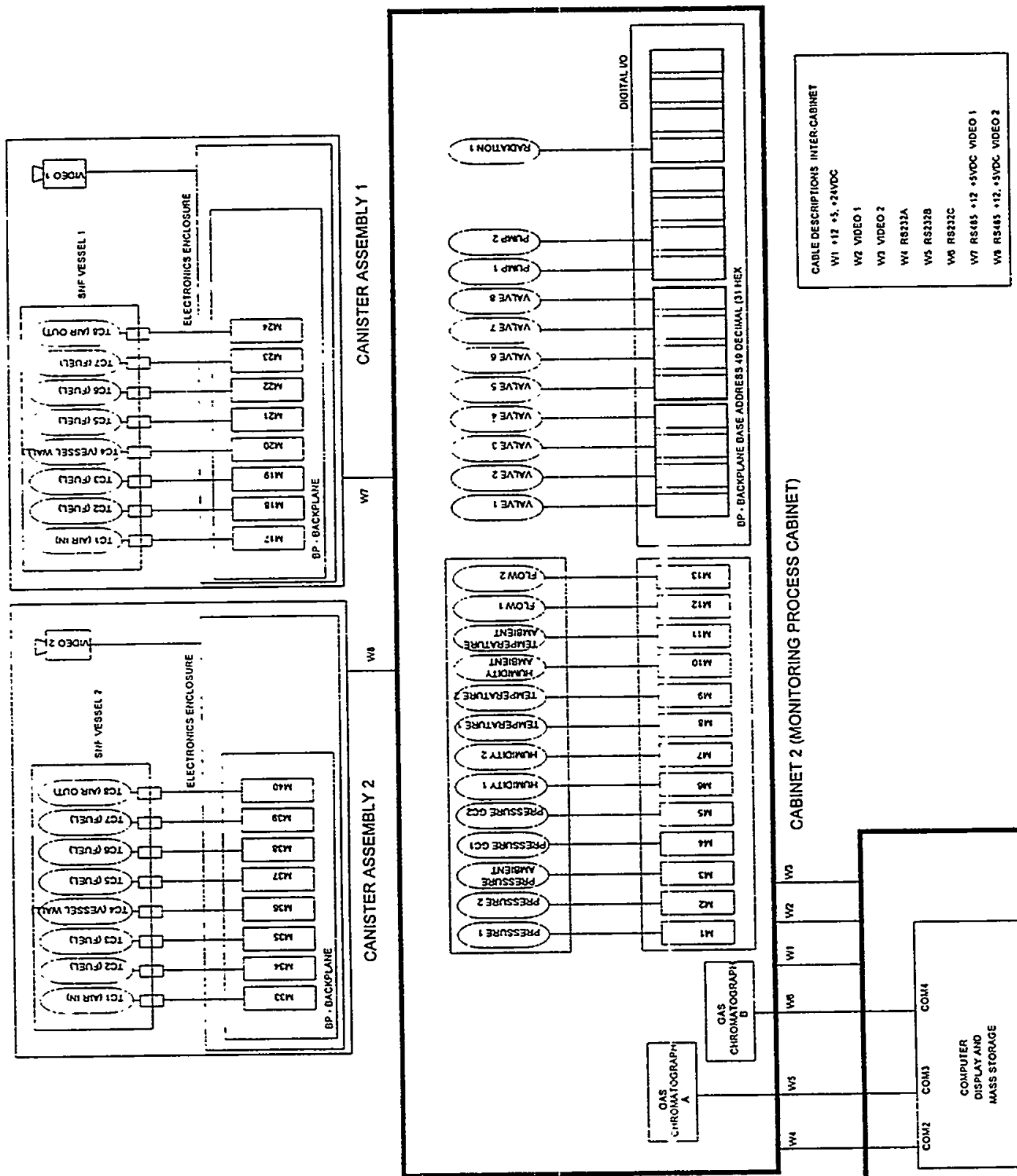

N

Figure II-8 DAS Schematic 


\section{WSRC-TR-97-00269, Part III \\ Vacuum Drying of Al SNF for Canister Storage by W. S. Large, K. Chen, and R. L. Sindelar}

\section{Background}

Vacuum drying at slightly elevated temperatures $\left(\sim 120^{\circ} \mathrm{F}\right)$ appears to be an acceptable method of preparing aluminum SNF for extended dry storage. Achieving a vacuum below the triple point of water ( $\sim 4.5$ torr) within a heated canister will vaporize all free liquid water. High temperature drying to remove water of hydration from the aluminum oxide on the SNF cladding is not practical, as the temperature required to dehydrate the oxide is high $\left(>300^{\circ} \mathrm{C}\right)$. The quantity of hydrated water is insufficient to cause excessive additional corrosion.

Proposed conditions for vacuum drying [1] are based in part on evaluation of spent nuclear fuel (SNF) drying and stabilization methods under development at the Hanford and Idaho National Environmental Engineering Laboratory (INEEL) sites [2]. SRS experience with vacuum drying methods has also been considered.

A vacuum drying test program at SRS began in August 1997 to demonstrate the feasibility of drying mock (Materials Test Reactor type) MTR SNF assemblies to below 5 torr. The tests quantified vacuum drying times versus initial water volume, and provided operating experience with the drying apparatus and instrumentation. All drying tests were conducted within the Building 105-L assembly area. The primary objectives in the drying tests are :

- Demonstrate feasibility of drying to below 5 torr in an unheated canister system; and

- Provide check-out of drying apparatus in preparation for underwater loading followed by drying of the MTR SNF in the instrumented canister.

\section{Aluminum SNF Drying Concerns}

Three sources of water can potentially contribute to corrosion of aluminum SNF:

- Free water on the SNF surface and in pits, crevices, etc.;

- Water of hydration within the aluminum oxide surface coating;

- Adsorbed water on the surface of aluminum oxide and aluminum metal

The major potential contributor to corrosion is free water on the SNF surface. An acceptance criterion of 1 milliliter of water per 0.1 square meter of surface area has been established for interim dry storage of aluminum SNF to meet the corrosion limit. This criterion to $\sim 18$ milliliters ( 0.04 pounds) per cropped MTR assembly and could produce $\sim 0.0001$ inches of uniform aluminum corrosion. A more limiting criterion is the avoidance of the generation of hydrogen above $4 \%$ in a sealed canister.

The preliminary drying specification for fuels to be placed inside the shielded canisters for the test includes to:

- Dry to less than 5 torr with minimal or no heat input; and

- Backfill the canisters with air and a finite amount of water. 
The maximum predicted hydrogen pressure as a function of hydrogen volume percent is shown in Figure II-6 assuming all of the residual free water reacts with aluminum to form Boehmite and hydrogen gas.

\section{Vacuum Drying Test Setup}

The vacuum drying test hardware include the test canister, mock MTR fuel assembly, vacuum pump, instrumentation and data acquisition equipment.

\section{Vacuum Canister and Mock Fuel Assembly}

A test canister, similar in design to the instrumented canisters, and a mock MTR fuel assembly were designed by EES and utilized in the tests (see part II to this report). The canister, constructed of Type 304 stainless steel, is 6 inches diameter, 35.4 inches high, with a volume of -934 cubic inches. The removable lid is sealed with a standard copper vacuum gasket. The mock assembly contains 18 aluminum plates and variable wattage heaters on the outer two plates. A photograph of the canister and mock-up in L assembly is in figure III-1. A photograph of the vacuum canister stand and scale is in figure III-2. A photograph of the assembled canister in a test is in figure II-3. A photograph of the assembly in the canister is in figure III-4. A photograph showing the dry can post-test is in figure III-5.

\section{Vacuum Equipment}

Drying tests utilized a 480 VAC skid-mounted Kinney KLRC 300KFA liquid ring rotary vacuum pump in series with a KMBD 1604 blower and an air ejector, as shown in Figure III-6. The oil-free liquid ring pump utilizes water as the vacuum chamber sealant and coolant. Nominal pump capacity is $300 \mathrm{cfm}$ at $100 \mathrm{torr}$, and the pump and blower combination can achieve a maximum vacuum of $\sim 0.5$ torr. The pump was connected to the canister via 50 feet of $1-1 / 2$ inch diameter flexible stainless steel hose. The $1 / 2$-inch diameter port on the test canister was connected to the stainless steel hose via $\sim 6$ inches of 3/8-inch $\mathrm{ID}$ Tygon tubing.

Water mass changes within the canister during tests was measured with new Mettler Toledo precision bench scales. The scales have a readability of 0.0002 pounds with a maximum capacity of 70 pounds. The canister and assembly weighed $\sim 47$ pounds and remained on the scales during drying.

\section{Instrumentation and Data Acquisition}

Two calibrated vacuum gages monitored the approach to dryness during tests. A Varian model WV110-2 digital vacuum gage with a range of 0.001 to 1500 torr was installed in the canister lid to monitor pressure. A Varian model 801 thermocouple vacuum gage with a range of 0 to 2 torr was installed at the 1-1/2 inch hose inlet. SRTC equipped the canister with two thermocouples and a humidity sensor to monitor interior conditions. The thermocouples measured side plate temperatures at the top of the assembly. A thermocouple was also taped to the canister exterior below the initial water level for selected tests.

The digital scales, humidity sensor, interior thermocouples, and vacuum gage were connected to a computerized data acquisition system that displayed and stored readings 
every 5 seconds during tests. Readings were also recorded manually at $\sim 10$ minute intervals during tests. Figure III-7 shows the test loop.

\section{Test Methodology}

The empty canister and mock SNF were weighed prior to the start of each test to establish baseline weights. A measured quantity of water was then added directly to the canister or poured over the assembly, and the lid was sealed. The sealed canister was weighed at least five times to establish the gross weight of the canister, mock SNF, and water. The weight/volume of water added was determined by the weight difference. The vacuum hose and instrumentation cables were connected to the canister after weighing, and data acquisition was initiated upon startup of the vacuum pump. Vacuum immediately stabilized at 25-30 torr as water inside the canister began to boil.

Strip heaters on the mock SNF were operated at 14 or 5 watts during selected tests to simulate heat generating SNF. Heat generation was controlled by regulating the voltage and current on an adjustable power supply.

Temperatures, vacuum, and humidity readings were recorded throughout each test. Drying continued until a vacuum of 1 torr or better was achieved inside the canister indicating all water had been removed. Typical final vacuum was 0.4 to 0.7 torr. The canister was backfilled with room air to atmospheric pressure after completing drying. Hoses and cables were disconnected prior to obtaining a final gross weight.

Condensate on the exterior of the canister and scale platform during nonheated drying tests skewed weights. The scale platform and canister were hand-dried to remove all condensate prior to final weighing for these tests. The canister was opened after drying was completed, the mock SNF was removed, and the canister and assembly were visually inspected to ensure no moisture remained.

\section{Test Matrix}

A series of drying tests was conducted over a two week period with varying initial quantities of water and heat inputs to obtain baseline drying performance data. The water content inside the test canister varied from 15 to $689 \mathrm{ml}$. The 300 milliliter tests equate to $\sim 1$ inch of standing water ( 0.6 pint) inside the canister, and the 450 milliliter tests equate to $\sim 1-1 / 2$ inches of standing water (1.5 pints) inside the canister. The actual instrumented test canisters are expected to retain $1 / 2$ to 1 inch of water after the SNF is loaded and the bulk water is pumped out. The power input to the test varied from 0.0 to 14 watts, compared to an estimated decay heat from a spent MTR fuel assembly of 1 watt. The results from the high power input conditions provide information to improve the drying time when the vacuum dry system is used to dry the MTR fuel assemblies. Short duration drying tests with a dry assembly, damp assembly, and dripping assembly were also conducted to provide reference data. Table III-1 lists the major test matrix.

\section{Test Results}

Appendix 1 contains the field procedure with data collected. Drying tests with the mock MTR assembly demonstrated that vacuum drying is feasible for the two shielded, instrumented canisters after loading SNF. The general configuration of the vacuum pump, hose, and instrumentation was satisfactory. 
The parameters measured during the vacuum test were pressure, temperature and relative humidity inside the canister, pressure in the vacuum hose and weight of the test assembly.

Figures III-8 to III-13 show measured pressure transients. It was found that air inside the canister was sucked out rapidly when the vacuum pump was turned on. This was indicated by a sharp pressure drop inside the canister. After this initial pressure drop, the pressure inside the canister remained constant at an equilibrium value determined by the rate of evaporation of water inside the canister and the rate of evacuation of vapor by the vacuum pump. The pressure inside the canister experienced another sharp drop when the canister became dry and no more water could evaporate to make up for the vapor that was evacuated. This same pressure drop pattern was observed at the vacuum hose line, except that the pressures there were lower than inside the canister.

Figures III-14 to III-19 depict relative humidities inside the canister. The initial drop of the relative humidity indicates that the vacuum suction was sufficient to control the vapor content inside the canister. After the pump evacuated the initial vapor in the canister, the relative humidity inside the canister remained at a constant level controlled by the evaporation and evacuation rates. The relative humidity dropped sharply when the water inside the canister was depleted.

Figures III-20 to III-25 compare measured temperatures and pressures inside the canister. The temperature inside the canister dropped as the water evaporated due to the heat of vaporization ( $\sim 1000$ Btu per pound of water). When the water inside the canister became depleted, evaporation ceased, and the temperature inside the canister increased due to ambient heat transfer and the power input. The rate of temperature increase for powered tests was higher than that for unpowered tests.

A thermocouple taped to the canister exterior below the internal water level was monitored during selected tests. Figures III-26 to III-28 compare these measured exterior temperatures with pressures inside the canister. Initially, the canister exterior temperature decreased due to heat transfer into the canister. Later, this temperature returned to ambient levels after evaporation inside the canister ceased. For the unpowered tests, the canister exterior temperature was below $\sim 5^{\circ} \mathrm{C}$ and condensation occurred on the exterior surface. Condensate accumulated on the scale surface and ran off onto the floor.

For the unpowered test with $461 \mathrm{ml}$ water added to the canister, four pieces of napkin were placed on the scale to prevent condensate from running off. The amount of condensate collected was $0.09 \mathrm{lb}$, which accounts for a transfer of 4 watts to the canister due to condensation.

Figures III-29 to III-34 show the measured weight during the vacuum process. This weight includes canister, mock fuel, water, condensate and forces from hose connection and instrumentation lines.

Figure III-35 shows that the drying time decreased when heat was applied to the mock fuel assembly and increased when the amount of water added to the canister increased.

\section{Recommendations for Instrumented SNF Drying}

Figures III-8 to III-28 show that any of the measurements (pressure, relative humidity and temperature) could be used as an indication of dryness during the vacuum dry process. To 
minimize personnel radiation exposure and design complications, the pressure measurement on the vacuum hose is recommended to monitor dryness for vacuum drying of irradiated SNF.

Drying tests using the shielded SNF canisters and the mock MTR assembly are planned prior to loading irradiated SNF. The Saphir SES02 assembly proposed for loading into one of the canisters has a very low heat output ( $\sim 1$ watt), which suggests that drying of this assembly could be expedited by external heating. Simple concepts such as a warm air purge also will be evaluated.

Thermocouples within the instrumented canisters are intended for long-term monitoring after drying is completed. Consideration will be given to using thermocouple data to confirm dryness.

\section{Acknowledgments}

The following individuals contributed to the success of this work: D. J. Pak for vacuum canister design and oversight of fabrication by the 717-A, 749-A shops; P. J . French for canister design and preparation of the field procedure; R. F. Eakle for sensor system design, fabrication, and calibration; C. S. Stripling for calibrations, photographs, and test support; and G. Reeves for sensor data logging.

\section{References for Part III}

1. WSRC-TR-97-0075, "Review of Drying Methods for Spent Nuclear Fuel (U)," W. S. Large and R. L. Sindelar, Westinghouse Savannah River Co. report, April 1997.

2. SRS-SNF-970064, "Trip Report - SNF Drying Review at INEEL," W. S. Large, May 28, 1997. 
Table III-1 Test Matrix and Measured Drying Time

$\begin{array}{ccc}\begin{array}{c}\text { Water Volume in Canister } \\ \text { (ml) }\end{array} & \begin{array}{c}\text { Heat Input } \\ \text { (Watt) }\end{array} & \begin{array}{c}\text { Drying Duration } \\ \text { (Minute) }\end{array} \\ 14.3 & 14.0 & 6 \\ 15.5 & 0.0 & 27 \\ 300 & 14.0 & 230 \\ 448 & 14.0 & 378 \\ 297 & 4.8 & 290 \\ 297 & 0.0 & 348 \\ 461 & 0.0 & 518 \\ 689 & 0.0 & 779\end{array}$




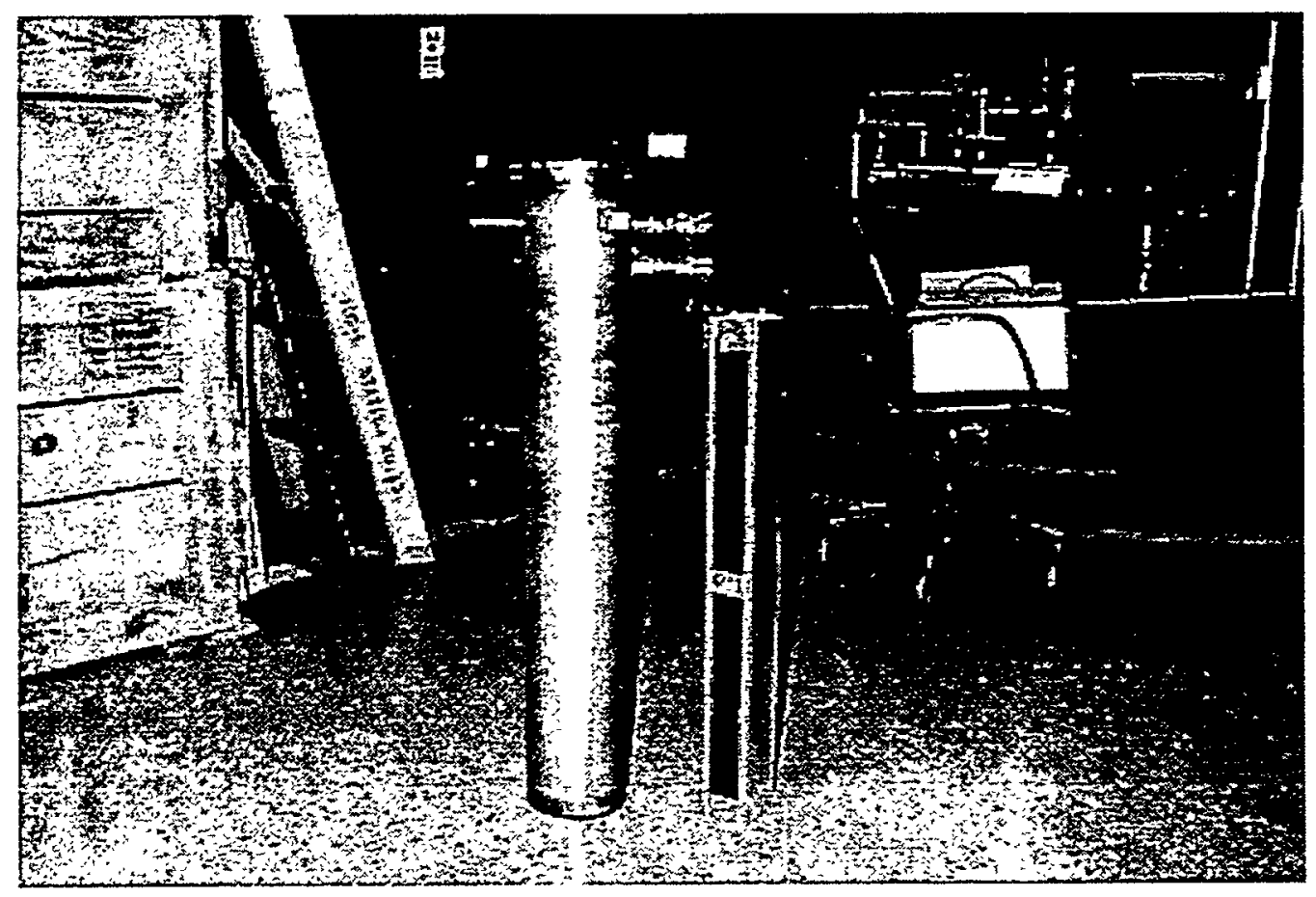

Figure III-1 Vacuum canister and electrically-heated fuel mock-up

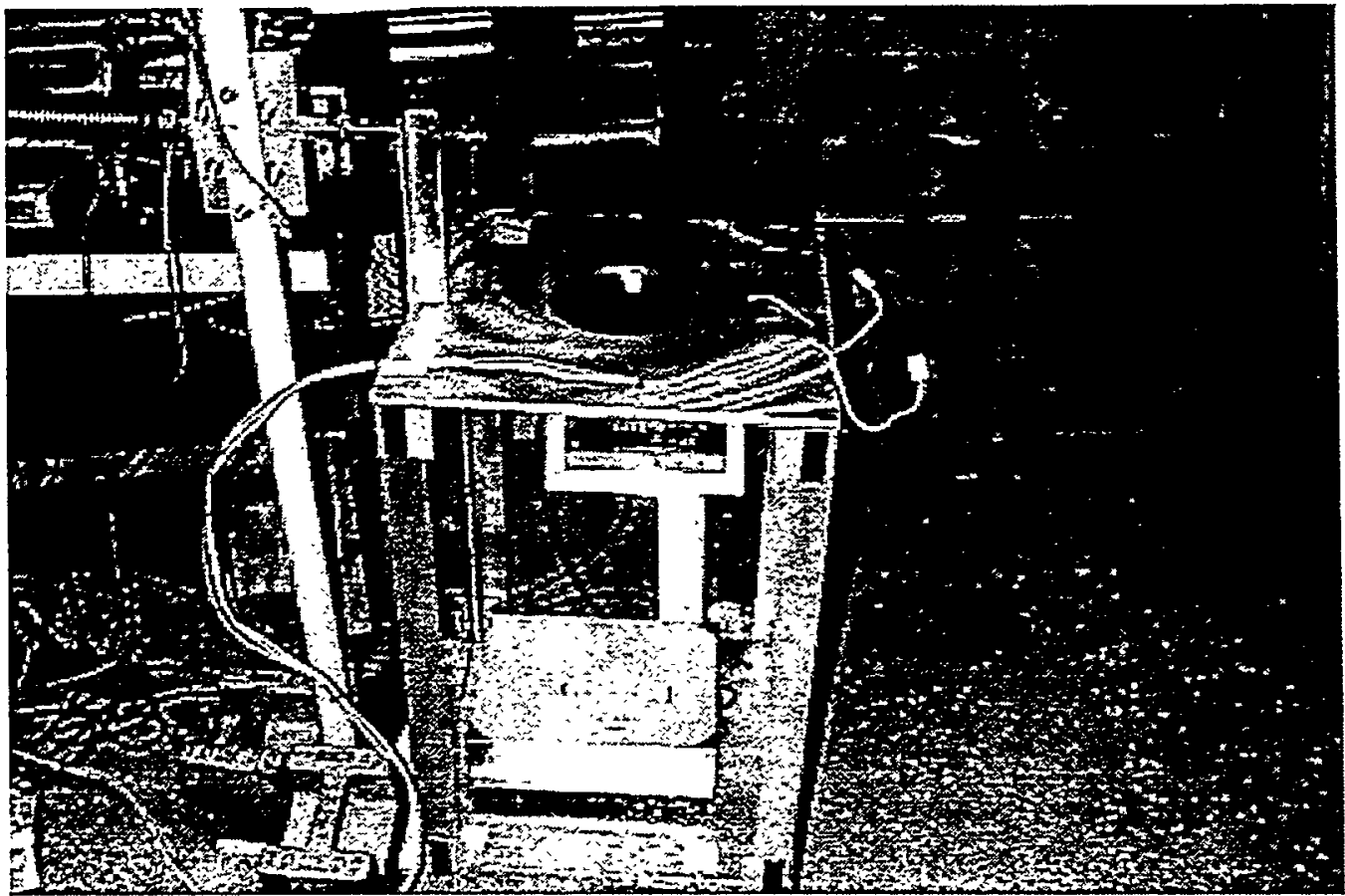

Figure III-2 Stand to hold vacuum canister. Note the scale on which the canister rests. 


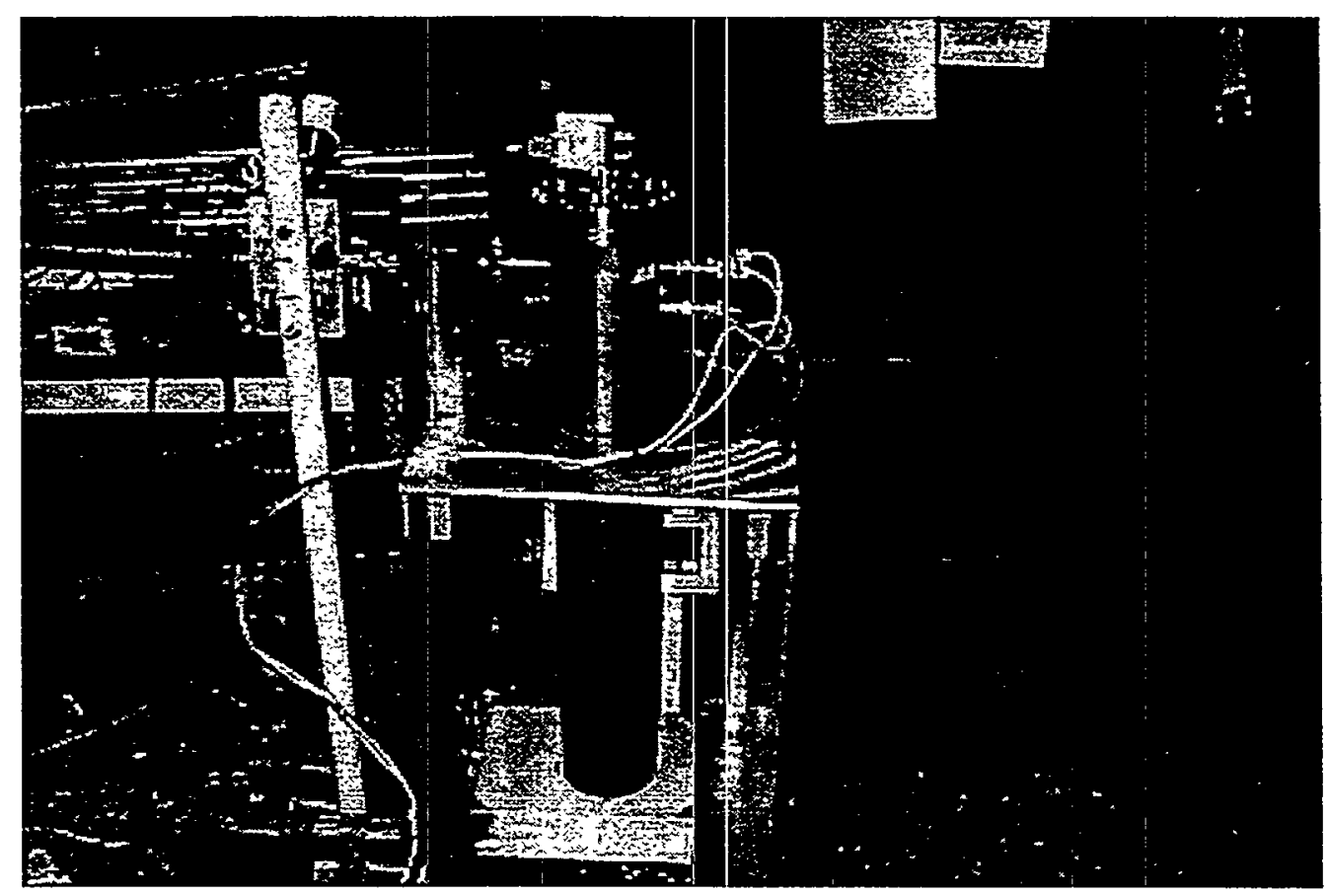

Figure III-3 Assembled Canister in a Test

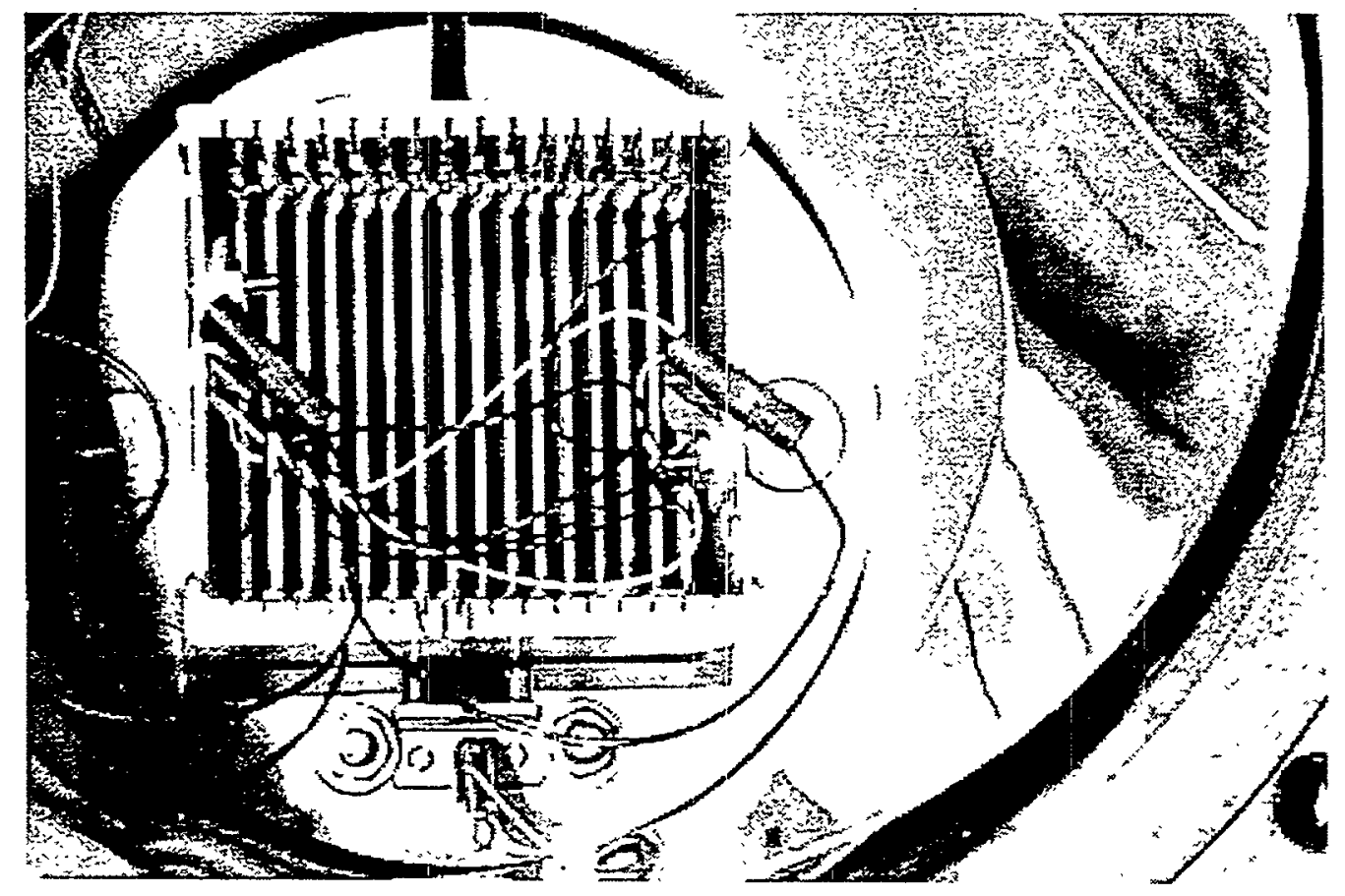

Figure III-4 Assembly inside the Canister 


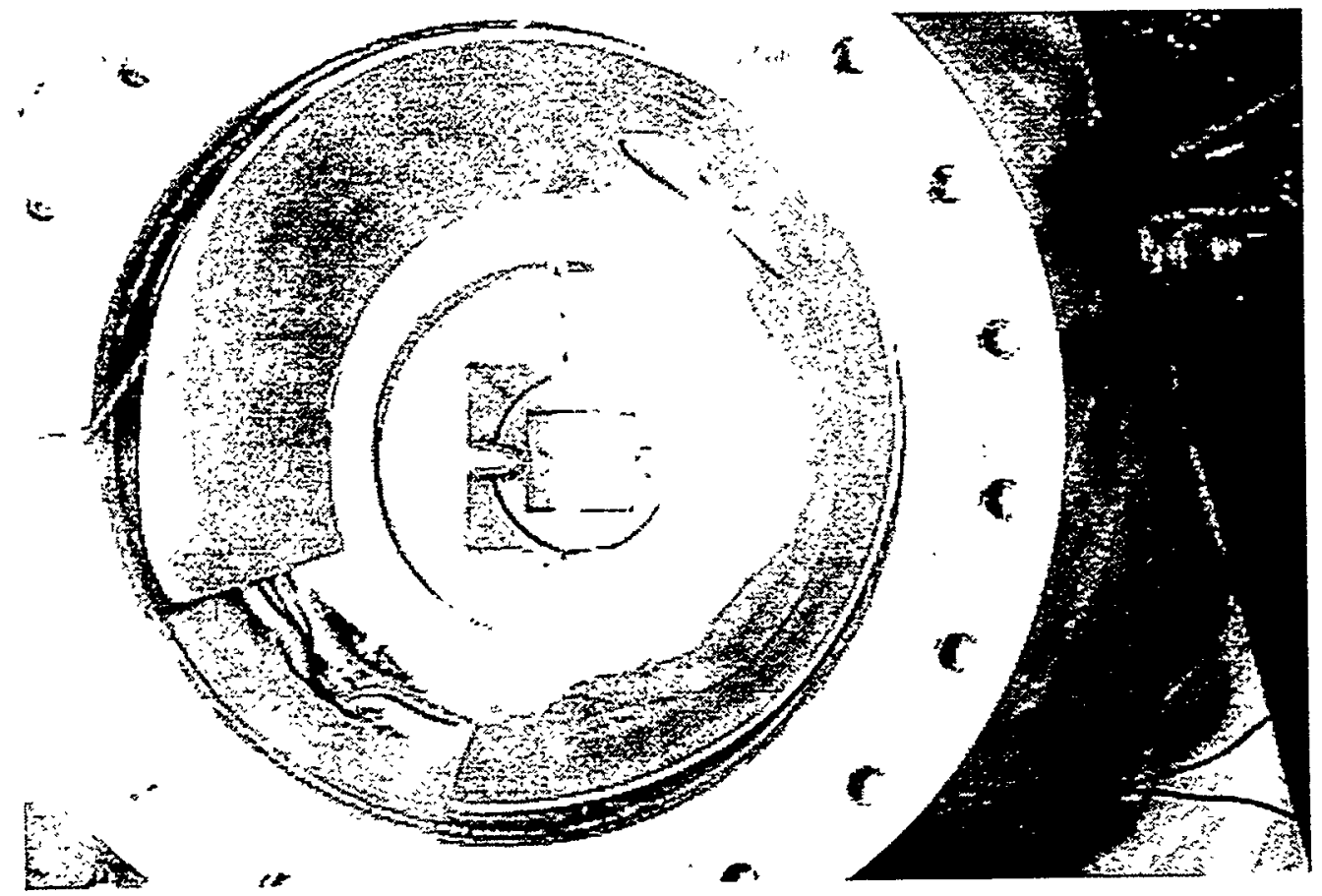

Figure III-5 Post Test Canister Interior

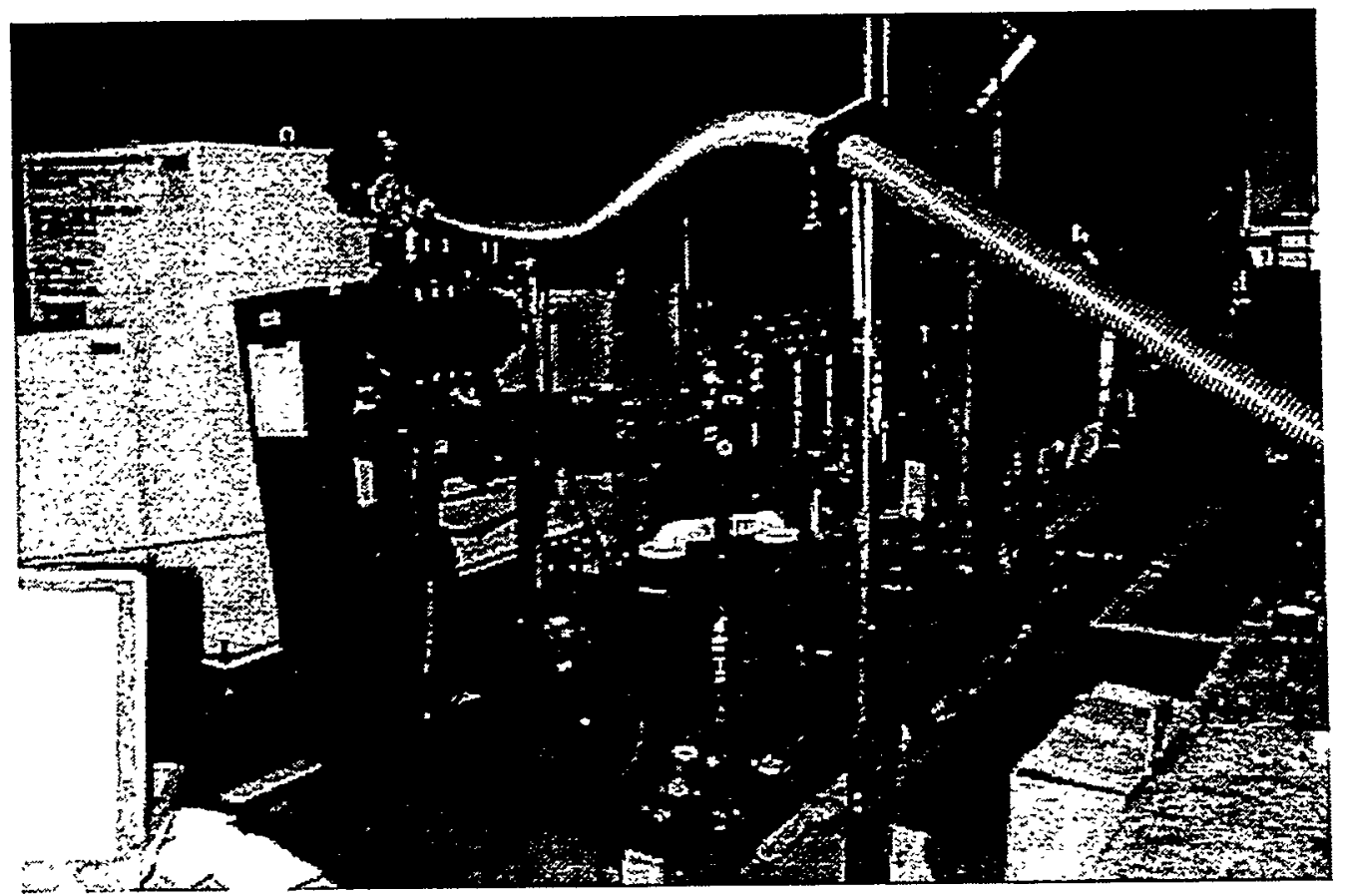

Figure III-6 Vacuum Pump 


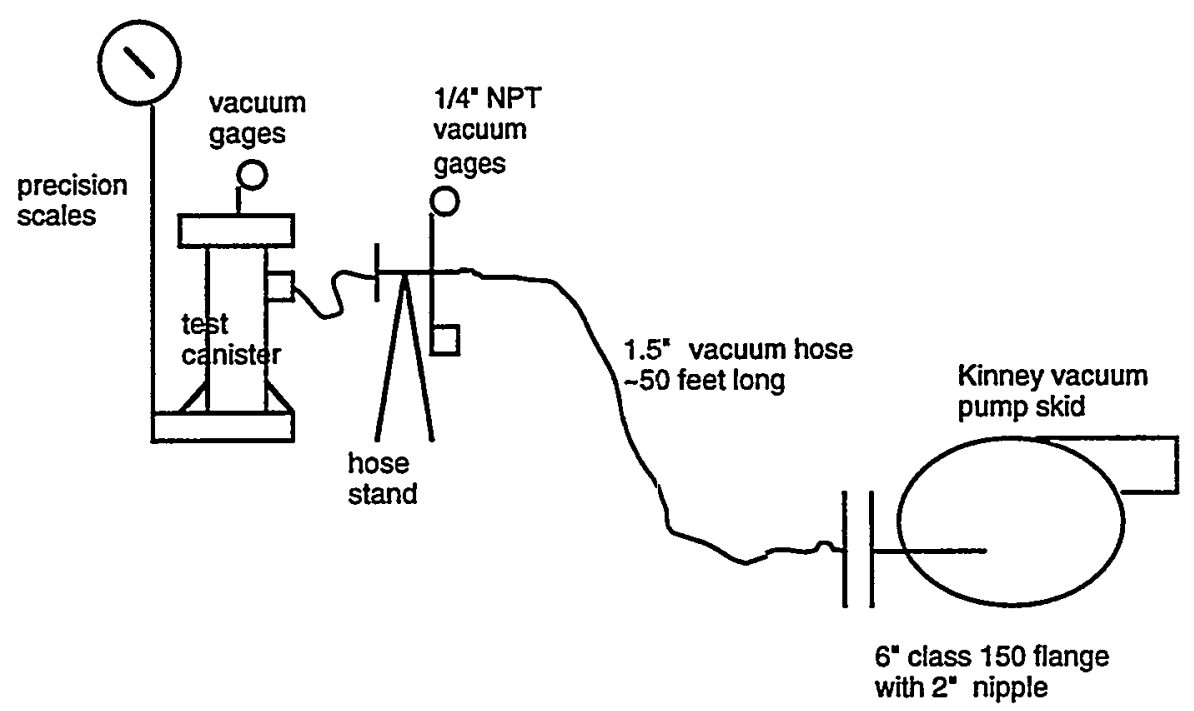

Figure III-7 Test Loop (Not to scale)

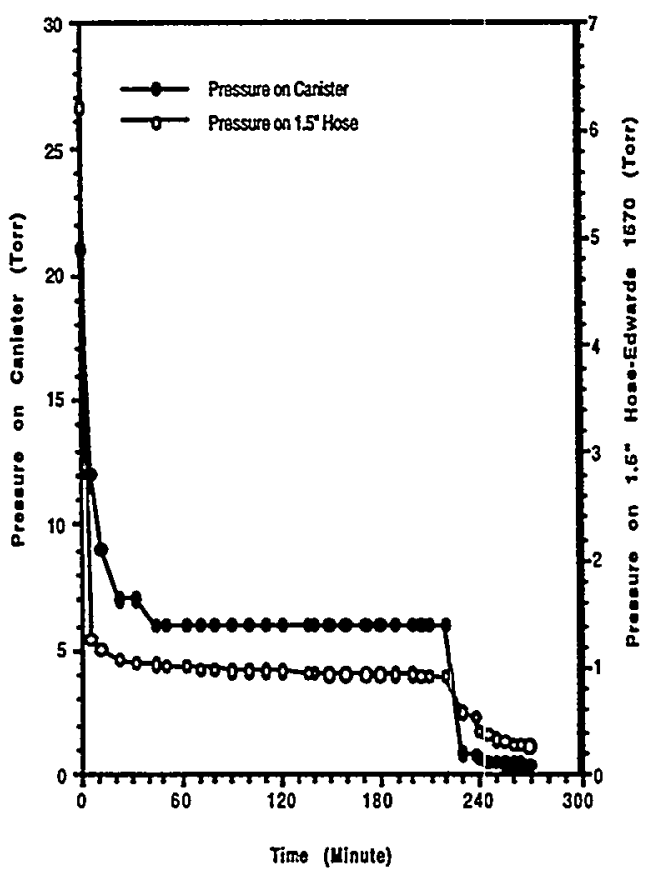

Figure III-8 Measured Vacuum Pressure (300 ml, 14 Watts, 8/19/87) 


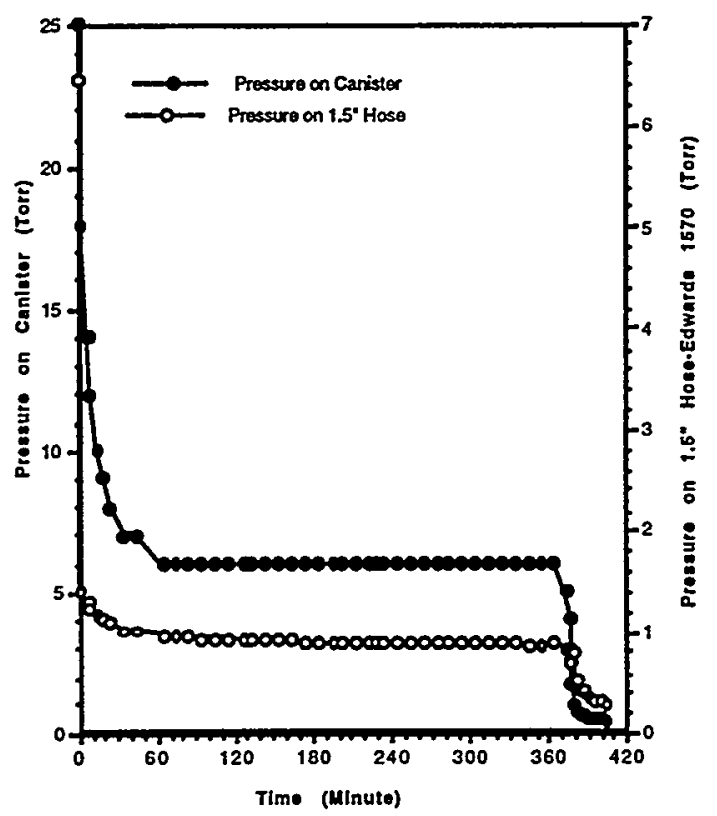

Figure III-9 Measured Vacuum Pressure (448 ml, 14 Watts, 8/20/87)

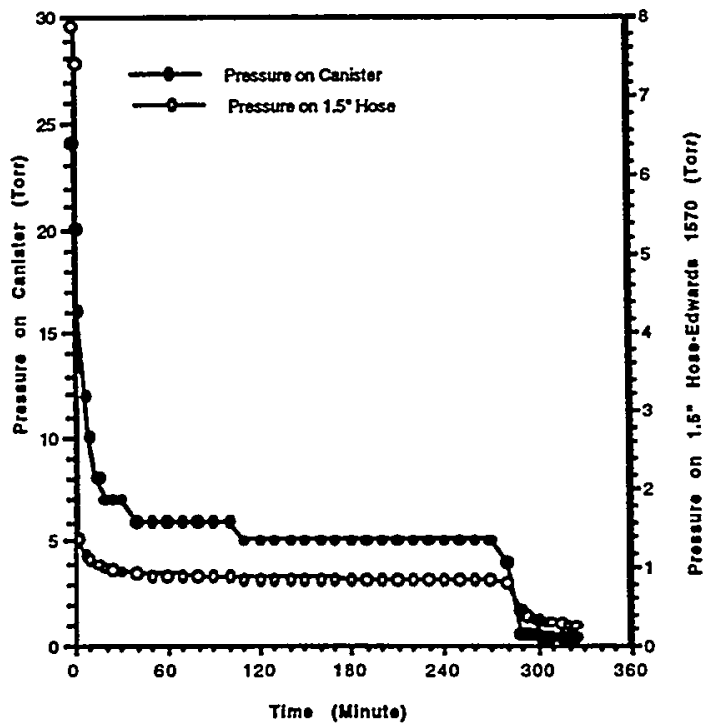

Figure III-10 Measured Vacuum Pressure (297 ml, 4.8 Watts, 8/21/87) 


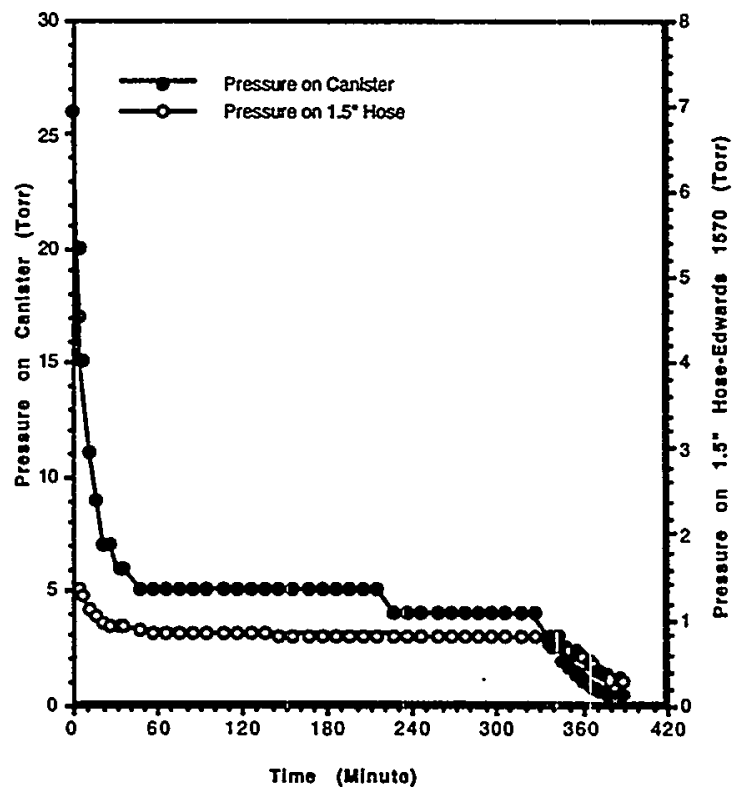

Figure III-11 Measured Vacuum Pressure (297 ml, 0.0 Watts, 8/25/87)

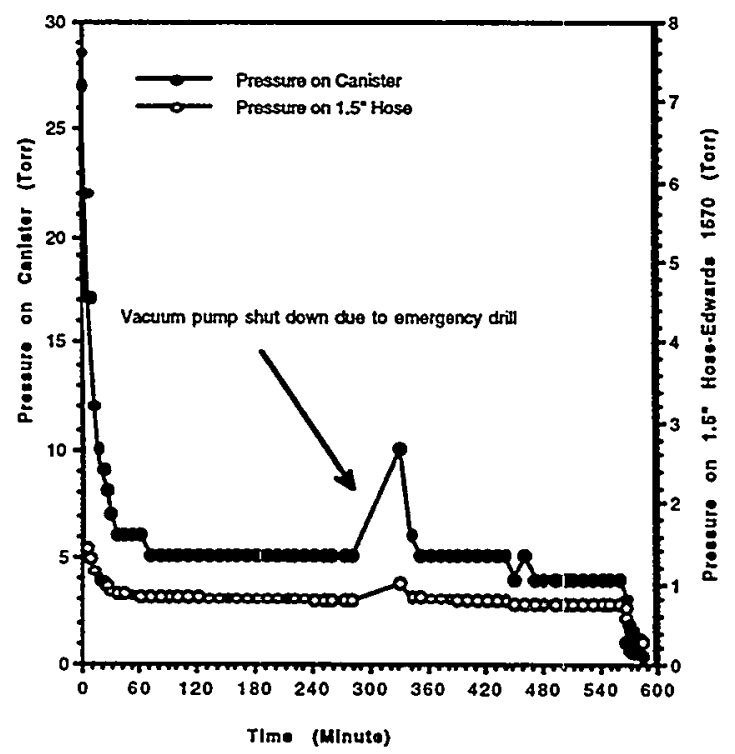

Figure III-12 Measured Vacuum Pressure (461 ml, 0.0 Watts, 8/27/87) 


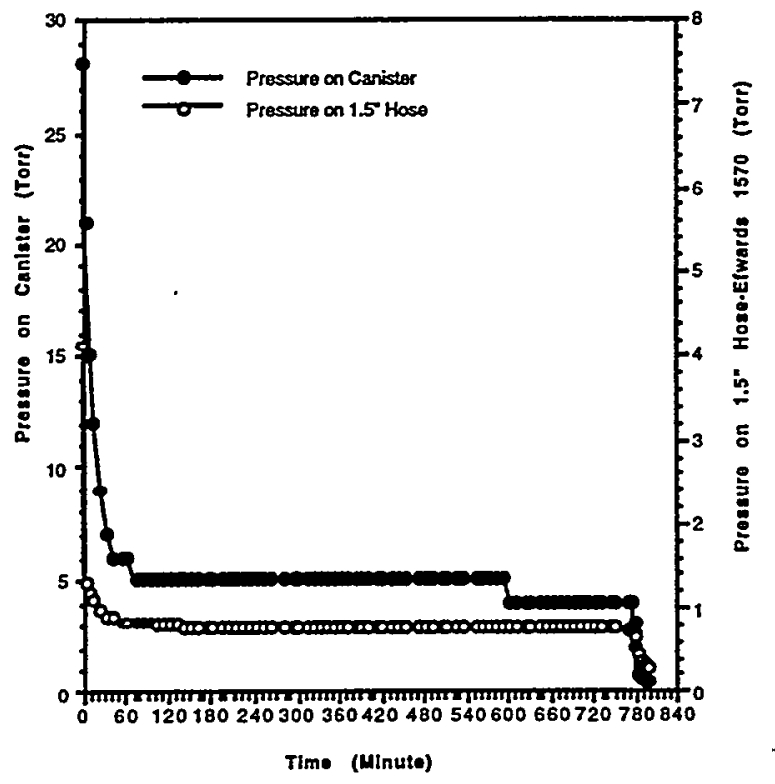

Figure III-13 Measured Vacuum Pressure (689 ml, 0.0 Watts, 8/28/87)

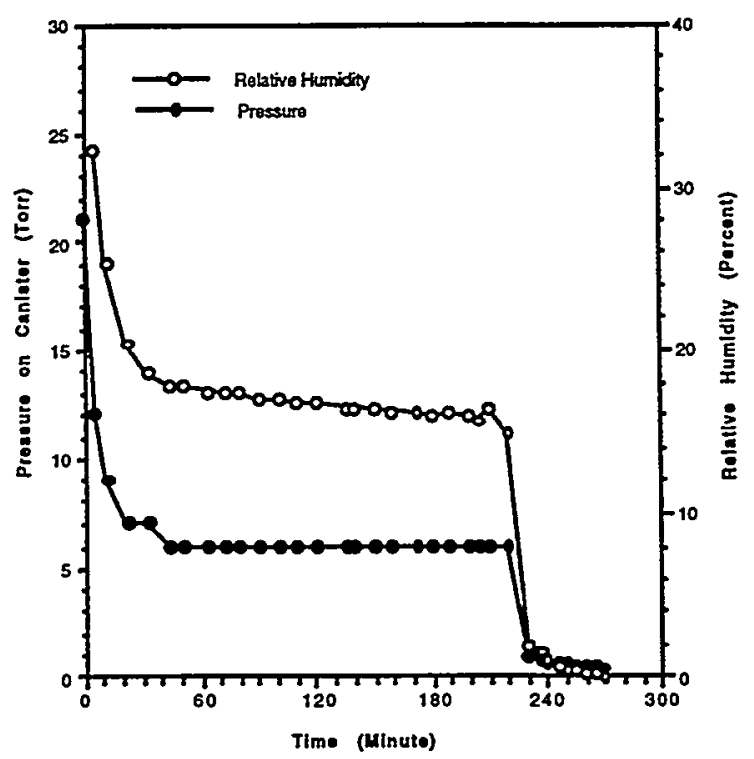

Figure III-14 Measured Relative Humidity inside the Canister (300 ml, 14 Watts, 8/19/97) 


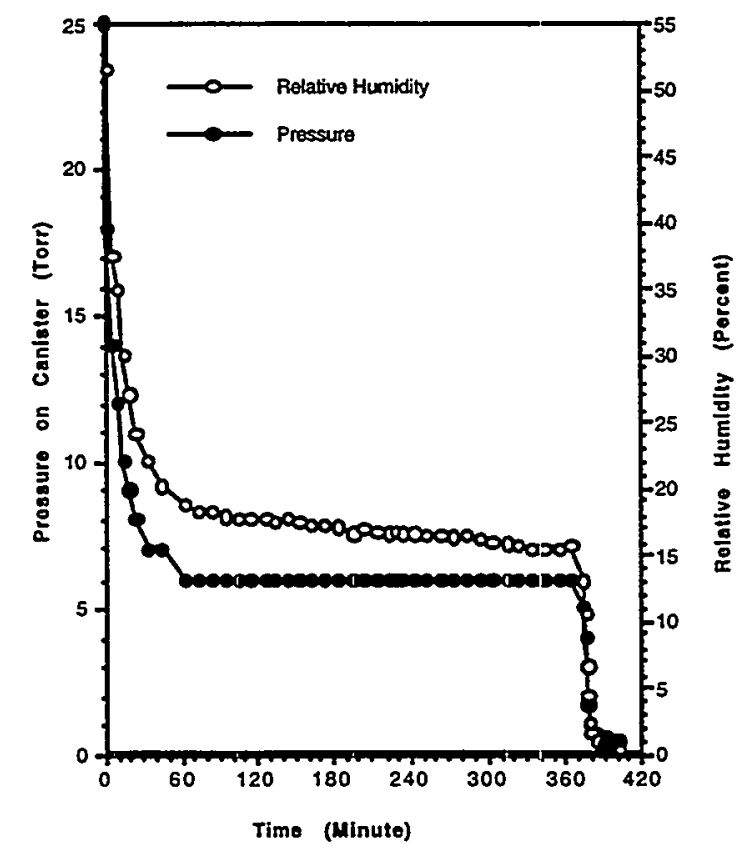

Figure III-15 Measured Relative Humidity inside the Canister (448ml, 14 Watts, $8 / 20 / 97)$

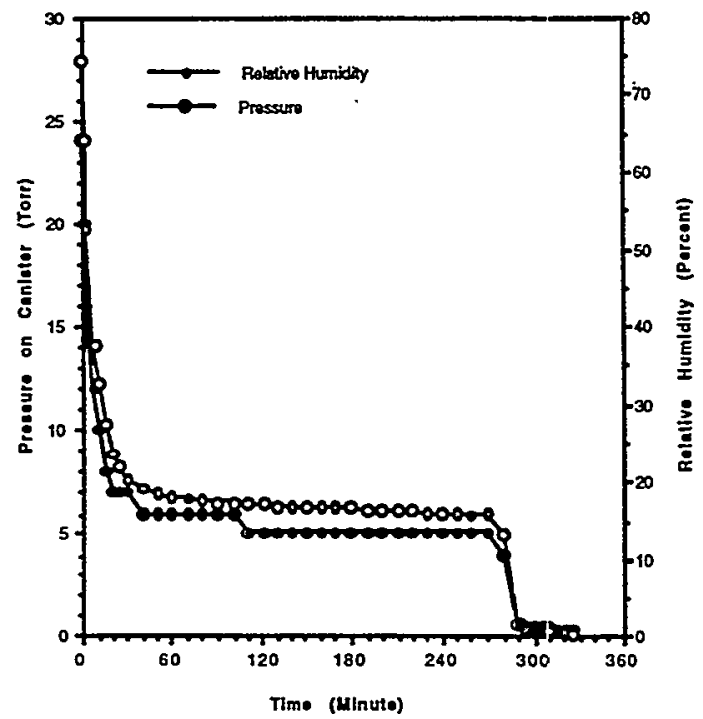

Figure III-16 Measured Relative Humidity inside the Canister (297ml, 4.8 Watts, 8/21/97) 


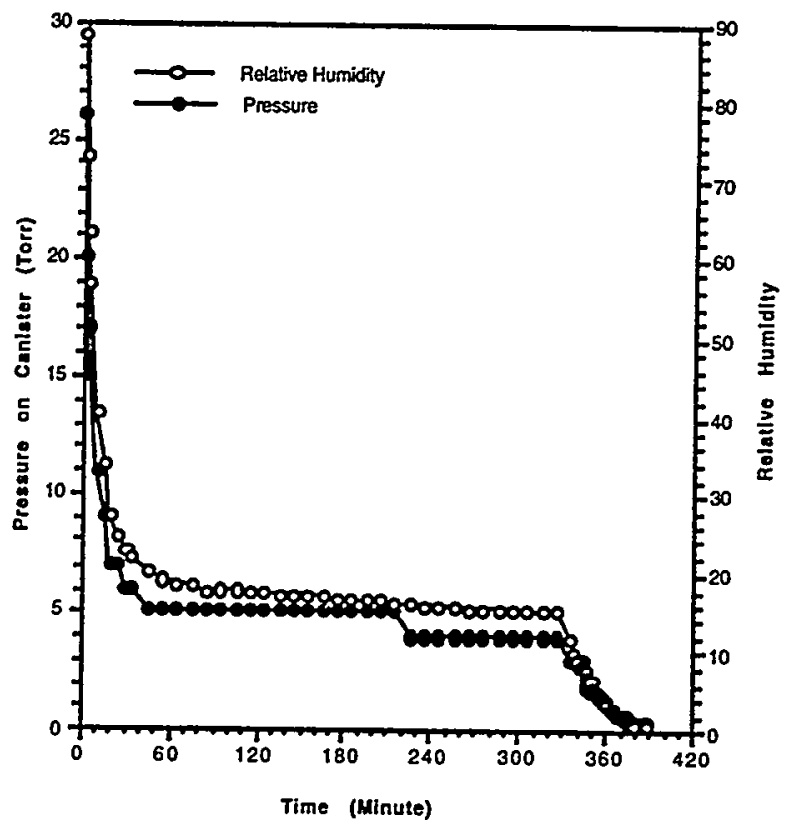

Figure III-17 Measured Relative Humidity inside the Canister (297ml, 0.0 Watts, $8 / 25 / 97$ )

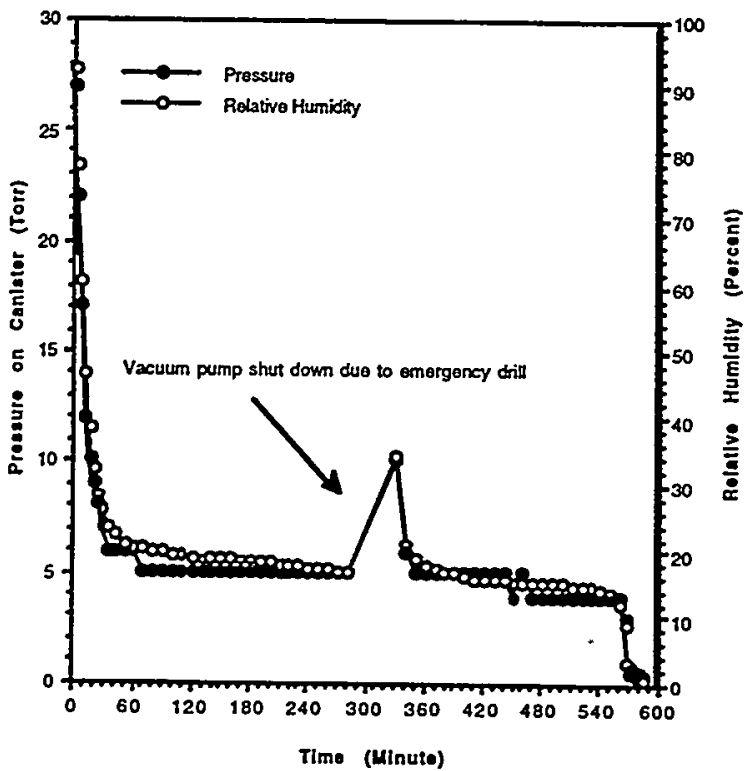

Figure III-18 Measured Relative Humidity inside the Canister (461ml, 0.0 Watts, 8/27/97) 


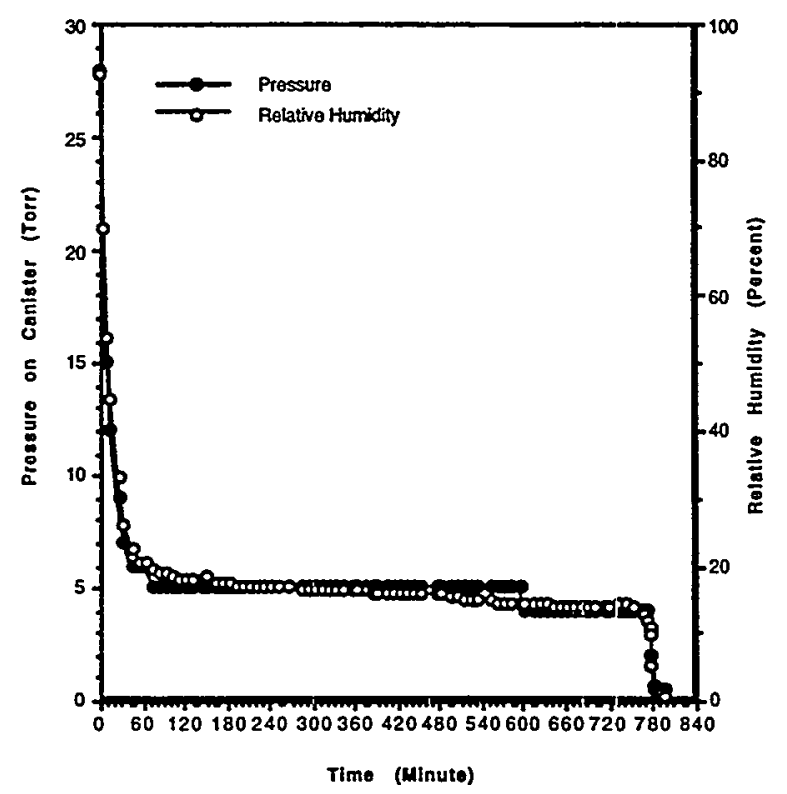

Figure III-19 Measured Relative Humidity inside the Canister (689 ml, 0.0 Watts, 8/28/97)

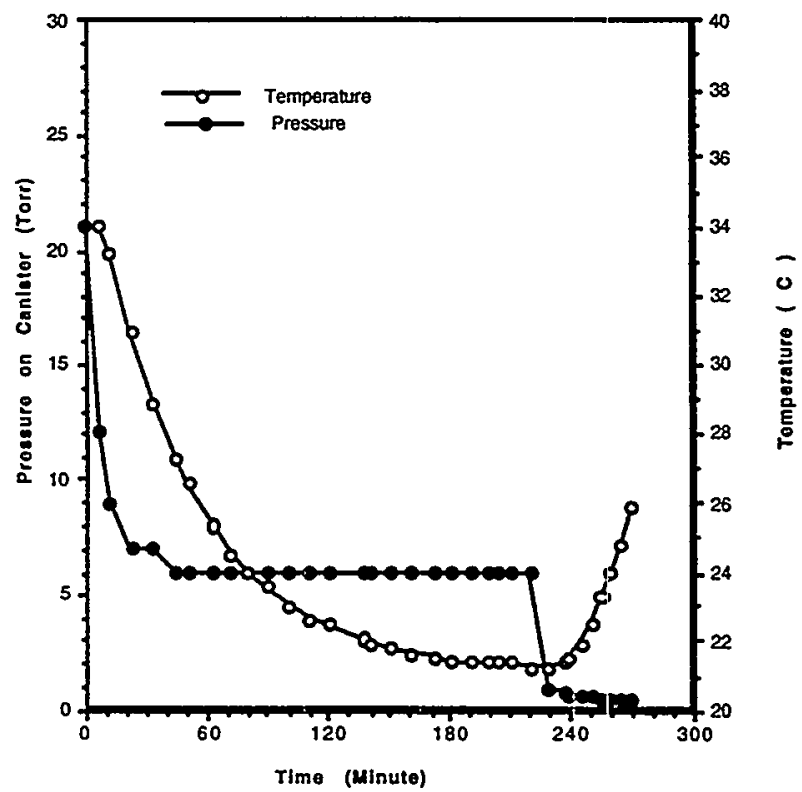

Figure III-20 Measured Temperature inside the Canister (300 ml, 14 Watts, 8/19/97) 


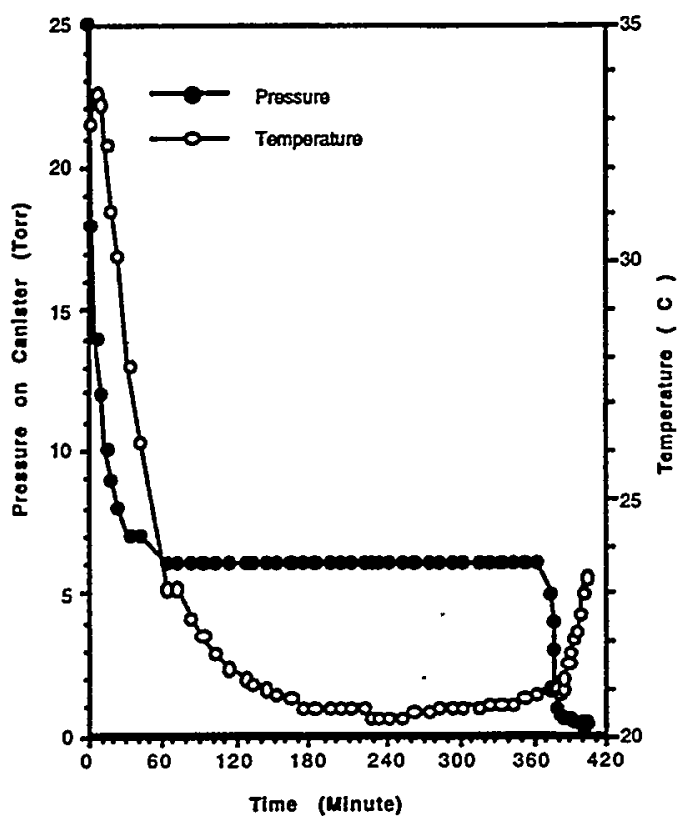

Figure III-21 Measured Temperature inside the Canister (448 ml, 14 Watts, 8/20/97)

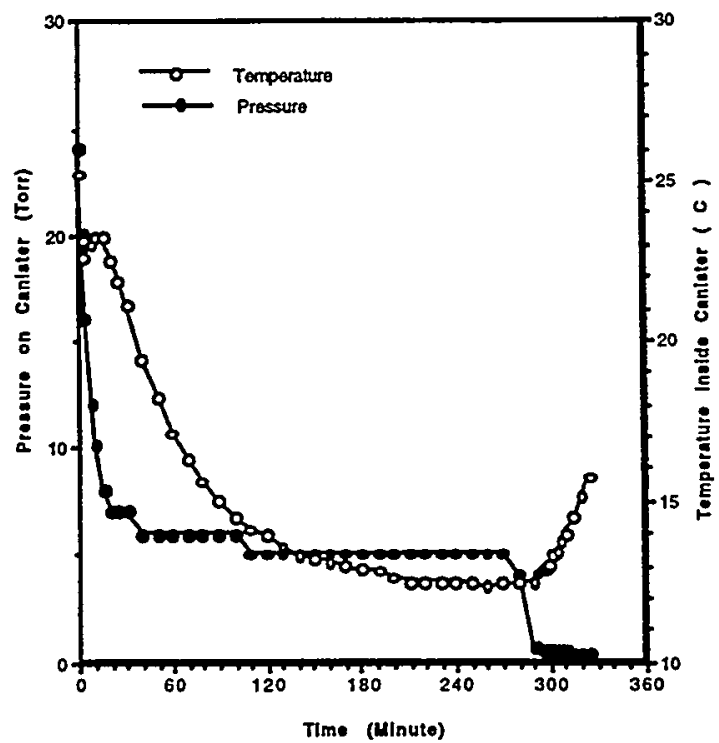

Figure III-22 Measured Temperature inside the Canister (297 ml, 4.8 Watts, 8/21/97) 


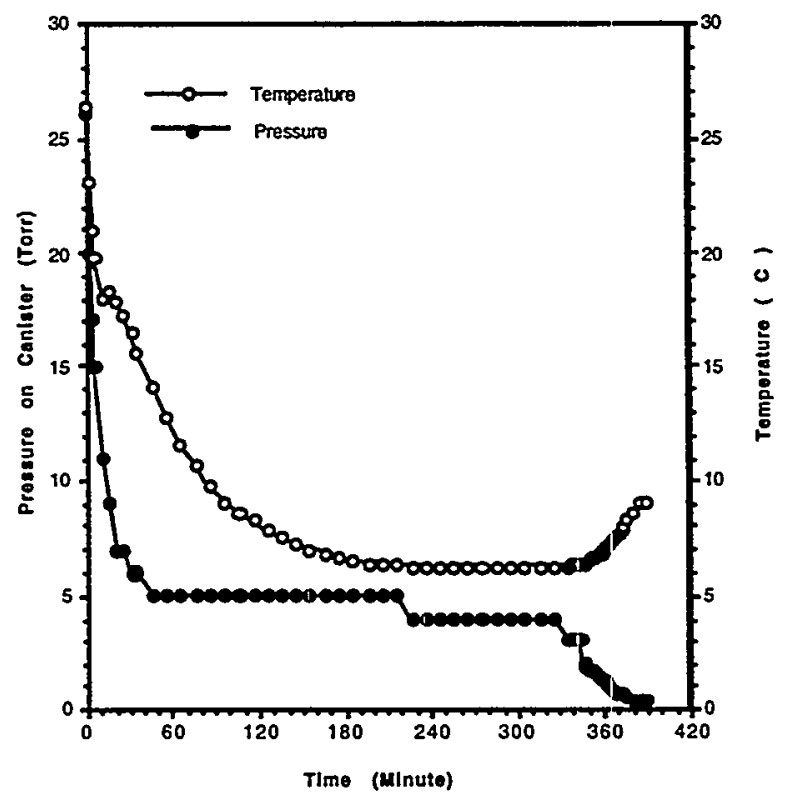

Figure III-23 Measured Temperature inside the Canister (297 ml, 0.0 Watts, 8/25/97)

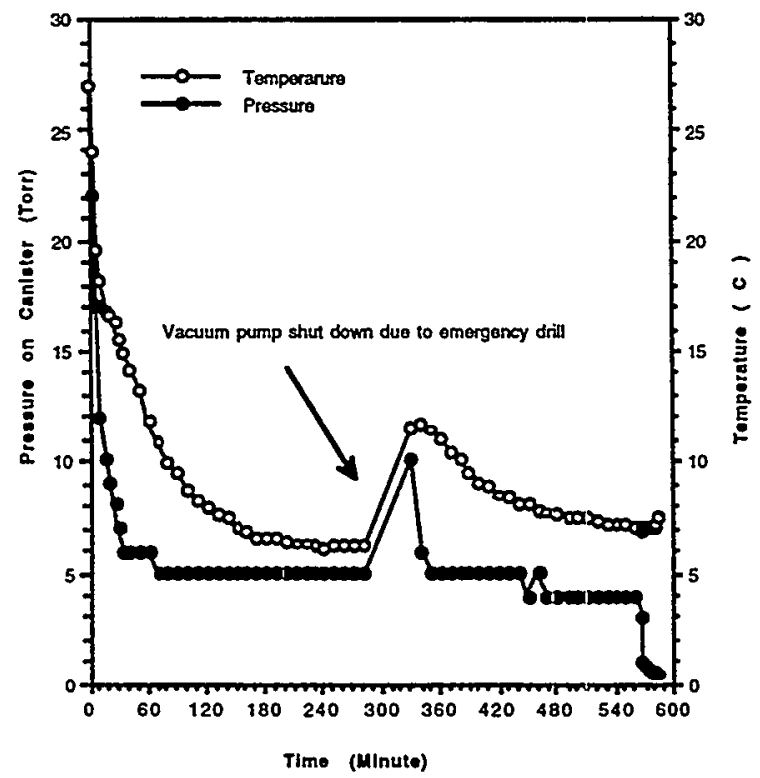

Figure III-24 Measured Temperature inside the Canister (461 ml, 0.0 Watts, 8/27/97) 


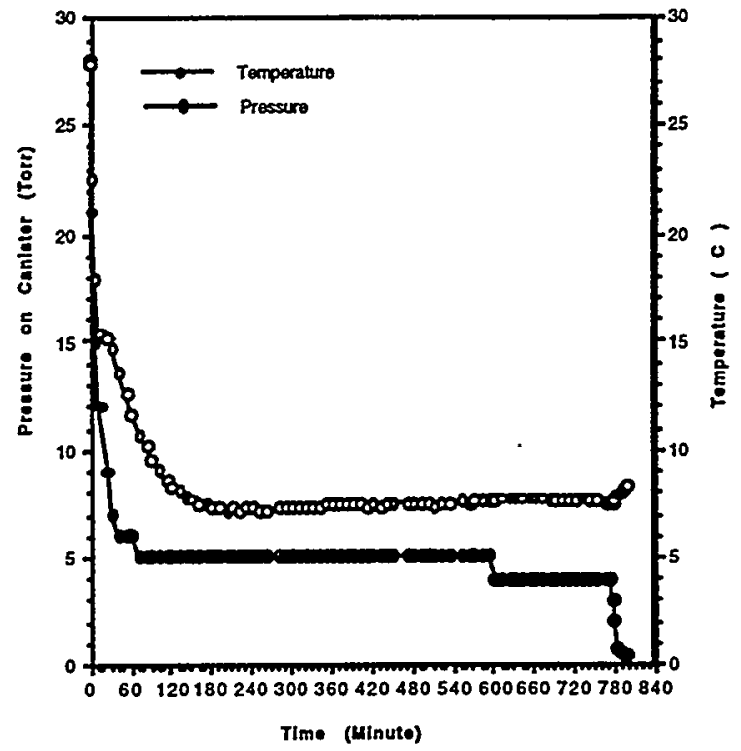

Figure III-25 Measured Temperature inside the Canister (689 ml, 0.0 Watts, 8/28/97)

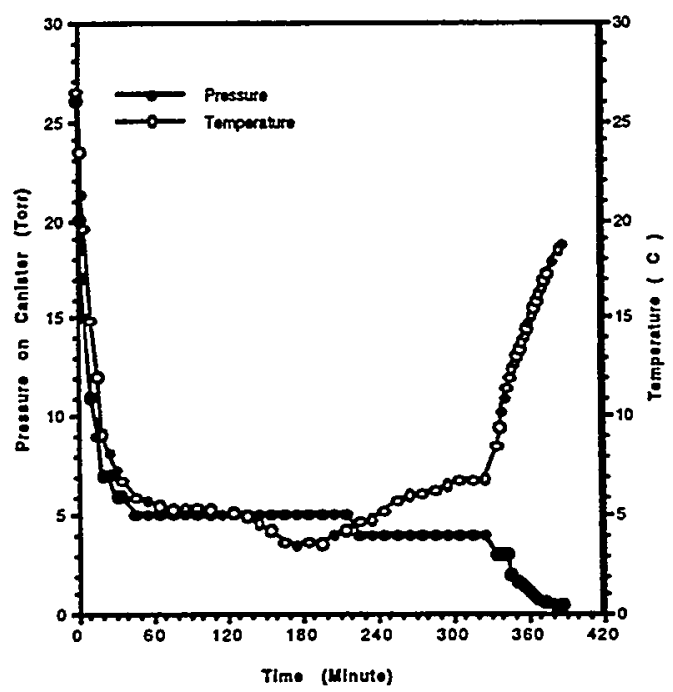

Figure III-26 Measured Temperature at the Bottom of Canister Outer Surface $(297 \mathrm{ml}$, 0.0 Watts, $8 / 25 / 97$ ) 


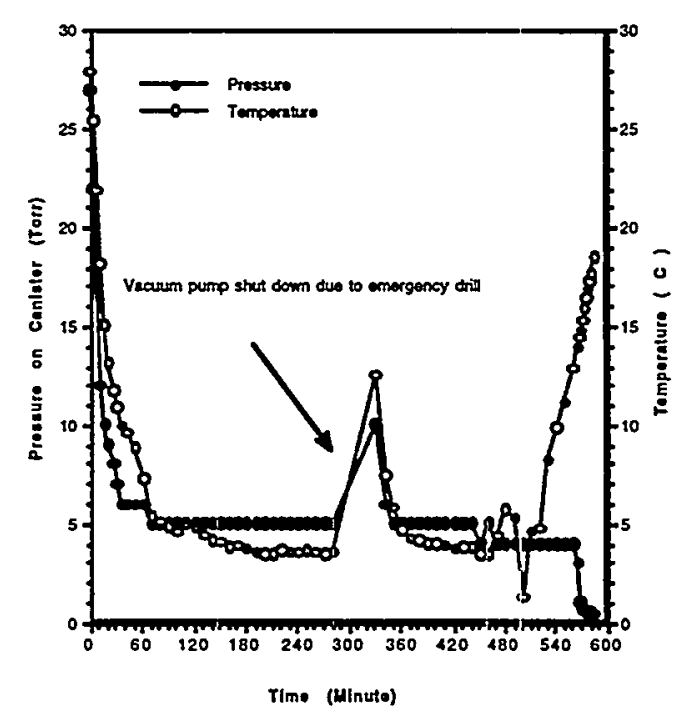

Figure III-27 Measured Temperature at the Bottom of Canister Outer Surface ( $461 \mathrm{ml}$, 0.0 Watts, $8 / 27 / 97$ )

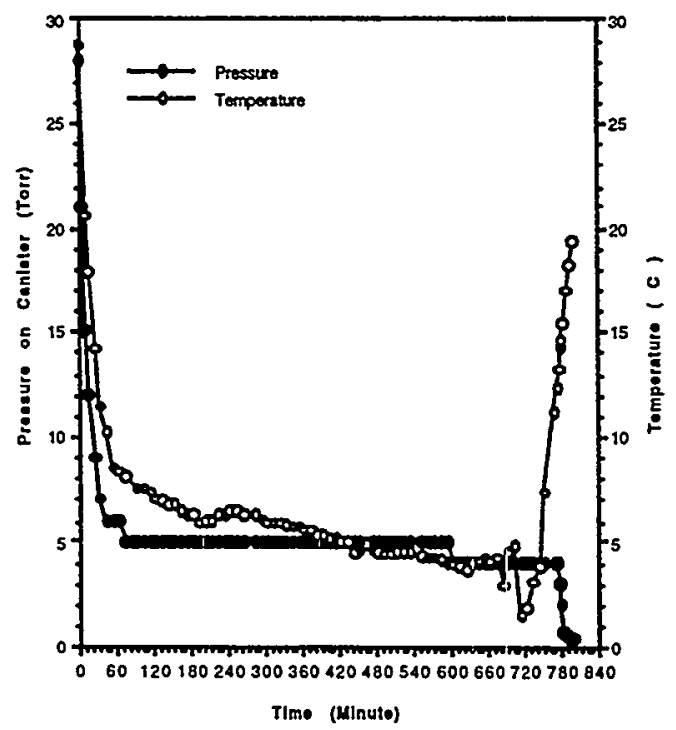

Figure III-28 Measured Temperature at the Bottom of Canister Outer Surface $(689 \mathrm{ml}$, 0.0 Watts, $8 / 28 / 97$ ) 


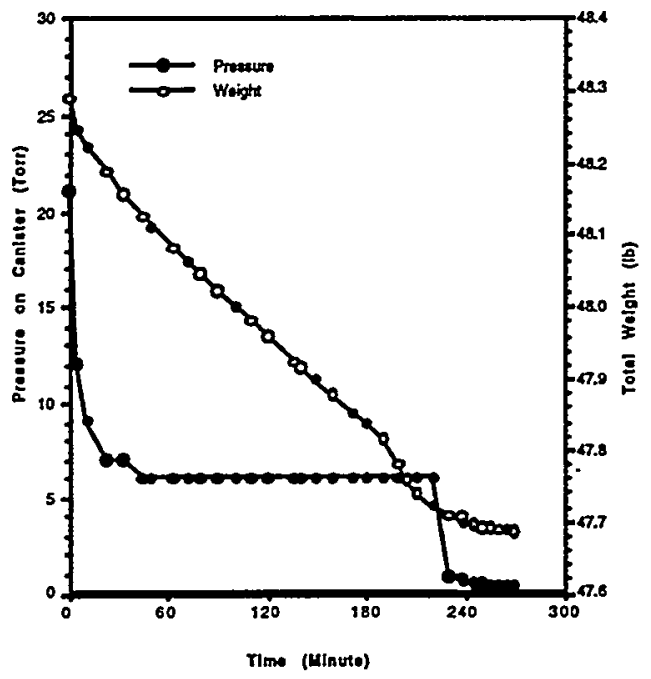

Figure III-29 Measured Total Weight (300 ml, 14 Watts, 8/19/97)

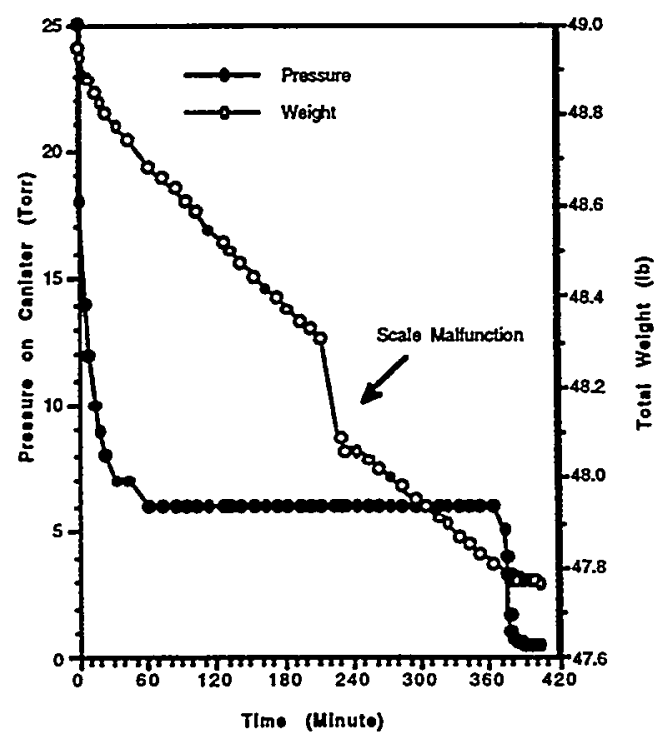

Figure III-30 Measured Total Weight (448 ml, 14 Watts, 8/20/97) 


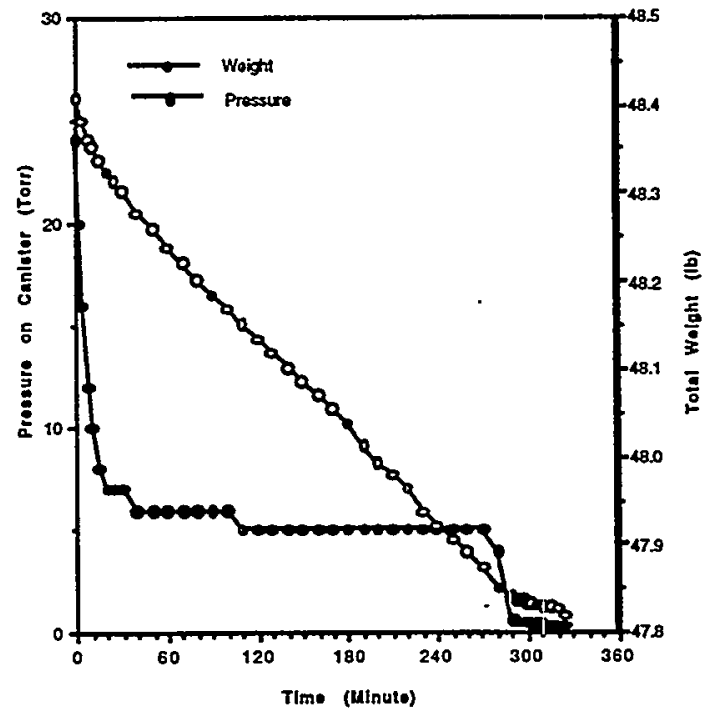

Figure III-31 Measured Total Weight (297 ml, 4.8 Watts, 8/21/97)

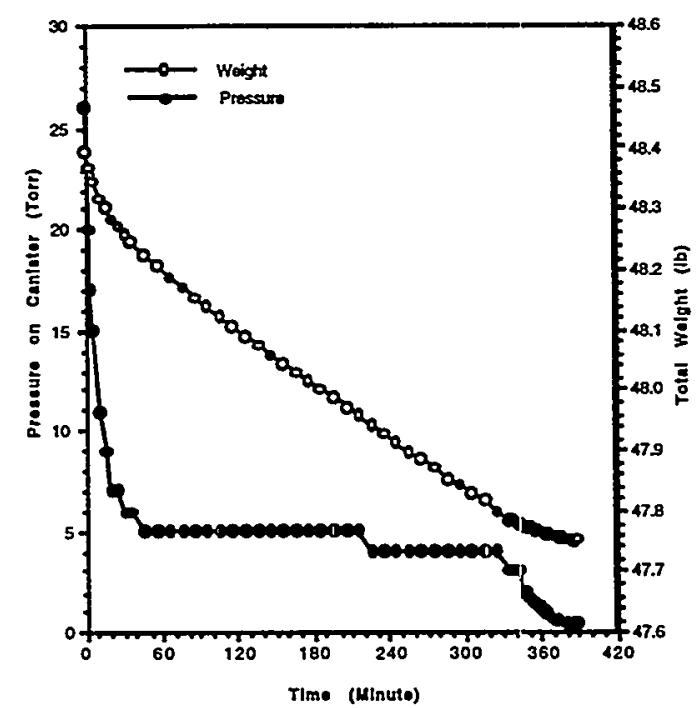

Figure III-32 Measured Total Weight (297 ml, 0.0 Watts, 8/25/97) 


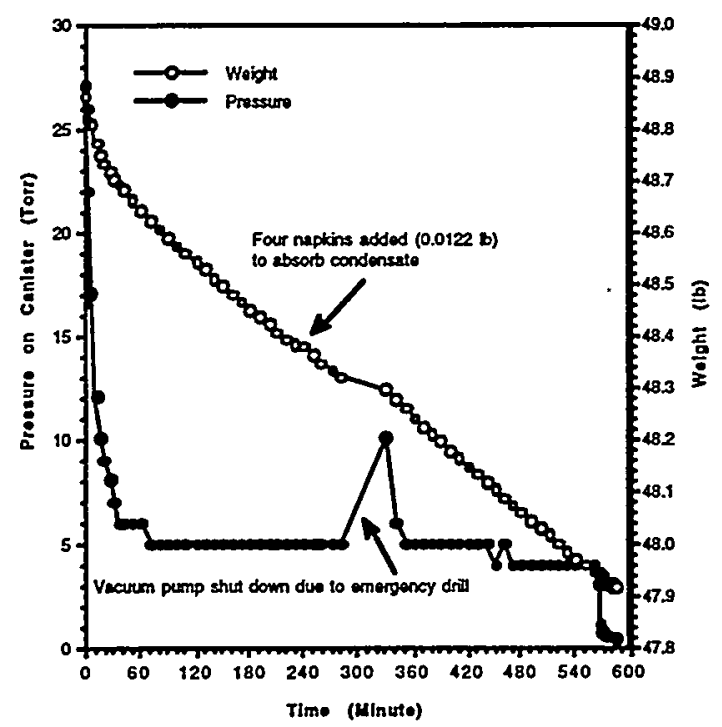

Figure III-33 Measured Total Weight (461 ml, 0.0 Watts, 8/27/97)

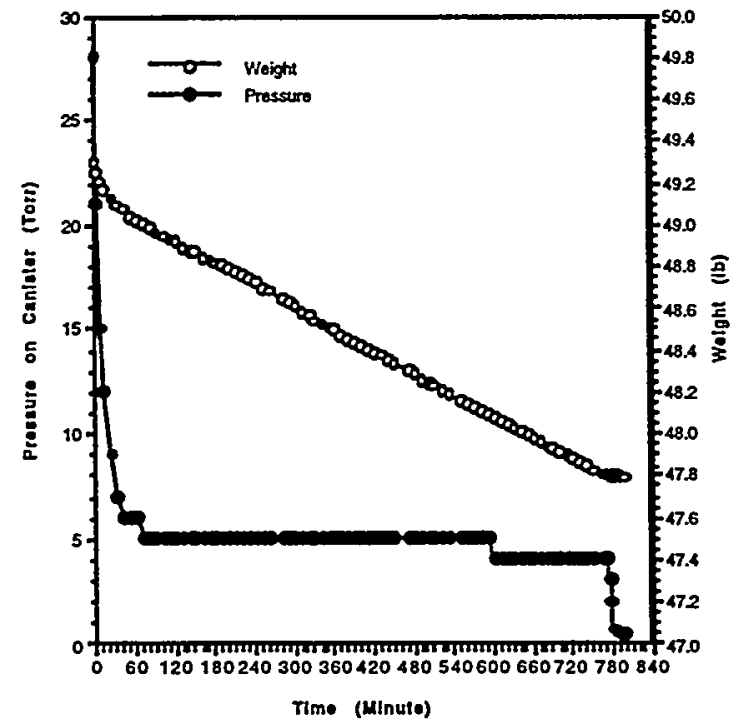

Figure III-34 Measured Total Weight (689 ml, 0.0 Watts, 8/28/97) 


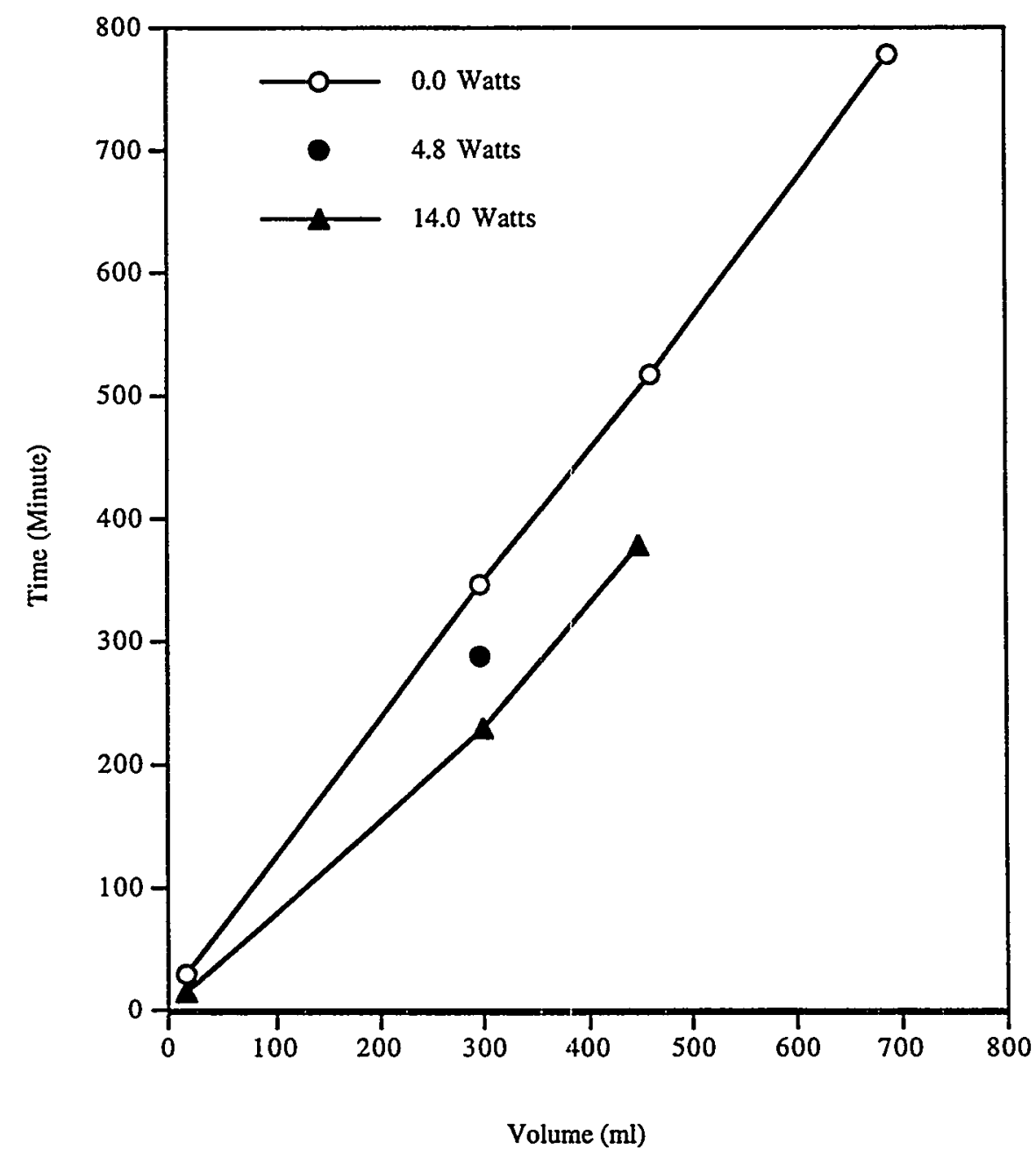

Figure III-35 Measured Drying Duration as a Function of Water Content inside the Canister and Power Input 
Appendix 1 to WSRC-TR-97-00269

Dry Monitored Storage Canister Shielding (U)

Calculation Set No. N-CLC-L-00009

by S. J. Nathan 


\section{Calculation Cover Sheet}

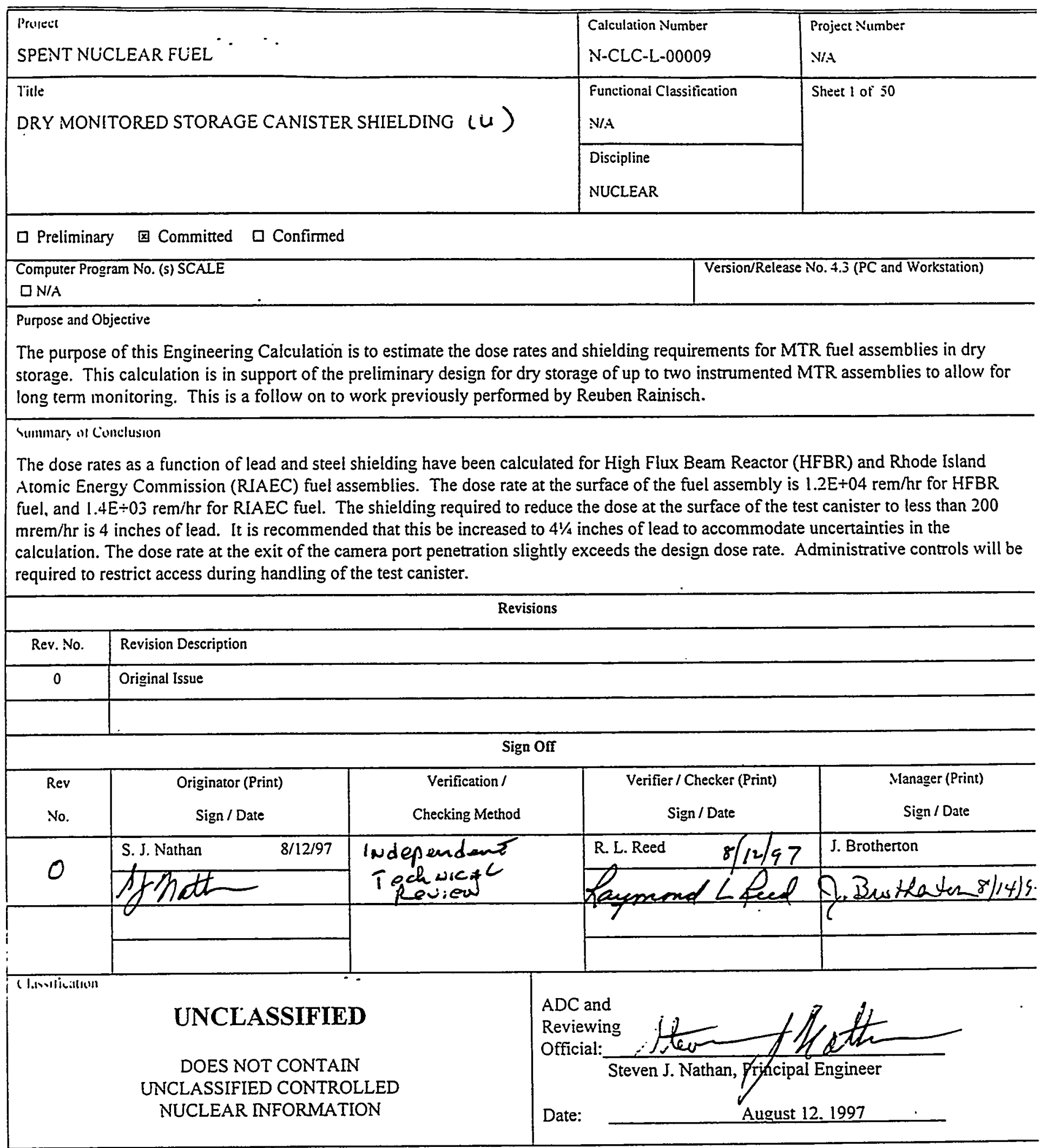




\section{TABLE OF CONTENTS}

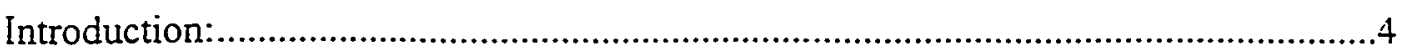

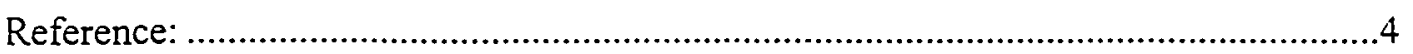

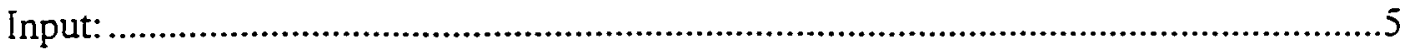

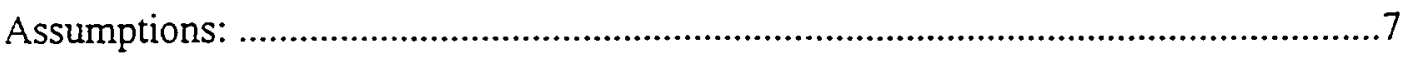

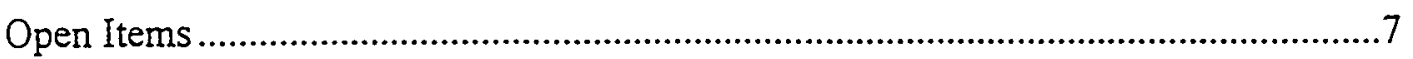

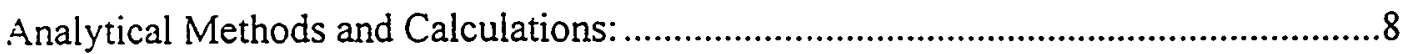

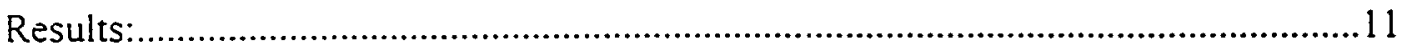

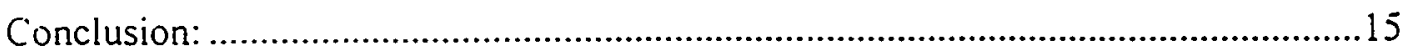

Figure 1 Homogenized HFBR Fuel Assembly ................................................... 16

Figure 2 Schematic of QAD Geometry............................................................17

Figure 3 Schematic of Actual Canister Arrangement ...............................................18

Figure 4 Schematic of Simplified Canister Arrangement........................................19

Figure 5 Plan View at Mid-Plane of Camera Port Penetration .................................20

Figure 6 Cross Section on Center of Camera Port Penetration..................................20

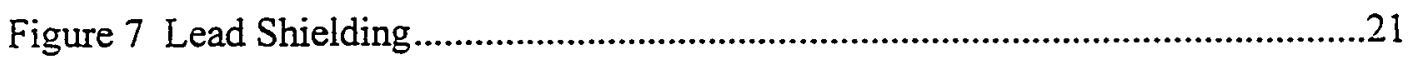

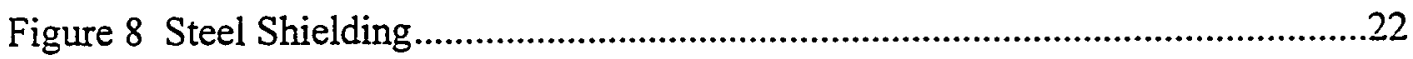

Appendix A HFBR MATHCAD Worksheet .......................................................23

Appendix B RIAEC MATHCAD Worksheet.....................................................28

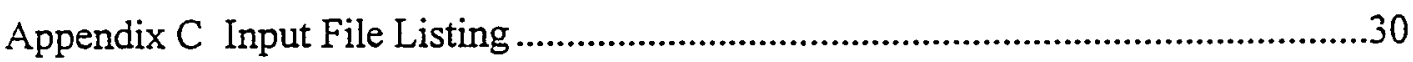

HFBR SAS-2, ORIGENS and QADS Lead Shield .......................................30

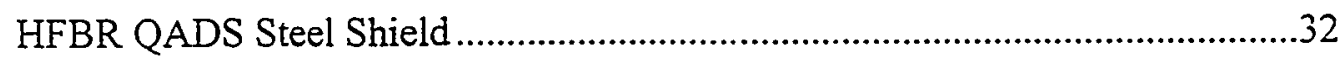

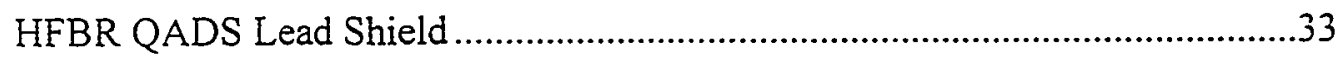

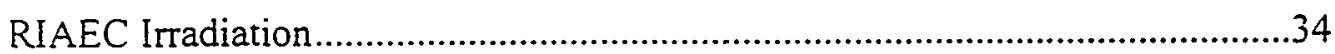

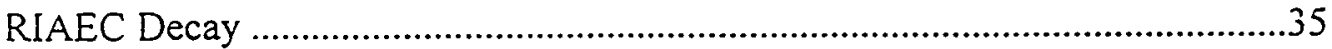

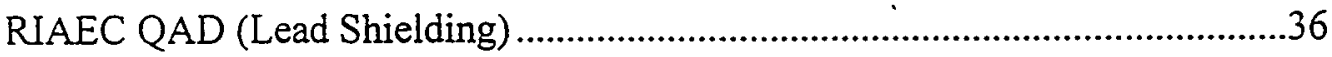

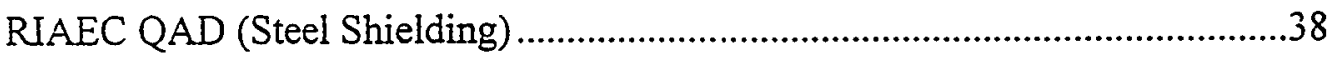

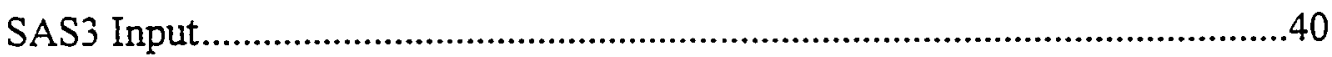

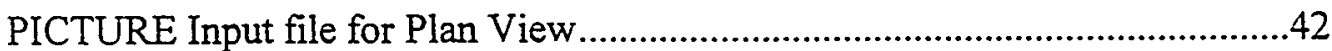

PICTURE Input file for.Plan View............................................................43

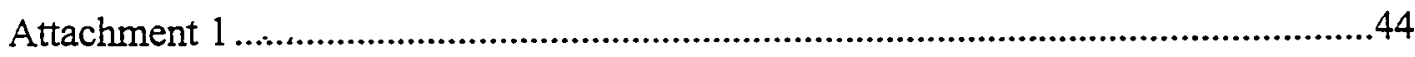

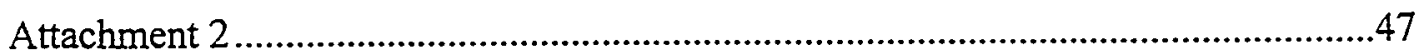


COMPUTER PROGRAMS USED

VAME

CONFIGURATION

If no, description on page/in reference CONTROL VERSION

$\mathrm{SAS} 2 \mathrm{H}$

\begin{tabular}{|l|l}
\hline Yes & No \\
Nes & No \\
Nes & No \\
\cline { 1 - 1 } &
\end{tabular}

ORIGENS

QADS

SAS3 


\section{Introduction:}

This Engineering Calculation estimates the dose rates and shielding requirements for Material Test Reactor (MTR) fuel assemblies in dry storage. This calculation is in support of the preliminary design for dry storage of instrumented MTR assemblies to allow for long term monitoring. The assemblies will be stored in test canisters fabricated of steel plates. This is a follow on to work previously performed by Reuben Rainisch [1].

Dose rates are calculated using the QADS module of the SCALE Code System. The assemblies identified as candidates for dry monitoring [2] are from the High Flux Beam Reactor (HFBR) and the Rhode Island Atomic Energy Commission (RIAEC). The HFBR assembly was chosen since it is expected to bound any assembly that could be used in the test. The RIAEC assembly was chosen as representative of lower burnup fuel.

\section{Reference:}

1. Rainisch, R., "Scoping Calculation for Shielding MTR Fuel in Dry Monitoring," cc:Mail to D. Pak, 2/28/97.

2. Informal e-mail, R. Sindelar to Distribution, "Test Canister Development Actions (U)," dated 6/12/96 (Attachment 1).

3. Shepherd, G., Appendix A - Agreement. Spent Nuclear Fuel Acceptance Criteria, DOESRAA-96-001, Rev. 0, Brookhaven National Laboratory, Upton, NY. February 8, 1996. Transmitted as an attachment to: Stout, G. W. (PAI), "High Beam Flux Reactor Appendix A," Memorandum to Trent Andes, et al (WSRC), February 21, 1996.

4. Simoneau, W. Appendix A Agreement No. 3 Under Contract No. DEACO2-76ER03488, Transmitted as an attachment to: Johnson, D. G. (RIAEC/RINSC), "Appendix A Agreement for Alloy Type Fuel," FAX to M. J. Beckum (WSRC), November 30, 1992.

5. Aluminum and Zinc Alloy Products, Information obtained from TVT Die Casting and Manufacturing, at web-site www.tvtdiecast.com/adpage/properties.html (Attachment 2).

6 Instumented Test Canister for Spent Nuclear Fuel, Rack for Sensors Weldment and Details, Development Drawing EES-22585-R3-003, Rev A, 6/26/97.

7 Instumented Test Canister for Spent Nuclear Fuel, Container Weldment and Details, Development Drawing EES-22585-R3-003, Rev A, 6/26/97.

8 Untitled Sketch of Instumented Test Canister for Spent Nuclear Fuel obtained from D. J. Pak 6/30/97.

9. Hermann, O. W., and Parks, C. V., "SAS2H: A Coupled One-Dimensional Depletion And Shielding Analysis Module," NUREG/CR-0200, Revision 5, Volume 1, Section S2, (ORNL/NUREG/CSD-2/V2/R5), Draft, Oak Ridge National Laboratory, Oak Ridge, TN, September 1995.

10. Hermann, O. W., and Westfall, R. M., "ORIGEN-S: Scale System Module To Calculate Fuel Depletion, Actinide Transmutation, Fission Product Buildup And Decay, And Associated Radiation Source Terms," NUREG/CR-0200 Revision 5 Volume 2, Section 
F7 (ORNLNUUEG/CSD-2/V2/R5), Draft, Oak Ridge National Laboratory, Oak Ridge. TN. September 1995.

11. SCALE: A Modular Code System for Performing Standardized Computer Analyses for Licensing Evaluation," NUREG/CR-0200, Rev. 5.(ORNL/NUREG/CSD-2/R5), Vols. I, II, and III. Final Draft, Oak Ridge National Laboratory, Oak Ridge, TN, January 1997.

12. West, J. T., "SAS3: An Automated Monte Carlo Shielding Analysis Module," NUREG/CR-0200, Revision 5, Volume 1, Section S3 (ORNL/NUREG/CSD-2/V1/R5), Draft, Oak Ridge National Laboratory, Oak Ridge, TN, September 1995.

\section{Input:}

The parameters for the HFBR fuel element (plate) and fuel assembly are [3]:

Fuel Plate Data

$\begin{array}{ll}\text { Element thickness (including clad) } & 0.127 \mathrm{~cm} . \\ \text { Element Active length } & 57.79 \mathrm{~cm} \\ \text { Element width } & 6.63 \mathrm{~cm} \\ \text { Element Active width } & 5.69 \mathrm{~cm} \\ \text { Chemical form of SNM } & \mathrm{U}_{3} \mathrm{O}_{8} \mathrm{blended} \\ & \text { with Al powder } \\ \text { Dispersing material weight } & 0.043 \mathrm{~kg} \mathrm{Al} \\ & 0.0038 \mathrm{~kg} \mathrm{O} \\ \text { Clad Material } & \mathrm{Al} 6061 \\ \text { Clad thickness } & 0.034 \mathrm{~cm} \\ \text { Clad weight } & 84.5 \mathrm{gm}\end{array}$

\section{Assemblv Data}

Number of Elements per Assembly

Assembly Dimensions

thickness

$7.19 \mathrm{~cm}$

width

$8.13 \mathrm{~cm}$

cut length

$62.23 \mathrm{~cm}$

Assembly Uranium weight

377. $\mathrm{gm}^{\mathrm{a}}$

Assembly Uranium-235 weight

351. $\mathrm{gm}^{\mathrm{b}}$

Overall Assembly weight

$4.425 \mathrm{~kg}$

Non fuel end plate thickness

$0.257 \mathrm{~cm}$

Assembly side plate thickness

$0.439 \mathrm{~cm}$

2 Maximum of all assemblies reported in reference 3. Data is for assembly 663

b Maximum of all assemblies reported in reference 3. Data is for assemblies 513 and 514 


$\begin{array}{ll}\text { Irradiation History } & \\ \text { Power Level } & 2.148 \mathrm{MW}^{\mathrm{c}} \\ \text { Irradiation Time } & 55.667 \text { days }^{\mathrm{d}} \\ \text { Decay Time } & 4369 \text { days }^{\mathrm{e}}\end{array}$

The parameters for the RIAEC fuel element (plate) and fuel assembly are [4]:

Fuel Plate Data

$\begin{array}{ll}\text { Element thickness (including clad) } & 0.06 \mathrm{in} \\ \text { Element width } & 2.774 \mathrm{in} \\ \text { Element Active length } & 25 \mathrm{in} \\ \text { Element total weight } & 190 \mathrm{gm} \\ \text { Element Uranium weight } & 7.4 \mathrm{gm} \\ \text { Element Uranium-235 weight } & 6.88 \mathrm{gm} \\ \text { Chemical form of SNM } & \mathrm{U} \text { and Al } \\ \text { Clad Material } & \mathrm{Al} 6061 \\ \text { Clad thickness } & 0.024 \mathrm{in}\end{array}$

\section{Assembly Data}

$\begin{array}{ll}\text { Number of Elements per Assembly } & 18 \\ \begin{array}{l}\text { Assembly Dimensions } \\ \text { thickness }\end{array} & 3 \text { in } \\ \text { width } & 3 \text { in } \\ \text { length } & 25 \mathrm{in} \\ \text { Overall Assembly weight } & 4.661 \mathrm{~kg} \\ \text { Side plate thickness } & 0.187 \mathrm{in} \\ \text { Irradiation History } & \\ \text { Power Level } & 8 \mathrm{~kW} \text { (estimated) } \\ \text { Irradiation Time } & 1793 \text { days } \\ \text { Decay Time } & 6 \text { years }\end{array}$

- Maximum of all assemblies reported in reference 3. Data is for assembly 621

- Maximum of all assemblies reported in reference 3. Data is for assemblies 584 through 597

- Minimum of all assemblies reported in reference 3. Data is for assemblies 596 and 640. Data is adjusted from values in reference 3 by adding 540 days ( 18 months * 30 days/month) to account for time from $1 / 1 / 96$ to $7 / 1 / 97$. 
The composition of Aluminum 6061 is [5]:

The test canister dimensions are $[6,7,8]$ :

\begin{tabular}{|l|l|}
\hline Element & Weight Percent \\
\hline $\mathrm{Al}$ & 95.925 \\
\hline $\mathrm{Mg}$ & 1.0 \\
\hline $\mathrm{Cu}$ & 0.275 \\
\hline $\mathrm{Fe}$ & 0.7 \\
\hline $\mathrm{Si}$ & 0.6 \\
\hline $\mathrm{Mn}$ & 1.5 \\
\hline $\mathrm{Z}$ & 0.25 \\
\hline
\end{tabular}

Description

Outer width

Side Wall thickness

Height of main canister

Bottom Thickness

Top Plate Thickness

Lid

Camera Port Shield Height

Camera Port Shield Depth

Camera Port Tube OD

Camera Port Tube Wall Thickness

Camera Port Tube Center Line

(Relative to base of Cavity)

Fuel Base

(Relative to base of Cavity)

\section{Dimension (inches)}

$271 / 2$

8

$373 / 4$

8

2

8

$12 \frac{1}{2}$

$13 \frac{1}{2}$

4

0.085

7.875

0.12

\section{Assumptions:}

- The RIAEC fuel is operated at $8 \mathrm{~kW}$ power. This is based on averaging the power level calculated from the time in reactor and the burnup.

\section{Open Items}

The following open items must be certified by the customer before this calculation can be confirmed:

- The selection of fuel assemblies to be used in the test canisters. 
- The dose criterion for selecting shielding thickness (currently assumed to be 200 $\mathrm{mrem} / \mathrm{hr}$ based on shipping cask limits).

- The drawings used for canister details $[6,7$, and 8$]$ are preliminary or sketches.

\section{Analytical Methods and Calculations:}

The SCALE Code System will be used to determine the source term and the photon transport for a single fuel assembly. Calculations of dose rate are performed using the ANSI Standard dose conversion factors that are provided with the cross-section libraries.

The fuel properties presented above were used in a MATHCAD worksheet (Appendix A and B) to develop input for the SAS2H module of the SCALE Code System [9]. The following description of SAS2H is excerpted from reference 9.

Using a prescribed reactor history and cooling time, the SAS2H module is able to determine the spent fuel characteristics (isotopics, heat generation, and radiation sources). Nuclide compositions are computed for a specified reactor assembly, which is allowed to decay for a given cooling time after discharge. The subsequent gamma source includes radiation from fission products, activation products of both the fuel and structural materials, and $(n, \gamma)$ reactions resulting from neutrons produced by some of the heavy isotopes. The neutron source includes neutrons from spontaneous fission and $(\alpha, n)$ reactions with oxygen isotopes.

The fuel assembly model used for SAS2 is shown schematically in Figure 1.

The decay of the products of the fuel irradiation was calculated using the ORIGEN-S module of the SCALE Code System [10]. The following description of ORIGEN-S is excerpted from reference 10 .

ORIGEN-S computes time-dependent concentrations and source terms of a large number of isotopes, which are simultaneously generated or depleted through neutronic transmutation, fission, radioactive decay, input feed rates, and physical or chemical removal rates. The calculations may pertain to fuel irradiation within nuclear reactors, or the storage, management, transportation, or subsequent chemical processing of removed fuel elements. The matrix exponential expansion model of the ORIGEN code is unaltered in ORIGEN-S. Essentially all features of ORIGEN were retained, expanded, or supplemented within new computations.

The assembly data were also used to develop input for the QADS module of the SCALE Code System [11]. The following description of QADS is excerpted from reference 11.

The QADS module analyzes three-dimensional gamma-ray shielding problems using point kernel techniques.

The QADS model is shown schematically in Figure 2. 
The canister data were used to develop inputs for the SAS3 (MORSE) module of the SCALE Code System [12]. The following description of SAS3 is excerpted from reference 12.

SAS3 is the SCALE Shielding Analytical Sequence for three-dimensional geometry problems. The system incorporates the input and cross-section processing capabilities found in CSAS with the radiation transport capabilities of the MORSE-SGC Monte Carlo code. Three-dimensional geometry features of the combinatorial MARS (Multiple Array System) package can be used within the MORSE model specification. The SAS3 control module executes in sequence BONAMI, NITAWL-II, XSDRNPM (optionally), ICE, and the MORSE-SGC codes.

The canister model is shown in Figures 3 through 6 . Figure 3 shows the actual layout of the canister. Figure 4 shows the simplified model used to make geometry setup tractable. This model retains the important geometric features while allowing the use of simple geometric shapes for the bodies in MORSE. Figures 5 and 6 are prepared using the SCALE Picture utility that draws sections through the geometry based on the MARS input data. This model was used specifically to calculate the streaming through the camera port penetration.

Biasing is required to facilitate computation in reasonable time when using Monte Carlo techniques. SAS3 implements several techniques for biasing as described in Reference 12. The biasing used is based on empirical considerations:

- Biasing region 1 includes the fuel assembly, the air gap, the internal void (region outside the shield and penetration) and the shield region immediately surrounding the bend in the penetration, and an annular region 2 inches thick around the first leg of the penetration. No splitting is allowed, no path length stretching is performed, russian roulette is played with WTLO $=0.2$, and WTAVE $=1.0$.

- Biasing region 2 includes the first leg of the penetration, and the duct surrounding it. Splitting is allowed with WTHIGH=0.5, path length stretching is performed along the axis of the penetration (positive $\mathrm{x}$ direction, russian roulette is played with WTLO $=0.02$, and WTAVE=0.1.

- Biasing region 3 includes most of the shield material. No splitting is allowed, no path length stretching is performed, russian roulette is played with WTLO $=10^{34}$, and WTAVE $=10^{3}$ (essentially no particles survive entering these zones).

- Biasing region 4 includes the second leg of the penetration and the duct surrounding it. Splitting is allowed with WTHIGH=0.5, no path length stretching is performed, russian roulette is played with WTLO $=0.02$, and WTAVE $=0.1$

The SAS2H and QADS calculations were performed using the PC-SCALE versions of the codes. The SAS3 calculations were performed on the UNIX workstation because of the length of the runs. Input Files for all cases are presented in Appendix C. 
DRY MONITORED STORAGE CANISTER SHIELDING

\begin{tabular}{|l|}
\hline Calculation No. N-CLC-L-00009 \\
\hline Sheet No. 10 of 50 \\
\hline Rev. $\quad 0$ \\
\hline
\end{tabular}

\begin{tabular}{|l|l|}
\hline File Name & Description \\
\hline hfbra & $\begin{array}{l}\text { SAS2H and ORIGENS input file for HFBR assembly irradiation and decay } \\
\text { calculation }\end{array}$ \\
\hline hfbral & QADS input file for HFBR assembly with steel shield \\
\hline hfbrbI & QADS input file for HFBR assembly with lead shield \\
\hline riaec & SAS2H input file for RIAEC assembly irradiation calculation \\
\hline driaec.in & ORIGENS input file for RIAEC assembly decay \\
\hline riaecqad.in & QADS input file for RIAEC assembly with lead shield \\
\hline riaecqada.in & QADS input file for RIAEC assembly with lead shield additional points \\
\hline riaecss.in & QADS input file for RIAEC assembly with steel shield \\
\hline riaecssa.in & QADS input file for RIAEC assembly with steel shield additional points \\
\hline sas3ssb & SAS3 input file for HFBR assembly in canister with penetration \\
\hline sspic & PICTURE input file for plan view on penetration midplane \\
\hline sspicl & PICTURE input file for cross section on penetration axis \\
\hline
\end{tabular}

Files with the suffix "out" appended or replacing the suffix "in" are the respective output files for each case. Pictures are stored as file00.gif where file is the input file name.

Files on the UNIX workstation are located in directory /afs/sitc.srs.gov/u3/s8033/snf/mtrsnf. Files on the PC are located in a "zipped" archive canister.zip in directory c:/snf/mtr/monitor on the author's computer. 


\section{Results:}

The photon source for HFBR Fuel as calculated using ORIGEN-S is: GYMMI SOYRCE S?ECMRUM SOR HEBR EUEL TIMESTE? 3

4369.00 DAY TIME OE THE REQUESTED NUCIIDES

ENERGY INTERVAL IN MEV

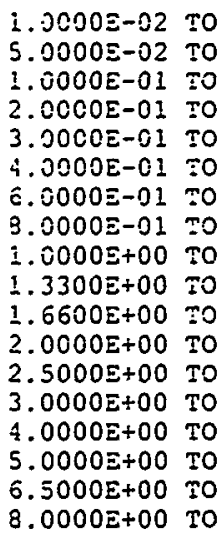

TOTALS

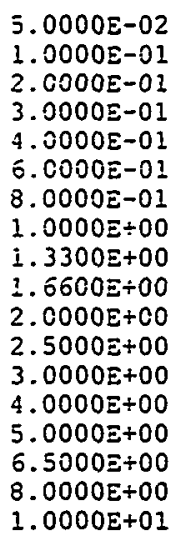

$1.0000 \mathrm{E}+01$
PEOTONS / SECOND

MEV / SECOND
$1.96195+11$

$1.4250 \mathrm{E}+11$

i. $95455 \div 11$

$1.0234 \mathrm{E}+11$

$1.01495+11$

$\therefore .5788 \mathrm{i}+\mathrm{i}$

$6.54078+12$

$9.4942 \equiv \div 10$

$7.7343 \mathrm{E}+10$

1. $3830 \varepsilon \div 10$

$1.3978 E+09$

3.1148 $2+08$

$5.0194 \mathrm{E}+06$

$7.6712 \Xi \div 05$

3. $6198 \mathrm{E}+01$

1. $3047 E+01$

A. $3498 E+00$

1. $1259 \Xi+00$

$7.6243 \mathrm{E}+12$

TOTAL ENERGY EROM NUCLIDES WITH SPECTRUM DATA $=7.6243 E+12$

TOTAL ENERGY EROM NUCLIDES WITH NO SPECTRUM DATA $=2.5866 \mathrm{0}+06$

The photon source for RIAEC Fuel as calculated using ORIGEN-S is:

GAMMA SOURCE SPECTRUM FOR RIAEC EUEL TIMESTEP 3

\subsection{YEAR TIME OE THE REQUESTED NUCLIDES}

ENERGY INTERVAL IN MEV

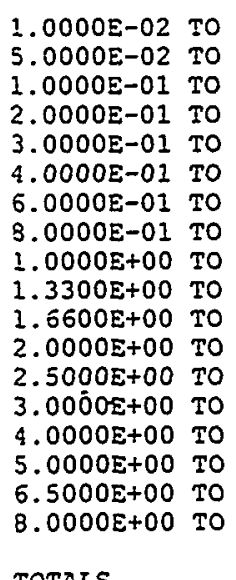

$5.0000 E-02$

$1.0000 \mathrm{E}-0 \mathrm{I}$

2. $0000 \mathrm{E}-01$

3. $0000 \mathrm{E}-01$

$4.0000 E-01$

$6.0000 E-01$

$8.0000 E-01$

1. $0000 \mathrm{E}+00$

1. $3300 \mathrm{E}+00$

1. $5600 \mathrm{E}+00$

2. $0000 \mathrm{E}+00$

2. $5000 E+00$

$3.0000 E+00$

$4.00005+00$

$5.0000 \mathrm{E}+00$

$6.5000 \varepsilon+00$

8. $0000 E+00$

1. $0000 \mathrm{E}+01$

TOTALS
PHOTONS / SECOND

MEV / SECOND

TOTAL ENERGY EROM NUCIIDES WITH SPECTRUM DATA $=9.7921 E+11$

TOTAL ENERGY EROM NUCLIDES WITH NO SPECTRUM DATA $=4.5490 E+05$ 
The QADS calculated dose rate on the mid-plane near the surface ${ }^{f}$ of the fuel assemblies with steel buildup factors is:

\begin{tabular}{|l|l|}
\hline Assembly & $\begin{array}{l}\text { Dose Rate } \\
(\text { Rem } / \mathrm{hr})\end{array}$ \\
\hline HFBR & $1.43 \mathrm{E}+04$ \\
\hline RIAEC & $1.64 \mathrm{E}+03$ \\
\hline
\end{tabular}

The QADS calculated dose rate as a function of shield thickness is given in the tables below, and is plotted in Figures 2 and 3. The dose point is located at the surface of the shield on the fuel mid-plane.

\section{Lead Shielding}

\begin{tabular}{|c|c|c|}
\hline \multirow{2}{*}{$T$} & \multicolumn{2}{|c|}{ DOSE RATE (REM/HR) } \\
\cline { 2 - 3 } & HFBR & RIAEC \\
\hline 0 & $2.96 \mathrm{E}+03$ & $3.66 \mathrm{E}+02$ \\
\hline 1 & $1.32 \mathrm{E}+02$ & $1.46 \mathrm{E}+01$ \\
\hline 2 & $6.57 \mathrm{E}+00$ & $7.66 \mathrm{E}-01$ \\
\hline 3 & $4.68 \mathrm{E}-01$ & $5.17 \mathrm{E}-02$ \\
\hline 4 & $4.34 \mathrm{E}-02$ & $5.24 \mathrm{E}-03$ \\
\hline 5 & $6.21 \mathrm{E}-03$ & $8.06 \mathrm{E}-04$ \\
\hline 6 & $1.07 \mathrm{E}-03$ & $1.58 \mathrm{E}-04$ \\
\hline 7 & $2.02 \mathrm{E}-04$ & $3.49 \mathrm{E}-05$ \\
\hline 8 & $4.21 \mathrm{E}-05$ & $8.17 \mathrm{E}-06$ \\
\hline 9 & $8.63 \mathrm{E}-06$ & $1.98 \mathrm{E}-06$ \\
\hline 10 & $1.94 \mathrm{E}-06$ & $4.94 \mathrm{E}-07$ \\
\hline
\end{tabular}

f Actual dose point is located $4.1 \mathrm{~cm}$ from the assembly center line. This corresponds to $0.013 \mathrm{~cm}$ from the surface of HFBR fuel, and $0.29 \mathrm{~cm}$ from the surface of RIAEC fuel. 


\begin{tabular}{|l|}
\hline Calculation No. N-CLC-L-00009 \\
\hline Sheet No. 13 of 50 \\
\hline Rev. $\quad 0$ \\
\hline
\end{tabular}

\begin{tabular}{|r|c|c|}
\hline \multicolumn{3}{|c|}{ Steel Shielding } \\
\hline \multirow{2}{*}{$T$} & \multicolumn{2}{l|}{ DOSE RATE (REM/HR) } \\
\cline { 2 - 3 } & HFBR & RIAEC \\
\hline 0 & $3.50 \mathrm{E}+03$ & $4.31 \mathrm{E}+02$ \\
\hline 1 & $1.10 \mathrm{E}+03$ & $1.31 \mathrm{E}+02$ \\
\hline 2 & $2.92 \mathrm{E}+02$ & $3.46 \mathrm{E}+01$ \\
\hline 3 & $7.91 \mathrm{E}+01$ & $9.32 \mathrm{E}+00$ \\
\hline 4 & $2.00 \mathrm{E}+01$ & $2.35 \mathrm{E}+00$ \\
\hline 5 & $5.30 \mathrm{E}+00$ & $6.22 \mathrm{E}-01$ \\
\hline 6 & $1.37 \mathrm{E}+00$ & $1.61 \mathrm{E}-01$ \\
\hline 7 & $3.52 \mathrm{E}-01$ & $4.12 \mathrm{E}-02$ \\
\hline 8 & $9.34 \mathrm{E}-02$ & $1.10 \mathrm{E}-02$ \\
\hline 9 & $2.37 \mathrm{E}-02$ & $2.80 \mathrm{E}-03$ \\
\hline 10 & $6.43 \mathrm{E}-03$ & $7.71 \mathrm{E}-04$ \\
\hline 11 & $1.74 \mathrm{E}-03$ & $2.13 \mathrm{E}-04$ \\
\hline 12 & $4.79 \mathrm{E}-04$ & $6.14 \mathrm{E}-05$ \\
\hline 13 & $1.36 \mathrm{E}-04$ & $1.86 \mathrm{E}-05$ \\
\hline 14 & $4.00 \mathrm{E}-05$ & $5.94 \mathrm{E}-06$ \\
\hline 15 & $1.22 \mathrm{E}-05$ & $2.01 \mathrm{E}-06$ \\
\hline
\end{tabular}

It should be noted that the difference in the dose rates at zero thickness (inner surface of the shield) is due to the use on single material buildup factors in QADS. That is the lead shield case uses lead buildup factors in all regions including the fuel assembly, while the steel shield case used iron buildup factors. This difference is not significant for optically thick shields since the buildup in the shield is the controlling factor. 
DRY MONITORED STORAGE CANISTER SHIELDING

\begin{tabular}{|l|}
\hline Calculation No. N-CLC-L-00009 \\
\hline Sheet No. 14 of 50 \\
\hline Rev. $\quad 0$ \\
\hline
\end{tabular}

The SAS3 calculated dose rate at the exit from the camera port penetration (normalized to one source photon per second) is:

\begin{tabular}{|r|l|l|l|l|}
\hline \multicolumn{3}{|c|}{ ANSI standard gamma dose rate (rem per hour) } \\
\hline detector & \multicolumn{2}{|c|}{ uncollided } & \multicolumn{2}{c|}{ total } \\
\hline & response & fsd $^{8}$ & response & fsd \\
\hline 1 & $1.20 \mathrm{E}-17$ & 0.0021 & $1.05 \mathrm{E}-14$ & 0.08313 \\
\hline 2 & $1.38 \mathrm{E}-17$ & 0.0020 & $1.51 \mathrm{E}-14$ & 0.70138 \\
\hline 3 & $1.53 \mathrm{E}-18$ & 0.0039 & $1.06 \mathrm{E}-14$ & 0.03827 \\
\hline
\end{tabular}

The dose points are located (1) on the axis of the penetration at the exit, (2) at the outer radius of the penetration at the exit, and (3) at the outer radius of the penetration near the shield wall.

The total dose rate at the exit from the camera port penetration (above values multiplied by the $2.03 E 13$ photons per second för HFBR fuel) is:

\begin{tabular}{|c|c|c|c|c|}
\hline \multicolumn{3}{|c|}{ ANSI standard gamma dose rate (rem per hour) } \\
\hline detector & \multicolumn{2}{|c|}{ uncollided } & \multicolumn{2}{c|}{ total } \\
\hline & response & fsd & response & fsd \\
\hline 1 & $2.43 \mathrm{E}-04$ & 0.00216 & $2.14 \mathrm{E}-01$ & 0.08313 \\
\hline 2 & $2.79 \mathrm{E}-04$ & 0.00198 & $3.07 \mathrm{E}-01$ & 0.70138 \\
\hline 3 & $3.10 \mathrm{E}-05$ & 0.00387 & $2.16 \mathrm{E}-01$ & 0.03827 \\
\hline
\end{tabular}

3 fsd is the fractional standard deviation of the result. 
DRY MONITORED STORAGE CANISTER SHIELDING

\begin{tabular}{|l|}
\hline Calculation No. N-CLC-L-00009 \\
\hline Sheet No. 15 of 50 \\
\hline Rev. $\quad 0$ \\
\hline
\end{tabular}

\section{Conclusion:}

The dose rates as a function of lead and steel shielding have been calculated. Based on these data, it will be possible to provide shielding requirements when target dose rates are specified.

For instance, the shielding required to meet the dose limits for various occupancy areas with one HFBR assembly would be:

\begin{tabular}{|c|c|c|c|c|}
\hline Zone & Designation & $\begin{array}{c}\text { Dose Rate } \\
\text { Limit }^{\mathrm{h}}\end{array}$ & \multicolumn{2}{c|}{$\begin{array}{c}\text { Required } \\
\text { Shielding }\end{array}$} \\
\cline { 3 - 5 } & & ${\left.\text { (mrem } \mathrm{h}^{-1}\right)}^{\text {In. Lead }}$ & In. Steel \\
\hline 1 & General Public & $<0.05$ & $81 / 2$ & 14 \\
\hline 2 & & $<0.25$ & $73 / 4$ & $123 / 4$ \\
\hline 3 & Radiation Area & $<5.0$ & 6 & $101 / 2$ \\
\hline 4 & High Radiation Area & $<100.0$ & $41 / 2$ & 8 \\
\hline 5 & Very High Rad. Area & $<500 \mathrm{rad} \mathrm{h}^{-1}$ & N/A & N/A \\
\hline & Design Dose Rate & $<200$ & 4 & $71 / 2$ \\
\hline
\end{tabular}

The shielding required for one RIAEC assembly would be:

\begin{tabular}{|c|c|c|c|c|}
\hline Zone & Designation & Dose Rate Limit & \multicolumn{2}{|c|}{$\begin{array}{c}\text { Required } \\
\text { Shielding }\end{array}$} \\
\cline { 3 - 5 } & & $\left(\mathrm{mrem} \mathrm{h}^{-1}\right)$ & In. Lead & In. Steel \\
\hline 1 & General Public & $<0.05$ & 7 & $12^{1 / 4}$ \\
\hline 2 & & $<0.25$ & $61 / 4$ & $11 \frac{1}{4}$ \\
\hline 3 & Radiation Area & $<5.0$ & $4^{3 / 4}$ & $8^{3 / 4}$ \\
\hline 4 & High Radiation Area & $<100.0$ & $31 / 4$ & $61 / 2$ \\
\hline 5 & Very High Rad. Area & $<500 \mathrm{rad} \mathrm{h}^{-1}$ & N/A & N/A \\
\hline & Design Dose Rate & $<200.0$ & 3 & 6 \\
\hline
\end{tabular}

The HFBR fuel assembly governs the shielding requirements. For the postulated design dose rate of $200 \mathrm{mrem} / \mathrm{hr}$ at the surface, it is recommended that 8 inches of steel or $4 \frac{1}{4}$ inches of lead be used as the design shielding thickness to accommodate uncertainties in the shielding analysis.

The dose rate at the exit of the camera port penetration slightly exceeds the design dose rate. Administrative controls will be required to restrict access during handling of the test canister.

in The dose rate limit is at the outer surface of the shield wall. 


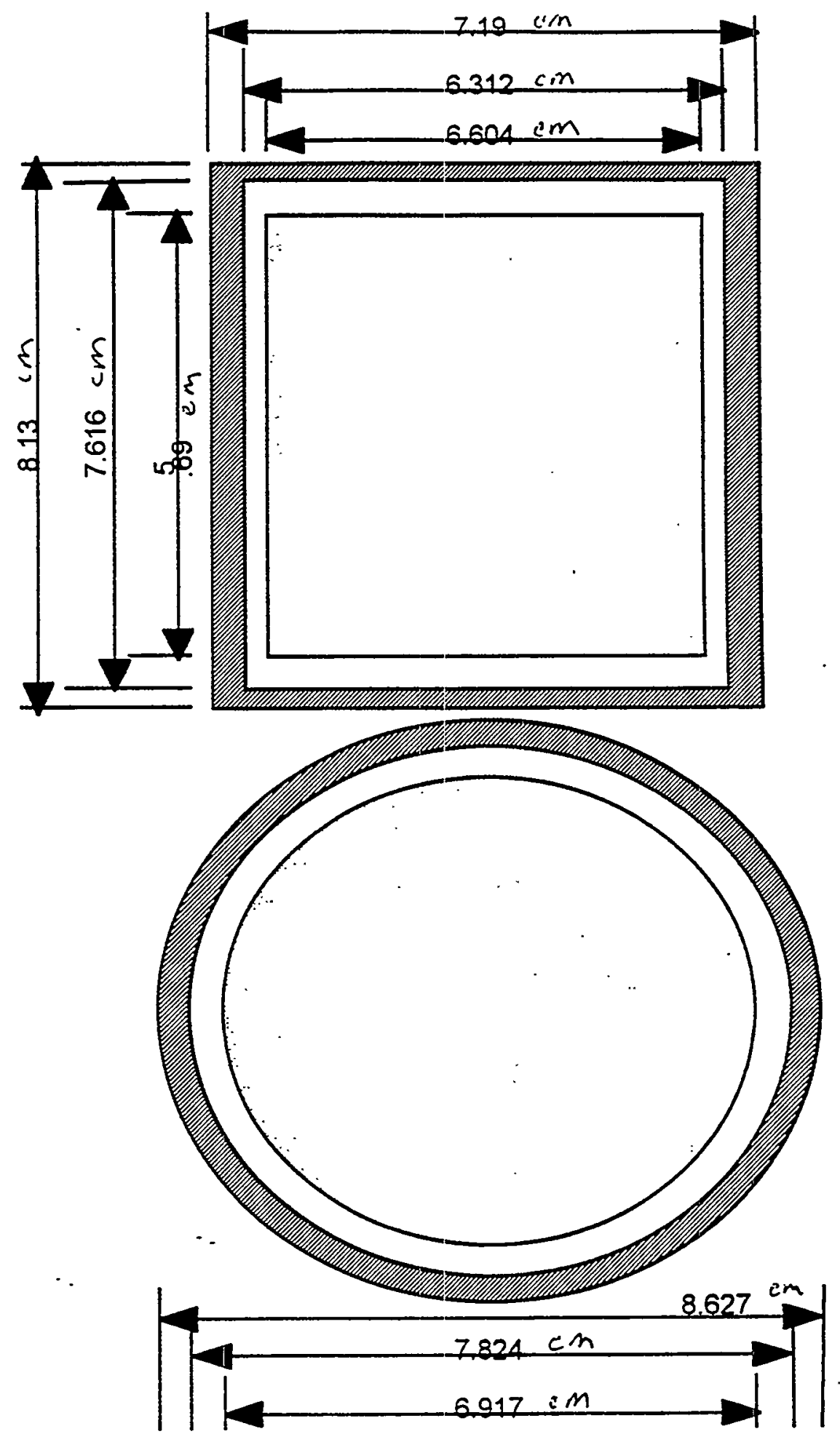

Figure 1 Homogenized HFBR Fuel Assembly 
0

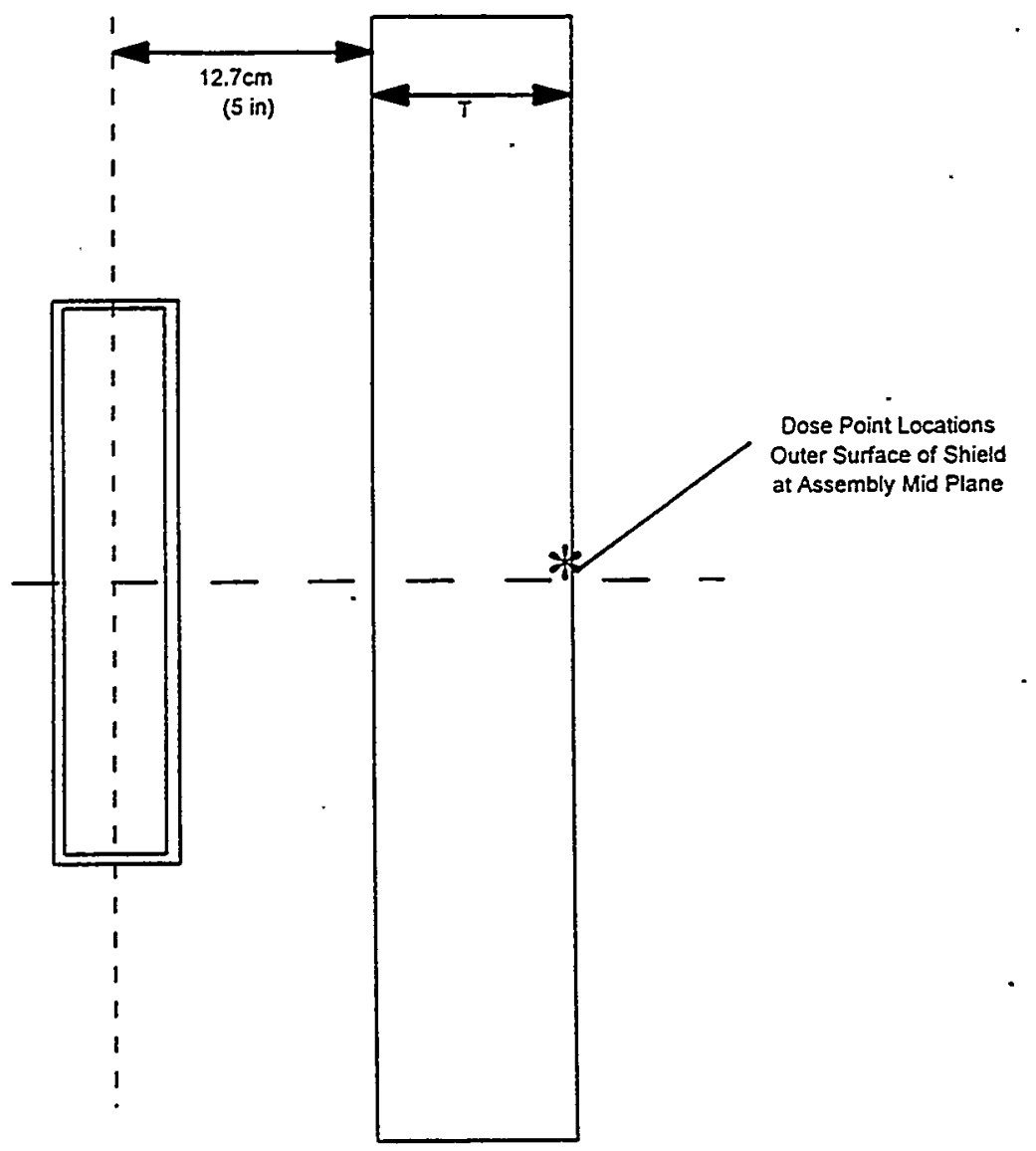

Figure 2 Schematic of QAD Geometry 


\begin{tabular}{l|l|}
\hline Calculation No. N-CLC-L-00009 \\
\hline Dheet No. 18 of 50 \\
\hline Rev. 0 \\
\hline
\end{tabular}

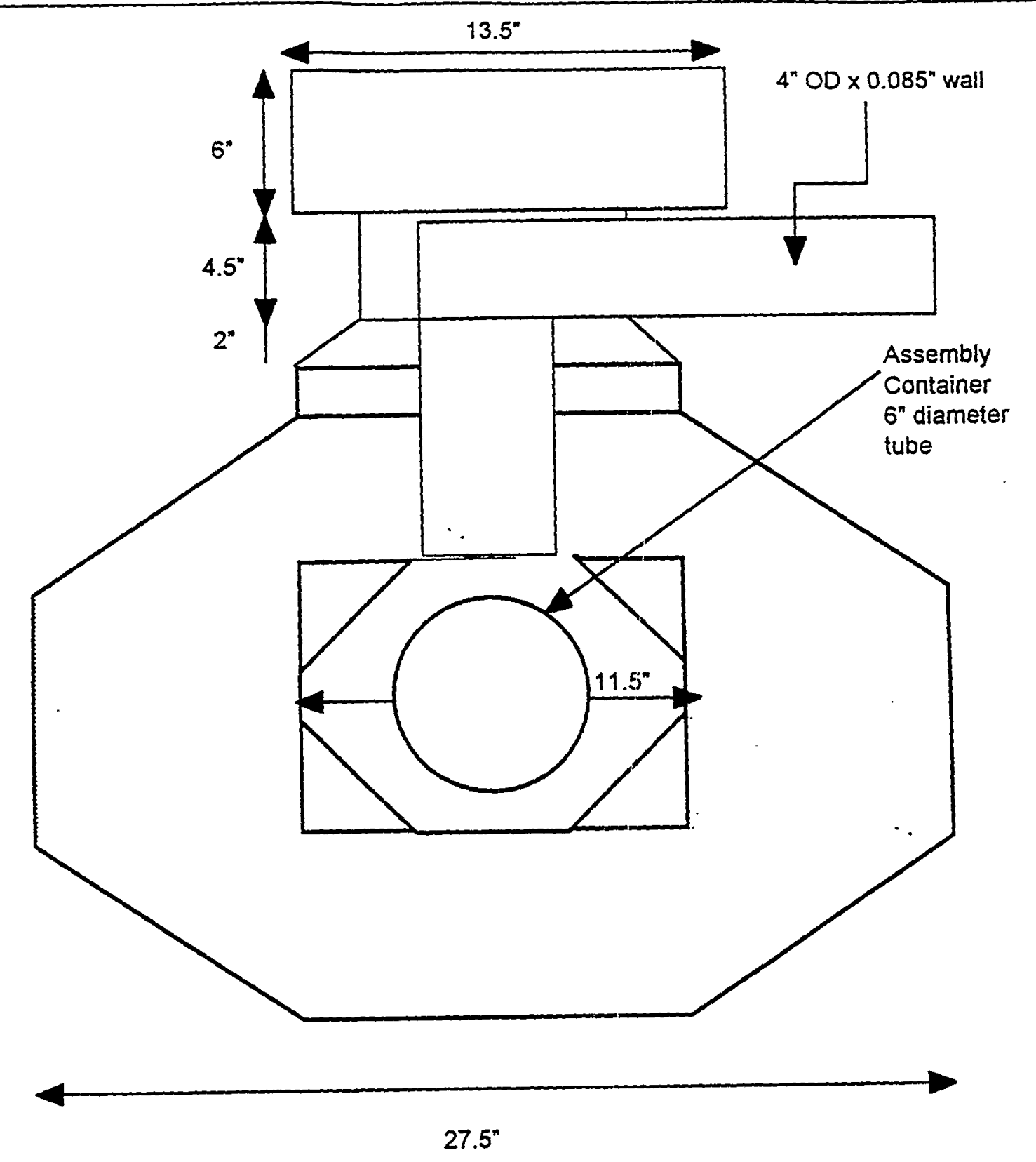

Figure 3 Schematic of Actual Canister Arrangement 


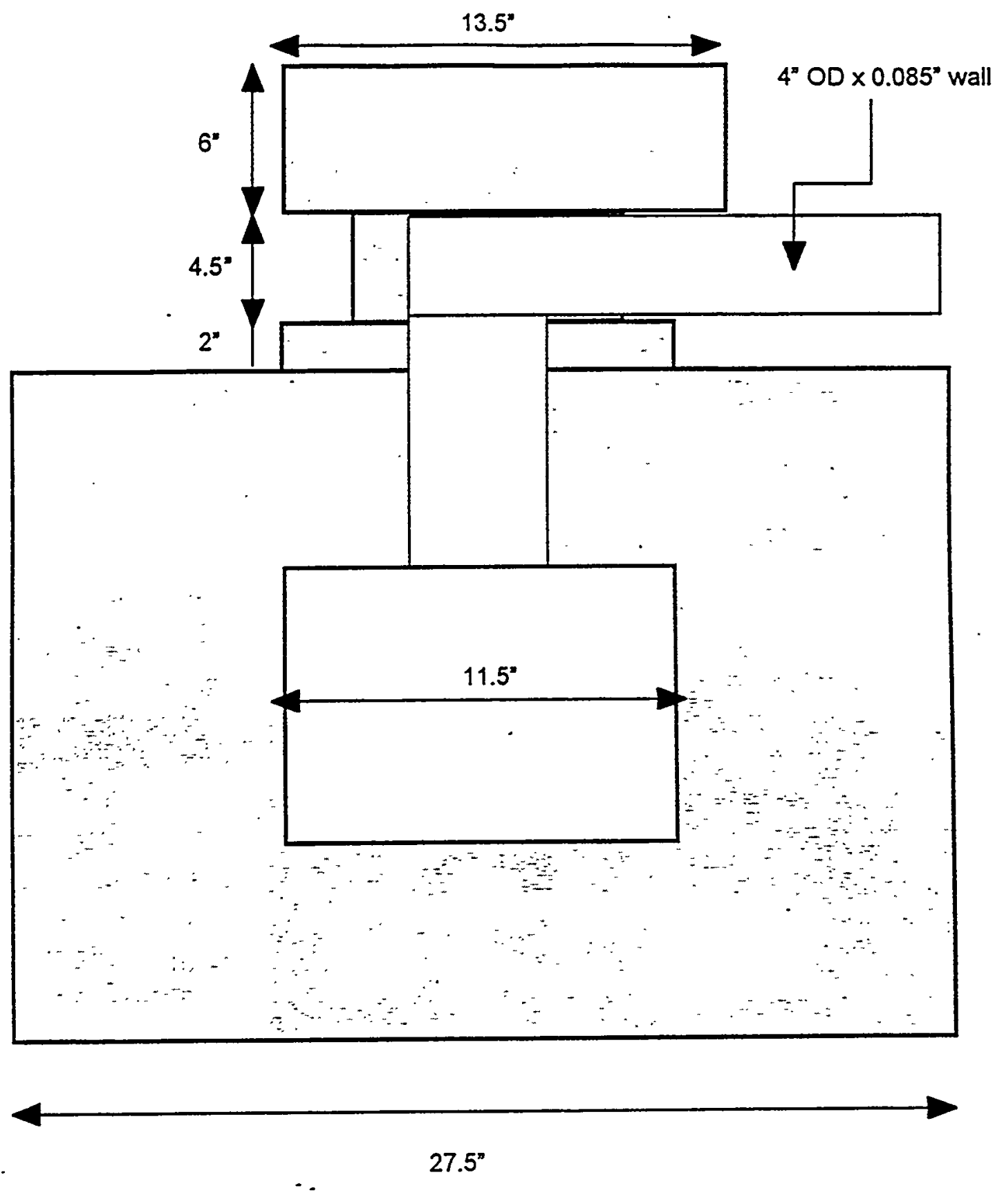

Figure 4 Schematic of Simplified Canister Arrangement 


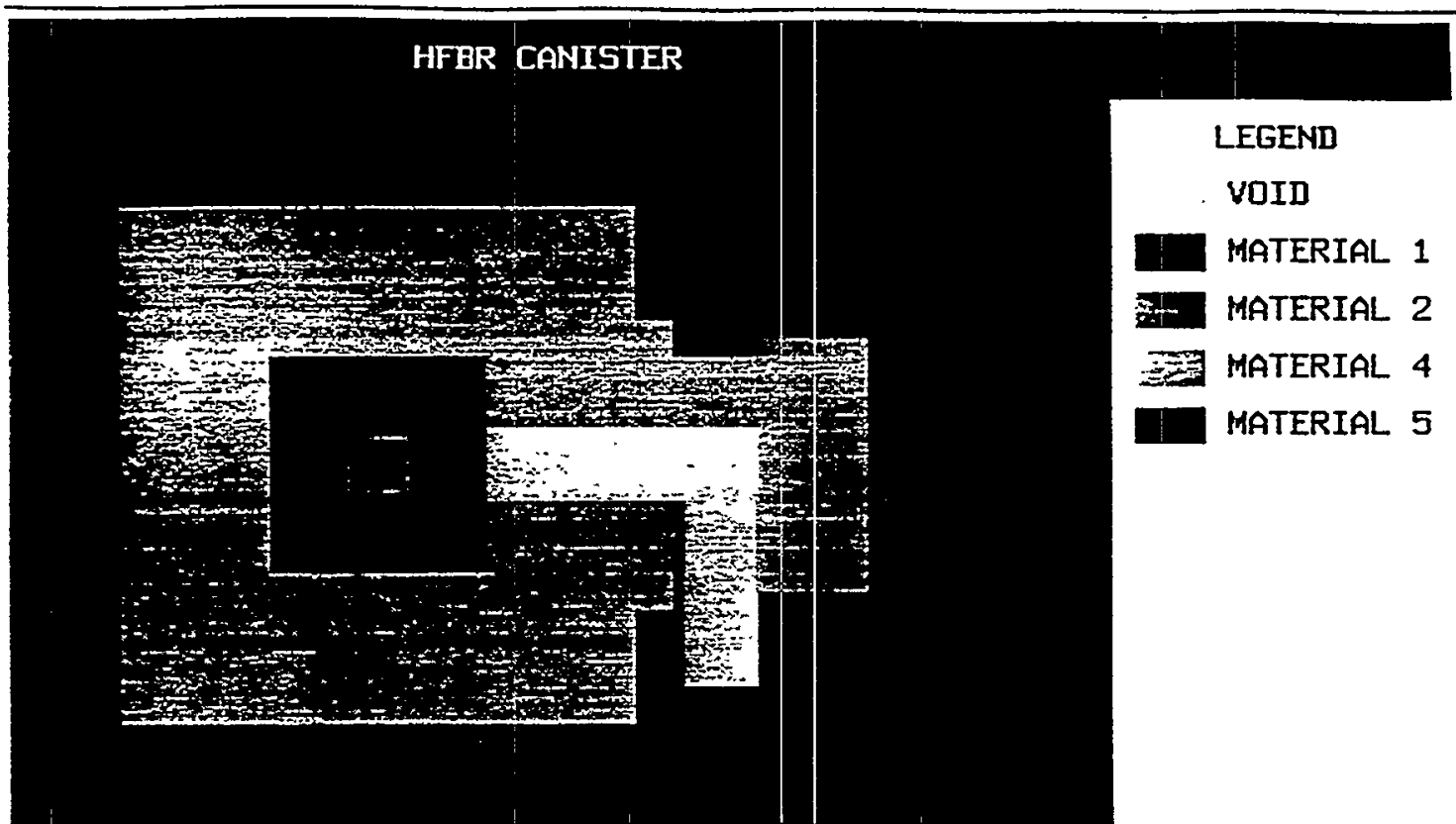

Figure 5 Plan View at Mid-Plane of Camera Port Penetration

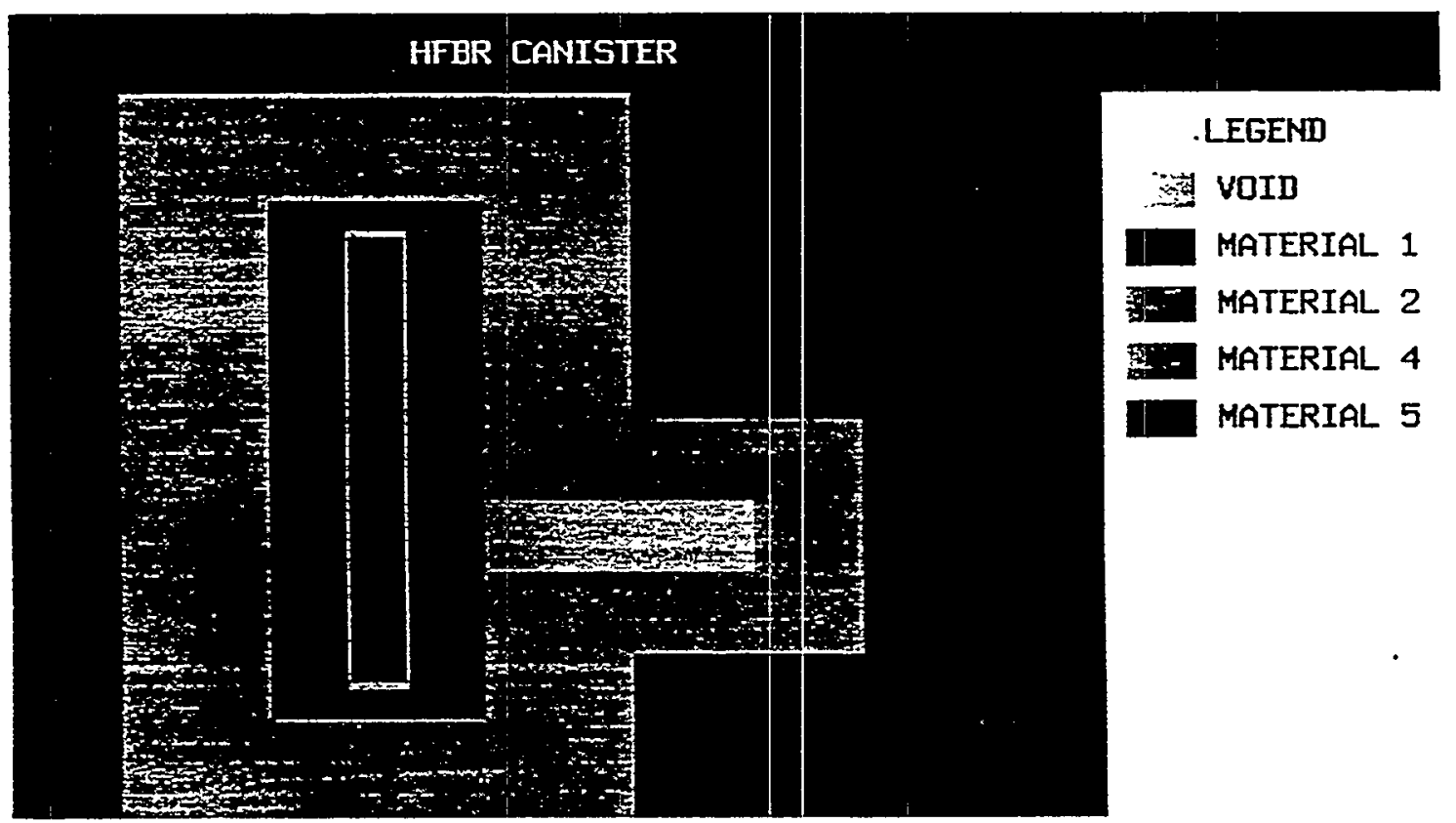

Figure 6 Cross Section on Center of Camera Port Penetration 


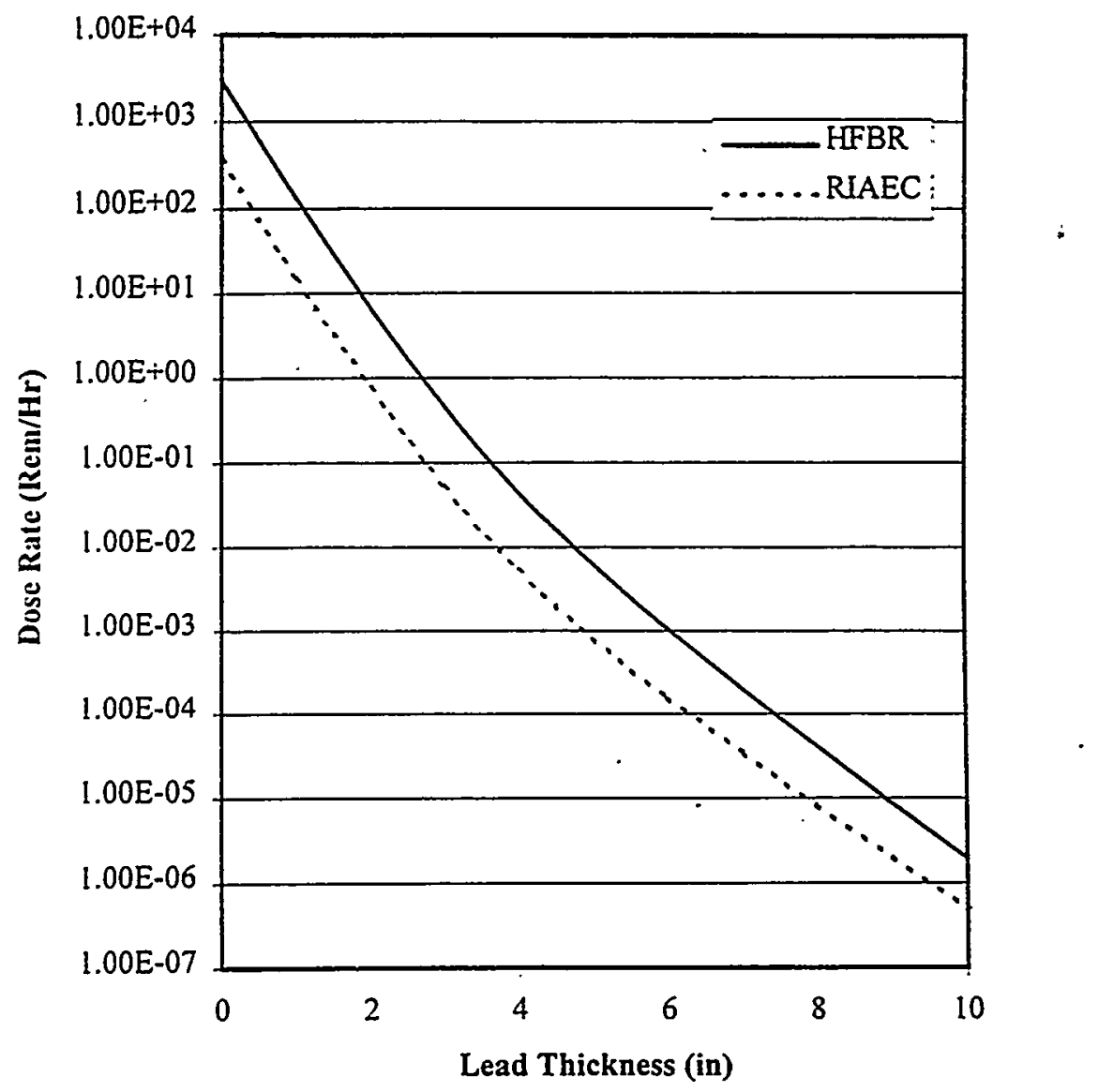

Figure 7 Lead Shielding 


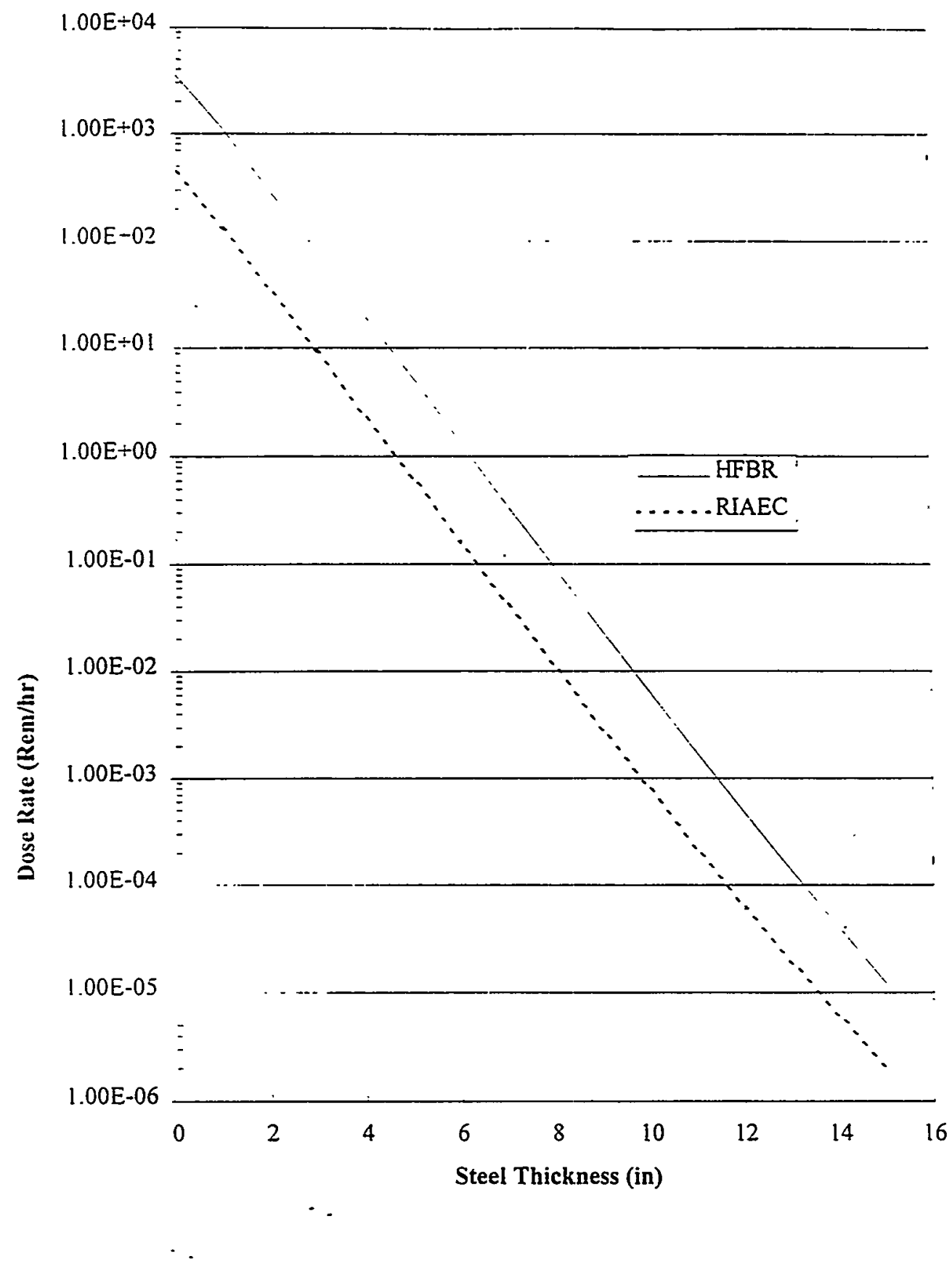

Figure 8 Steel Shielding 
cc $\mathrm{mL}$

\section{HFBR FUEL}

\section{Input Data}

\section{Element Data}

\section{Parameter}

$\mathrm{I}_{\text {fuel }}=58.05 \cdot \mathrm{cm}$

$\mathrm{w}_{\text {plate }}=6.63 \cdot \mathrm{cm}$

$\mathrm{w}_{\text {fuel }}=5.69 \cdot \mathrm{cm}$

$t_{\text {plate }} \quad 0.127 \cdot \mathrm{cm}$

1 plate $23.75 \cdot$ in

$\mathrm{t}_{\text {clad }} \quad 0.034 \cdot \mathrm{cm}$

${ }^{n}$ plates 18

$\mathrm{m}_{\text {Uassy }} \quad 377 . \mathrm{gm}$

$\mathrm{m}_{\mathrm{U}}=\frac{\mathrm{m}_{\text {Uassy }}}{\mathrm{n}_{\text {plates }}}$

$\mathrm{m}_{U}=20.944444 \cdot \mathrm{gm}$

$\mathrm{m}_{235 \text { assy }}=351 . \mathrm{gm}$

$\mathrm{m}_{235}=\frac{\mathrm{m}_{235 \text { assy }}}{\mathrm{n}_{\text {plates }}}$

$\mathrm{m}_{235}=19.5 \cdot \mathrm{gm}$

$\mathrm{m}_{\mathrm{O}}=3.8 \cdot \mathrm{gm}$

$\mathrm{m}_{\mathrm{fill}}=43 \cdot \mathrm{gm} \quad \cdots$

$\mathrm{m}_{\text {clad }}=84.5 \cdot \mathrm{gm}$
Description

Active Fuel Length

Width of plate (fuel and clad)

Width of fuel region

Thickness of plate (fuel and clad)

Length of plate

Thickness of Clad

Number of fuel plates per assembly

Mass of Uranium per assembly

Mass of Uranium per plate

Mass of U-235 per assembly

Mass of U-235 per plate

Mass of Oxygen in fuel

Mass of aluminum fill

Mass of aluminum clad 


\begin{tabular}{|l|}
\hline Calculation No. N-CLC-L-00009 \\
\hline Sheet No. 24 of 50 \\
\hline Rev. $\quad 0$ \\
\hline
\end{tabular}

DRY MONITORED STORAGE CANISTER SHIELDING

\section{Assembly Data}

\section{Parameter}

$\mathrm{w}_{\text {assy }}-8.13 \cdot \mathrm{cm}$

$\mathrm{m}_{\text {assy }} 4.425 \cdot \mathrm{kg}$

$t$ end $\quad 0.257 \cdot \mathrm{cm}$

t assy $7.19 \cdot \mathrm{cm}$

tside $\quad 0.439 \cdot \mathrm{cm}$

t chan $0.1 \cdot$ in
Description

Width of assembly

Mass of assembly

Thickness of end plate

Transverse (outer) dimension of assembly

Side plate thickness

Water channel thickness

\section{Calculated Data}

\section{Element Data}

$$
\begin{aligned}
& t_{\text {fuel }}=\mathrm{t}_{\text {plate }}-2 \cdot \mathrm{t} \text { clad } \\
& \mathrm{t}_{\text {fuel }}=0.059 \cdot \mathrm{cm} \\
& \text { vol fuel }=1_{\text {fuel }}{ }^{\mathrm{w}} \text { fuel }{ }^{\mathrm{t}} \text { fuel } \\
& \text { vol }_{\text {fuel }}=19.487966 \cdot c c
\end{aligned}
$$

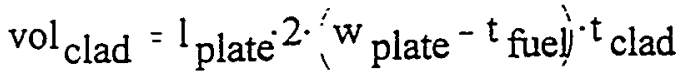

$$
\begin{aligned}
& \mathrm{vol}_{\mathrm{clad}}=27.438947 \cdot \mathrm{cc} \\
& \mathrm{m}_{\text {fuel }}=\mathrm{m}_{U}-\mathrm{m}_{\mathrm{O}}-\mathrm{m}_{\text {fill }} \\
& \mathrm{m}_{\text {fuel }}=67.744444 \cdot \mathrm{gm} \\
& m_{\text {plate }} \mathrm{m}_{\text {fuel }}{ }^{-\mathrm{m}_{\text {clad }}} \\
& \mathrm{m}_{\text {plate }}=152.244444 \cdot \mathrm{gm} \\
& \rho_{\text {fuelU }} \frac{\mathrm{m}_{\mathrm{U}}}{\mathrm{vol}_{\text {fuel }}} \\
& \rho_{\text {fuelU }}=1.074737 \cdot \frac{\mathrm{gm}}{\mathrm{cc}} \\
& \rho_{\text {fuelO }}=\frac{\mathrm{m}_{\mathrm{O}}}{\text { vol }_{\text {fuel }}} \\
& \rho_{\text {fuelO }}=0.194992 \cdot \frac{\mathrm{gm}}{\mathrm{cc}} \\
& \rho_{\text {fuelAl }}=\frac{m_{\text {fill }}}{\text { vol }_{\text {fuel }}} \\
& \rho_{\text {fuelAI }}=2.20649 \cdot \frac{\mathrm{gm}}{\mathrm{cc}} \\
& \rho_{\text {fuel }}=\frac{m_{\text {fuel }}}{\text { vol }_{\text {fuel }}} \\
& \rho_{\text {fuel }}=3.476219 \cdot \frac{\mathrm{gm}}{\mathrm{cc}}
\end{aligned}
$$


Fraction of Uranium in homogenized fuel and bonding

$w_{U} \quad \rho_{\text {fuelU }}$

wf $_{U}=0.309168$

Fraction of Aluminum in homogenized fuel and bonding

$w_{\mathrm{Al}}=\frac{\rho_{\text {fuelAl }}}{\rho_{\text {fuel }}} \quad \mathrm{wf}_{\mathrm{Al}}=0.634738$

Fraction of Oxygen in homogenized fuel and bonding

$w_{O}=\frac{\rho_{\text {fuelO }}}{\rho_{\text {fuel }}} \quad$ wf $_{\mathrm{O}}=0.056093$

Isotopic weight fractions

$w_{235}=\frac{m_{235}}{m_{U}} \quad \cdot \quad w_{235}=0.931034$

$w_{238}=1-w_{235} \quad w_{238}=0.068966$

Volume of fuel for input to SAS2

volume $=n_{\text {plates }}{ }^{\text {vol }}$ fuel

volume $=350.783379 \cdot \mathrm{mL}$

pitch $=t_{\text {plate }}{ }^{-t}$ chan

pitch $=0.381 \cdot \mathrm{cm}$

$\mathrm{m}_{\text {light }}=\mathrm{m}_{\text {assy }}-\mathrm{n}_{\text {plates }} \mathrm{m}_{\text {plate }}$

$\mathrm{m}_{\text {light }}=1.6846 \cdot \mathrm{kg}$ 


\section{Assembly Data}

Smeared assembly without side plates

Transvers dimension of fueled region

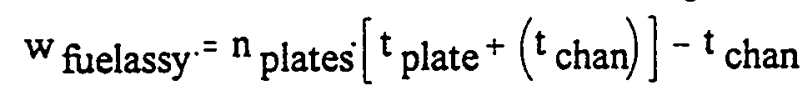

$$
\begin{aligned}
& \mathrm{w}_{\text {fuelassy }}=6.604 \cdot \mathrm{cm} \\
& \text { vol }_{\text {assy }}:=\left(\mathrm{w}_{\text {fuelassy }}\right) \cdot \mathrm{w}_{\text {fuel }} \mathrm{l}_{\text {fuel }} \quad \mathrm{vol}_{\text {assy }}=2.181331 \cdot 10^{3} \cdot \mathrm{mL} \\
& \mathrm{m}_{\mathrm{Al}}:=\left(\mathrm{m}_{\text {clad }}+\mathrm{m}_{\text {fill }}\right) \cdot \mathrm{n}_{\text {plates }} \quad \mathrm{m}_{\mathrm{Al}}=2.295 \cdot 10^{3} \cdot \mathrm{gm} \\
& \mathrm{m}_{\text {Oassy }}=\mathrm{m}_{\mathrm{O}} \cdot \mathrm{n}_{\text {plates }} \quad \mathrm{m}_{\text {Oassy }}=68.4 \cdot \mathrm{gm} \\
& m_{\text {fuelassy }}=m_{\mathrm{Al}}+\mathrm{m}_{\text {Uassy }}+\mathrm{m}_{\text {Oassy }} \quad \mathrm{m}_{\text {fuelassy }}=2.7404 \cdot 10^{3} \cdot \mathrm{gm} \\
& \rho_{\text {assy }}:=\frac{\mathrm{m}_{\text {fuelassy }}}{\text { vol }_{\text {assy }}} \quad \rho_{\text {assy }}=1.256297 \cdot \frac{\mathrm{gm}}{\mathrm{mL}} \text {. } \\
& \text { wf }_{\mathrm{Ala}}:=\frac{\mathrm{m}_{\mathrm{Al}}}{\mathrm{m}_{\text {fuelassy }}} \quad \mathrm{wf}_{\mathrm{Ala}}=0.837469 \\
& \text { wf }_{U a}=\frac{m_{\text {Uassy }}}{m_{\text {fuelassy }}} \quad \text { wf }_{U a}=0.137571 \\
& \text { wf }_{\mathrm{Oa}}:=\frac{\mathrm{m}_{\text {Oassy }}}{\mathrm{m}_{\text {fuelassy }}} \quad \text { wf }_{\mathrm{Oa}}=0.02496
\end{aligned}
$$




\section{Smeared Cylindrical Regions}

Smeared cylinder fuel region

$$
r_{\text {cyl }} \frac{{ }^{W}}{r_{\text {cyl }} \text { fuel }^{W} \text { fuelassy }}
$$

Smeared Așsembly

$$
\begin{array}{ll}
\mathrm{w}_{\text {in }}=\mathrm{w}_{\text {assy }}-2 \cdot \mathrm{t}_{\text {end }} & \mathrm{w}_{\text {in }}=7.616 \cdot \mathrm{cm} \\
\mathrm{t}_{\text {in }}=\mathrm{t}_{\text {assy }}-2 \cdot \mathrm{t}_{\text {side }} & \mathrm{t}_{\text {in }}=6.312 \cdot \mathrm{cm} \\
\mathrm{r}_{\text {in }}=\frac{\mathrm{w}_{\text {in }} \mathrm{t}_{\text {in }}}{\pi} & \mathrm{r}_{\text {in }}=3.911758 \cdot \mathrm{cm} \\
\frac{\mathrm{w}_{\text {assyt }} \mathrm{t}_{\text {assy }}}{\pi} & \\
: \frac{\mathrm{r}_{\text {out }}=4.313549 \cdot \mathrm{cm}}{\pi} &
\end{array}
$$




\section{Appendix B RIAEC MATHCAD Worksheet}

$\mathrm{cc}=\mathrm{mL}$

Input Data

RIAEC fuel

$I_{\text {fuel }}=25 \cdot$ in

$w_{\text {fuel }}=2.774 \mathrm{in}$

t plate -0.06 in

$\mathrm{t}_{\text {clad }}=0.024$ in

${ }^{n}$ plates -18

$w_{\text {assy }} \cdot 3 \cdot$ in

$t_{\text {side }}-0.187$ in

$\mathrm{m}_{\text {assy }}-4.66 \mathrm{l} \cdot \mathrm{kg}$

$\mathrm{m}_{\mathrm{U}} \quad 7.4 \mathrm{gm}$

$m_{\text {plate }} \cdot 190 \mathrm{gm} \mathrm{m}_{\mathrm{O}} \cdot 0 . \mathrm{gm}$

$\mathrm{m}_{235} \cdot 6.88 \mathrm{gm} \quad \rho_{\mathrm{al}} \quad 2.7 \cdot \frac{\mathrm{gm}}{\mathrm{cc}}$

Calculated Data
${ }^{t}$ fuel $t$ plate $\cdot 2 \cdot t$ clad
${ }^{t}$ fuel $=0.03048 \mathrm{~cm}$
${ }^{v o l}$ fuel ${ }^{1}$ fuel $^{-w}$ fuel ${ }^{-t}$ fuel
vol fuel $_{\text {ful }}=13.637315 \mathrm{cc}$
${ }^{\mathrm{vol}}$ clad $2 \cdot \mathrm{t} \mathrm{clad}^{-1} \mathrm{fuel}^{-\mathrm{w}}$ fuel
$\mathrm{vol}_{\text {clad }}=54.549259 \mathrm{cc}$
$\mathrm{m}_{\text {clad }} \rho_{\text {al }}{ }^{\text {vol }}$ clad
$\mathrm{m}_{\mathrm{clad}}=147.282998 \mathrm{gm}$
$m_{\text {fill }} m_{\text {plate }} m_{\text {clad }} m_{U}-m_{O}$
$\mathrm{m}_{\mathrm{fill}}=35.317002 \mathrm{gm}$
$\mathrm{m}_{\text {fuel }}=\mathrm{m}_{\text {plate }}-\mathrm{m}_{\text {clad }}$
$\mathrm{m}_{\text {fuel }}=42.717002 \mathrm{gm}$
$\rho_{\text {fuelU }}=\frac{m_{U}}{\text { vol fuel }_{\text {fuel }}}$
$\rho_{\text {fuelU }}=0.542629 \frac{\mathrm{gm}}{\mathrm{cc}}$
$\rho_{\text {fuelo }}=\frac{\mathrm{m}_{\mathrm{O}}}{\mathrm{vol}_{\text {fuel }}}$
$\rho_{\text {fuelO }}=0 \cdot \frac{\mathrm{gm}}{\mathrm{cc}}$
$\rho_{\text {fuelAl }}=\frac{m_{\text {fill }}}{v_{\text {fuel }}}$
$\rho_{\text {fuelAl }}=2.589733-\frac{\mathrm{gm}}{\mathrm{cc}}$
$P$ fuel $\frac{m_{\text {fuel }}}{v_{\text {vol fuel }}}$
$P_{\text {fuel }}=3.132362 \frac{\mathrm{gm}}{\mathrm{cc}}$
$v f_{U}=\frac{\rho_{\text {fuelU }}}{\rho_{\text {fuel }}}$
$v f_{U}=0.173233$
$v f_{O}=\frac{\rho \text { fuelo }}{\rho_{\text {fuel }}}$.
$\mathrm{vf}_{\mathrm{O}}=0$
$\mathrm{vf}_{\mathrm{Al}}=\frac{\rho_{\text {fuelAl }}}{\rho_{\text {fuel }}}$
vf $_{\mathrm{Al}}=0.826767$ 


\begin{tabular}{|c|c|c|}
\hline$w f_{235}$ & $\frac{m_{235}}{m_{L}}$ & $w f_{235}=0.92973$ \\
\hline wt 238 & I $\quad$ wf 235 & $w^{238}=0.07027$ \\
\hline pitch & ${ }^{w^{\prime}}{ }_{\text {assy }}^{2 \cdot t}$ side & pitch $=0.370558 \mathrm{~cm}$ \\
\hline $\mathrm{m}_{\text {light }}$ & $=m_{\text {assy }}-n^{n}$ plates ${ }^{-m}$ plate & $\mathrm{m}_{\text {light }}=1.241 \cdot \mathrm{kg}$ \\
\hline volum & ne $=n_{\text {plates }}{ }^{-v o l}$ fuel & volume $=245.471664 \mathrm{~mL}$ \\
\hline
\end{tabular}

Assebly Data

$$
\begin{aligned}
& \text { vol assy }={ }^{\prime} w_{\text {assy }}-2 \cdot \mathrm{t} \text { side } j^{\prime} \mathrm{w}^{\text {fuel }}{ }^{-1} \text { fuel } \\
& \text { vol }_{\text {assy }}=2.98429910^{3} \cdot \mathrm{mL} \\
& m_{A l}=m_{\text {clad }}-m_{\text {fili }} \cdot n_{\text {plates }} \quad m_{A l}=3.286810^{3} \cdot \mathrm{gm} \\
& m_{\text {Uassy }} \cdot m_{U^{n}} \text { plates } \quad m_{\text {Uassy }}=133.2 \cdot \mathrm{gm} \\
& \mathrm{m}_{\text {Oassy }} \cdot \mathrm{m}_{\mathrm{O}} \cdot \mathrm{n}_{\text {plates }} \quad \mathrm{m}_{\text {Oassy }}=0 \cdot \mathrm{gm} \\
& m_{\text {assy }}=m_{A l}-m_{\text {Uassy }}-m_{\text {Oassy }} \\
& \mathrm{m}_{\text {assy }}=3.4210^{3} \cdot \mathrm{gm} \\
& \rho_{\text {assy }}=\frac{\mathrm{m}_{\text {assy }}}{\text { vol }_{\text {assy }}} \quad \rho_{\text {assy }}=1.145998 \frac{\mathrm{gm}}{\mathrm{mL}} \\
& w_{\mathrm{Al}}=\frac{\mathrm{m}_{\mathrm{Al}}}{\mathrm{m}_{\text {assy }}} \quad \mathrm{wf}_{\mathrm{Al}}=0.961053 \\
& w_{O}=\frac{m_{\text {Oassy }}}{m_{\text {assy }}} \quad w_{O}=0
\end{aligned}
$$

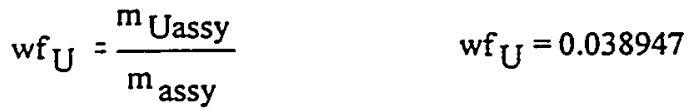




\section{Appendix $C^{*}$ Inpúf File Listing}

\section{HFBR SAS-2, ORIGENS and QADS Lead Shield}

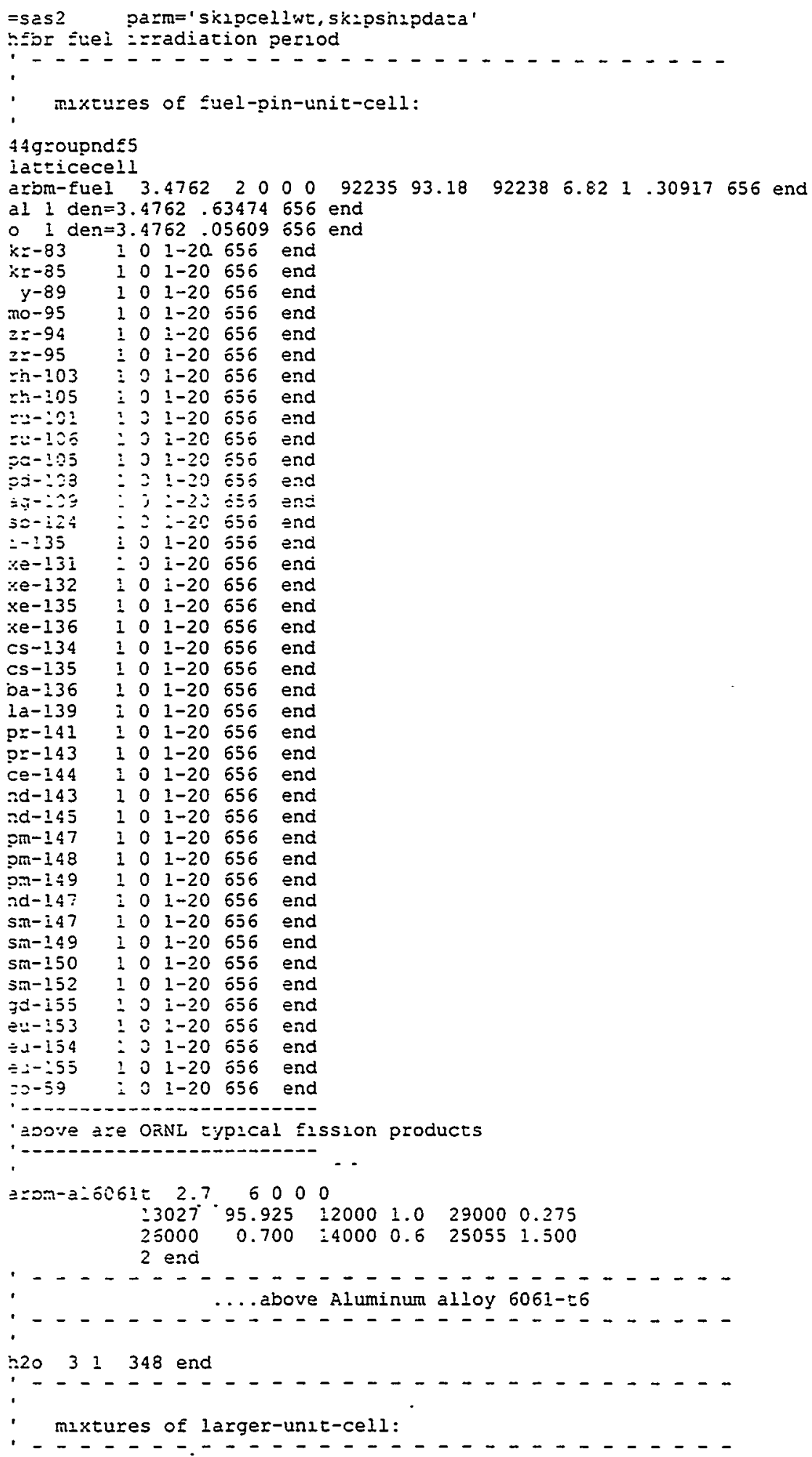




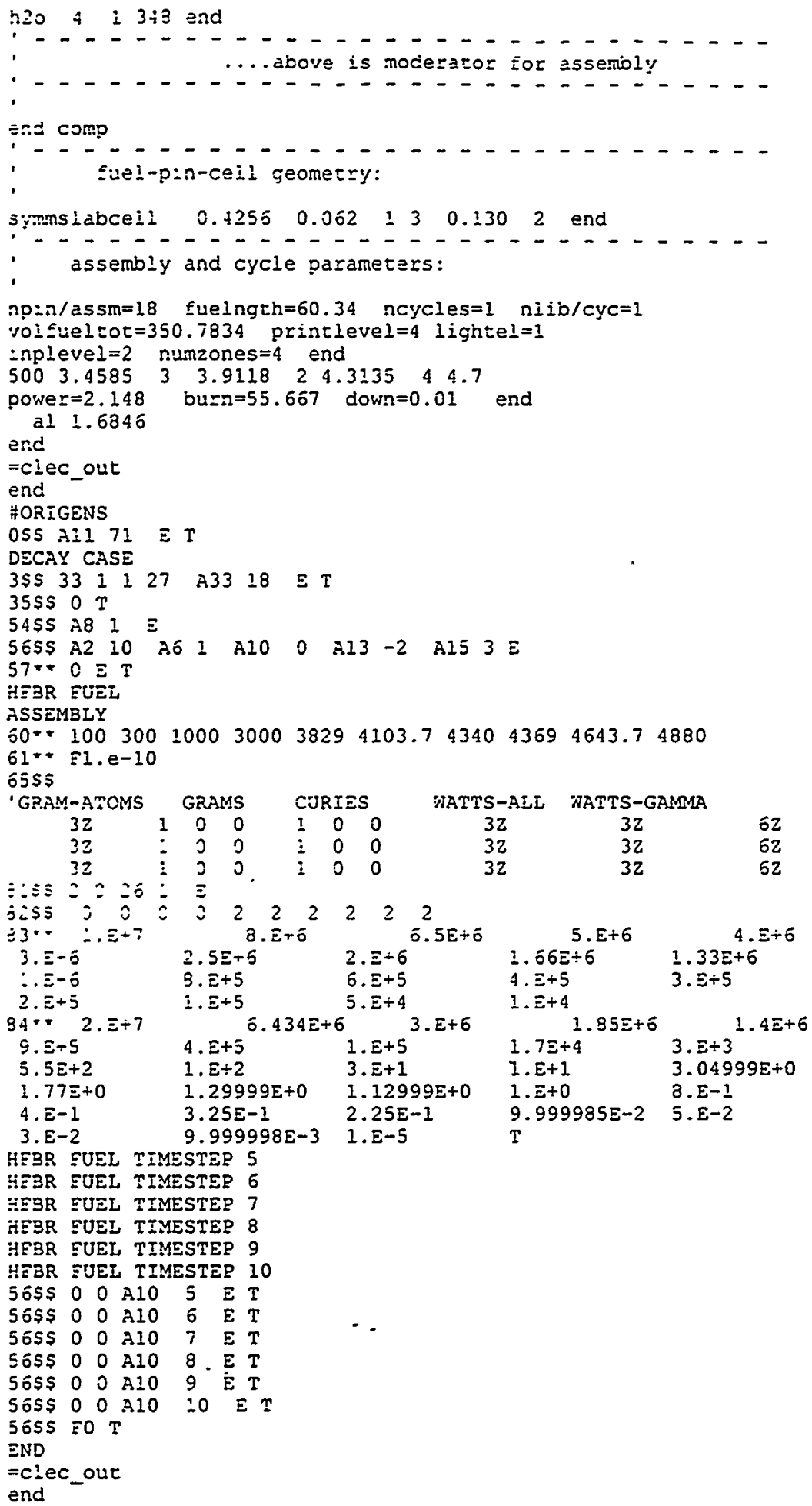




\section{HFBR Q:ADS Steel Shield}

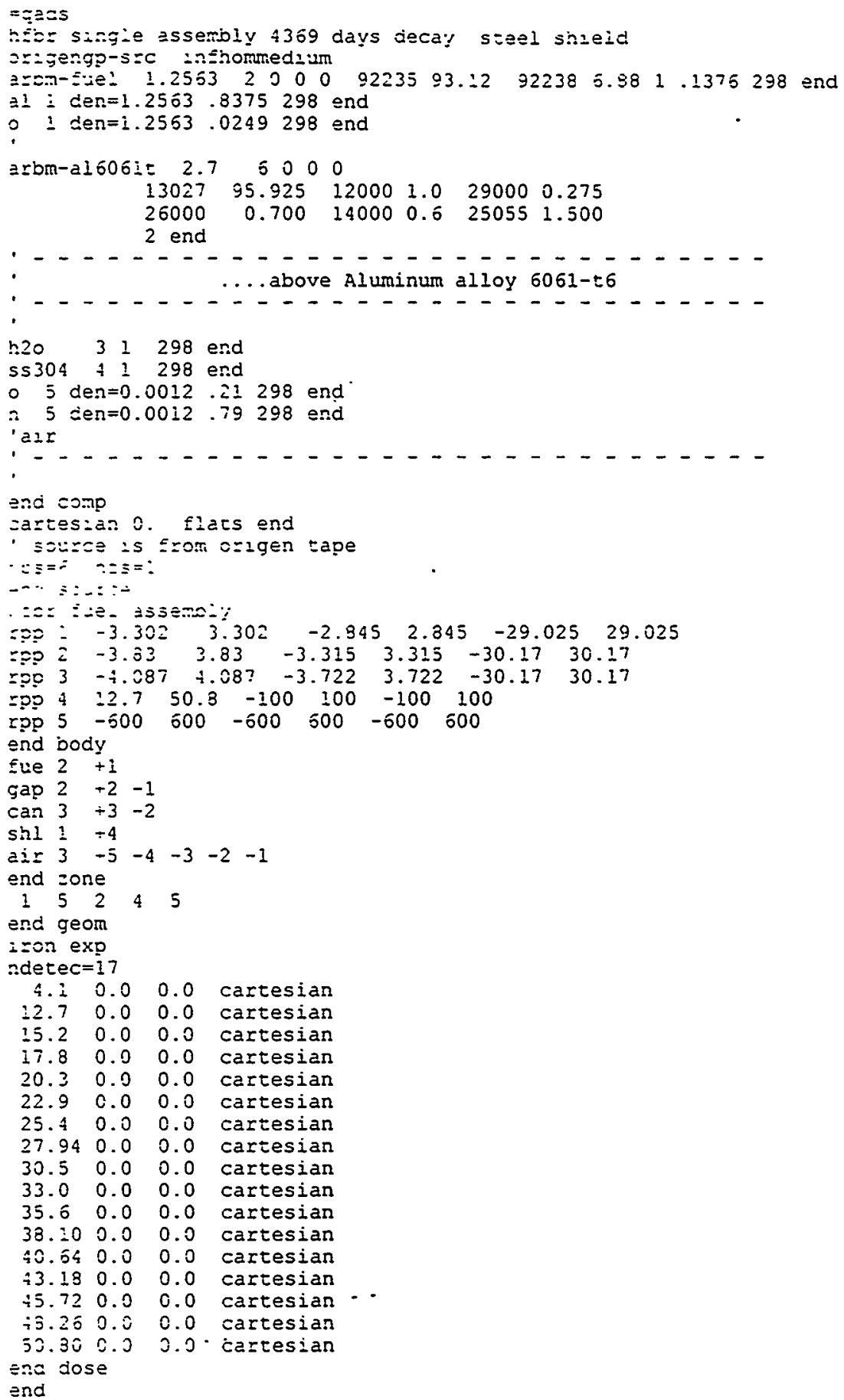




\section{HFBR QADS Lead Shield}

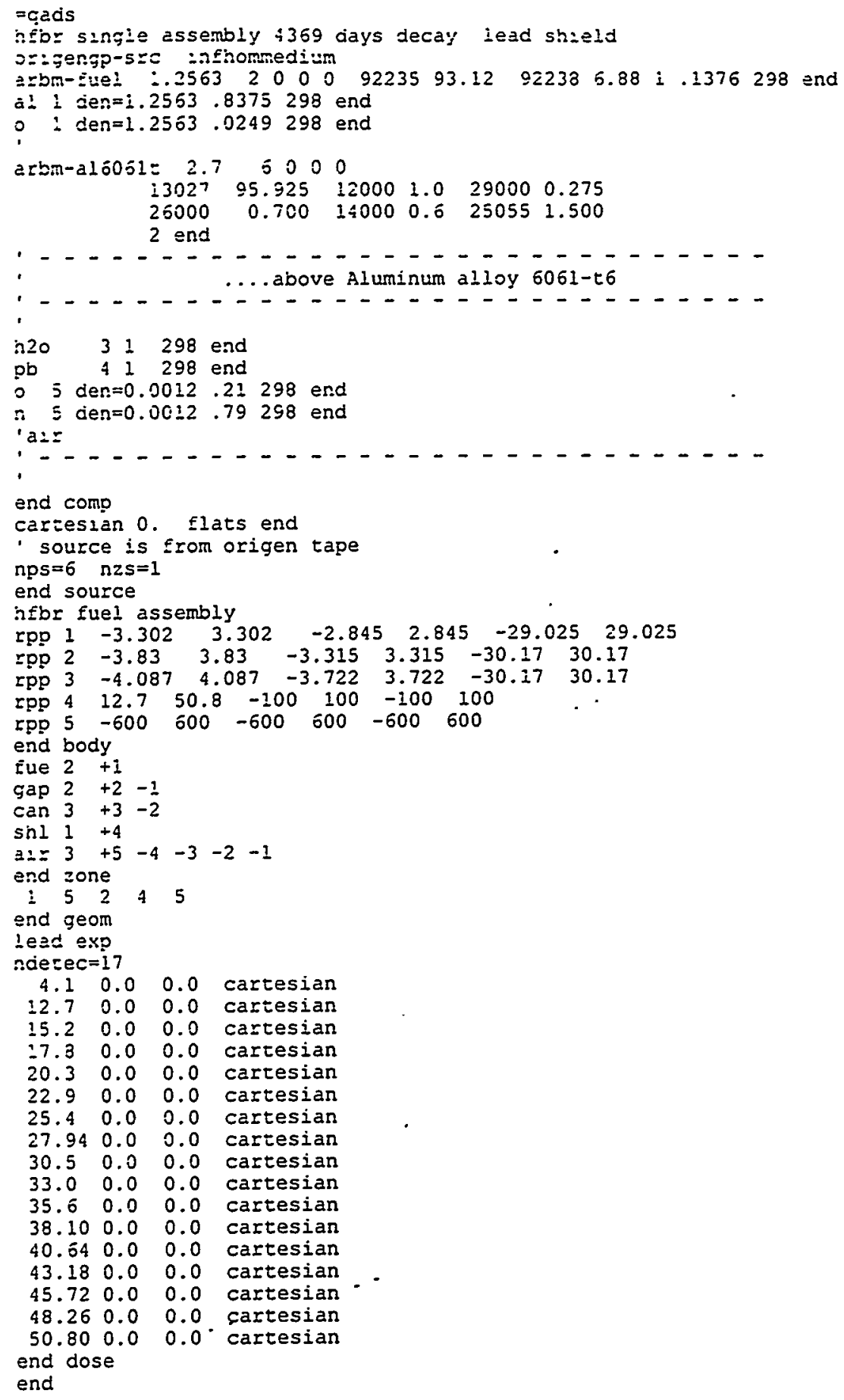




\section{RIAEC Irradiation}

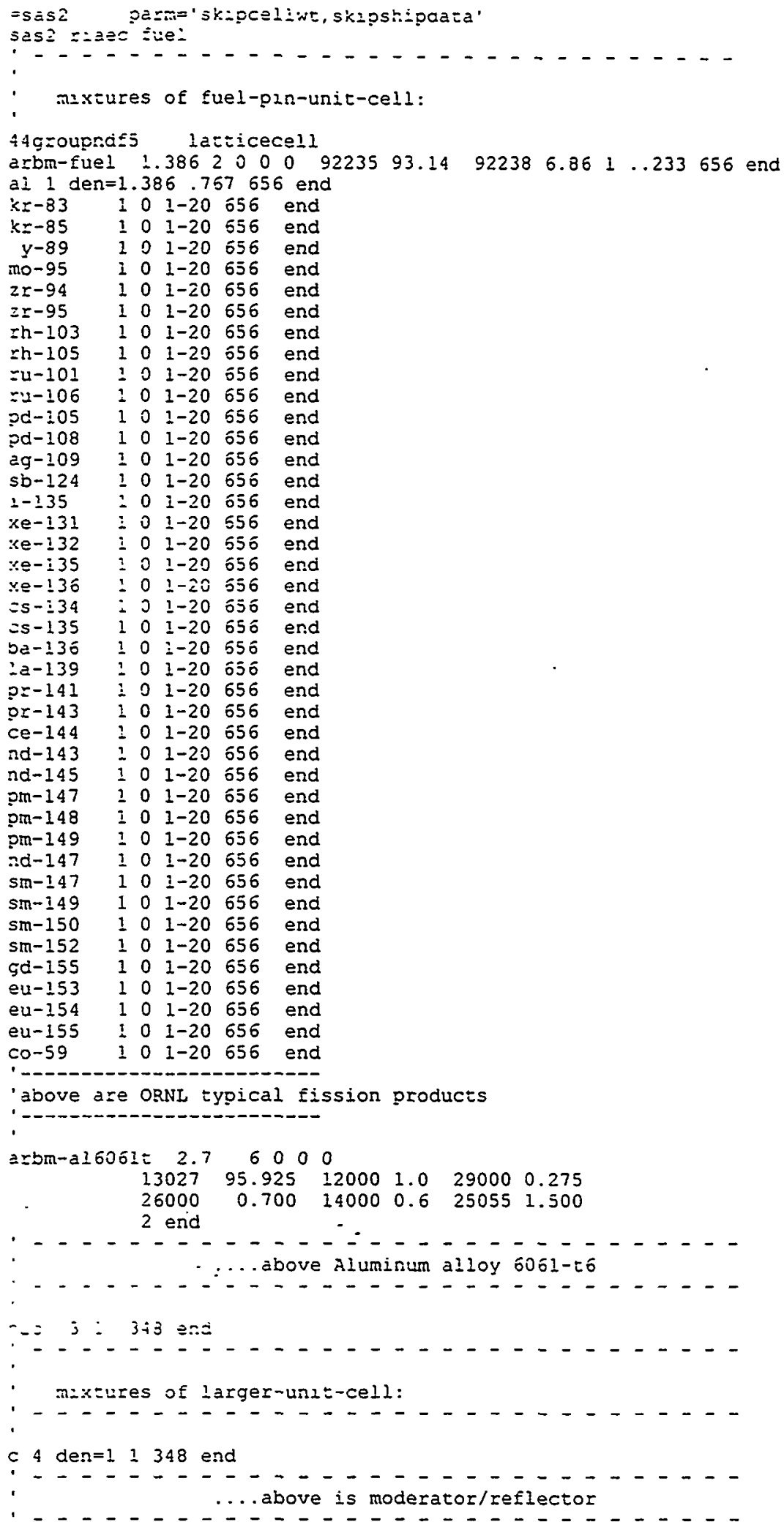




\section{$R I A E C$ Decay}

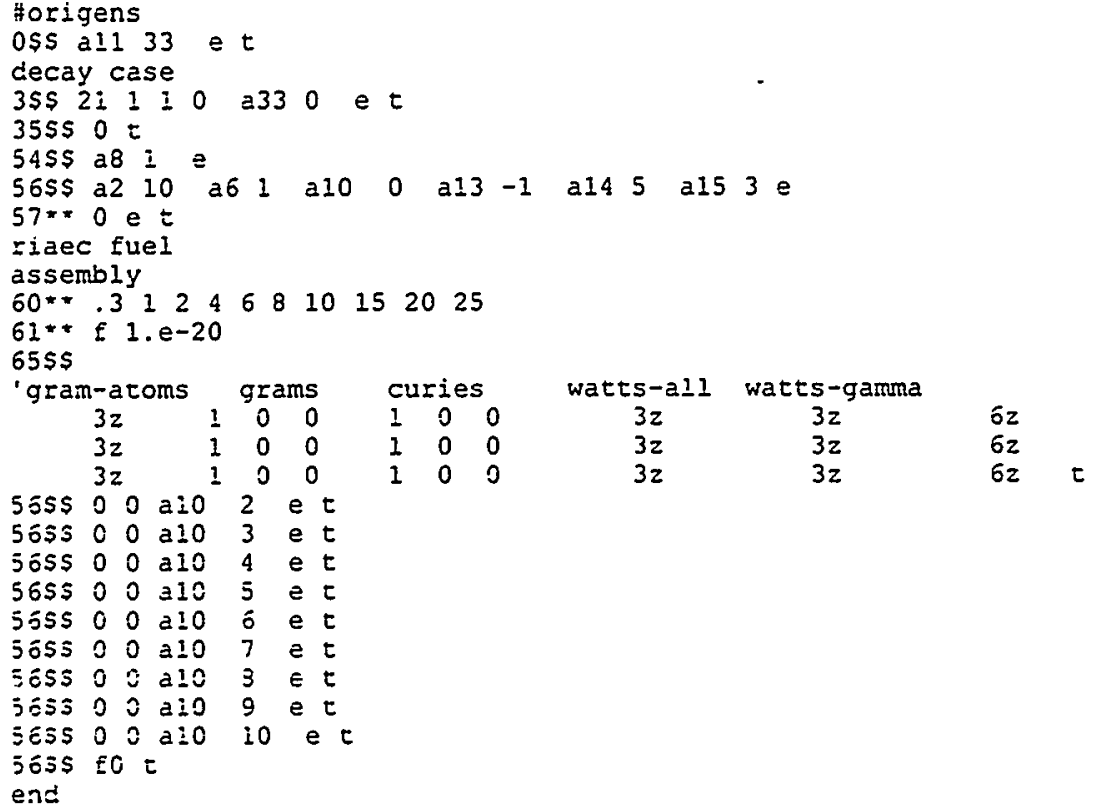

watts-all watts-gamma

$\begin{array}{cccc}3 z & 3 z & 6 z & \\ 3 z & 3 z & 6 z & \\ 3 z & 3 z & 6 z & \end{array}$




\section{$R I A E C \underline{Q} A D$ (Lead Shielding)}

$=\sum \equiv \pm s$

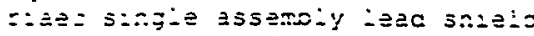

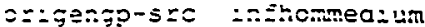

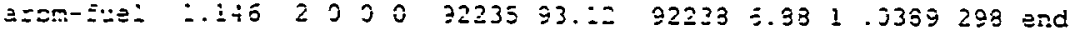

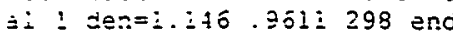

$2=b m-a i 505 i=2.7$ б 0000

$\begin{array}{llllll}13027 & 95.925 \quad \vdots 2000 \quad 1.0 & 29000 & 0.275\end{array}$

$\begin{array}{llllll}26000 & 0.700 & 14000 & 0.6 & 25055 & 1.500\end{array}$

2 end

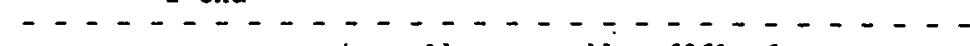

....above Aluminum alloy 6061-t6

h20 31298 end

pb $\quad 41298$ end

5 der: $=0.001251298$ end

'ais

$\therefore$

erd comp

cartesian 0 . fiats end

- solice is irom origen tape

$: 205=4 \quad:: 25=1$

end souzce

:iaec Elel assembly

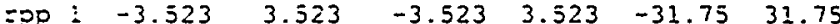

$=202-3.810 \quad 3.810 \quad-3.810 \quad 3.310 \quad-31.75 \quad 31.75$

$=20 \quad: 2.7 \quad 38: 2-100$ iGo 3 - $300 \quad 100$

$=00 ;-302 \quad 000 \quad-500 \quad 600-600 \quad 600$

?:S: $200 \mathrm{y}$

E*? $?-:$

$=\sin 3+2-1$

st: $1 \quad 1 \quad-3$

$\varepsilon=2+4-3-2-1$

end zone

1245

end geom

lead exp

nderec $=12$

$\begin{array}{lllll}4.2 & 0.0 & 0.0 & \text { cartesian }\end{array}$

$\because 2.7 \quad 0.0 \quad 0.0$ cartesian

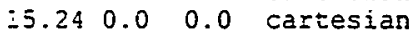

$17.780 .0 \quad 0.0$ cartesian

$20.32 \quad 0.0 \quad 0.0$ cartesian

$22.86 \quad 0.0 \quad 0.0$ cartesian

$25.4 \quad 0.0 \quad 0.0$ cartesian

$27.94 \quad 0.0 \quad 0.0$ cartesian

$30.480 .0 \quad 0.0$ cartesian

$\begin{array}{llll}33.02 & 0.0 & 0.0 & \text { cartesian }\end{array}$

$35.56 \quad 0.0 \quad 0.0$ cartesian

$38.100 .0 \quad 0.0$ cartesian

end cose

end

=cads

¿iaec single assembly lead shield

orzgengp-src inshomedium

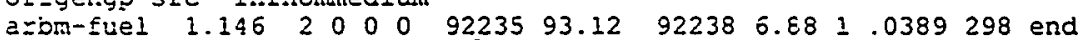

21 I den $=1.146 .9611298$ end

əะรm-21ร061 $2.7^{\circ}$ б 000

$\begin{array}{llllll}-3027 & 95.925 & 12000 & 1.0 & 29000 & 0.275\end{array}$

$\begin{array}{llllll}25000 & 0.700 & 14000 & 0.0 & 25055 & 1.500\end{array}$

$=$ end

. - . - . . . . . . . . . . . . . . .

- $\quad$... above Aluminum alloy 606l-t6

in 31298 end

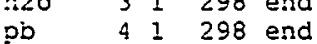

05 den $=0.001251298$ end

'als 


\section{RIAEC QAD (Steel Shielding)}

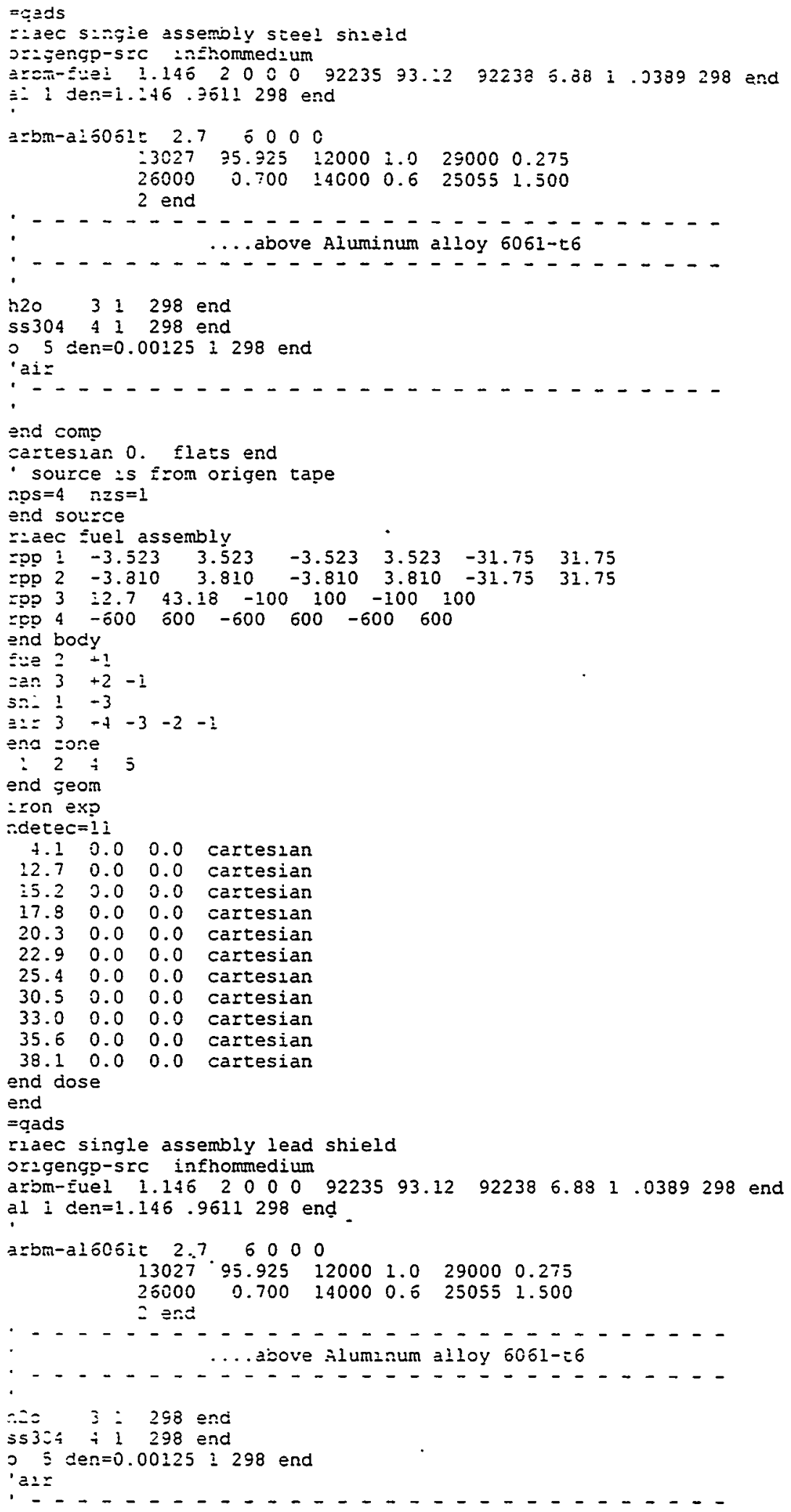




\section{SAS3 Input}

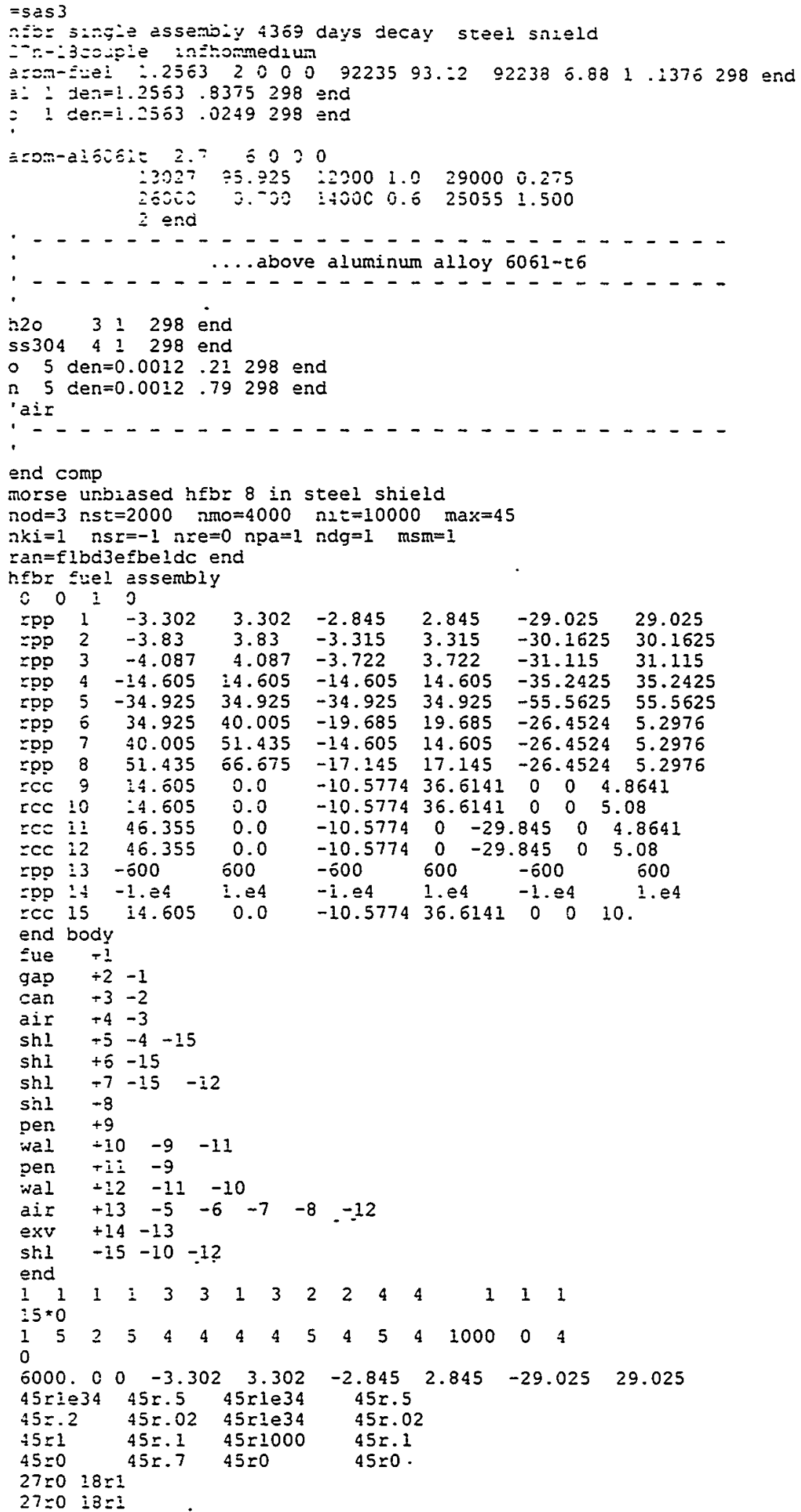


Calculation No. N-CLC-L-00009

Sheet No. 41 of 50

DRY MONITORED STORAGE CANISTER SHIELDING

Rev. 0

\begin{tabular}{|c|c|c|c|c|c|}
\hline $\begin{array}{l}27=0 \quad i 3 r i \\
27=0 \quad i 8 z- \\
25=0 \\
5 . \vdots 7 e-i \Xi \\
0.33 e-06 \\
0.01 \equiv 567\end{array}$ & $\begin{array}{c}\cdot \\
2.95 e-14 \\
3.77 e-05 \\
0.014295\end{array}$ & $\begin{array}{l}1.55 e-i 3 \\
0.000456 \\
0.020182\end{array}$ & $\begin{array}{l}3.97 e-13 \\
0.003273 \\
0.054239\end{array}$ & $\begin{array}{l}1.38 e-08 \\
0.005201 \\
0.093671\end{array}$ & $\begin{array}{l}\text { ye-08 } \\
0.450055 \\
0.322416\end{array}$ \\
\hline
\end{tabular}

1.

$46.355 \quad-29.9 \quad-10.5774$

$51.435 \quad-29.9 \quad-10.5774$

$\begin{array}{lll}51.5 & -23.495 & -10.5774\end{array}$

end 


\section{PICTURE Inpuit file for Plan View}

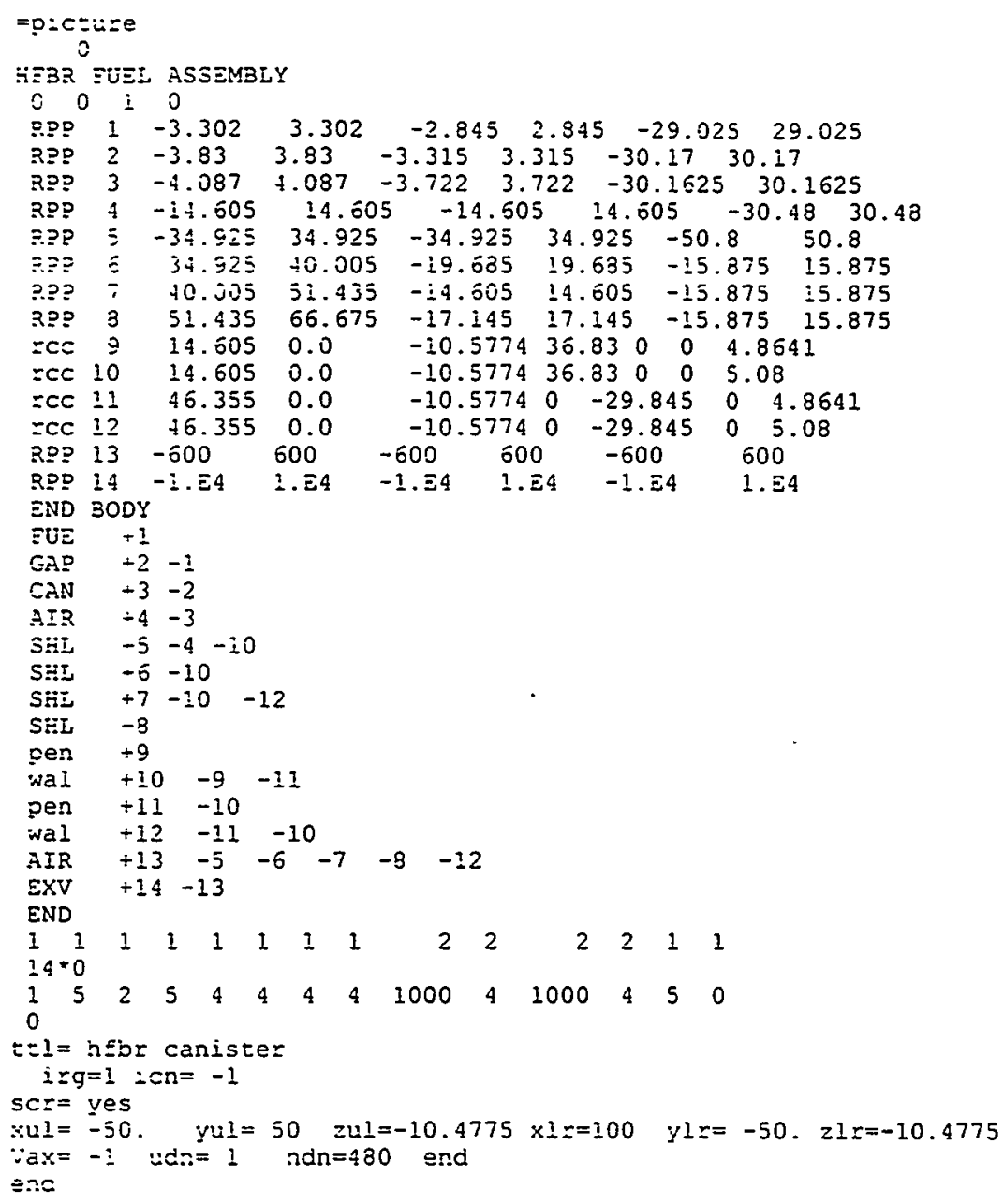


PICTURE Inpuit file for Plan View

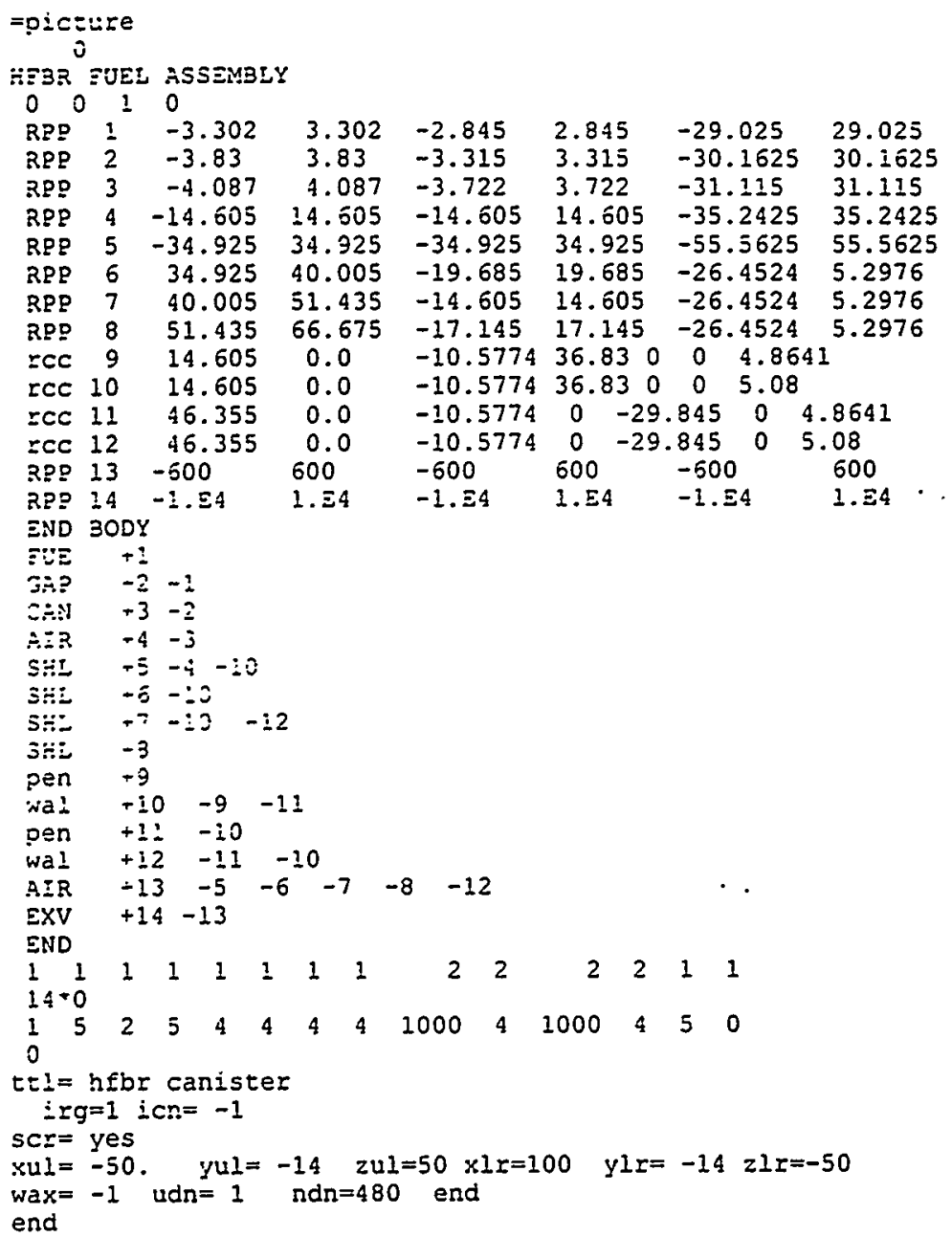




\title{
Attachment $1^{\circ}$
}

Author: Robert Sindelar at SRCCA07

Date: 6/12/97 12:05 PM

Priority: Normal

TO: William Epling at SRCCC10

TO: David Blanchard at SRCCH06

TO: Kent Rosenberger at SRCCA04

TO: Gerard Couture at SRCCCO4

TO: Tony Lentz at SRCCC03

TO: Anthony Cappucci at SRCCB07

TO: Steven Nathan at SRCCB02

TO: John Zino at SRCCB08

TO: William Large at SRCCC04

TO: Trent Andes at SRCCCO4

TO: Robert Eakle at SRCCA 19

TO: Phillip French at SRCCA03

TO: Donald Pak at SRCCA19

TO: Jon Guy at SRCCCOI

CC: Richard Murphy at SRCCC06

CC: Natraj lyer at SRCCA20

CC: S-David Burke at SRCCC04

Subject: Test Canister Development Actions (U)

A planning meeting was held June 5 to discuss needed actions to design/ fabricate/stage/use the Test Canister for the Alternative Treatment Technology Program.

The following action items capture the actions from discussions at the meeting along with other actions which have been identified. This is the latest update to the running list intended to keep the task on track to meet the PBI milestone and to keep all team members informed of the status of the activities. Please contact me for changes and updates to your item(s) or if a new item is needed. Action items will be removed from the list when fully completed.

\section{ACTION ITEMS (Lead personnel):}

\author{
**Instrumented Test Canister Design, Fabrication. Check-Out Testing Activities** \\ 1. Modify the instrumented canister design for underwater loading (Pak/Eakle/ \\ French). Status: Complete. Drawings were reviewed at $6 / 5$ meeting and were \\ subsequently sent to machine shop. The shielding will be added to the cansiter \\ after fabrication (see item 6 below). Refer to tolerance of Square Tube \\ Dissolver for RBOF bundles for canister (contact Trent Andes).<smiles>[Mg]</smiles>

2. Procure/Calibrate/Instaly/Check-out Sensor Equipment (Eakle/French). Status: All sensor equipment (temperature, pressure, humidity, gas analyzers) has been ordered and several items have been received and are calibrated. A change has been made to use an on-line gas chromatograph instead of separate sensors dedicated to NOx, Cs, etc gas monitoring. An existing GC system is available for use with the test canisters; new systems have been ordered.

3. Design/Fabricate Vacuum Drying Test Canister and Mock Fuel Assembly for 
Vacuum-Drying Testing and for Check-out Testing of Instrumented. Shielded Cansiter (PakiFrench/Large). Status: The vacuum test canister mock assembly fabrication are nearly complete and should be done by $6 / 17$.

4. Vacuum Drying Testing (Large). Status: All equipment is nearly assembled. The balance for determined weight changes and free water measurements has been ordered and should be on site within the next week. The Works Clearance Permit is sufficient for the testing to be in L-assembly and testing should begin by 61 27. The conditions for drying of SNF loaded into the shielded instrumented test canisters will be determined through this activity. A support personnel to assist Steve Large is needed.

\section{**Planning for Safe SNF Movement and Storage**}

5. Selection of the SNF Assemblies for the Test Canister (Sindelar/Zino/Guy/ Andes). Status: Based on fuel condition and with regards to availabilty and basin storage, the Sapphire Reactor assembly SES02 (currently unbundled in RBOF) and an assembly from the R2 Reactor (scheduled to arrive in August) have been selected. The SESO2 assembly has about 0.5 in 2 area of exposed fuel core apparently caused when an attached T/C was removed. The fuel had $60 \mathrm{gm} \mathrm{U} 235$ initially and currently has an estimated 58 grams (data to be verified). Fuel from the R2 reactor typically had 260 gms U235 initially and is currently at 90 gms. The specific $R 2$ assembly remains to be identified and it may have to be bundled when it arrives until just before loading into the test canister in late ' 97 or early' 98

6. Documentation of Shielding Requirements for Test Canister (Nathan/Blanchard). Status: Initially, HFBR fuel was planned for and calculations performed by Reuben Rainisch indicated about $8+$ inches of lead or steel for canister shielding would be needed to reduce to the exposure rate to $200 \mathrm{mR} / \mathrm{hr}$ outside surface of the shield for this fuel. After discussion at the $6 / 5$ meeting, the path forward was to: 1) Use 8 inches of shielding in the test canister design regardless of the fuel selection 2) Make dose rate meausurements (in water) of an assembly (e.g. SES02) at RBOF to provide confidence in the dose estimation from the SES02 assembly and the R2 assembly in shielded canisters through the calculation benchmarked for water shielding. 3) Prepare a technically-reviewed report on the required shielding for these assemblies including dose rate limits at the shielding surface and the basis for the limits. The measurements with the report are needed to be completed by $7 / 18$. Steve Nathan should talk to Luis Canas regarding RBOF Fuel Counter Data.

7. USQ/TA/Other Safety Documentation (Couture/Guy/ et al). Status: A TA should not be prepared at this time until the testing is imminent.

8. Get SHO on board (Blanchard). Status: Completed. Kent Rosenberger is the appointed POC to support this task.

9. Review Design with Site Pressure Vessel Committee (Pak/French). Status: The maximum expected pressure in the canister is several psig. The pressure vessel committee will be contacted to evaluate need/adequacy for pressure relief capability of canister.

10. Assess Weight of Two Shielded (8") Instrumented Test Canisters with Respect 
to Floor Loading Capacity (Couture (Sharman sp?)/Pak/French). Status: PakJ French to estimate weight and give to Couture.

11. Perform Walkdown of L Area for Fuel Movernent Plan (Guy/Blanchard). Stanus:

12. Prepare Plan of Fuel Movement (from Transfer Bay Loading into Instrumented Test Canister to Placement of Canister into L Dry Cave) (Blanchard/Guy/Pak). Status: Plan to be drafted following walkdown and used at next meeting to review handling.

13. Hold Meeting(s) to Discuss Handling/Failed-Test Contigency Plans (Sindelar/ Blanchard/Pak). Status: The next status meeting for the canister team will be scheduled first week in July. Plans for handling (see item 12) and for test duration/contigencies will be discussed.

**Instrumented Test Canister Program**

14. Test Canister Report (Pak/Sindelar). Status: The extended outline for the report due as part of the $\mathrm{PBI}$ milestone is being prepared and will be discussed at the next status meeting.

Other Notes:

1) Please ensure that Blanchard, Couture, Pak, and Sindelar are on distribution for all reports, memos, calc sets, that are performed for this project.

2) LWT Outage starts in October and will tie up Operations. 
DRY MONITORIEI STORAGE CANISTIER SHIELDING

\section{Attachment 2}

\section{$\leq$ BODY ... $>$ Error! Not a valid filename.}

\section{Aluminum and Zinc Alloy Properties}

If you are not using Netscape Enhanced or are having trouble with this chart click here.

\section{MECHANICAL PROPERTIES}

\begin{tabular}{|c|c|c|c|c|c|c|c|c|c|c|}
\hline *ALLOY & *\#3 ZINC & *\#5 ZINC & *ZA-8 & ${ }^{*} \mathrm{ZA}-12$ & ${ }^{*} \mathrm{ZA}-27$ & $*_{360 \mathrm{AL}}$ & $* 380 \mathrm{AL}$ & $* 384 \mathrm{AL}$ & $* 356$ & ${ }^{*} 6061 \mathrm{~T}-6$ \\
\hline & & & & & & . & & & & \\
\hline $\begin{array}{c}\text { Tensile } \\
\text { Strength } \\
\text { (psi x 10) }\end{array}$ & 41 & 48 & 54 & 58 & 61 & 44 & 48 & 48 & 33 & 45 \\
\hline $\begin{array}{c}\text { Yield } \\
\text { Strength } \\
(0.2 \% \\
\text { offset) } \\
\text { (psi x 10) }\end{array}$ & - & - & 42 & 46 & 53 & 25 & 24 & 24 & $\overline{24}$ & 40 \\
\hline $\begin{array}{c}\text { Elongation } \\
\text { (\% in } 2 ")\end{array}$ & 10 & 7 & 8 & 6 & 2 & 4 & 3 & 3 & 4 & 17 \\
\hline $\begin{array}{c}\text { Shear } \\
\text { Strength } \\
\text { (psi x 10) }\end{array}$ & 31 & 38 & 40 & 43 & 47 & 28 & 28 & 29 & 28 & 28 \\
\hline $\begin{array}{l}\text { Hardness } \\
\text { (Brinell) }\end{array}$ & 82 & 91 & 105 & 105 & 115 & 85 & 85 & 85 & 80 & 30 \\
\hline
\end{tabular}


DRY MONITORED STORAGE CANISTIER SIIIIILDING;

\section{PHYSICAL PROPERTIES}

*

\begin{tabular}{|c|c|c|c|c|c|c|c|c|c|c|}
\hline *ALLOY & *\#3 ZINC & ${ }^{*} \# 5 \mathrm{ZINC}$ & $* 2 A-8$ & $*_{2 A-12}$ & $\pm Z \mathrm{ZA-27}$ & $* 360 \mathrm{AL}$ & $\pm 380 \mathrm{Al}$ & $* 384 \mathrm{AL}$ & $\stackrel{*}{356}$ & $\pm 6061 \mathrm{~T}-6$ \\
\hline $\begin{array}{c}\text { Density } \\
\text { (lb./ci) }\end{array}$ & 0.240 & 0.240 & 0.227 & 0.218 & 0.181 & 0.095 & 0.098 & 0.102 & 0.097 & 0.098 \\
\hline $\begin{array}{l}\text { Melting } \\
\text { Point (F) }\end{array}$ & 728 & 727 & 759 & 810 & 903 & 1105 & 1100 & 1080 & 1135 & 1206 \\
\hline $\begin{array}{c}\text { Electrical } \\
\text { Conductivit } \\
\text { y (\%IACS) }\end{array}$ & 27 & 26 & 28 & 28 & 30 & 30 & 20 & 30 & 20 & 43 \\
\hline $\begin{array}{l}\text { Coefficient } \\
\text { of Thermal } \\
\text { Expansion } \\
(68-212 F) \\
(\mathrm{U} \text { in/in/F) }\end{array}$ & 15.2 & 15.2 & 12.9 & 13.4 & 14.4 & 11.6 & 12.2 & 11.5 & 11.9 & 13.1 \\
\hline $\begin{array}{c}\text { Die } \\
\text { Shrinkage } \\
\text { (in/in) }\end{array}$ & 0.005 & 0.005 & 0.007 & 0.007 & 0.008 & 0.005 & 0.005 & 0.005 & - & - \\
\hline
\end{tabular}


DRY MONITORED STORAGE CANISTER SHIELDING

CHEMICAL SPECIFICATIONS (Per ASTM) (\% by weight)

$\stackrel{*}{-}$

\begin{tabular}{|c|c|c|c|c|c|c|c|c|c|c|}
\hline *ALLOY & *\#3 ZINC & * $\# 5 \mathrm{ZINC}$ & ${ }^{*} \mathrm{ZA}-8$ & $\stackrel{*}{\mathrm{ZA}-12}$ & ${ }^{*} Z \mathrm{AA}-27$ & $* 360 \mathrm{AL}$ & ${ }^{*} 380 \mathrm{AL}$ & ${ }^{*} 384 \mathrm{AL}$ & $* 356$ & *6061T -6 \\
\hline$\overline{\mathrm{Al}}$ & $3.5-4.3$. & $3.5-4.3$ & $8-8.3$ & $10.5-11.5$ & $25-28$ & Balance & Balance & Balance & Balance & Balance \\
\hline$\overline{\mathrm{Mg}}$ & $.02-.05$ & $.03-.08$ & $.015-.030$ & $.015-.030$ & $.010-.020$ & .6 & .1 & .1 & $.20-.45$ & $.8 \div 1.2$ \\
\hline $\mathrm{Cu}$ & $.25 \mathrm{Max}$ & $.75-1.25$ & $.8-1.3$ & $.5-1.25$ & $2-2.5$ & $.4 \operatorname{Max}$ & $3-4$ & $\overline{3-4}$ & $.25 \mathrm{Max}$ & $.15-.4$ \\
\hline $\mathrm{Fe}$ & .10 & .10 & .075 & .075 & .075 & $2 \operatorname{Max}$ & $2 \operatorname{Max}$ & $1.3 \mathrm{Max}$ & $.6 \operatorname{Max}$ & $7 \operatorname{Max}$ \\
\hline$\overline{\mathrm{Cd}}$ & .004 & .004 & .006 & .006 & .006 & - & - & - & - & - \\
\hline SI & .003 & .003 & $.003>$ & .003 & .003 & $9-10$ & $7.5-9.5$ & $10.5-12$ & $6.5-7.5>$ & $.4-.8$ \\
\hline$\overline{\mathrm{Mn}}$ & - & - & - & - & - & .35 & $.5 \operatorname{Max}$ & $.5 \mathrm{Max}$ & $.35 \mathrm{Max}$ & $15 \operatorname{Max}>$ \\
\hline $\bar{Z}$ & Balance & Balance & Balance & Balance & Balance & $.5 \mathrm{Max}$ & $3 \operatorname{Max}$ & $3 \operatorname{Max}$ & $.35 \operatorname{Max}$ & $.25 \mathrm{Max}$ \\
\hline
\end{tabular}

\section{INDUSTRY STANDARDS}

*

\begin{tabular}{|c|c|c|c|c|c|c|c|c|c|c|}
\hline *ALLOY & *\#3 ZINC & *\#5 ZINC & ${ }^{*} \mathrm{ZA-8}$ & ${ }^{*} \mathrm{ZA}-12$ & ${ }^{*} \mathrm{ZA}-27$ & $* 360 \mathrm{AL}$ & $* 380 \mathrm{AL}$ & $* 384 \mathrm{AL}$ & $* 356$ & ${ }^{*} 6061 \mathrm{~T}-6$ \\
\hline \multirow[t]{2}{*}{$\overline{\text { ASTM }}$} & B86-88 & $\overline{B 86-88}$ & $\overline{B 791-88}$ & $\overline{B 791-88}$ & B791-88 & SG100-B & SC84-B & SCl14-A & SG70-A & B209 \\
\hline & $A G-40$ & AC4IA & & & & & & & & \\
\hline \multirow[t]{2}{*}{$\overline{\mathrm{SAE}}$} & $\mathrm{J} 468 \mathrm{~B}$ & $\mathrm{~J} 468 \mathrm{~B}$ & $=$ & - & - & - & 308 & 303 & $\mathrm{~J} 4542$ & - \\
\hline & 903 & 925 & & & & & & & & \\
\hline UNS & 233520 & 235531 & 235636 & 235631 & 235841 & A03600 & A03800 & A03840 & $\mathrm{A} 03560$ & A96061 \\
\hline
\end{tabular}




\section{Error! Not a valid filename.}

Return to Front Page

$\leq \mathrm{HB}$ size $6 \geq$

Designed by em2.

Intended for viewing in Netscape 
Appendix 2 to WSRC-TR-97-00269

Field Procedure FP-721 for Vacuum Canister Drying Tests (by P. J. French) and Data Records 


\section{SNF Instrumented Test Canister}

\section{Vacuum Drying Test Procedure (U)}

Field Procedure: FP-721

Revision: 0

EES Job Number: 22555 22585 $\$ 87 / 4197$

Effective Date: $7 / 16 / 97$

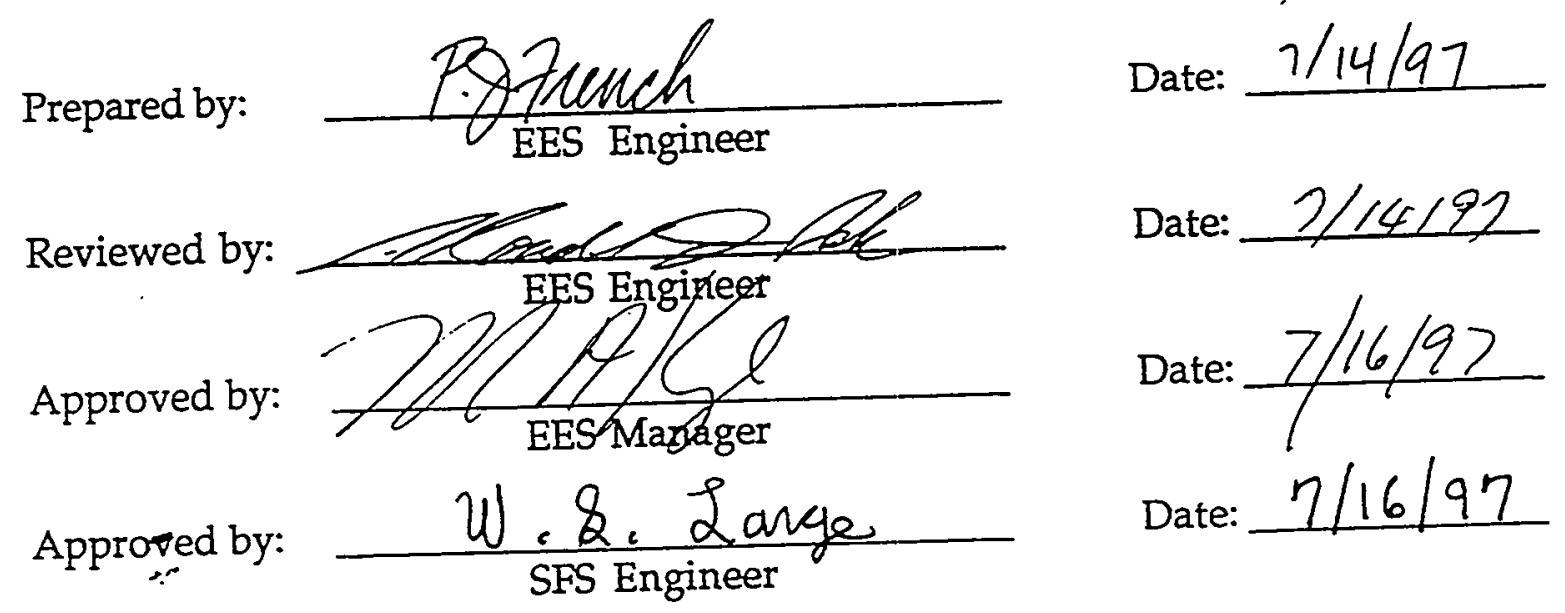


Savannah River Technology Center

FP-721

Engineered Equipment and Systems

Rev. 0

SNF Instrumented Canister Vacuum Drying Test Procedure

\section{Revision History Log}

Revision Date Description of Revision

$0 \quad 7 / 10 / 97 \quad$ Initial Issue 


\section{Table of Contents}

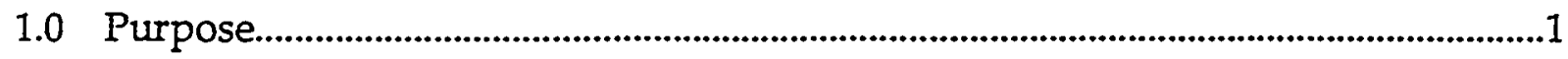

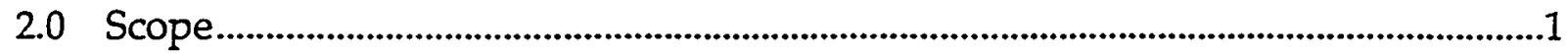

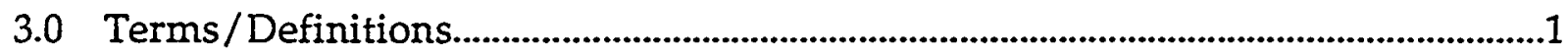

4.0 Responsibilities ............................................................................................................

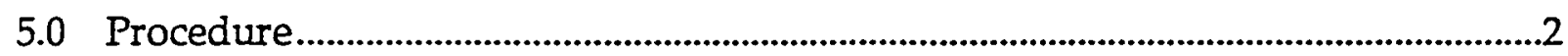

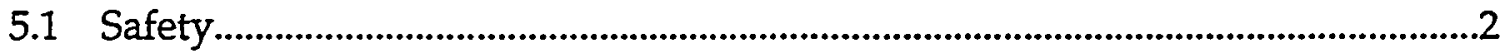

5.2 Acceptance Criteria ....................................................................................................2

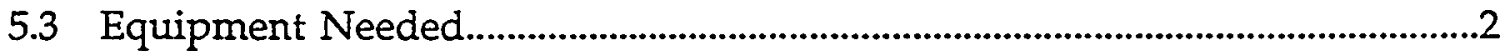

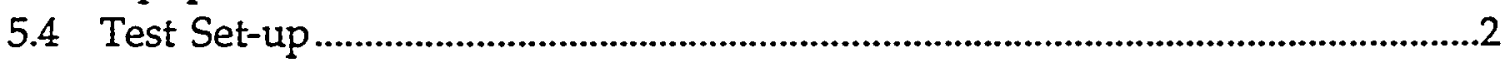

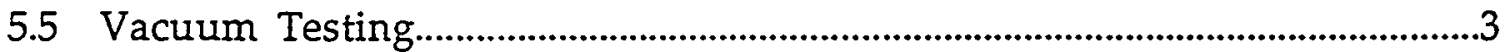

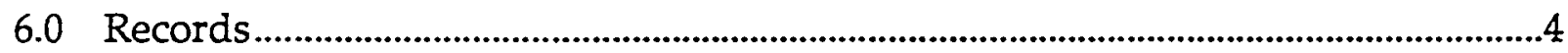

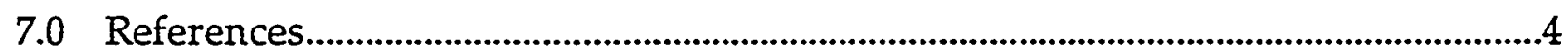

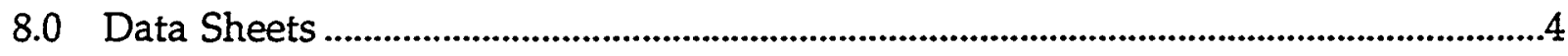




\subsection{PURPOSE}

The purpose of this testing is to demonstrate a cold vacuum drying technique for an instrumented test canister intended for dry storage of spent nuclear fuel. This procedure outlines the test plan to evaluate the performance and determine the ability of an existing vacuum pumping system to adequately dry the instrumented canister and contents.

\subsection{SCOPE}

This procedure covers the testing to be performed by EES and SFS in the assembly area of building 105-L.

\subsection{TERMS/DEFINITIONS}

3.1 EES - Engineered Equipment and Systems Department.

3.2 SFS - Spent Fuel Storage Division.

\subsection{RESPONSIBILITIES}

4.1 EES engineers shall be responsible for:

4.1.1 Performing the execution of this procedure with the exception of operating the vacuum pump.

4.1.2 Assisting in the coordination, scheduling, and controlling of activities associated with implementation of this procedure.

4.1.3 Data documentation as specified in this procedure.

4.2 SFS engineers shall be responsible for:

4.2.1 Operation of the vacuum pump.

4.2.2 Assisting with the implementation of this procedure.

4.2.3 Serving as a liaison with building 105-L Facility Operations. 


\subsection{PROCEDURE}

5.1 Safety

5.1.1 All SRS safety rules will be followed. Personal protection items such as safety glasses, gloves, and safety shoes will be worn as appropriate.

5.1.2 Prepare the test area by installing barricade rope around the work perimeter, display appropriate safety signs, and clear work space to insure safe movement of personnel.

5.1.3 A safety inspection shall be performed before testing begins.

5.1.4 A cold walk-through shall be performed by the personnel performing the test to ensure complete understanding of the work required.

\subsection{Acceptance Criteria}

5.2.1 The vacuum level within the canister shall reach and sustain a pressure of 15 torr or less when the internal temperature is at or above 72 degrees $F$.

\subsection{Equipment Needed}

5.3.1 Vacuum pump

5.3.2 Canister frame

5.3.3 Canister mock-up

5.3.4 Thermocouple rack

5.3.5 Mock MTR type fuel assembly

5.3.6 Scale capable of reading in $0.005 \mathrm{lb}$. min. increments or equivalent.

5.3.7 Data acquisition system

5.3.8 115 vac power supply

\section{$5.4 \quad$ Test Set-up}

5.4.1 Place canister framework at desired location.

5.4.2 Place scale onto bottom plate of canister frame.

5.4.3 Install canister into frame and onto scale. 
5.4.4 Connect vacuum hose between canister and vacuum pump.

5.4.5 Install thermocouple rack into canister.

5.4.6 Install dry mock fuel assembly into thermocouple rack.

5.4.7 Attach canister top flange with gasket per manufacturer's recommendations.

5.4.8 Ensure initial weight reading is less than $70 \mathrm{lbs}$.

5.4.9 Perform vacuum pump check out per reference 7.5.

\subsection{Vacuum Test}

5.5.1 Observe and record initial conditions from digital display system onto data sheet (See Data Sheets).

5.5.2 Start up vacuum pump and observe system for signs of leakage. See reference 7.5 on vacuum system operation.

5.5.3 If leakage is indicated, shut down vacuum pump, vent system, and repair leaks before restarting .

5.5.4 Slowly open isolation valve near canister to begin evacuation.

5.5.5 Record maximum vacuum produced (i.e. vacuum level at which system reaches steady state) and system conditions at that point.

5.5.6 Isolate pump and relieve vacuum from canister.

5.5.7 Record system conditions.

5.5.8 Attach any data sheets generated by the digital display system to completed procedure data sheets.

5.5.9 Repeat procedure beginning with step 5.4.6 substituting the following for the dry fuel assembly:

5.5.9.1 Assembly lightly sprayed with water and allowed to drip dry. 
5.5.9.2 Assembly transferred immediately from being submerged in water into dry canister.

5.5.9.3 Assembly transferred immediately from being submerged in water into canister containing one inch of water.

5.5.9.4 Other fuel assembly conditions as determined by EES.

5.5.10 Repeat procedure beginning with step 5.4.6 for conditions in 5.5.9.1 and 5.5.9.2. Stop vacuum pumping when the canister pressure reaches 40 torr. Record system conditions per data sheets 8.5 and 8.6 .

5.5.11 Shut down vacuum pump and vent system.

\subsection{RECORDS}

6.1 Completed copies of this procedure shall be maintained in accordance with the SRTC records control procedure and retention schedule.

\subsection{REFERENCES}

7.1 Canister Mock-up Sketch

7.2 Thermocouple Rack Sketch

7.3 Mock Fuel Assembly Sketch

7.4 Canister Framework Sketch

7.5 Operation of Portable Vacuum Drying Equipment, EFR-RMT-95-00960.

7.6 Instruments and Equipment Calibration Procedure, L9.2-3848.

\subsection{DATA SHEETS}

8.1 Dry Fuel Assembly in Dry Canister

8.2 Drip Dry Fuel Assembly $t$ in Dry Canister at Maximum Vacuum

8.3 Wet Fuel Assembly in Dry Canister at Maximum Vacuum

8.4 Wet Fuel Assembly with Standing Water in Canister

8.5 Drip Dry Fuel Assembly in Dry Canister at 40 Torr

8.6 Wet Fuel Assembly in Dry Canister at 40 Torr 


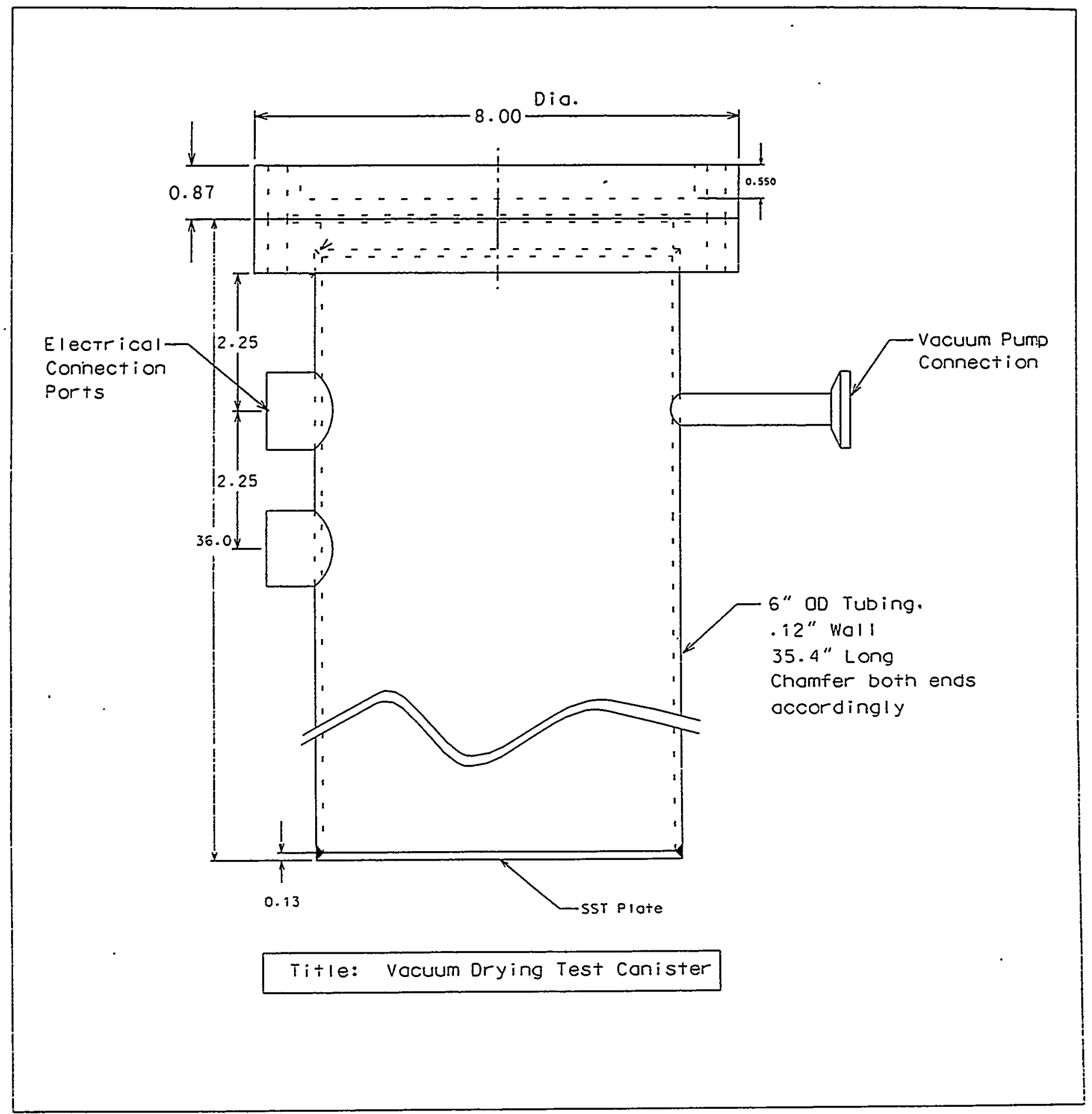

FWB $121 \mathrm{MB}:$ Microstation 4.2:Dgn:SN Jul. 23, $1997 \underset{\mathrm{N}}{\mathrm{14}: 16: 38}$ 


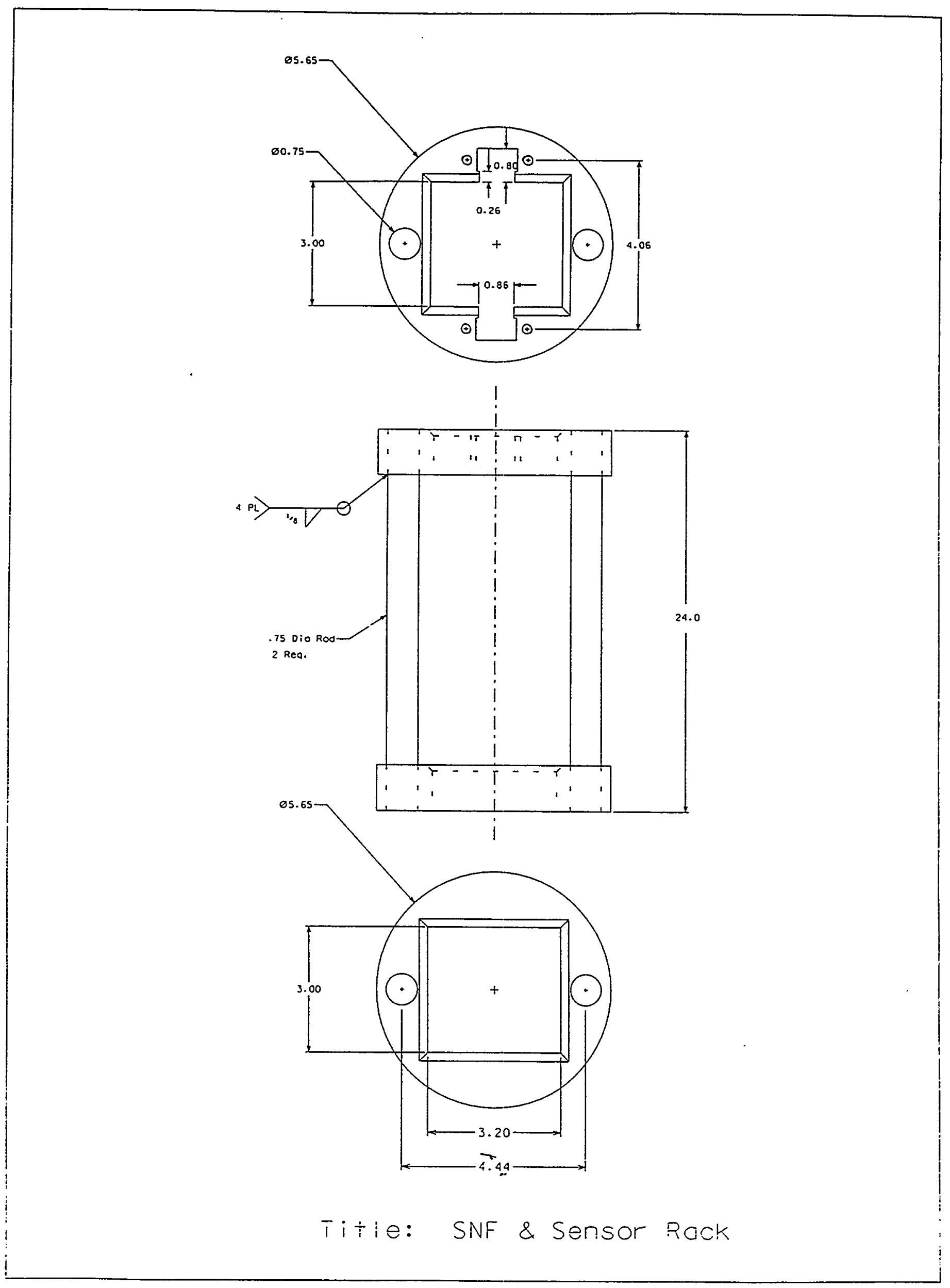




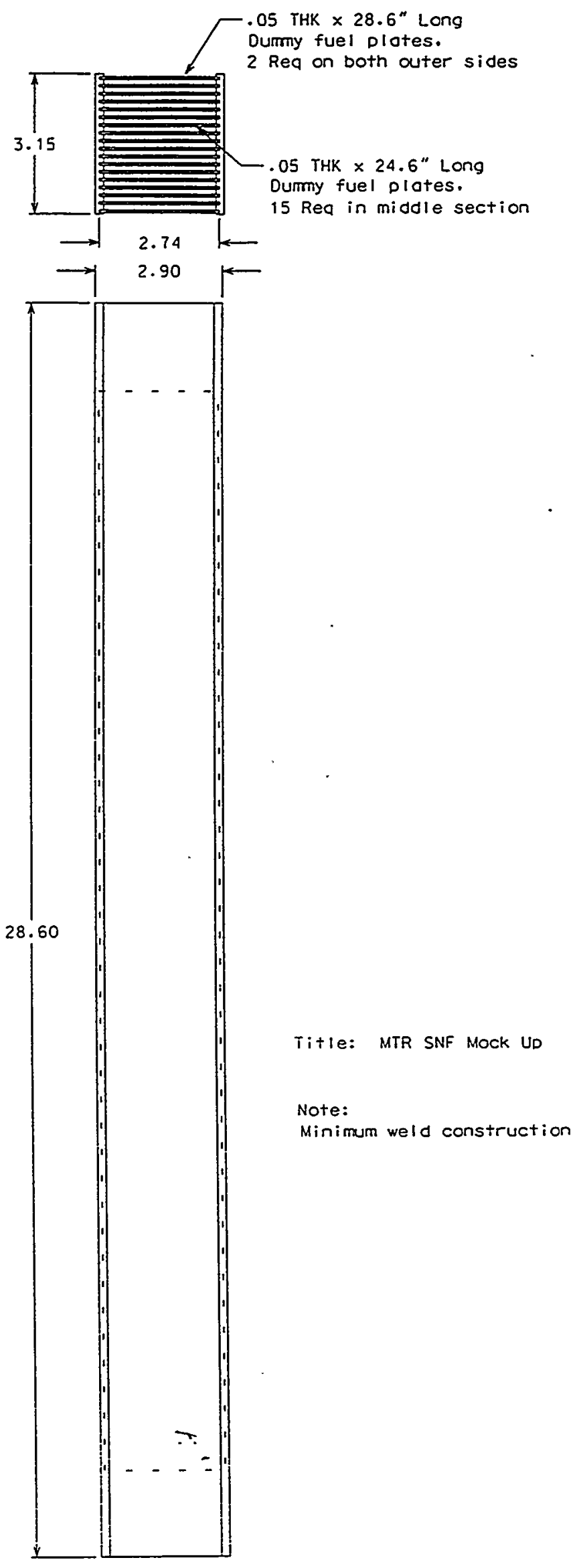



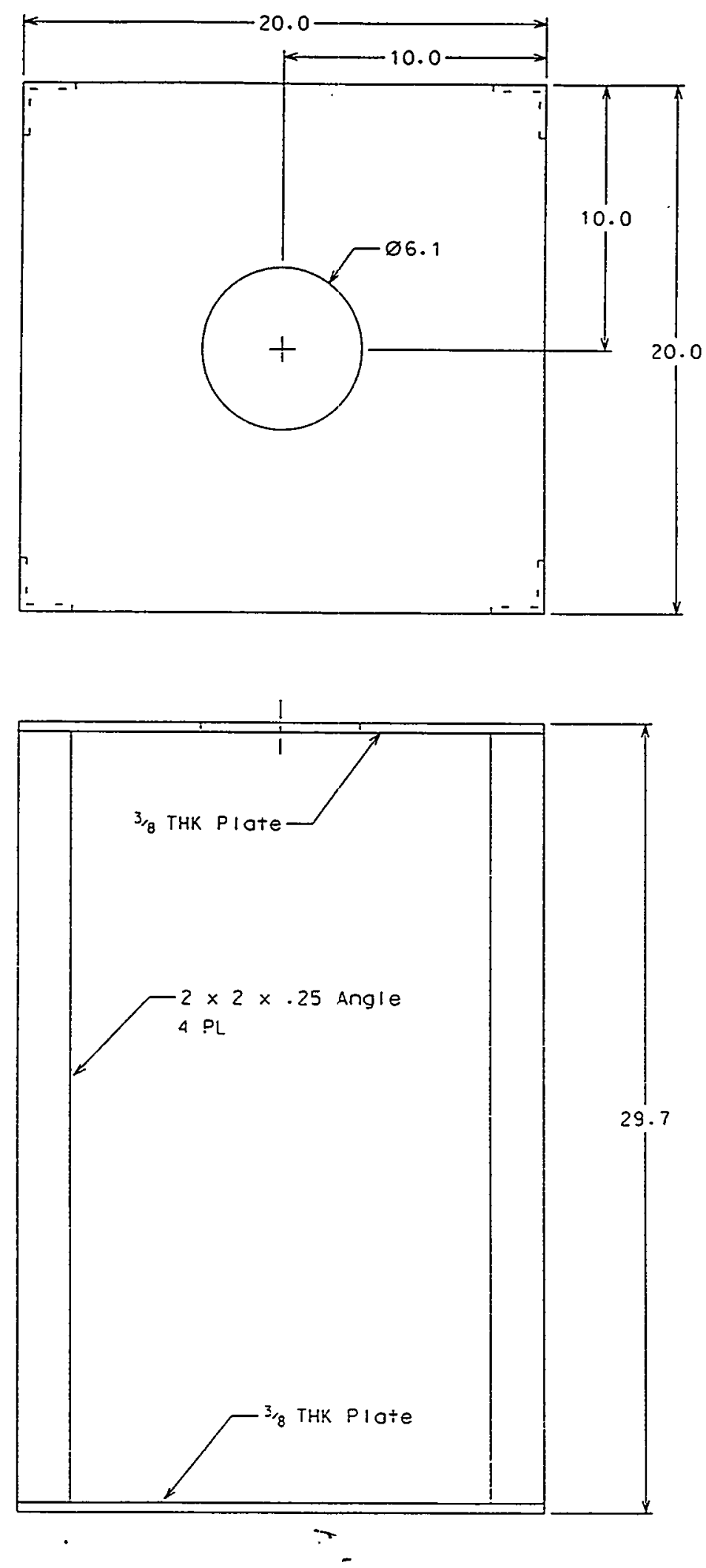

Titie: Test Car: ster Stand

FWB 121 MB:Microstation 4.2:Dgn:SN Jul. 23, $1997 \quad 14: 28: 45$ 
Vacuum Drying Test Data for

Dry Fuel Assembly in Dry Canister

$\underline{\text { Step \# }}$

5.5.1

Initial system conditions.

Fuel Assembly Weight

9.1243 37.8498

Canister Weight 46.9738

Combined Weight

Time $8: 29 \mathrm{am}$

Pressure 759

Temperature Humidity
$28.4 / 28.3$ 50.8 pounds. avg of 5 readings pounds. " " " pounds. " ." :"

torr. degrees $\not . C$ percent.

5.5.5 System conditions at maximum vacuum.

Time $8: 45 \mathrm{am}$

Pressure

530 milli torr.

Temperature $28.3 / 28.2$

Humidity 0.1

Combined Weight 47.7468 degrees $f . C$ percent. pounds.

System conditions at minimum relative humidity. Time $8: 53$ a m

Pressure 759

Temperature Humidity $28.3 / 28.2$

Combined Weight 46

Canister Weight 46.9743 Fuel Assembly Weight 37.8504 9.1242 torr. degrees $\not$. $C$ percent. pounds. avg of 5 readings pounds. avg of 5 readings pounds. aug of 5 readings

Tester

W. S. Large (ptint / sign)

W. \&. Large Date

$8 / 26 / 97$ 
Vacuum Drying Test Data for

Drip Dry Fuel Assembly in Dry Canister at Maximum Vacuum

$\underline{\text { Step \# }}$

5.5 .1

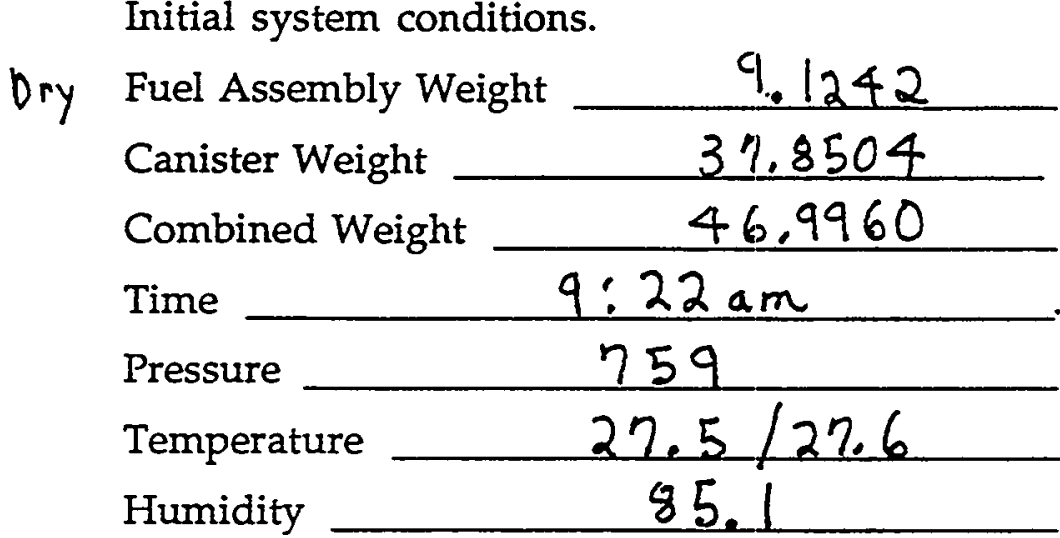

pounds. From ${ }_{\text {Step }}$ previous pa: pounds. \&ug of 5 reach in pounds. avg of 5 readir

torr.

degrees $\not \cdot C$

percent.

5.5.5 System conditions at maximum vacuum.

Time 9:50 am

\begin{tabular}{lcl}
\hline Pressure & 510 & milli \\
Temperature & $23.6 / 23.3$ & dorr. \\
Humidity & 0.7 & degrees $7 . C$ \\
Combined Weight & 47.7152 & percent. \\
\cline { 2 - 3 } & pounds.
\end{tabular}

5.5.7 System conditions at minimum relative humidity.

Time 9:54 am

Pressure

759

Temperature

$23.8 / 23.7$

Humidity 41.8

Combined Weight 46.9743

Canister Weight 37.8505

Fuel Assembly Weight 9.1243 torr. degrees $f \cdot C$ percent. pounds. avg of 5 reading pounds. avg " " " pounds. avg " " "

Tester $\frac{W, 5 \text {. Large /w, \&. Large Date } 8 / 26 / 97}{\text { (print / sign) }}$ $M+T E$ Nos. $\begin{cases}32077 & \text { Scales } \\ 7 C-\infty 1 & \text { Varian } 801 \text { vacuar gage } \\ 7 C-002 & \text { WV }-100 \text { gauge } \\ 3-2097 & \text { Humidity sensor } \\ 3-2076 & \text { Temoornture sensor }\end{cases}$ 
$\underline{\text { Step \# }}$

Vacuum Drying Test Data for

5.5.1 Initial system conditions.

Fuel Assembly Weight

9.1243

Canister Weight

Combined Weight $37: 8505$

Time 47.0394

Pressure

Temperature

Humidity $10: 33$ am 759 $26.0 / 25.9$ 80.0 pounds. From previous pag: pounds. From previous pas pounds.

torr.

degrees $F . C$

percent.

5.5.5 System conditions at maximum vacuum.

Time

Pressure

Temperature

Humidity

Combined Weight
$11: 05 \mathrm{am}$

525

$18.9 / 18.6$ 1.

47.8122 milli torr. degrees F. C percent. pounds.

5.5.7 System conditions at minimum relative humidity.

Time $11: 10 \mathrm{am}$

Pressure 759

Temperature $8.9 / 18.9$

Humidity

Combined Weight

Canister Weight

Fuel Assembly Weight
41.4 $46.97466_{\text {WSL }}$ 37.8508 9.1242 torr.

degrees $F$.

percent. pounds. avy of 5 reading pounds. " " " " pounds. " 1111

Tester $\frac{W, S \text {. Large } W, \&, L \text { ange Date } 8 / 26 / 97}{\text { (print Ksign) }}$

$$
M+T E \text { Nos. } \begin{cases}\eta C-001 & \text { Jariain } 801 \text { vacuum gage } \\ 7 C-002 & \text { WV-100 gage } \\ 3-2097 & \text { Humidity sensor } \\ 3-2076 & \text { Temperature sensor } \\ 3-2075 & \text { Temperature sensor } \\ 3-2077 & \text { Scales }\end{cases}
$$


Savannah River Technology Center

Engineered Equipment and Systems

SNF Instrumented Canister Vacuum Drying Test Procedure
FP-721

Rev. 0

Page 8 of 10

Vacuum Drying_Test Data for

Wet Fuel Assembly with Standing Water in Canister

Step \#

5.5.1

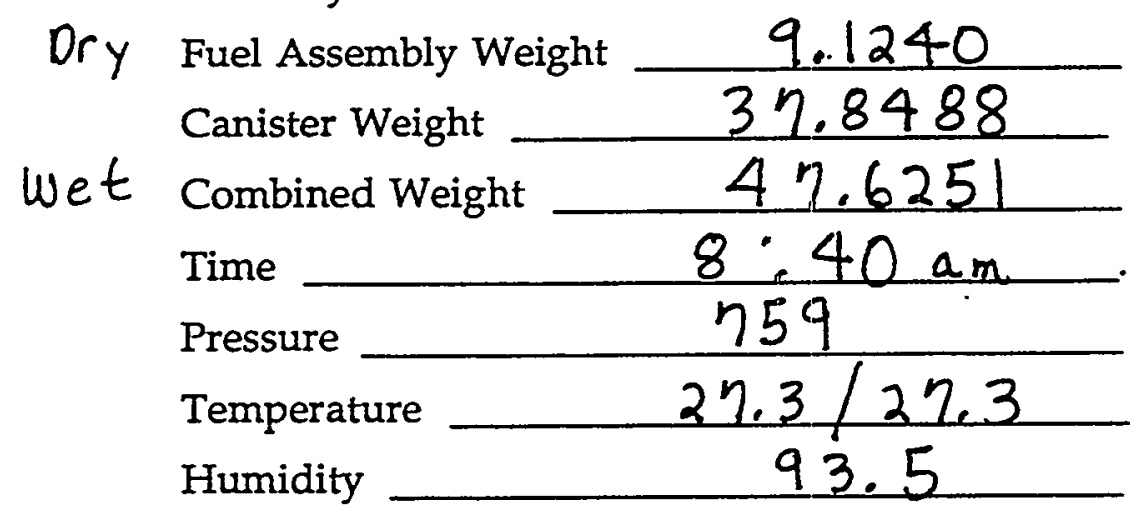

pounds. avg of 8 read pounds. " " " pounds. " 1 " 11 torr. aSL percent.

5.5.5 System conditions at maximum vacuum.

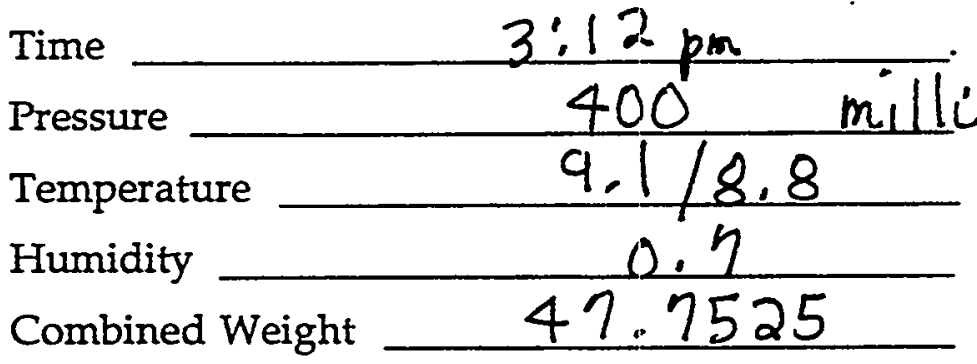
degrees $F \cdot C^{\text {USK }}$ percent. pounds.

5.5.7 System conditions at minimum relative humidity.

\begin{tabular}{lc} 
Time & $3: 180 \mathrm{~m}$ \\
Pressure & $75 \%$ \\
Temperature & $10.2 / 10.1$ \\
\cline { 2 - 2 } Humidity & 29.5 \\
Combined Weight & 46.9753 \\
\cline { 2 - 2 } Canister Weight & 37.8490 \\
\cline { 2 - 2 } & 9.1245
\end{tabular}
torr. degrees $\not C^{\operatorname{coc}} C^{2}$ percent. pounds. pounds. pounds.

$$
\begin{aligned}
& \text { Tester } \frac{w=5 . \text { Large W. \&. Large Date 8/25/97 }}{\text { (prift/sign) }}
\end{aligned}
$$

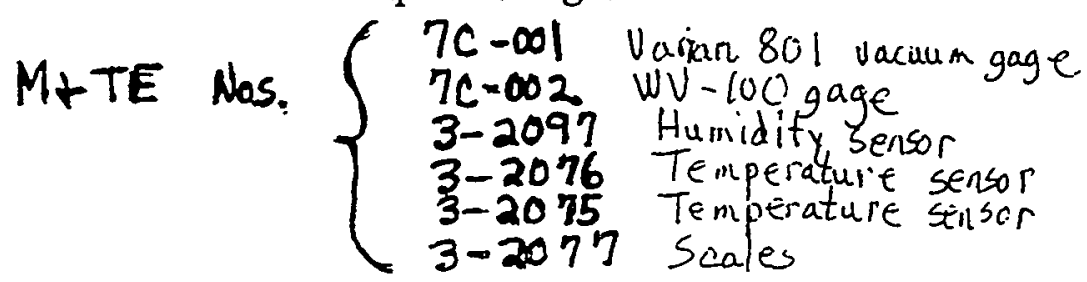


Savannah River Technology Center

FP-721

Engineered Equipment and Systems

Rev. 0

SNF Instrumented Canister Vacuum Drying Test Procedure

Page 9 of 10

Vacuum Drying Test Data for

Drip Dry Fuel Assembly in Dry Canister at 40 Torr

Step \#

5.5.1 Initial system conditions.

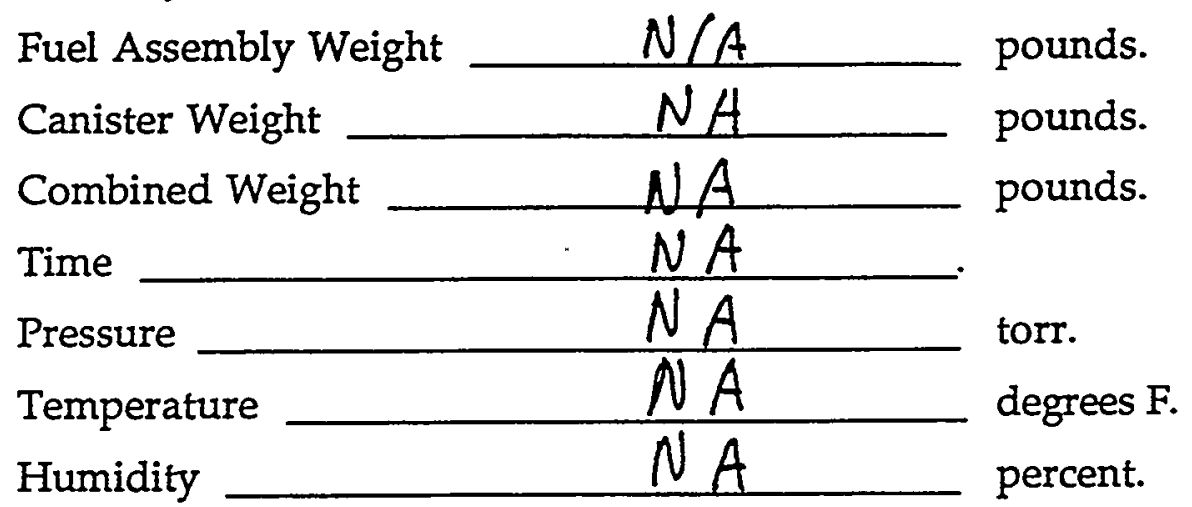

5.5.5 System conditions at 40 torr.

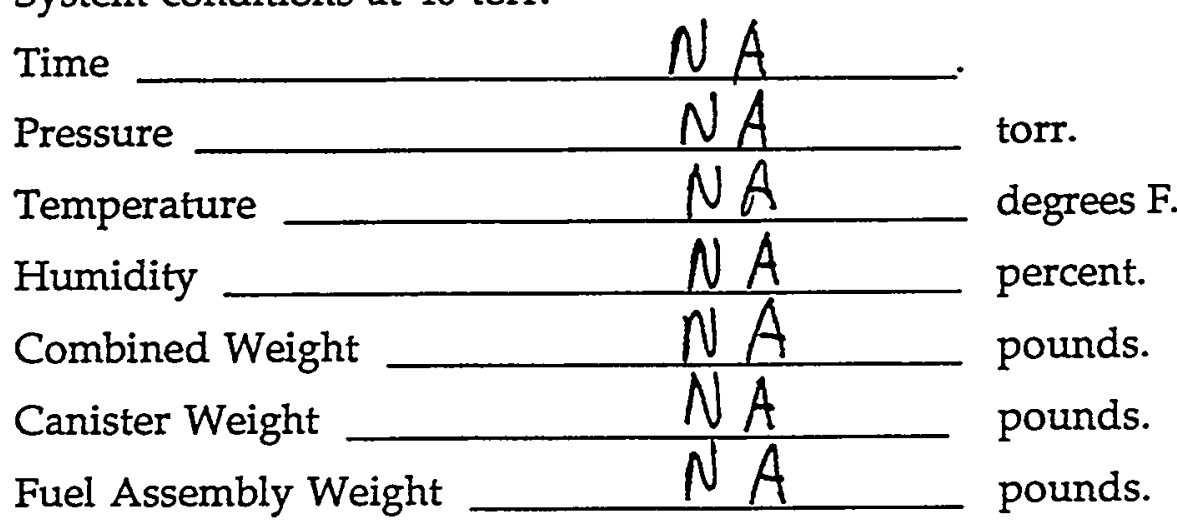

Tester

W.S. Large W. \&. Large Date

$8 / 26 / 97$

lan not perform drying test at 40 Torr because initial steady state pressure is $\sim 25$ Torr. 
Step \#

Vacuum Drying Test Data for

Wet Fuel Assembly in Dry Canister at 40 Torr

5.5.1 Initial system conditions.

\begin{tabular}{lll} 
Fuel Assembly Weight & $N / A$ & pounds. \\
Canister Weight & $N A$ & pounds. \\
Combined Weight & $N A$ & pounds. \\
\cline { 2 - 3 } & $N A$ & \\
Time & $N A$ & torr. \\
Pressure & $N A$ & degrees F. \\
Temperature & $N A$ & percent. \\
Humidity & $N$
\end{tabular}

5.5.5 System conditions at 40 torr.

$\begin{array}{lll}\text { Time } & N A & \\ \text { Pressure } & N A & \text { torr. } \\ \text { Temperature } & N A & \text { degrees F. } \\ \text { Humidity } & N A & \text { percent. } \\ \text { Combined Weight } & N A & \text { pounds. } \\ \text { Canister Weight } & N A & \text { pounds. } \\ \text { Fuel Assembly Weight } & N A & \text { pounds. }\end{array}$

Tester $\frac{W, S, \text { Large W, \&. Lange Date } 8 / 26 / 97}{\text { (print/sign) }}$

Can not perform drying test at 40 Torn because initial steady state presaure la $\sim 25$ Torr. 
FP-721 Procedure

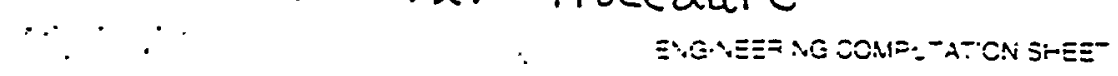

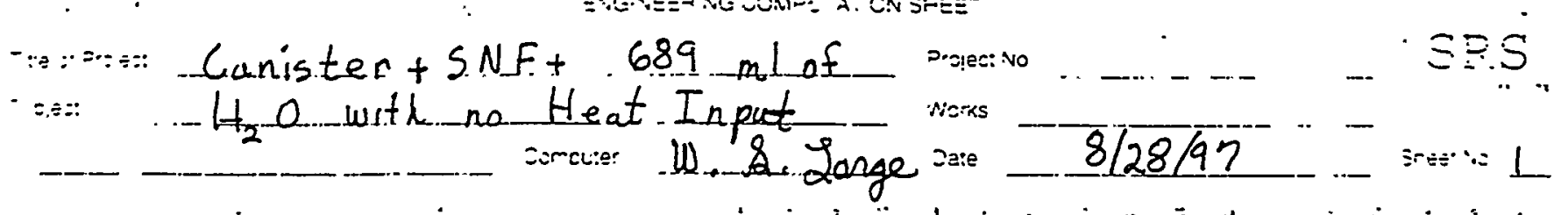

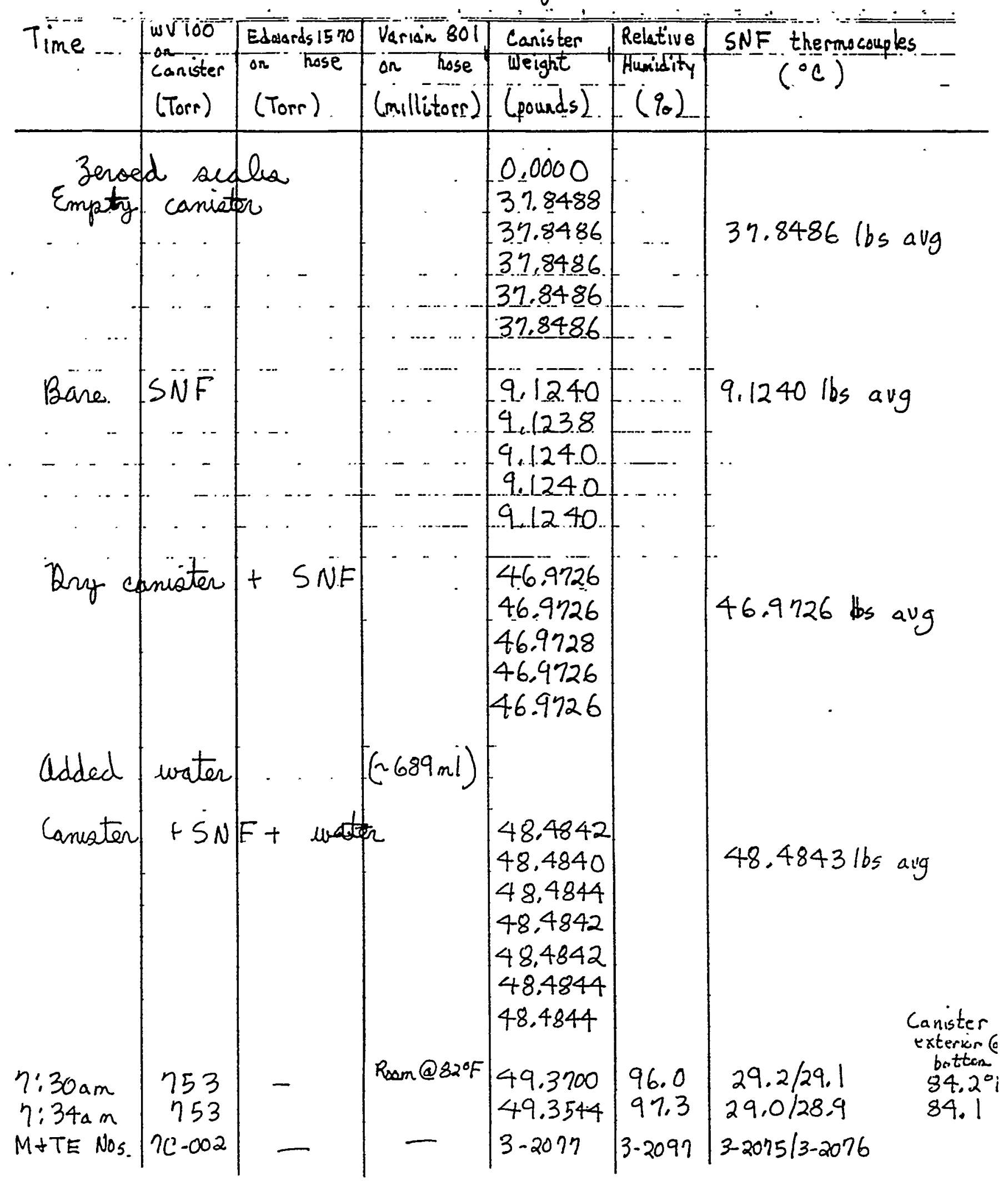




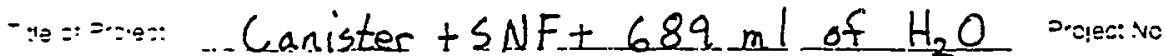

$\because$ - with no Heat Input

cimecter 211. \&. Lazge

$8 \longdiv { 2 8 / 9 2 }$

2

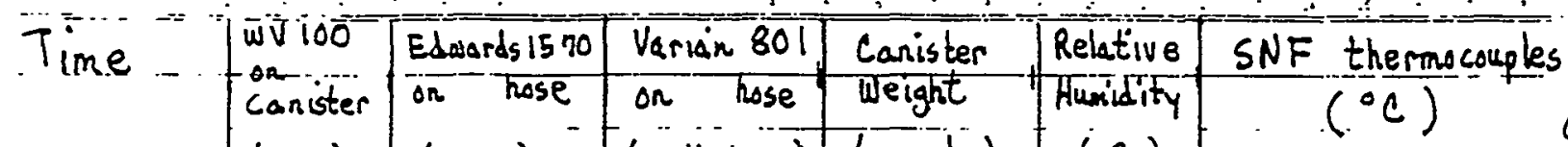

\begin{tabular}{|c|c|c|c|c|c|c|}
\hline & (Torr) & (Tors) & (millitorr) & (pounds) & $\left(q_{0}\right)$ & $\begin{array}{l}\text { extei } \\
\text { at } b_{c}\end{array}$ \\
\hline $\begin{array}{l}M+T E \text { Nos. } \\
\eta \cdot 3 E\end{array}$ & TC-002 & & $7 c-001$ & $3-201 n$ & $3-2097$ & $3-2075 / 3-2076$ \\
\hline
\end{tabular}

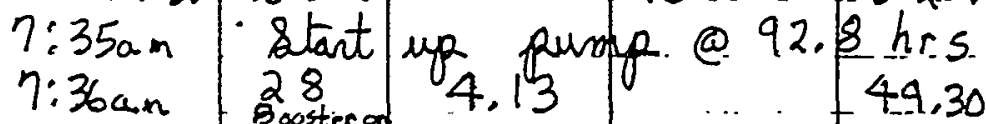

$7: 40$

$\eta: 45$

1.29

7.50

1.19

1300

$-49,3020$

92.7

$27.8 / 27.6$

83.6

$8: 00$

1.10

1300

$-49,202$

6.9 .9

$22.5 / 22.4$

$8: 10$

0.97

1200

$17.9 / 17.7$

69.0

12

$8: 20$

0.89

1000

$49.1696 \quad 44.5$

$15.4 / 14.8$

$64.0^{\circ}$

7.

1000.

49.1276

33.0

$15.1 / 11.7$

57,5

$49.0962 \quad 25.8$

$14,6.14,5$

8:30 am

$8: 40$

$8: 50$

$9: 00$

$9: 10$

$9: 20$

$9: 30$

$9: 40$

$9: 50$

$10: 00$

$10: 10$

$10: 20$

$10: 30$

$10: 40$

$10: 50$

$11: 00$

$11: 10$

$11: 20$

$11: 30$

$11: 40$

$11: 50$ am 5

$12: 00$
6.0 .87

$950^{\circ}$.

Visible conclenate on cantiater extenior.

6
6
5
5
5
5
5
5
5
5
5
5
5
5
5
5
5
5
5
5
5
5

0.84

950

49.0438

20.2

0.84

0.82

950

49,0226

20.

4.9 .0012

19.2.

$13,6 / 13,5$

0.82

950

0.82

0.81

0.80

0.80

0.80

0.79

0.79

0.79

0.79

0.79

0.79

0.79

0.79

0.78

0.78

0.78

0.78

0.78

Conderate
950.

48

925.

925

925

925

925

925.

900

900

900

900

900

900

900

900

900

48.9620

48.9450

18.2

$48.9300 \quad 18.0$

$48,9158 \quad 18,0$

48.8964

18.0

48.8756

17.8

48.8660

48.8458

17.5

17,3

48.8344

48.8194

48.8036

17,3

17,2

17.1

17.0

48.7882

48.7738

17,0

17.0

48.7584

48.7424

16.9

48.7214

16,8

900

48.6970

48.6828

16.7

16.7
18.8
$12.5 / 12.5$

$11.6 / 11.5$

$10.7 / 10.6$

$10.2 / 10.2$

$9.5 / 9.4$

$9.1 / 9.0$

$8.6 / 8.6$

$8.3 / 8.3$

8.018 .0

$7.8 / 7.8$

$7.7 / 7.7$

7.417 .4

$7.4 / 7.3$

$7.3 / 7.3$

$7.3 / 7.3$

$7.2 / 7,2$

$7.3 / 7.3$

$7.2 / 7.2$

$7.3 / 7.2$

$7.3 / 7.3$

Roon

$33^{\circ} \mathrm{F} 45$.

44

44

44

44

$4:$

43

43

42

42

42 ,

43

43.

43.

43

43 
Canister + SNF $+689 \mathrm{ml}$ of $\mathrm{H}_{2} \mathrm{O} \cdots \cdots$

with no Heat Input

\begin{tabular}{|c|c|c|c|c|c|c|c|}
\hline Time & $\left\{\begin{array}{l}w V 100 \\
\text { on } \\
\text { Canister } \\
\text { (Torr) }\end{array}\right.$ & $\mid \begin{array}{l}\text { Edolards } 1570 \\
\text { on hose } \\
\text { (Torr) }\end{array}$ & $\left|\begin{array}{c}\text { Voridin } 801 \\
\text { on hose } \\
\text { (millitorr) }\end{array}\right|$ & $\begin{array}{l}\text { Canister } \\
\text { Weight } \\
\text { (pounds) }\end{array}$ & $\left|\begin{array}{c}\text { Relative } \\
\text { Humidity } \\
\left(q_{0}\right)\end{array}\right|$ & $\begin{array}{l}\text { SNF thermocouple } \\
\left({ }^{\circ} \mathrm{C}\right)\end{array}$ & $\begin{array}{l}\text { ples } \\
\text { Canister } \\
\text { exteftior } \\
\text { exteftern }\end{array}$ \\
\hline $\begin{array}{c}M+T E \text { Nos. } \\
12: 20 \mathrm{pm} \\
12: 30 \mathrm{pm} \\
12: 40 \mathrm{pm} \\
12: 50 \mathrm{p} \\
1: 00 \mathrm{pm} \\
1: 10 \mathrm{pm} \\
1: 20 \mathrm{pm} \\
1: 30 \mathrm{pm} \\
1: 40 \mathrm{pm} \\
1: 50 \mathrm{pm} \\
2: 00 \mathrm{pm} \\
2: 10 \mathrm{pm} \\
2: 20 \mathrm{pm} \\
2: 30 \mathrm{pm} \\
2: 40 \mathrm{pm} \\
2: 50 \mathrm{pm} \\
3: 00 \mathrm{pm} \\
3: 10 \mathrm{pm} \\
3: 30 \mathrm{pm} \\
3: 40 \mathrm{pm} \\
3: 50 \mathrm{pm} \\
4: 00 \mathrm{pm} \\
4: 10 \mathrm{pm} \\
4: 20 \mathrm{pm} \\
4: 30 \mathrm{pm} \\
4: 50 \mathrm{pm} \\
5: 00 \mathrm{pm} \\
5: 10 \mathrm{pm} \\
5: 20 \mathrm{pm} \\
5: 30 \mathrm{pm}\end{array}$ & $\begin{array}{l}76-602 \\
5 \\
5 \\
5 \\
5 \\
5 \\
5 \\
5 \\
5 \\
5 \\
5 \\
5 \\
5 \\
5 \\
5 \\
5 \\
5 \\
5 \\
5 \\
5 \\
-5 \\
-5 \\
-3 \\
5 \\
5 \\
5 \\
5 \\
5 \\
5 \\
5 \\
5 \\
5\end{array}$ & $\begin{array}{l}0.78 \\
0.78 \\
0.78 \\
0.178 \\
0.78 \\
0.78 \\
0.78 \\
0.78 \\
0.78 \\
0.78 \\
0.78 \\
0.78 \\
0.78 \\
0.78 \\
0.78 \\
0.79 \\
0.78 \\
0.78 \\
0.72 \\
0.72 \\
0.72 \\
0.77 \\
0.77 \\
0.77 \\
0.77 \\
0.76 \\
0.76 \\
0.76 \\
0.76 \\
0.76\end{array}$ & $\begin{array}{l}76-001 \\
900 \\
900 \\
900 \\
900 \\
900 \\
900 \\
900 \\
900 \\
900 \\
900 \\
900 \\
9900 \\
900 \\
900 \\
900 \\
900 \\
900 \\
900 \\
900 \\
900 \\
900 \\
900 \\
900 \\
900 \\
900 \\
900 \\
900 \\
900 \\
900 \\
900 \\
900 \\
900\end{array}$ & 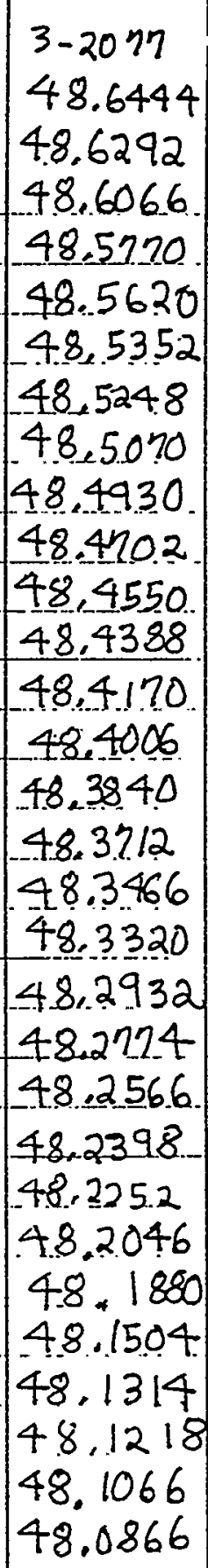 & $\begin{array}{l}3-2007 \\
16.5 \\
16.4 \\
16.4 \\
16.3 \\
16.4 \\
16.2 \\
16.2 \\
16.2 \\
16.1 \\
16.0 \\
15.9 \\
15.9 \\
15.8 \\
15.9 \\
15.8 \\
15.9 \\
15.8 \\
15.7 \\
15.5 \\
158 \\
15.3 \\
15.2 \\
15.0 \\
14.9 \\
14.7 \\
14.6 \\
14.5 \\
14.4 \\
14.4 \\
14.3\end{array}$ & 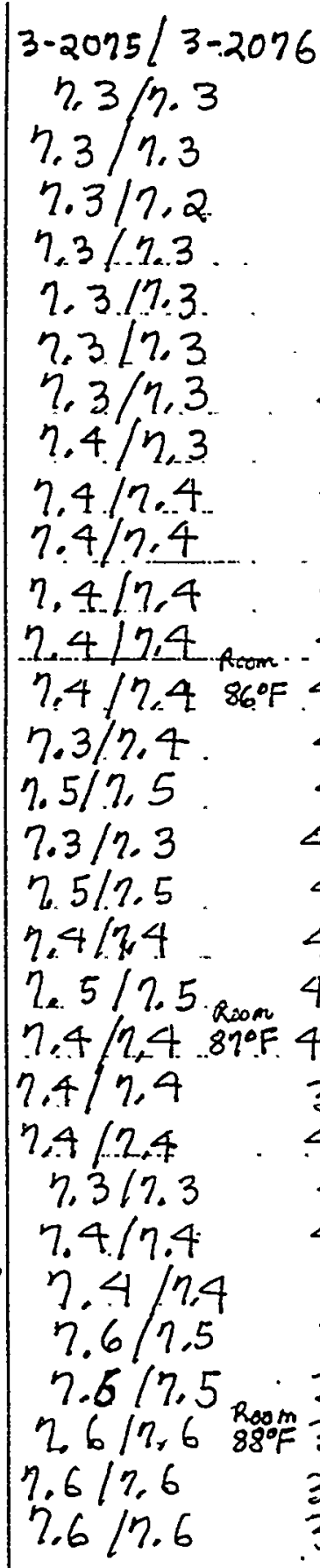 & $\begin{array}{l}6 \\
43.2^{2} \\
42.9 \\
42.6 \\
42.6 \\
42.6 \\
42.5 \\
42.3 \\
42.2 \\
42.0 \\
41.9 \\
41.5 \\
41.5 \\
41.3 \\
41.3 \\
41.0 \\
40.8 \\
40.1 \\
40.2 \\
40.2 \\
40.1 \\
39.9 \\
40.0 \\
40.1 \\
40.1 \\
40.1 \\
39.8 \\
39.6 \\
39.70 \mathrm{~F} \\
39.4{ }^{\circ} \mathrm{F} \\
39.1^{\circ} \mathrm{F}\end{array}$ \\
\hline
\end{tabular}


$\therefore \quad$ Lanister + SNF + $689 \mathrm{ml}$ of $\mathrm{H}_{2} \mathrm{O}$ with no Heat Input: c.: Lange $8 / 28 / 97$

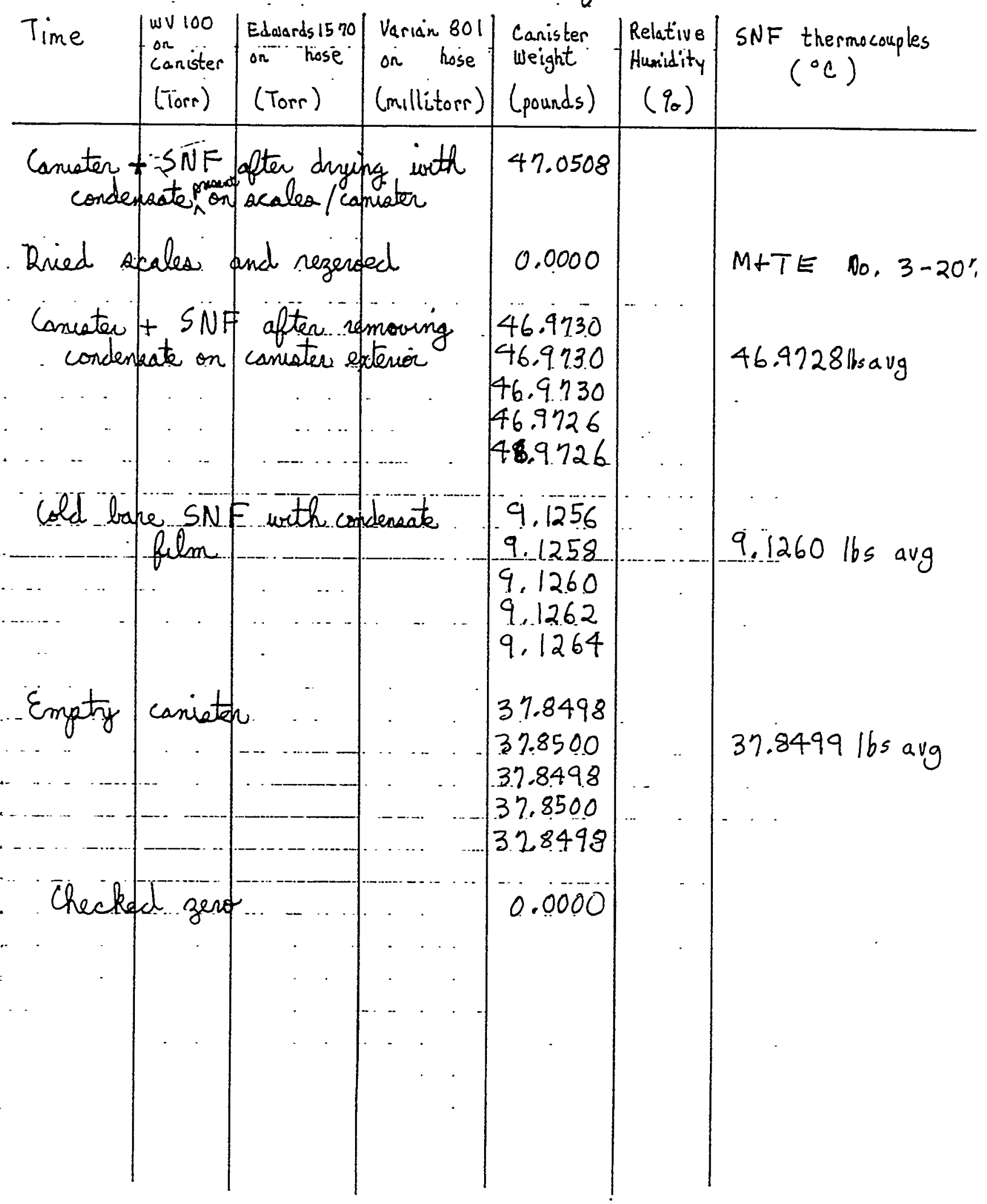


$\therefore$ Canister + SNF+ $689 \mathrm{ml}$ of

$\mathrm{H}_{2} \mathrm{O}$ with no Heat Input

con: $W$. Langer: $\quad 8 / 28 / 97$

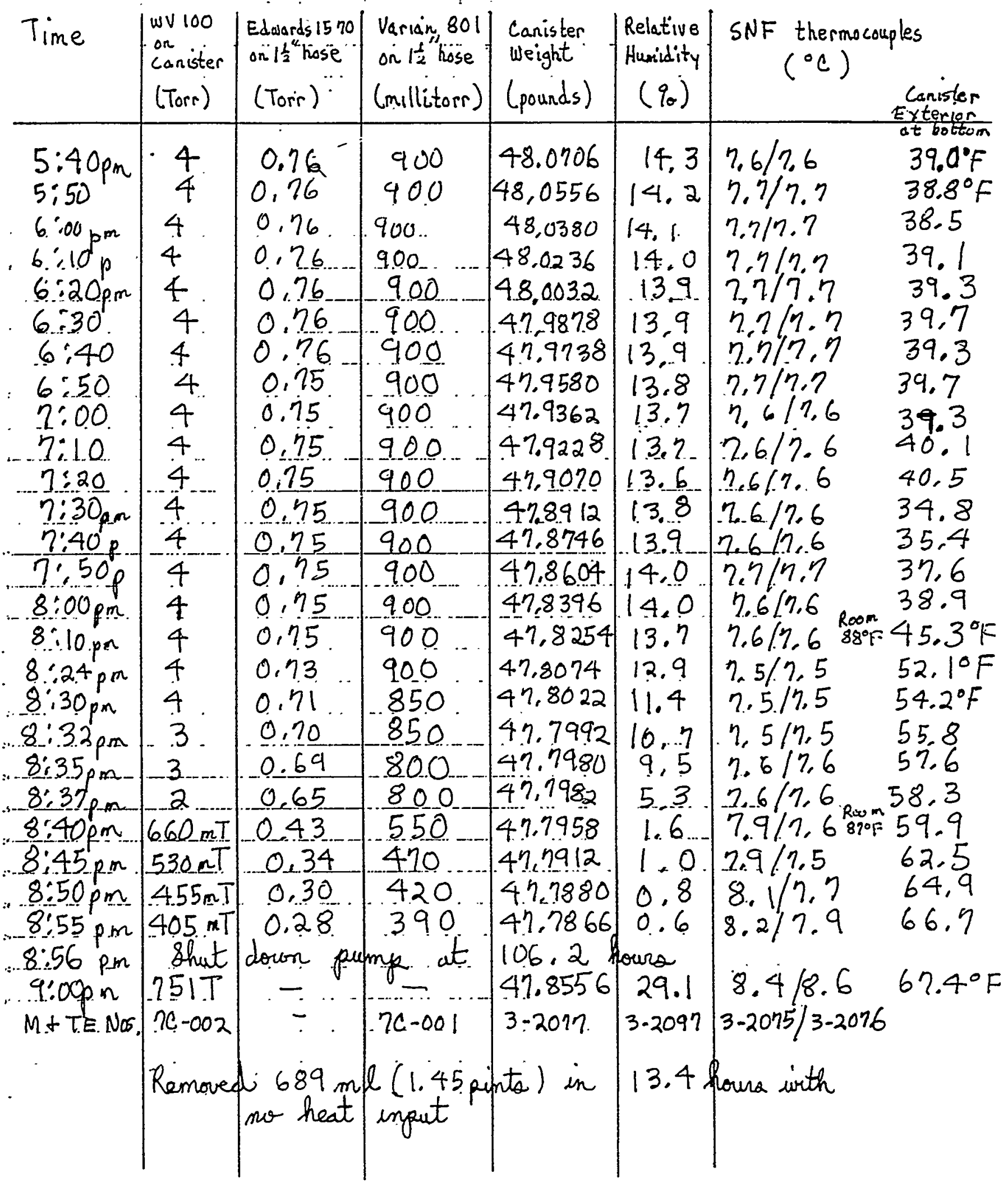


FP-721 Procedure

Z:.

$$
\begin{aligned}
& \text { Canister + SNF + } 46 \mid \mathrm{ml} \text { Ho } \\
& \text { with no Heat Input }
\end{aligned}
$$

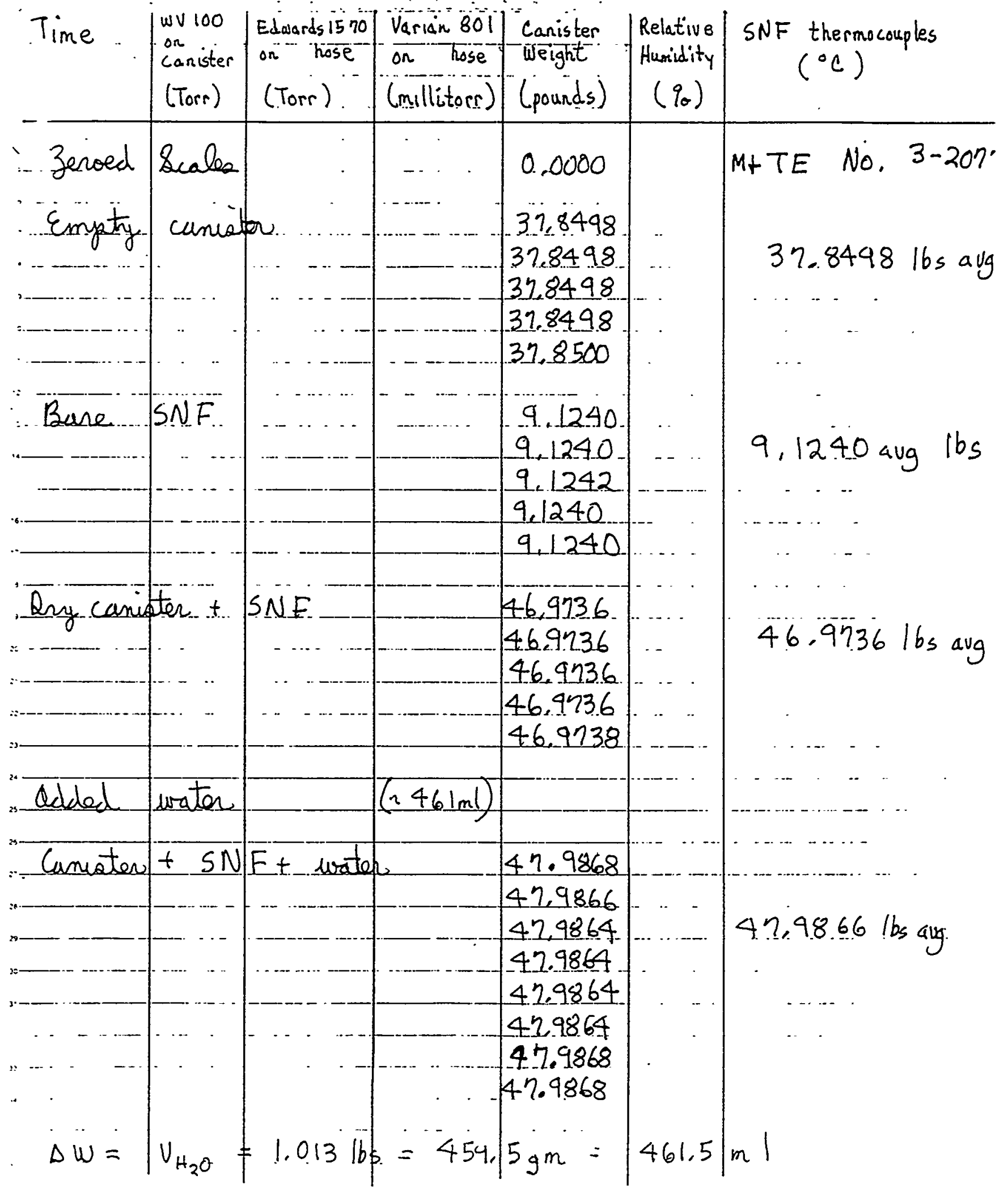


$F P-721$ Procedure

Canister + SN $\dot{F}+461 \mathrm{ml}$ of

$=3$

: $\mathrm{H}_{2} \mathrm{O}$ with no Heat Input

cornu: W. R. Lunge $8 / 27 / 97$

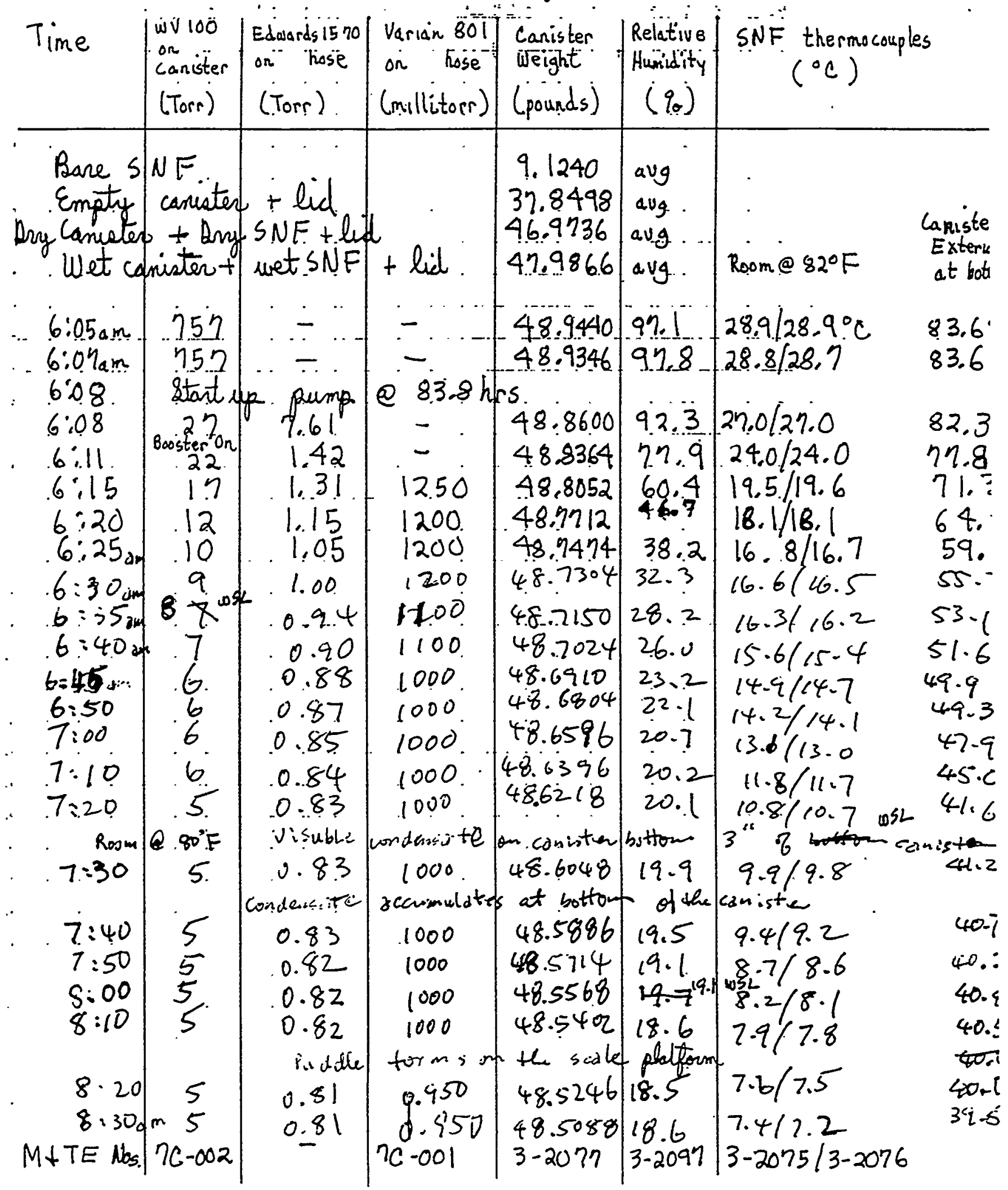


FP-721 Procedure

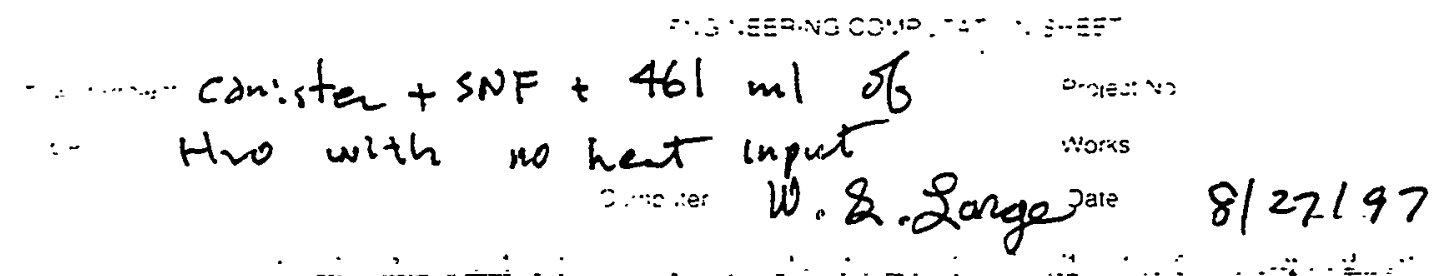

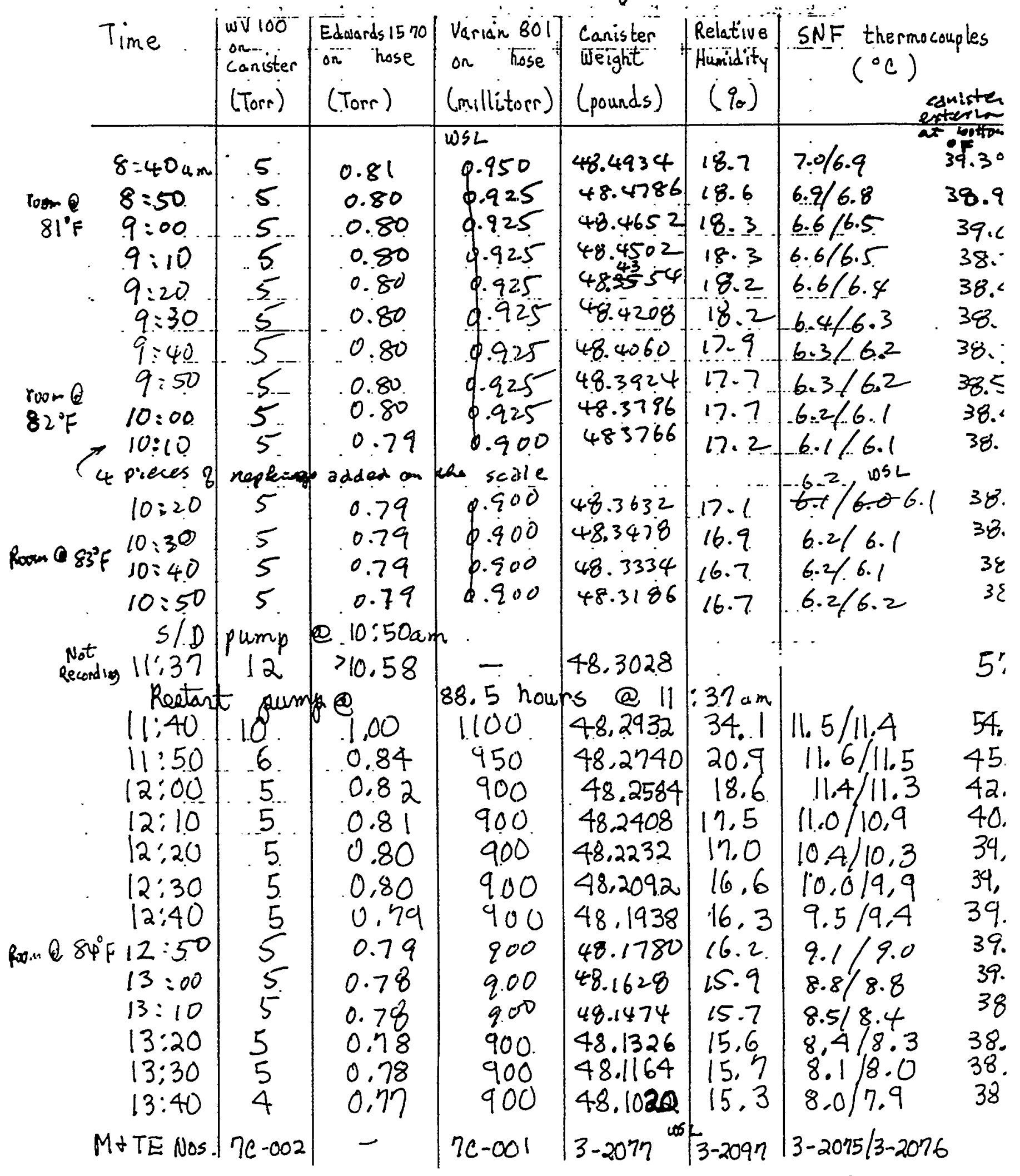


FP-721 Procedure

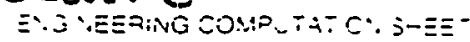
$\ldots \ldots$ Dry Fuel Assembly in Dry
Canister

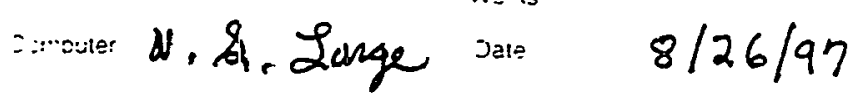

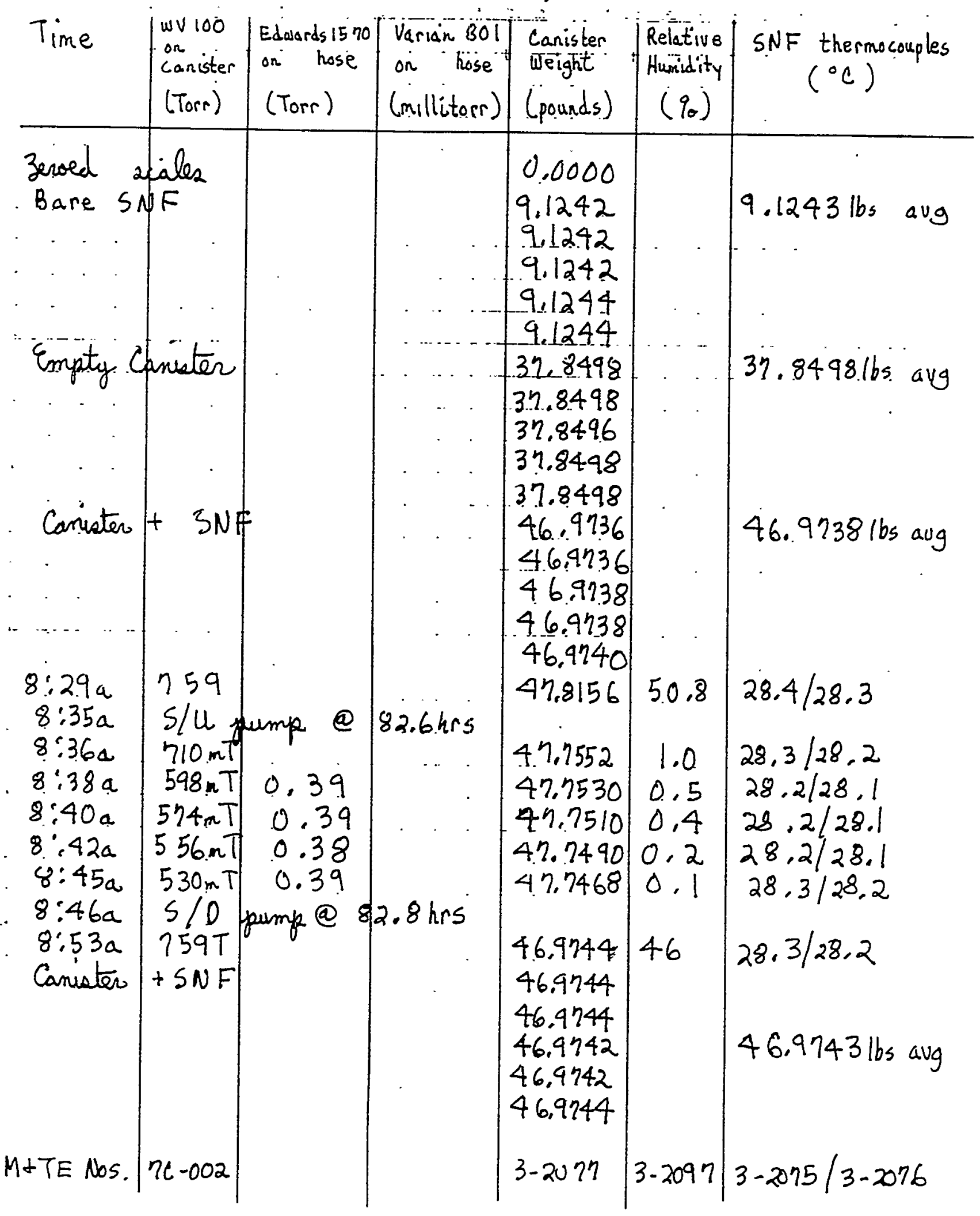


FP-721 Procedure

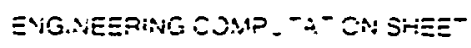

Dry. Fuel Assembly in Dry Canister

$$
\text { computer W. \&. Large ate } 8 / 26 / 97 \quad \text { sra z...2 } 2
$$

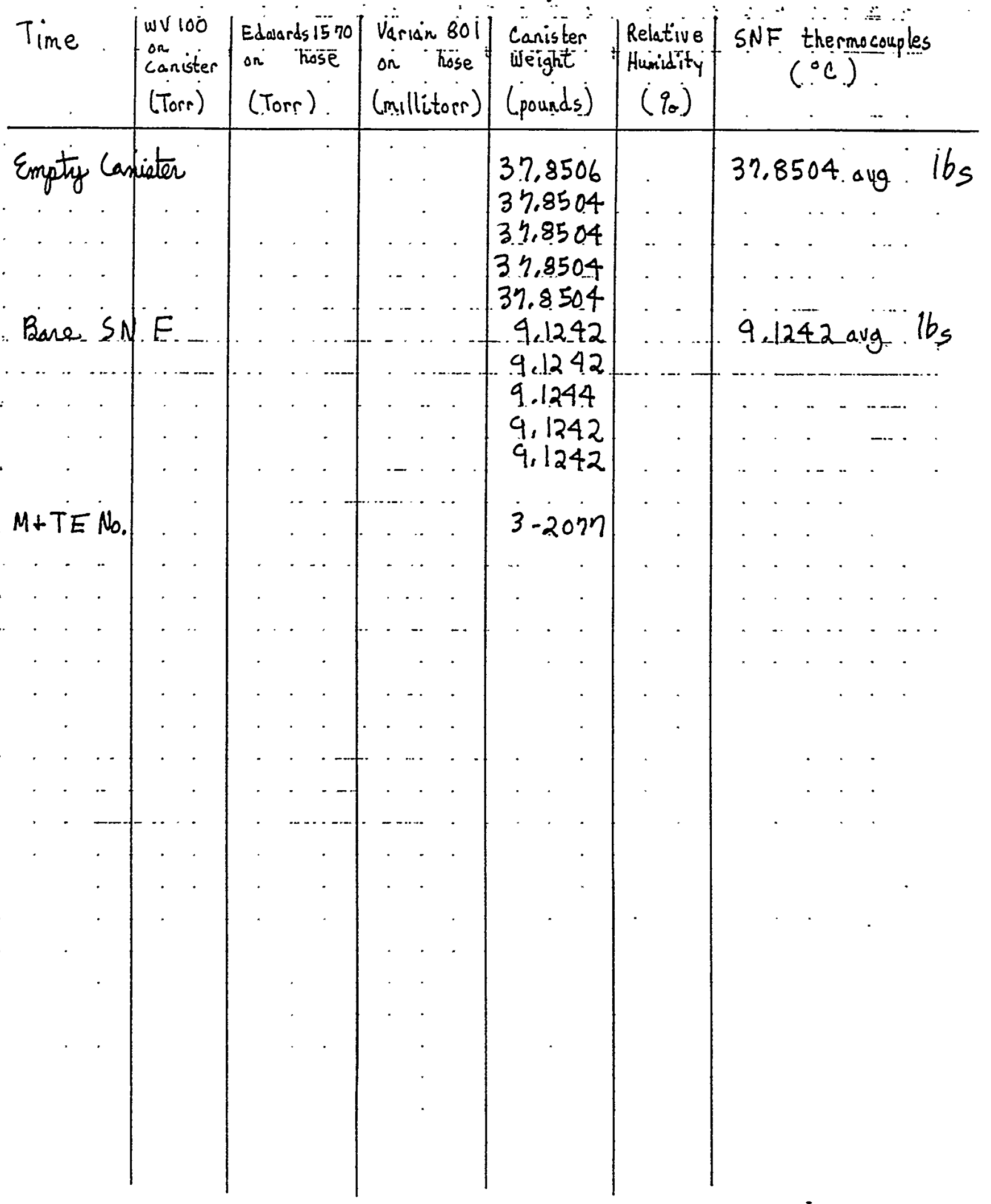


$F p-221$ Procedure

Io :Evans comp :-a: on: sr az-

Drip Dry Fuel Assembly in mon wo
Dry Canister

compute: W. \&. Large ate $8 / 26 / 97$

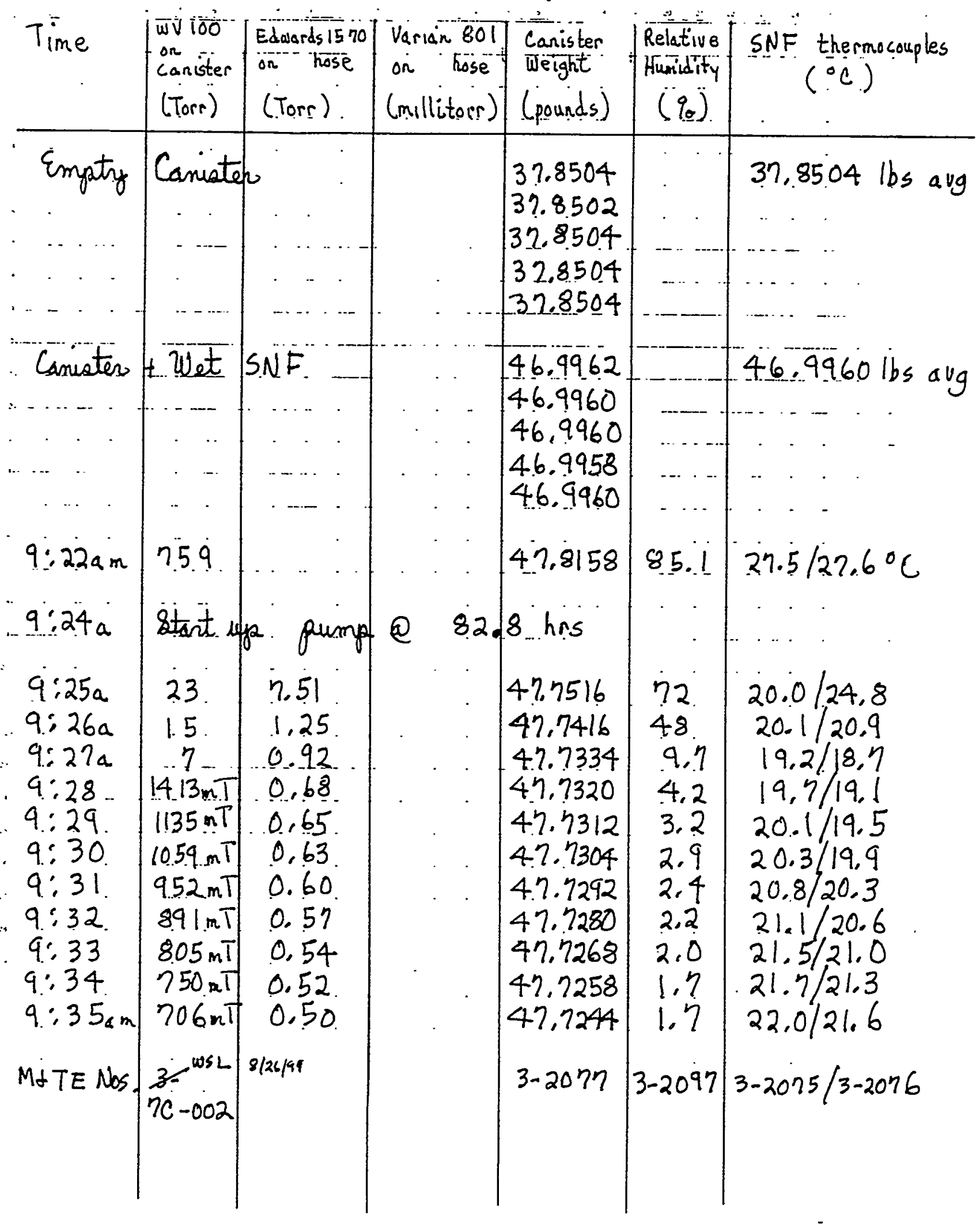


$F P-721$ Procedure

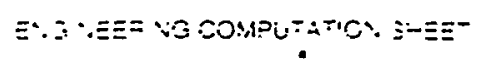

Drip Dry. Fuel Assembly in o.... Dat:

$\because \mathbb{P S}$

Dry Canister corpyuser W. \& Lunge $8 / 26 / 97$

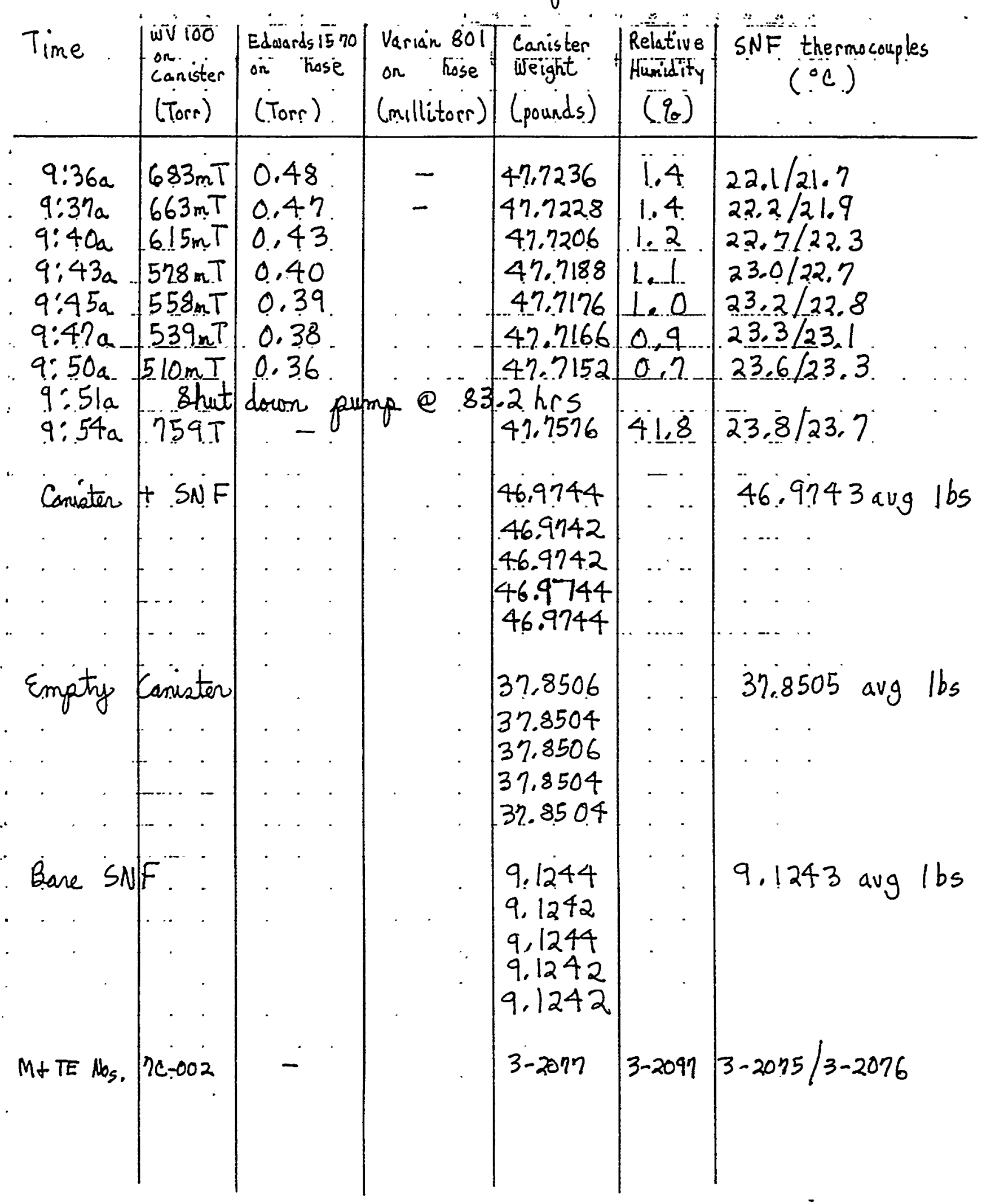


$F P-721$ Procedure

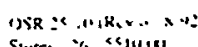

ENGINEERING COMPUTATION SHEET

Twe of rovect Su bmerged Assembly Transferced

c. ibject

into Dry Canister

$$
\text { computer W. \& Lange Date } 8 / 26 / 97
$$

Project No

\begin{tabular}{|c|c|c|c|c|c|c|}
\hline Time & $w V 100$ & Ediards 15 no & Váriah gol & Clanisteri & Relative & SiNF thermocouples \\
\hline & Canister & oni those & hoţe & weight & Hunididity & $(\circ \mathrm{c})$ \\
\hline & (Tore) & (Torr) & (millitor) & (pounds) & (q.) & \\
\hline Camister & I Wot & $S N E$ & & 1470396 & & \\
\hline & & & & 47.0394 & & 47.0394 av \\
\hline & & & & 47.0394 & $:$ & \\
\hline & & $i$ & 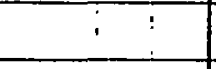 & 47.0394 & & \\
\hline & & & $\vdots:$ & $4 i .0394$ & & \\
\hline & & & $\begin{array}{l}\vdots \\
\vdots\end{array}$ & $i$ & & \\
\hline $10: 33 \mathrm{am}$ & 759 & $\vdots-$ & $\vdots-\vdots$ & 42.9526 & 80,0 & $26.0 / 25.9 i$ \\
\hline $10: 33 \mathrm{am}$ & $8 \tan t$ & & at & $8,3.2$ hirs & & \\
\hline & & & & & & \\
\hline $10: 34 \mathrm{am}$ & 24. & - & - & 47.8946 & 76.2 & $25.0 / 24,9$ \\
\hline $10: 36 \mathrm{~cm}$ & 18 & 12,9 & - & $4,7.871 .4$ & 57.2 & $20.6 / 20.2$ \\
\hline $10: 40 \mathrm{am}$ & $10^{\circ}$ & 1.02 & $-1 \quad \vdots$ & 47.8500 & 29.4 & $18.4 / 18.0$ \\
\hline $10: 45 \mathrm{am}$ & 3. & 0.75 & & 47.8438 & 9,2 & $18.8 / 18.5$ \\
\hline $10: 50 \mathrm{am}$ & $1125 \mathrm{mT}$ & 0.62 & & 47.8346 & 3.4 & $19.0 / 18.5$ \\
\hline $10.55 \mathrm{sm}$ & $665 \mathrm{~m} T$ & 0.42 & & 47.8232 & 1.8 & $19.0 / 18.5$ \\
\hline $11,0,0 \mathrm{am}$ & $596 \mathrm{mT}$ & 0.41 & & 42.8176 & 1.4 & $18.9 / 18.5$ \\
\hline $11: 05 \mathrm{am}$ & $525 \mathrm{mT}$ & 0.37 & & 47.8122 & 1.1 & $18.9 / 18.6$ \\
\hline $11: 08 \mathrm{am}$ & Shet & down put & ma at & $83.8 \mathrm{hrs}$ & & \\
\hline the & & & $0 \vdots \quad \vdots$ & & & \\
\hline $11: 10 \mathrm{am}$ & 759 & & & 47.8546 & 41.4 & $18.9 / 18.9$ \\
\hline M\&TENos. & $7 c-\infty$ & . & & $3-2077$ & $3-2097$ & $3-2015 / 3-2076$ \\
\hline Caminter & + SNF & & & 46.9248 & & $46.9742 \mathrm{lbs}$ \\
\hline & & & & 46.9746 & & \\
\hline & & & & 46.9748 & & ..... \\
\hline & & & & 46.9248 & & $\ldots$ \\
\hline & & 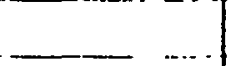 & & 46.9146 & & $-\ldots$ \\
\hline & & & & & & $\ldots-\cdots-\ldots$ \\
\hline & & & & & & $\ldots$ \\
\hline$\ldots$ & & $\cdots$ & & $\cdots$ & & $+\cdots+\cdots$ \\
\hline - & $\cdots$ & • & & 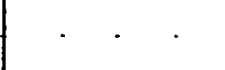 & . & . \\
\hline & & & $\cdots \cdot-$ & & & \\
\hline
\end{tabular}


FP-721 Procedure

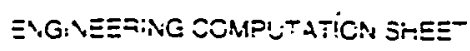

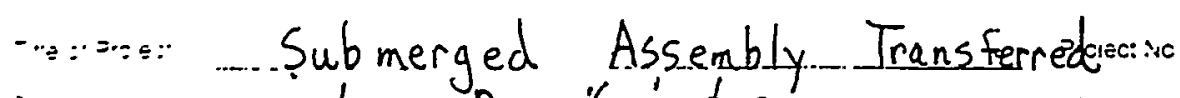

SES:

$\because \quad$.....into. Dry Canister

Wons

srees: 6

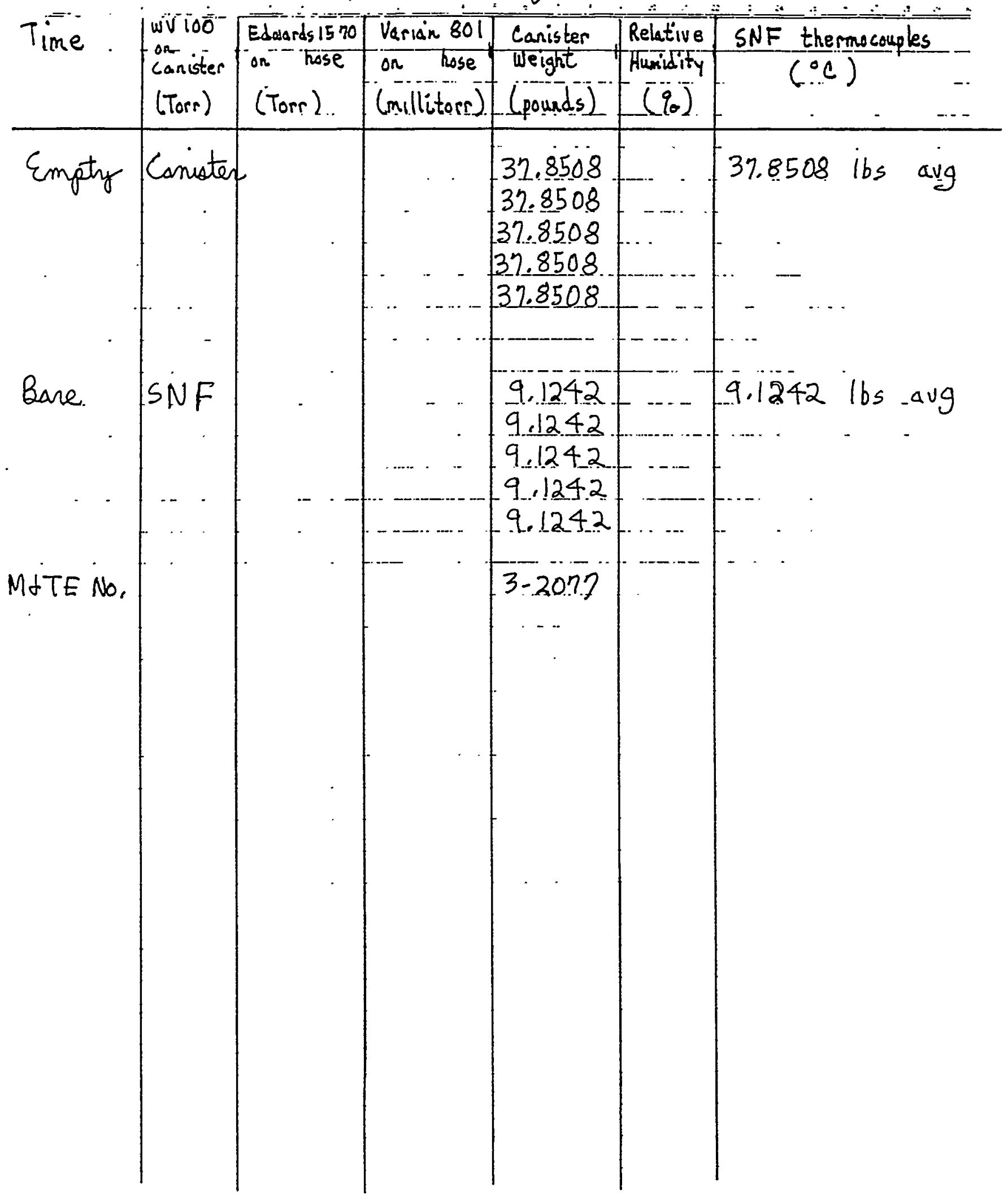


$\therefore \quad \therefore \therefore$ Procedure FP- 721

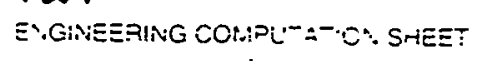

Canister + $5 N F+29 \eta_{\mathrm{m}} 1$ of

$\mathrm{H}_{2} \mathrm{O}$ at $\sim 4.8$ watts

project vo

$8=$

:Works

W. R. Large sate $8 / 21 / 97$

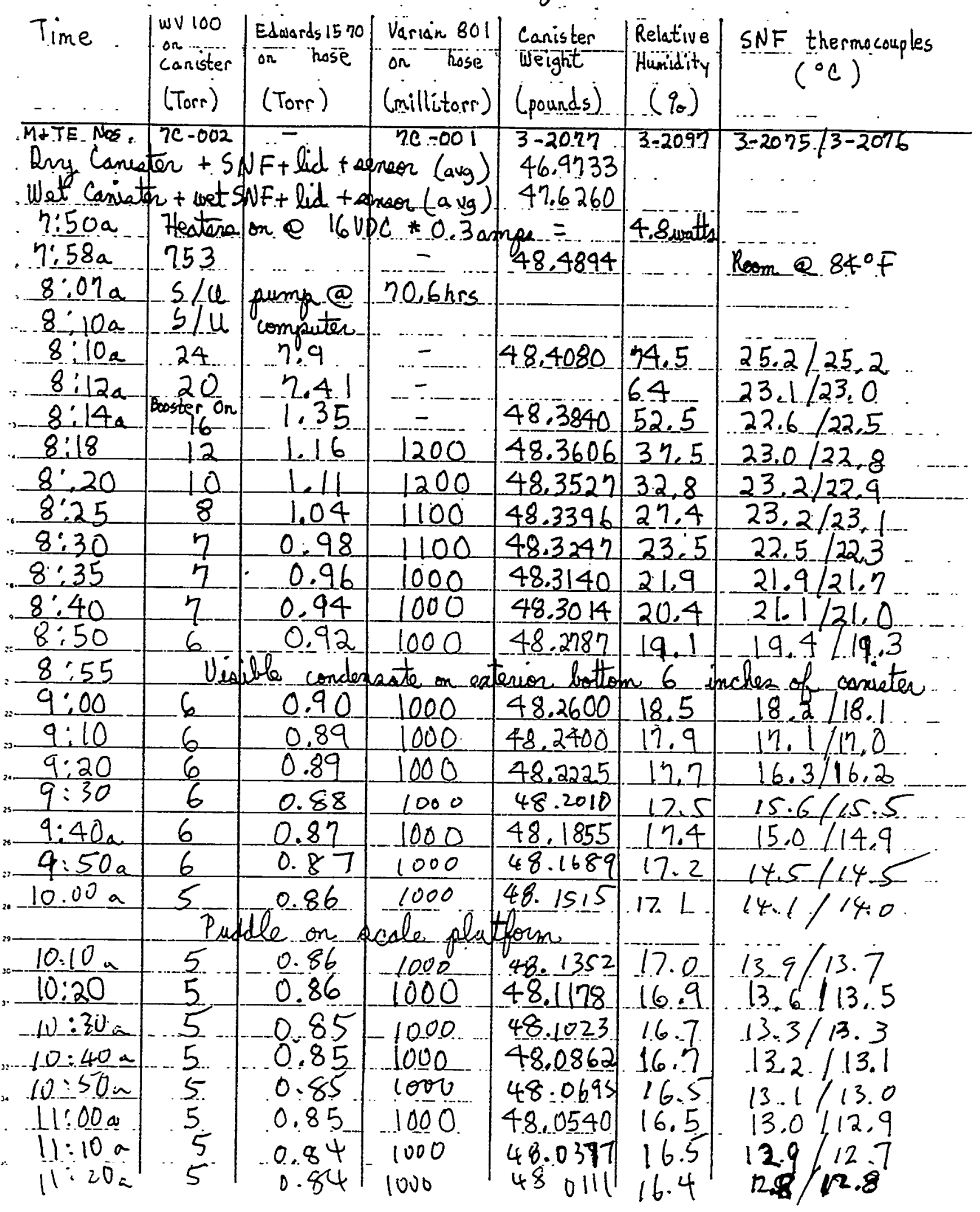


Procedure FP- 221

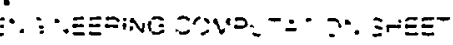

$\because \ldots . . . \% \quad$ conistar $+3 N \vec{F}+297 \mathrm{ml}$ of

D.jeat No

$B E$

$\mathrm{H}_{20} \mathrm{O}$ at $\sim 4.8$ watts

$\because$ orks

::-nouse W.K. Lange Jate $8 / 21 / 97$

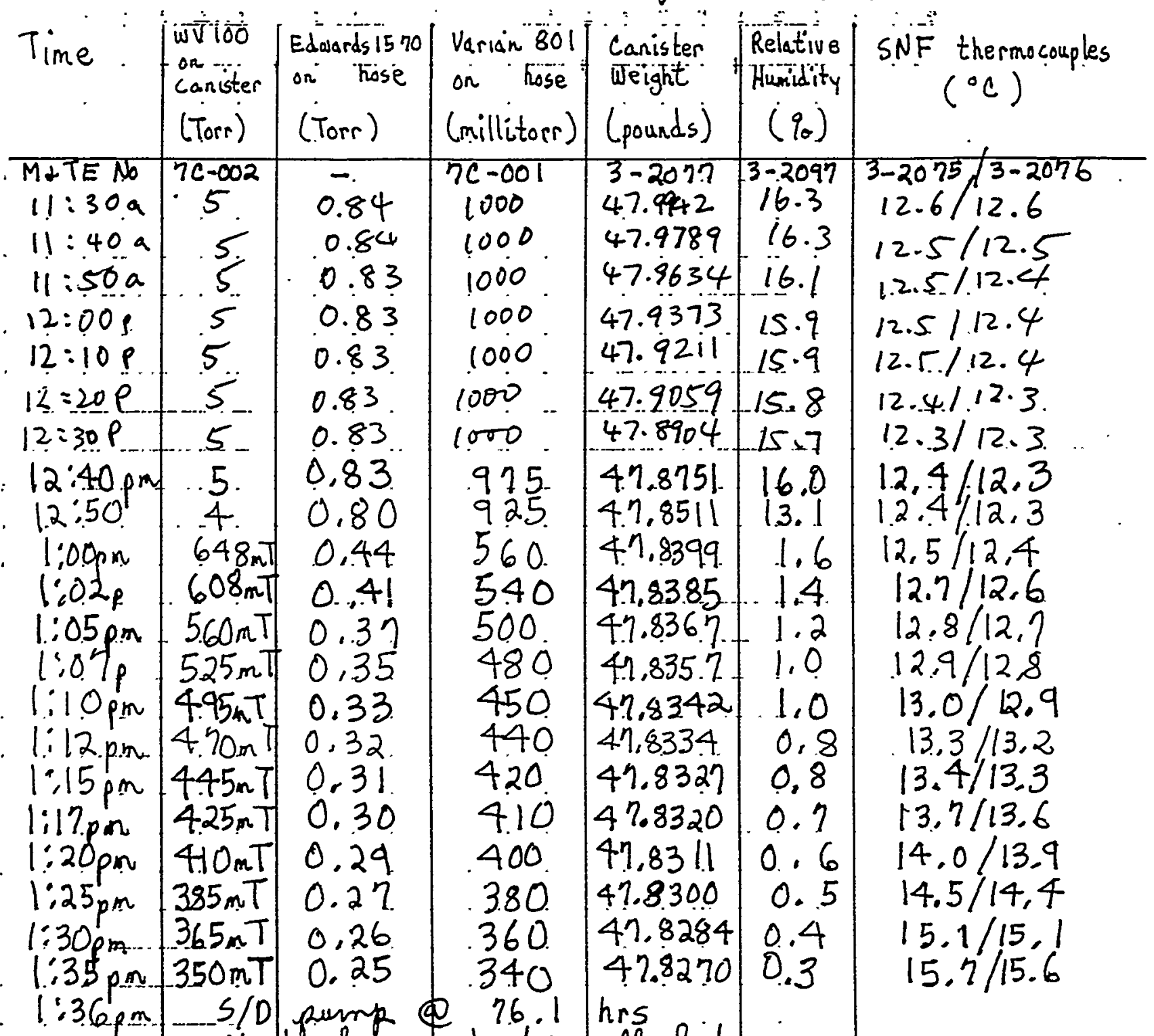

Vent heae fend turn off heatop.

Rempoed comeater from acales

Dried caniater exterior and acale platform

Rejersed scalea.
46.9748 (avg) or 0.7 grans higher

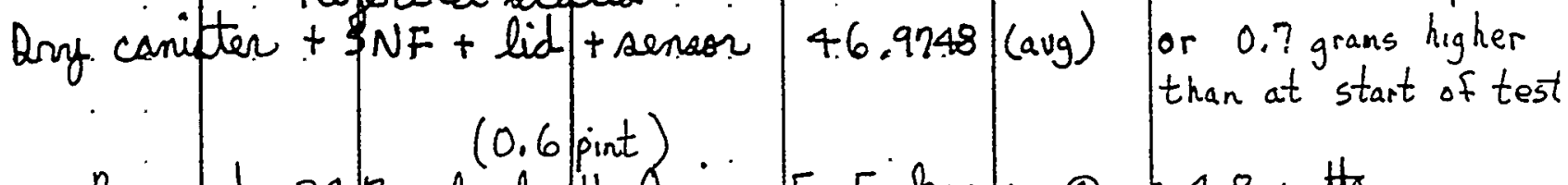

Remorted 29.7 mloof $\mathrm{H}_{2} \mathrm{O}$ in 5,5 houra @ 4.8 watto

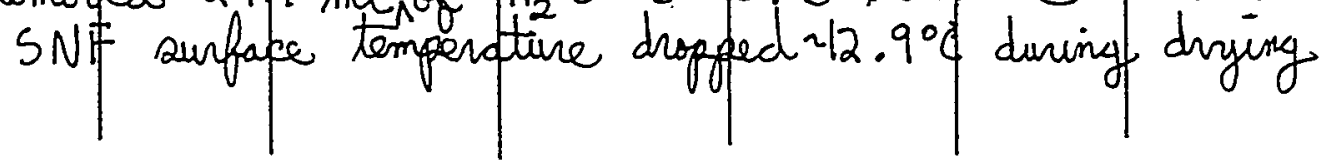


Pretest

Procedure $F P-721$

Sealer as - found

zeroed

Dor canister + SNF + lid

+ sensor
$-0.01105 \mathrm{lbs}$

$0.0000 \mathrm{lbs}$

$46.9732 \mathrm{lbs}$

46.9733

46.9734

46.9733

$A v g=46.9733$

W. 2. Lan

46.9732

$8121 / 9 i$

46.9732

added $2300 \mathrm{ml}$ of $\mathrm{H}_{2} \mathrm{O}$ to canister ( 1 " in bottom)

Wet canister + wet SNE + lid + sensor

$$
\begin{aligned}
& 47.6259 \text { lbs } \\
& 47.6260 \\
& 47.6260 \\
& 47.6260 \\
& 47.6259 \\
& 47.6259
\end{aligned} \quad A v g=47.62601 \mathrm{ll}
$$

$$
\mathrm{H}_{2} \mathrm{O} \text { weight }=\Delta W_{\mathrm{AUG}}=0.6527 \mathrm{lbs}=296.0 \mathrm{gm}=2 \mathrm{l}^{\mathrm{i} .3 \mathrm{l}}
$$

Post test

Dried converter + dried SNF

$$
\begin{aligned}
& 46.9747 \text { lbs } \\
& 46.9749 \\
& 46.9749 \\
& 46.9749 \quad \text { Avg }=46.9748 \mathrm{lbs} \\
& 46.9748 \\
& 46.9746
\end{aligned}
$$$$
+ \text { lid + sensor }
$$

* Dried canceler exterior

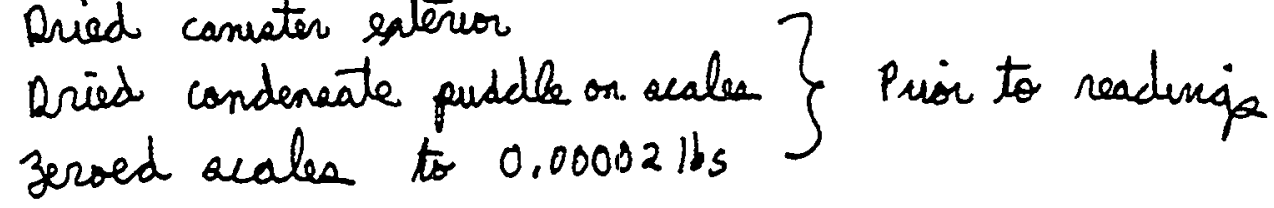

$$
\underset{\text { cross }}{\Delta W_{\text {check }}}=0.651216 \mathrm{~s}=295.4 \mathrm{gms}=296.6 \mathrm{~m}
$$

Scales M+TE No. 3-2077 


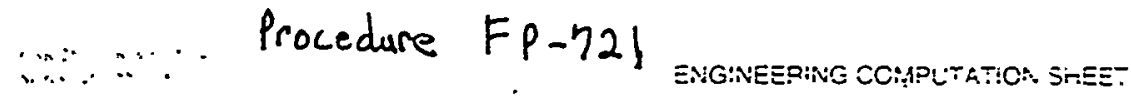

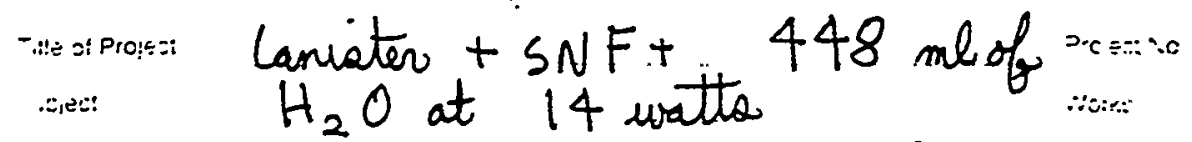

: PRS

emputer $W . \$$. Lange :i:-

$8 / 20 / 9 \eta \quad 1$

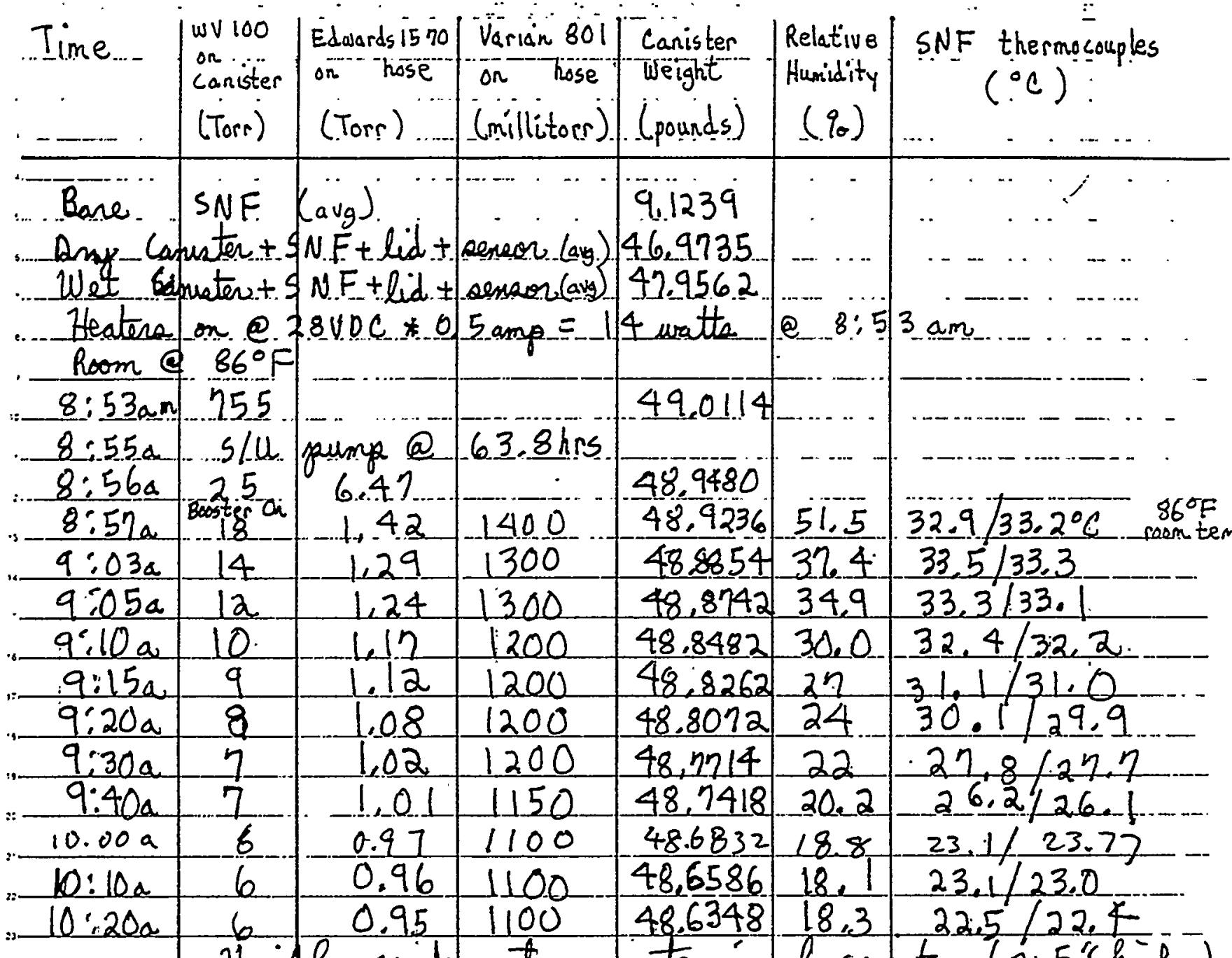

Vesiple condeprate on exterión of conterg ( $\sim 5$ "high) and pudde on arate platform

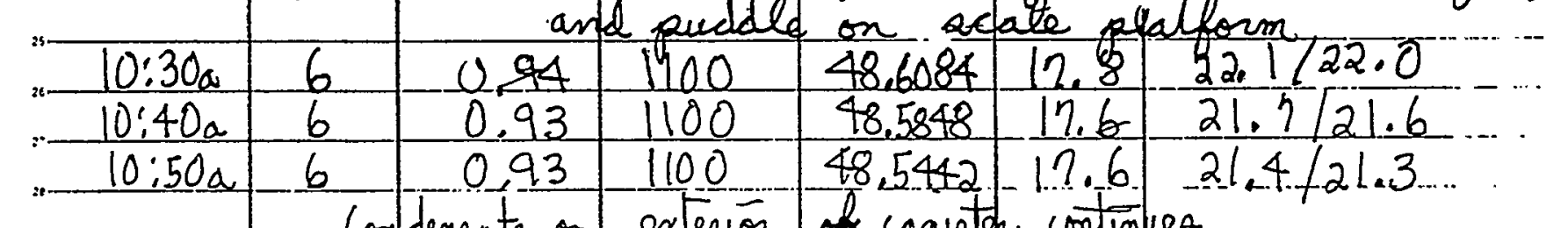

Coxdensate on exterior of canster contentese

Pudie on ecate ptotform. is dnis ping off edge of pcoles

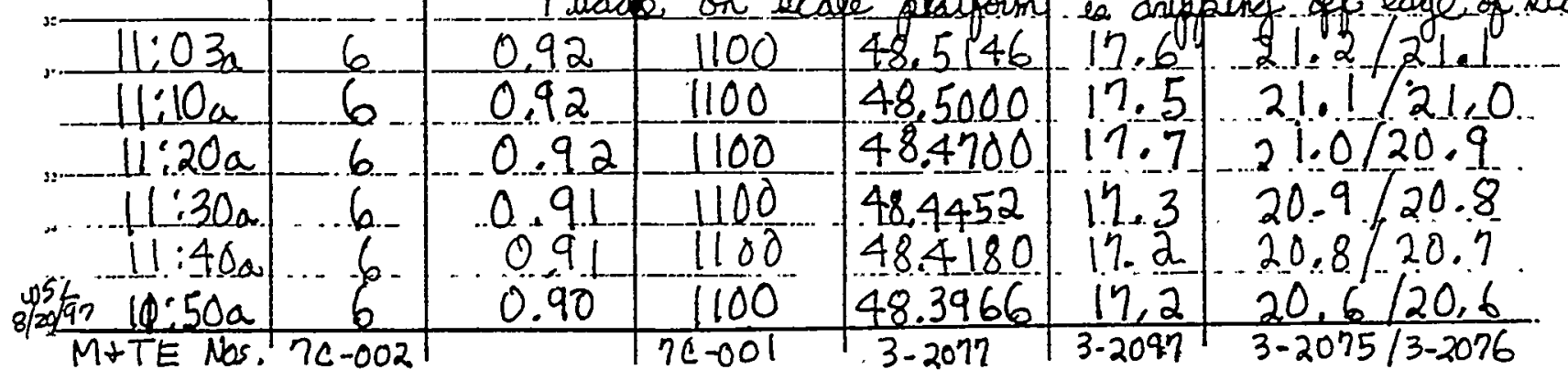


Procedure FP-721

$\Rightarrow r: \quad$ Conuster $+5 N F+448 \mathrm{ml}$ of $\mathrm{H}_{2} \mathrm{O}$ at 14 watta

Sompli:e: W. 2. Lange sate $8 / 20 / 9 \eta$

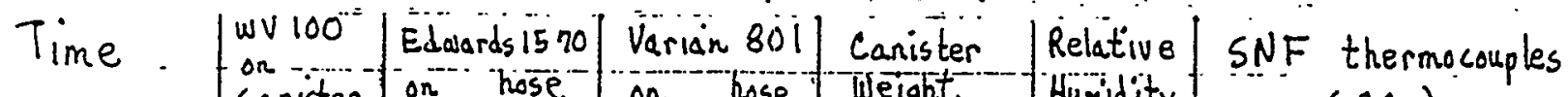
canster on hose on hose weight Humidity . ( $\left.{ }^{\circ} \mathrm{C}\right)$ (Torr) (Torr) (millitor) (pounds) (qo)

\begin{tabular}{c|c|c|c|c|c|c}
$12: 00 \mathrm{pm}$ & 6 & 0.90 & 1050 & 48.3722 & 17.0 & $20.6 / 20.5$ \\
$12512 \mathrm{~m}$ & 6 & 0.90 & 1050 & 48.343 & 16.6 & $20.57 / 20.5$ \\
$12: 20 p$ & 6 & 0.89 & 1050 & 48.3282 & 16.8 & $20.6 / 20.5$ \\
$12: 30 p$ & 6 & 0.89 & 1050 & 48.3050 & 16.7 & $20.6 / 20.5$
\end{tabular}
$12: 35 p$ Scaleo died - no display but computer reade value $12: 40$ p 6 - $0.89-1050$ - 16.5 20.6/20.5 Lifted caniater and atempted to zero scales

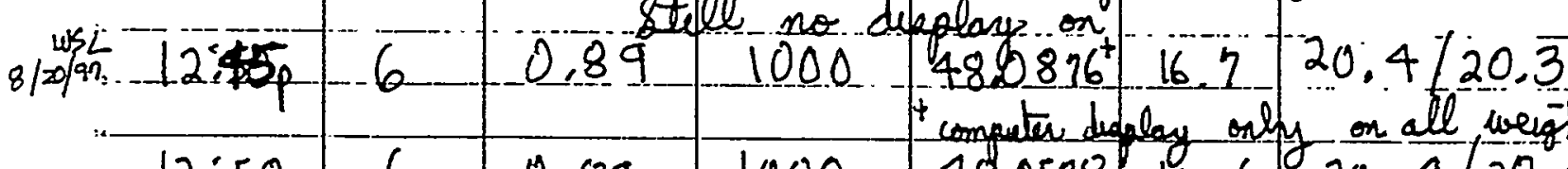

\begin{tabular}{|c|c|c|c|c|c|c|}
\hline $12: 5$ & 6 & 0.89 & 1900 & & & 4 \\
\hline $1: 00$ & 6 & 0.89 & 1000 & 48.0599 & $\begin{array}{l}16.6 \\
1.6 .6\end{array}$ & $204 / 203$ \\
\hline $1: 1$ & 6 & 0.88 & 1000 & 48.0395 & 16.4 & $20.4 / 20.3$ \\
\hline 1,2 & 6 & 0.88 & 1000 & 48,0198 & & $120.4^{5}$ \\
\hline $1: 30$ & 6 & 0.88 & 1000 & 48.0005 & & $20.5 / 20.5$ \\
\hline & & \&till & have & de on & & \\
\hline 140 & 6 & 0.88 & $1000^{0}$ & 41.9813 & 16 & 20 \\
\hline $1: 50 p$ & 6 & 0.88 & 1000 & $4 \eta, 9540$ & 16 & $20.6 / 20.6$ \\
\hline & & Bottom & $4^{\prime \prime}$ of & anuter con & ened & condenaute. \\
\hline & & & $x \operatorname{ten}$ & & & \\
\hline $2: 00 p$ & 6 & 0.88 & 1000 & 47.9355 & 16.0 & $20.6 / 20.6$ \\
\hline $2: 12 p$ & 6 & 0.87 & 1000 & 47.9123 & 5.8 & $20,6 / 20$, \\
\hline $2: 20 p$ & 6 & 0.87 & 1000 & 47.8971 & 5 & $20.7 / 20.6$ \\
\hline $2: 32 p$ & -6 & 0.87 & 1000 & 47.8672 & 15.5 & $20.7 / 20.7$ \\
\hline $2: 40 p$ & 6 & 0.86 & 1000 & 41.8512 & 15.4 & $20.7 / 20, \eta$ \\
\hline $2: 50 p$ & 6 & 0.86 & 1000 & 47.8325 & 15.4 & $20,8 / 20,8$ \\
\hline $3: 00 p$ & e & 0.87 & 1000 & 47.5133 & is & 20.9120 .8 \\
\hline 3.10 & 5 & 0.84 & 1000 & 47,2909 & 13,0 & $21.0 / 20.9$ \\
\hline & & 0.79 & 915 & 47.7884 & 10.4 & 21.0121 .0 \\
\hline $3: 13 p$ & 3 & 0.73 & 900 & $4.7,7865$ & 6.6 & $21.0 / 21,0$ \\
\hline $3: 14_{p}^{1}$ & $1713 \mathrm{mt}$ & 0,68 & 85.0 & 41.78 .52 & 4.3 & $21.0 / 20.9$ \\
\hline $3: 150$ & $1000 \mathrm{mI}$ & 0.61 & 750 & 47.7832 & 2.3 & $210 / 20.9$ \\
\hline$T F$ & & & & 32077 & & $32075 / 320$ \\
\hline
\end{tabular}


Procedure FP- 721

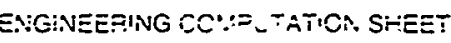

Canater + SNF + $448 \mathrm{ml}$

P.s:esi No

$\leqq \subseteq$

of $\mathrm{H}_{2} \mathrm{O}$ at 14 watts

scupule: $\quad W \cdot$ \&. Lange sate $8 / 20 / 97$

$\therefore 3$

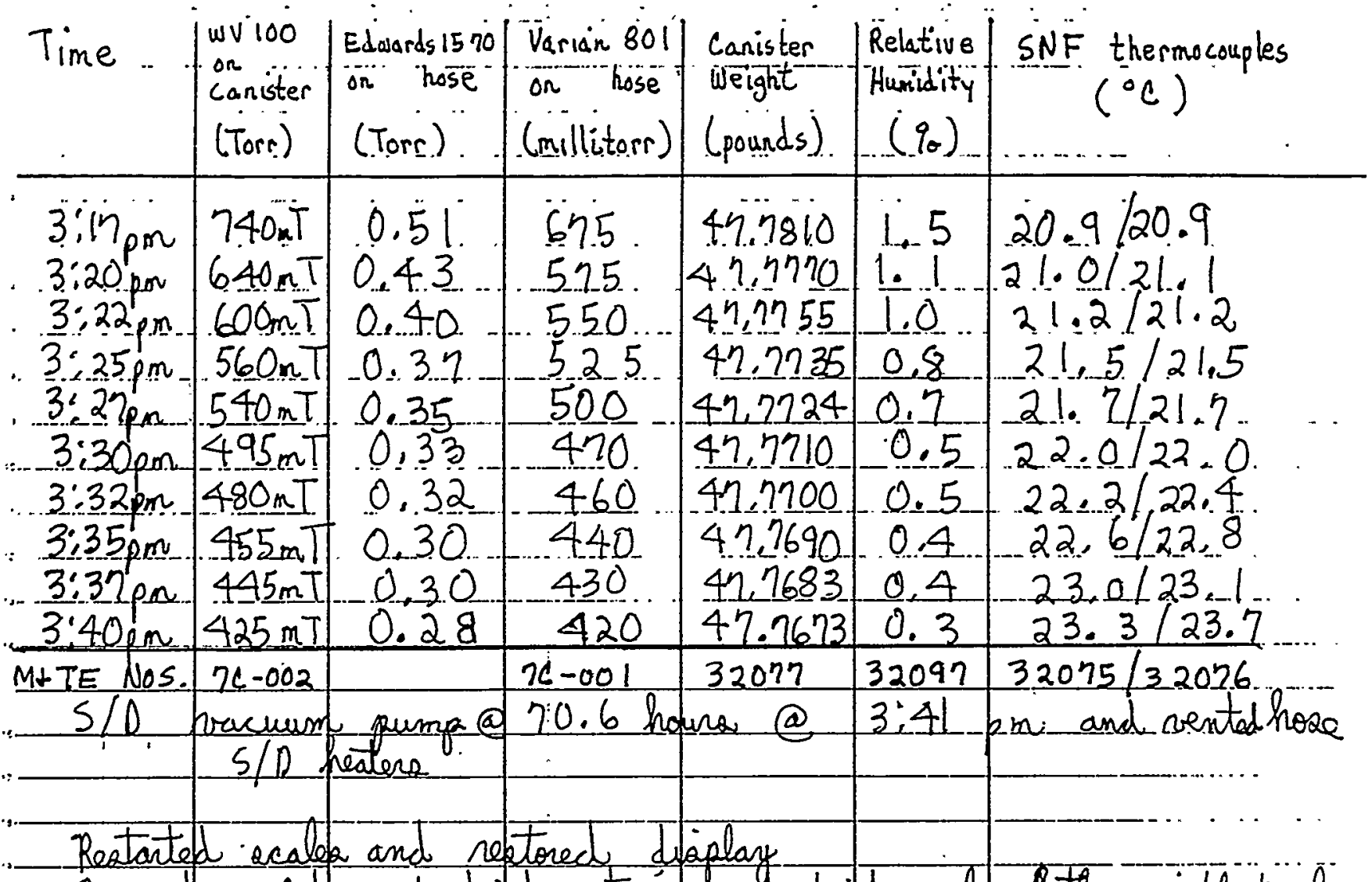

Removed coniato and dried exterion and drigd acabe flatform urth towels Placed dried chiceter back on dried acale flatform

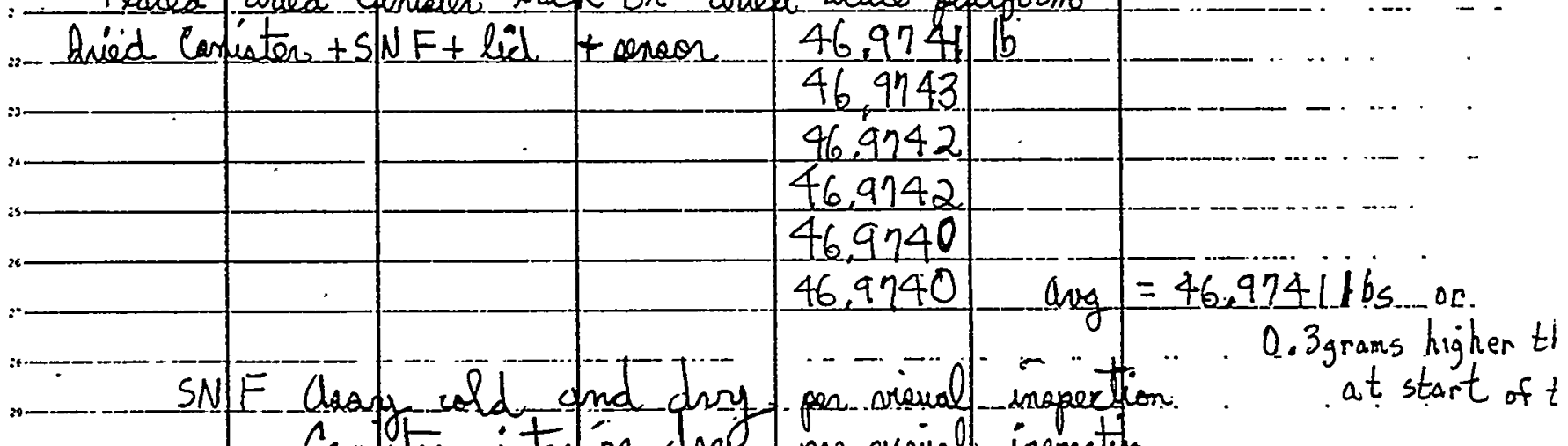

Caxpeter intentor dry per areval inapectip.

at start of $t$

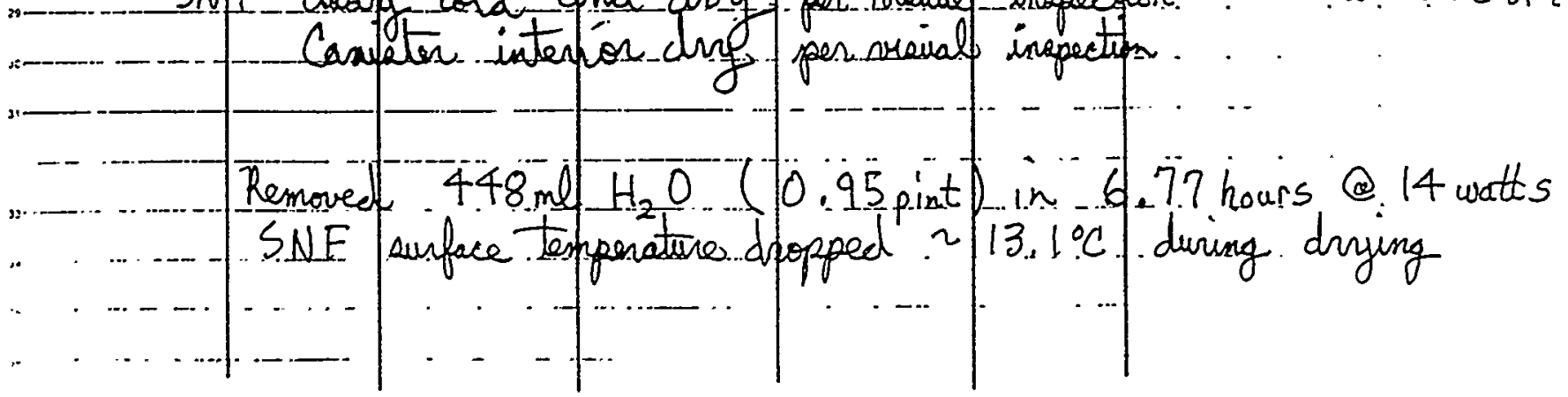


Prestartup

Scales as found zeroed scales

Bare SNF
Procedure FP-121

0.0002 lbs

$0.0000 \mathrm{lbs}$

$9.1238 \mathrm{lbs}$

9.1240

9.1240

9.1240

9.1238

lng canister + dry SNF + lid + sensor
$46.973416 \mathrm{~s}$

46.9736

46.9734

46.9 .736

46.9734
$8 / 20 / 97$

sheet 4

w. \&. Lar

$$
A v g=9.1239 \mathrm{lbs}
$$

Scales M+ TE Mo. $3207 \eta$

added $~ 475 \mathrm{ml} \mathrm{H}_{2} \mathrm{O}$ (1 $1 \frac{3}{4}$ water in bottom of canister)

8:33 am aborted pumps startup when scales bast power

Wet canister +

wet SNF + lid

+ senor after

aborted atartuge
$47.9562 \mathrm{lbs}$

47.956 .2

47.9562

47.9564

Avg $=47.9562 \mathrm{lbs}$

42.9560

47.9562

47.9562

47.9562

$\mathrm{H}_{2} O$ weight $=\Delta W_{A \cup G}=0.9827 \mathrm{lbs}=445.7 \mathrm{gms}=447.7 \mathrm{ml}$

Post test

breed comiater + dried

$S N F+$ lid + sensor

46.9741 lbs

after, drains canister

46.9743

46.9742

$A \cup g=46.9741 \mathrm{lbs}$

exterior, scale platform

46.9742

46.9740

46.9740

$$
\Delta w_{\text {check }}=0.98211 \mathrm{bs}=445.5 \mathrm{gms}=447.4 \mathrm{ml}
$$


Field Procedure FP-72!

$8 / 19 / 97 \quad$ Caniater $+5 N F+291 . \mathrm{ml}$ of $\mathrm{H}_{2} \mathrm{O}$ Page 1 at 14 ( 1 "Itts. in bottom of

\begin{tabular}{|c|c|c|c|c|c|c|c|}
\hline Time & $\mid \begin{array}{c}\text { wiloo } \\
\text { on comedere } \\
\text { (Torr) }\end{array}$ & 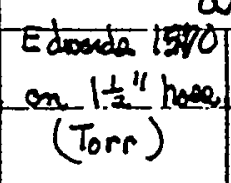 & $\begin{array}{l}\text { Varasingol } \\
\text { on litshose } \\
\text { (millitorr) }\end{array}$ & $\left|\begin{array}{l}\text { Caniated } \\
\text { Wight } \\
\text { (pounds) }\end{array}\right|$ & $\begin{array}{l}\text { Relative } \\
\text { quendedty } \\
\left(q_{\sigma}\right)\end{array}$ & & $\begin{array}{l}\text { SNF thermocone } \\
\left({ }^{\circ} C\right)\end{array}$ \\
\hline $7: 50 \mathrm{~cm}$ & $75.5 \mathrm{~T}$ & - & - & 48.3710 & $86 \%$ & $28 \cup 0 \sigma^{\circ}$ & $31.9 / 32.1$ \\
\hline $\begin{array}{l}7 \div 58 \\
7: 58 \\
8: 00\end{array}$ & $\begin{array}{l}3 / u \\
26 T \\
21 T\end{array}$ & $\begin{array}{l}\text { pump e } \\
6.62 T \\
6.22\end{array}$ & $\begin{array}{c}59.15 \mathrm{hrs} \\
-\end{array}$ & $\begin{array}{l}48.2990 \\
48.2860\end{array}$ & $\begin{array}{l}6890 \\
-\end{array}$ & $\begin{array}{l}0.5 \text { amp }= \\
14 \text { watte } \\
\text { A udible } \\
\text { "popping". as }\end{array}$ & \\
\hline $8: 06$ & $\begin{array}{c}\text { Booster on } \\
12 \text { - }\end{array}$ & 1,28 & 1300 & 48.2462 & 32,3 & & $34.0 / 33,9$ \\
\hline $8: 12$ & 9 & 1.17 & 1250 & 48.2200 & 25.2 & & $33.2 / 32.9$ \\
\hline $8: 22$ & $\eta$ & 1.07 & 1200 & 48,1874 & 20.4 & & $30.9 / 30.8$ \\
\hline $8^{\circ}, 33$ & $\eta$ & 1,04 & 1200 & 48.1566 & 18.6 & & $28.9 / 27.7$ \\
\hline $8: 45$ & 6 & 1.02 & 1150 & 48.1260 & 17.7 & & $27.2 / 27.1$ \\
\hline $8: 51$ & 6 & 1.01 & 1150 & 48.1106 & 14.7 & $\begin{array}{l}\operatorname{lom}_{80} \text { Tenpl } \\
86^{\circ} \mathrm{F}\end{array}$ & $26.5 / 26.4$ \\
\hline $9: 03$ & 6 & 1.00 & 1100 & 48,0822 & 17.4 & & $25,3 / 25,2$ \\
\hline 12 & 6 & 0.99 & 1100 & 48.0606 & 17.3 & & $24.5 / 24, \equiv$ \\
\hline $9: 20$ am & 6 & 0.99 & 1100 & 48.0448 & 17.3 & & $24.0 / 23.9$ \\
\hline $9: 30$ an & $\begin{array}{l}6 \\
\text { Vac. Pump } \\
\text { skid }\end{array}$ & $\begin{array}{c}0.97 \\
\text { Pump c } \\
\text { inlet }=77^{\circ} \mathrm{C}\end{array}$ & $\begin{array}{l}1100 \\
\text { Taxk (Pamp } \\
\text { oathet) }=90^{\circ} \mathrm{F}\end{array}$ & $\begin{array}{l}48,0222 \\
c . w_{1} \operatorname{intet=}= \\
22 p i g, 76^{\circ} \mathrm{F}\end{array}$ & $\begin{array}{l}16.9 \\
\text { CW out let } \\
=80^{\circ} \mathrm{F}\end{array}$ & $\begin{array}{l}88^{\circ} \mathrm{F} \\
\text { Rempinilet of } \\
\sim 2 \text { psig, }\end{array}$ & $\left\{\begin{array}{c}23.5 / 23,3 \\
\text { Pamp Inlet } \\
V_{\text {ac }}=29.5^{\prime \prime}+\text { ty }\end{array}\right.$ \\
\hline $9: 40 \mathrm{am}$ & 6 & 0.91 & 1100 & 48.0010 & 16.9 & & $23.0 / 22.9$ \\
\hline $9: 50 \mathrm{am}$ & 6 & 0.96 & 1100 & 47,9796 & 16.7 & & $22.6 / 22,5$ \\
\hline $10: 00 \mathrm{am}$ & 6 & 0.96 & 1100 & 47.9586 & 16.7 & & $22.5 / 22.3$ \\
\hline $10^{\prime}, 16 a n$ & 6 & 0.94 & 1100 & 47.9234 & 16.4 & & $22.0 / 21.9$ \\
\hline $10: 20 \mathrm{an}$ & 6 & 0.94 & 1100 & 47.9164 & 16.4 & & $21.9 / 21.8$ \\
\hline $10: 30 \mathrm{am}$ & $\begin{array}{c}6 \\
\text { Vaci } \\
\text { Skid }\end{array}$ & $\begin{array}{l}0.93 \\
\text { Pump Cire wte } \\
\text { Inlet }=76^{\circ} \mathrm{F}\end{array}$ & $\begin{array}{l}1100 \\
\operatorname{Tank}(\operatorname{Runp} \\
\text { Outlet })=90^{\circ} \mathrm{F}\end{array}$ & $\begin{array}{l}47.8970 \\
\text { c.w. inlet }= \\
22 \text { sig } 076 \%\end{array}$ & $\begin{array}{c}16.3 \\
\text { C.w. outlet }= \\
80^{\circ} \mathrm{F}\end{array}$ & $\begin{array}{l}\text { Pump inilet } \\
\text { cirn wader } \approx 2\end{array}$ & $21.8 / 21.7$ \\
\hline $10,40 \mathrm{an}$ & 6 & 0.93 & 1100 & 47.8170 & 16.1 & & $21.6 / 21.5$ \\
\hline$: 52 \mathrm{am}$ & 6 & 0,93 & 1100 & 47.8506 & 16.0 & & $21.5 / 21.4$ \\
\hline 11:00am & 6 & 0.92 & 1100 & 47.8370 & 15.9 & & $21.4 / 21.4$ \\
\hline $11: 10 \mathrm{am}$ & 6 & 0.92 & 1100 & 47.8140 & 16.0 & & $21,4 / 21.3$ \\
\hline $\begin{array}{l}M+T E \\
\text { Nos }\end{array}$ & $7 c-002$ & & $7 c-001$ & 32077 & 32097 & & $32075 / 32076$ \\
\hline
\end{tabular}


Field Procedure FP- 721

8/19/97 Caniater + SNF + $291 \mathrm{ml}$ of $\mathrm{H}_{2} \mathrm{O}$ continued Page W. \&. Jang

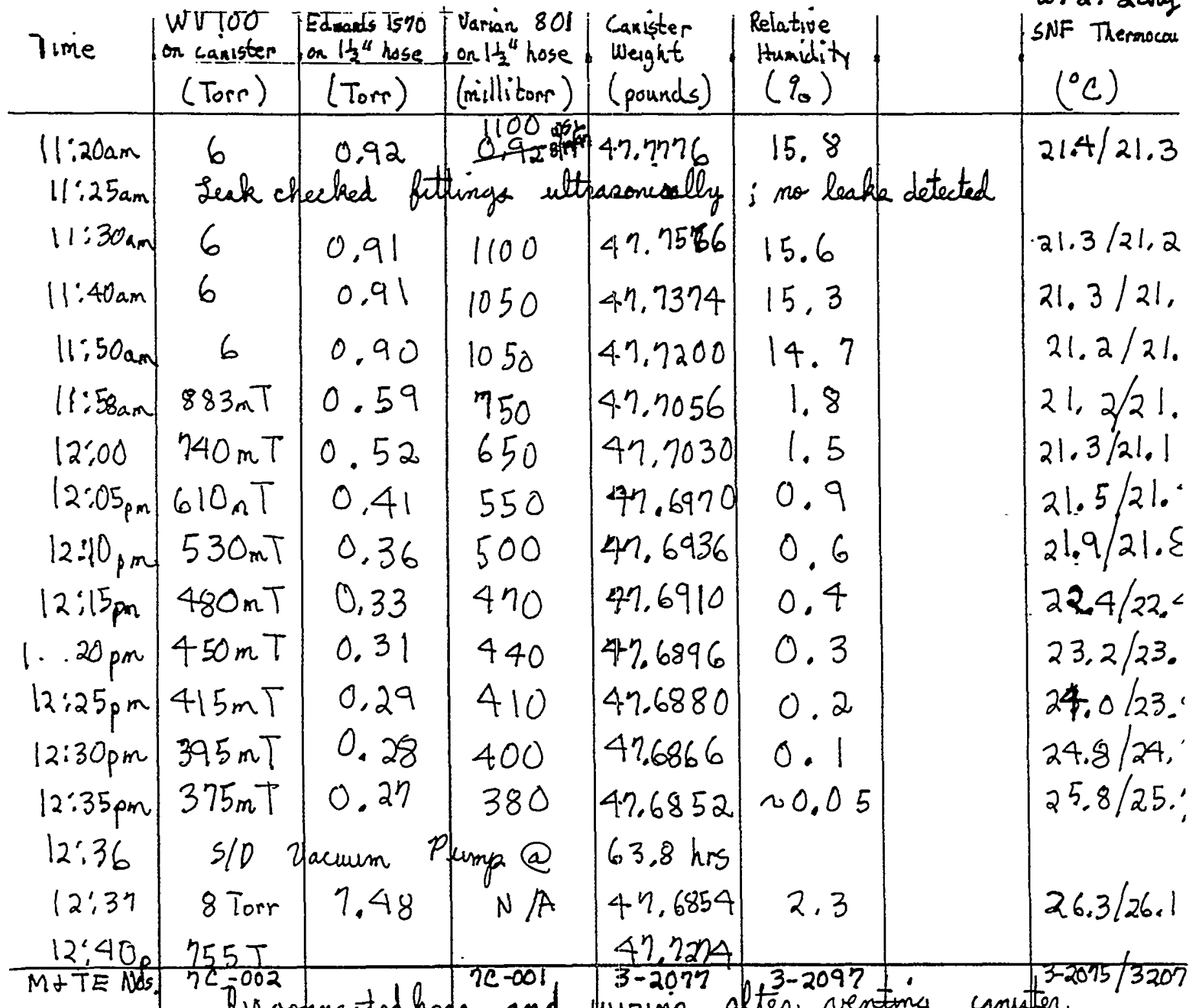

liscopnectedhose and wevring ofter venfing canuter

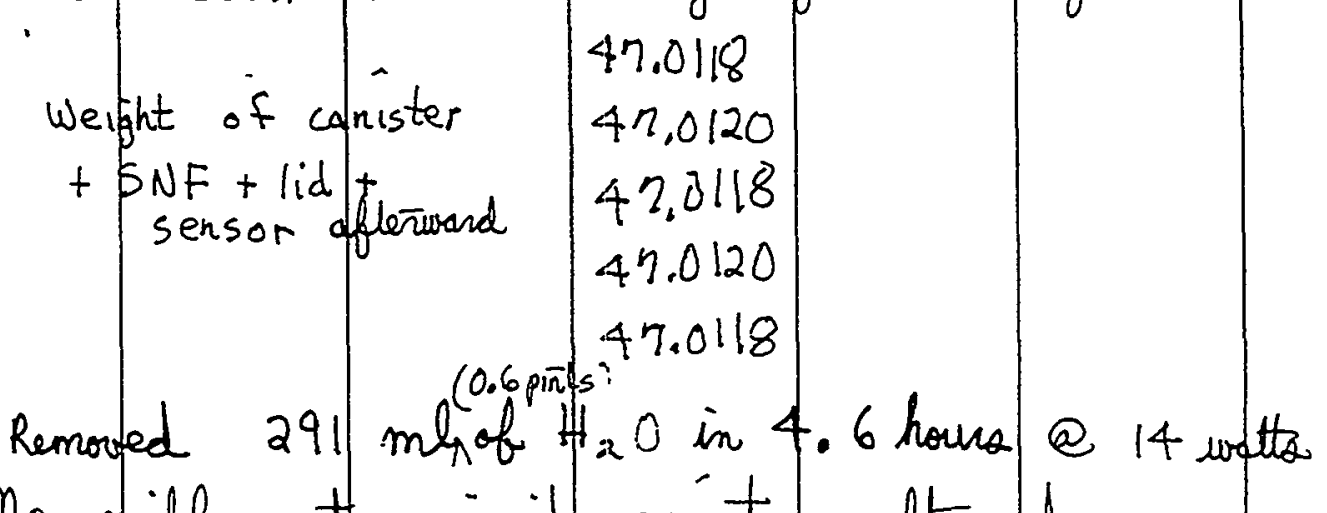

No riable urates insidd canseter afterwapd $S N F \mid$ aurface temperature dropped $\left|\sim 12.8^{\circ} \mathrm{C}\right|$ during dpying 
Prestartup

Field Procedure FP- 221

w.5. Large

$8 / 19 / 97$

Zeroed scales $\quad 0.0000 \mathrm{lbs}$

(a) ?: 12am

Page 3

dry Canisters dry SNF

$$
\begin{aligned}
& 46.9740 \\
& 46.9738 \\
& 46.9736 \\
& 46.9738 \\
& 46.9738
\end{aligned} \quad \text { Avg }=46.9738 \mathrm{lbs}
$$$$
+ \text { lid + censer }
$$

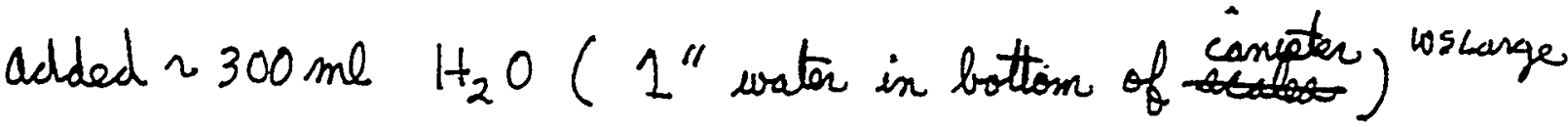

Wet canister + SNF

$$
+ \text { lid + serer }
$$

$$
\begin{aligned}
& 47.6134 \\
& 47.6134 \\
& 47.6132 \\
& 47.6132 \\
& 47.6132 \\
& 47.6132
\end{aligned}
$$$$
A \cdot g=47.6133 \mathrm{lbs}
$$

$$
\begin{aligned}
\Delta W_{\text {AVG }}=H_{2} \mathrm{O} \text { weight }=0.6395 \mathrm{bs}=290.05 \mathrm{grams} & =291.3 \mathrm{ml} \\
& =0.61 \mathrm{pints}
\end{aligned}
$$

Post test

ln y canister + SNF

+ lid + sensor

$$
\begin{aligned}
& 47.0118 \\
& 47.0120 \\
& 47.0118 \\
& 47.0120 \\
& 47.0118
\end{aligned} \quad \text { Aug }=47.0119 \mathrm{lbs}
$$

Scales M+TE Nb. $3207 \eta$ 
Procedure FP- 721

ENGINEERING COMPUTATION SHEET

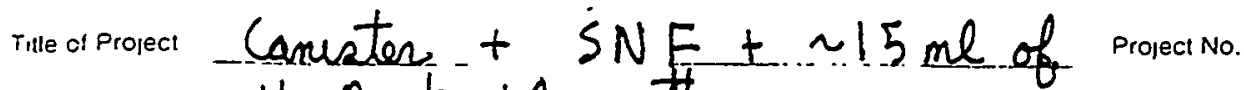

SR

$=+1$ object $\mathrm{H}_{2} \mathrm{O}$ at 14 watts

Computer W.S. Langer

Works

Date $8 / 18 / 97$

Sheet No

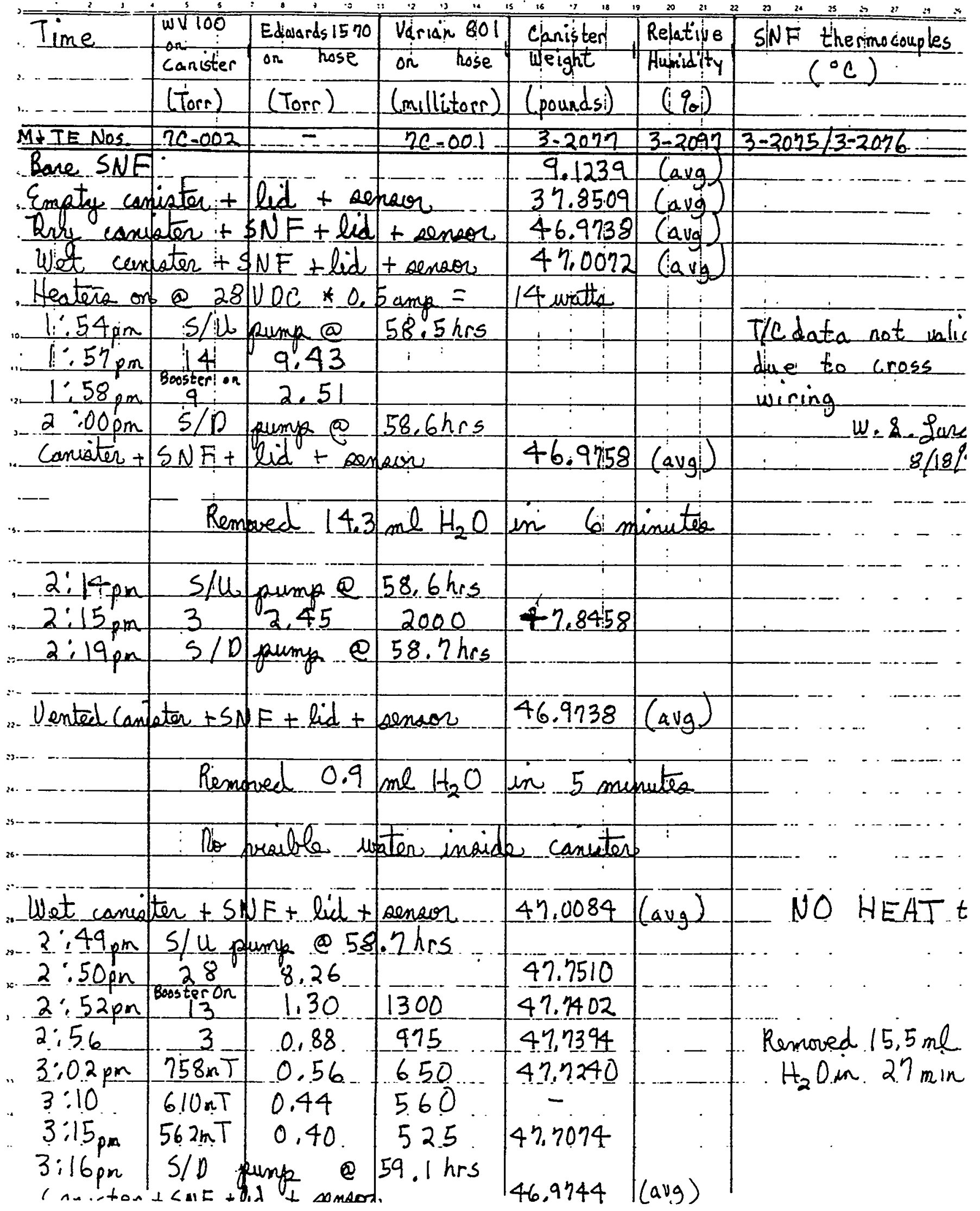


FP-721 Procedure

Caniater + SNF $+297 \mathrm{ml}$ of

$\mathrm{H}_{2} \mathrm{O}$ with no Heat elnput

sancis: W. R. Lange s:

$8 / 25 / 97$

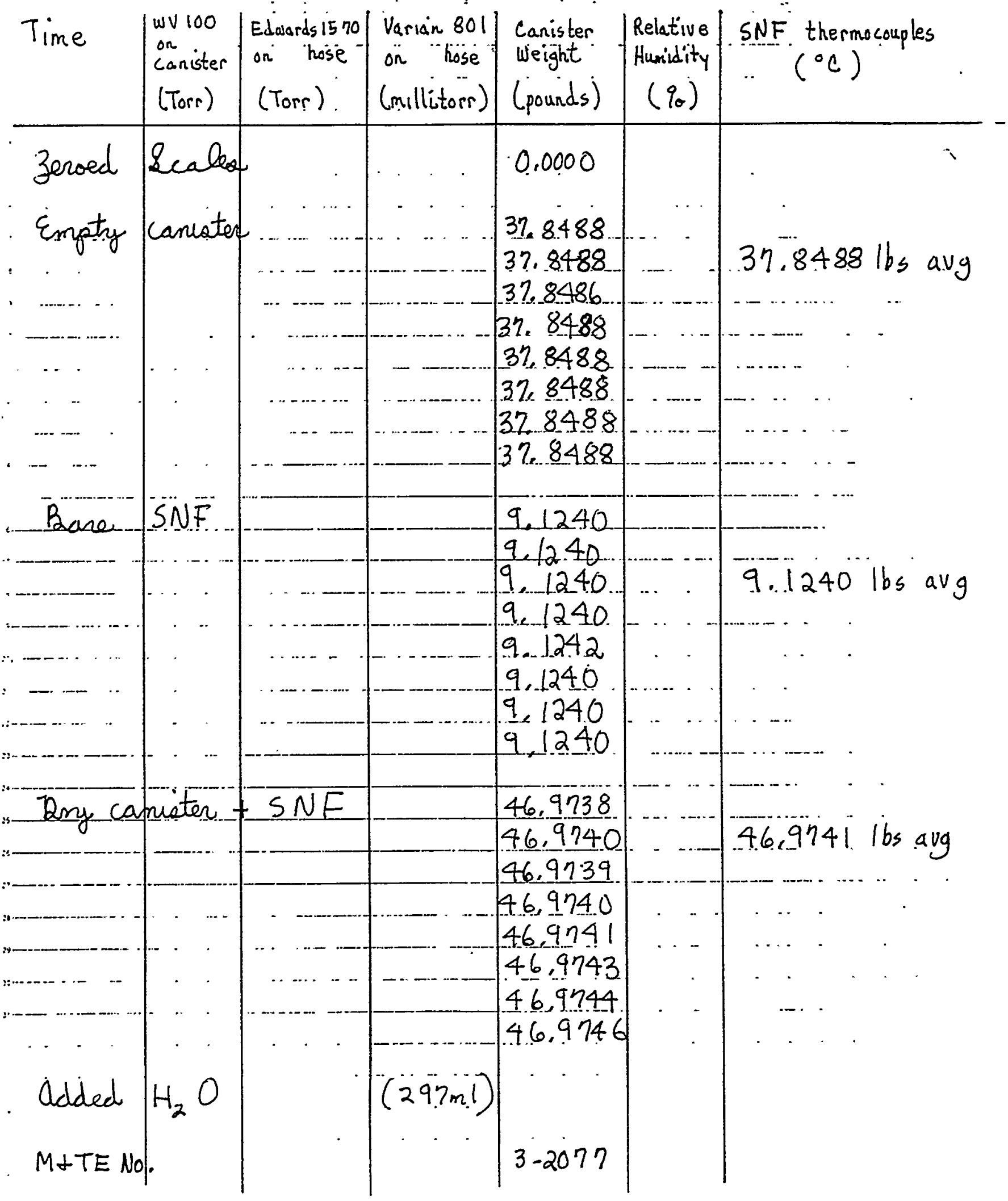


Procedure FP-721

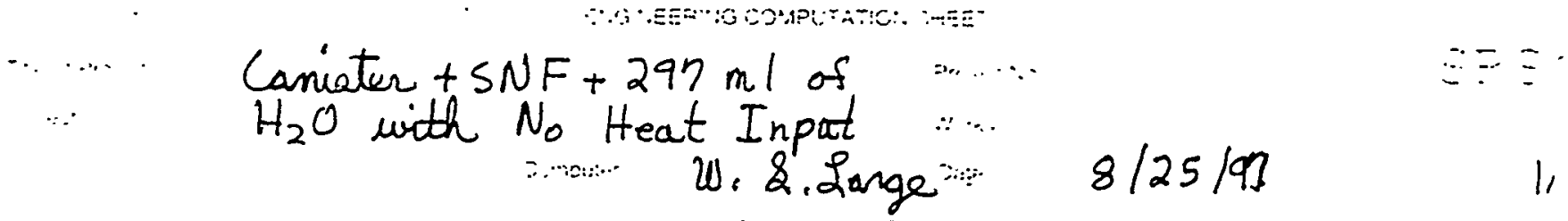

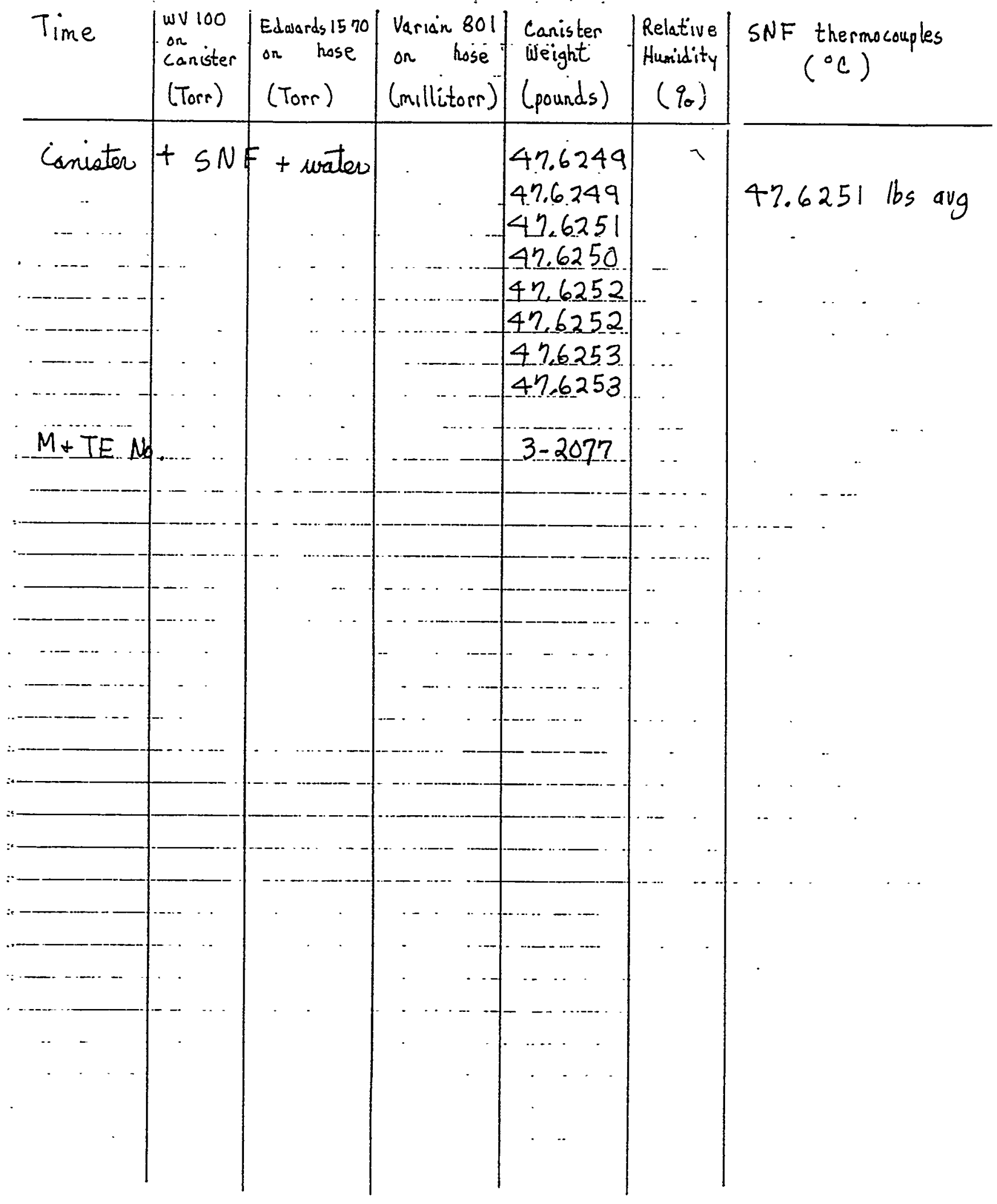


Procedure Fl-721

Canister + $5 N F+29 \eta \mathrm{ml}$ of

$\mathrm{H}_{2} \mathrm{O}$ with no Heat Input

W. R. Lange $8 / 25 / 97$ (Mon)

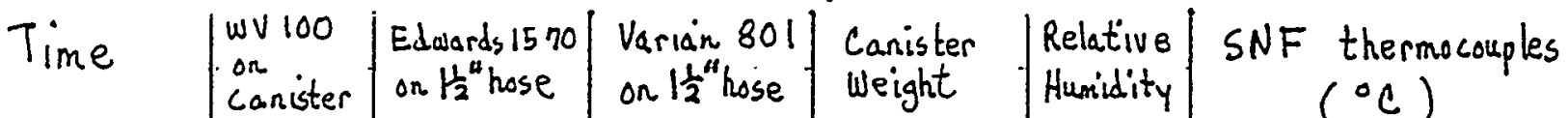

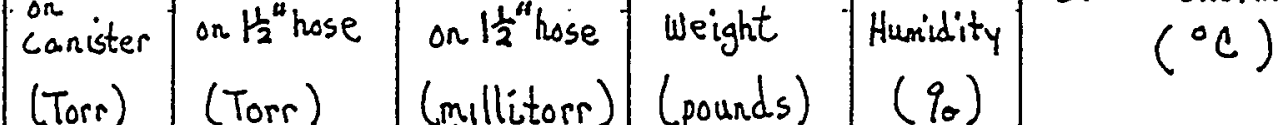

$8: 39 \mathrm{am}$. Start computa data acquivition
$8: 40$
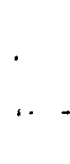
$8: 44$

$8: 44$

8.47

$8: 48$

$8: 50$

$8: 55$

s/u. 16,1 hours

26

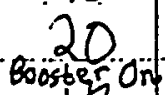

booster

.15

9:00 am

$9: 05$

$9: 10$

$p: 15$

$9: 20$

$9: 30 a$

a. 30 a

. 11

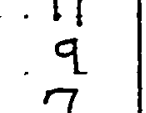

1.3

1,35

1.10

1.03

0,96

0,93

0.91

0.900 .950 48.2475

.........

48.9530

6

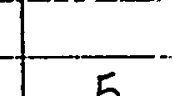

Visiles.

0.87

$9: 40 \mathrm{jm}$

$9=50$ a

lo:00am

10:10 am

$10: 20$ an

$10: 30$ am

$10: 30 \mathrm{am}$

$1.0: 40 a$

$10: 50 \mathrm{am}$

l. l:Dam

0.86

0.85

0.85

0.84

1300

1250

1100

1100

1000

1000

950

48,3950

48.3693

48.3519

48,3470

$48,3.190$

48,3035

48.2836

48.2712

48.2585

950

48.2475

condenpate on

$950-48.2367$

925

925

$48.2067=18.9$

48.1885

48.1720

925.

.925

0.84

925

0.83

Lma

925

5.

MH TE Nos.
0.83

0.82

0.82

ped

.925

925

925

$7 c-001$
48.1545

48.1376

48.1215

ff condeneate

48.1060

48.0895

48.0745

$3-2077$
18.5

18.1

19.5

17.7

17.6 on ecale

17.4

17.3

14.2

$3-2097$
Roon $000^{\circ} \mathrm{F}$

$27.3 / 27.3 \quad 80.5^{\circ}$

$26.3 / 26.2 \quad 79.6$

$23.0122,8 . \quad 74.1$

$21,0 / 208 . \quad 70.3$

$19.7 / 19.5 .67 .2$

$18.0 \% 17.9 \quad 58.7$

$18.3 / 18.2 \quad 53.7$

$1.3 .8 / 19.7 \quad 48.3$

$17.2117 .1 \quad 46.6$

$16.4 / 16.3 \quad 45.1$

$15.6 / 16.4) 44.2$
nister urile

$14.1 / 14.0 \quad 42.6$

$12.7 / 12.6 \quad 42.3$

$11.6 / 11.4 \quad 41.8$

$10.7 / 10.6 \quad 41.5$

$9.8 / 9.7 \quad 41.7$

$9.1 / 9.0 \quad 41.7$

$8.618 .541 .5^{\circ}$

$8.218 .1 \quad 41.1$

$7.8 / 7.7 \quad 41.2$

$7,5 / 7,4$

$3-2075 / 3-2076$ 
Procedure FP-721

Canister + SNF + $297 \mathrm{ml}$ of

$\mathrm{H}_{2} \mathrm{O}$ with no Heat Input

: W. Large jat: $8 / 25 / 97$

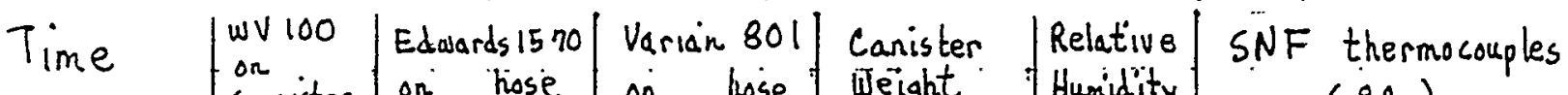
canister on hose on hose Weight. Humidity ( ${ }^{\circ} \mathrm{C}$ )

\begin{tabular}{l|l|l|l|l|l|r|} 
& (Torr) & (Torr) & (millitorr) & (pounds) & $\left(q_{0}\right)$ & Canis \\
\hline & 5 & 0.81 & 925 & 48.0585 & 17.0 & $\eta .21 \eta_{0} 1$
\end{tabular}

11:10an

$11: 20 \mathrm{am}$

$11: 30$ an

$1: 40 \mathrm{am}$

$11: 50$ am

$12: 00.9 \mathrm{~m}$

$12=10 \mathrm{Pm}$

$12 \cdot 20 \mathrm{pm}$

$12=30 \mathrm{gr}$

$12: 40 \mathrm{pm}$

$12:=0$

$1: 00 \mathrm{pm}$

$1: 10 \mathrm{pm}$

$1: 20 \mathrm{pm}$

$1: 30 \mathrm{pm}$

$1=40 \mathrm{pm}$

$1: 50 \mathrm{pm}$

Ed.1510 2:00 pm

started.

dropping

wi: Ippm

$2: 10 \mathrm{pm}$

$2 \div 20 \mathrm{pa}$

2:22pm

$2: 24 p m$

$2: 26$

2:28

2:30

$2: 31$

$2: 32$

2:34

$2: 36$

$2: 38$

$2: 40 \mathrm{gm}$

MLTE NOS.
5
5
5
5
5
5
5
5
4
4
4
4

4

4

4

4

4

3

3

3
3
3
2

3
3
2
$55_{m}$

$1870 \mathrm{mT}$

$1260 \mathrm{mT}$

$1625 n T$

$1515 n^{T}$

$1400 \mathrm{mT}$

$7 C-002$
0.81

0.81

0.81

0.80

0.80

0.80

0.80

0.80

0.80

0.79

0.79

0.79

0.79

0.78

0.78

0.79

0.78

0.78

0.78

0.74

0.71

0.70

0.69

0.68

0.68

0,67

0.65

0.64

0.63

0.61
925

925

900

900

900

900

900

900

900

900

900

900

900

900

900.

900

900

90.0

900

800

800

800

800

800

800

775

750

750

750

725

$7 c-\infty 1$
48.0585

48.0430

48.0285

48.0144

47.9998

47.9858

4.7 .9719

4.7 .9571

47.9428

47.9290

47.9153

47.8980

47.8855

47.8720

47.85

47.8423

47.8285

47,8150

47.7995

47.7855

427834

47.7820

47.7800

47.7780

$47.7760 \quad 7.8$

49.1743

41.1720

47.7695

47,7682

41.766 .5

3-2077

16.7

16.7

16.3

16.1

$15 \cdot 9$

15.7

15.0

9.8

8,8

8.4

8.1

7.8

4.6
$17.07 .2 / 7.1 \quad 40$.

$17.0 \quad 7.0 .17 .0 \quad 39$

16.9

16.4

16.2

15.6

15.4

15.3

15,2

15.2

15.1

15.0

$6.8 / 6.7$

38

$6.6 / 6.5 \quad 38$.

$6.5 \% 16.4 \quad 38$

$6.4+6.4 \quad 38$

$6.4 \% 6.3 \quad 36$

$6.3 / 6.3$.

$6.2 / 6.2$

6.216 .2

$6.1 / 6.1$

$6.2 / 6.1$

$6.2 / 6.2$

$6,2 / 6,2$

$6.1 / 6.0$

$6 \cdot 1 \cdot 16 \cdot 1$

$6.2 / 6.2$

$6.2 / 6.2$

$6.2 / 6,2$

11.6

$6.2 / 6.2$

$6,3 / 6.2$

$6.4 / 6.3$

$6.3 / 6.2$

$6,3 / 6,2$

$6,4 / 6,3$

4

Rm

$85^{\circ} \mathrm{F}$

4.

4

4

4

$5 C$

5

$5 \bar{z}$

53

54

$6.4 / 6.4$

$6,5 / 6.4$

54

$6.7 / 6.6 \quad 55$

$6,7 / 6,6$

56

5,0

$6.8 / 6,7$

$5 k$ 
Procedure Fp-721

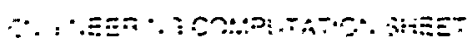

$\therefore: \cdots:$ Canister + SNF + $297 \mathrm{ml} \cdots \cdots$

$\because \quad \mathrm{H}_{2} \mathrm{O}$ irth no Heat Input $\because \cdots s$

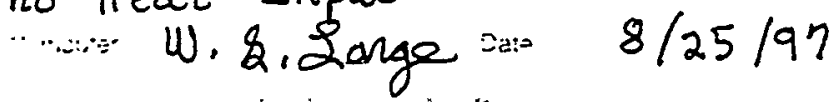

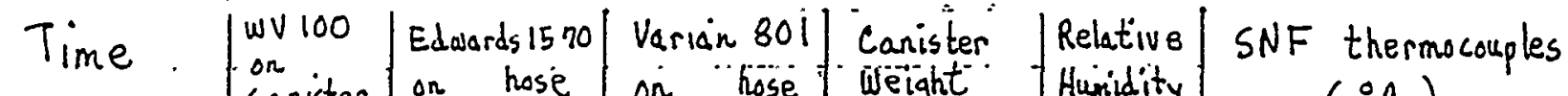

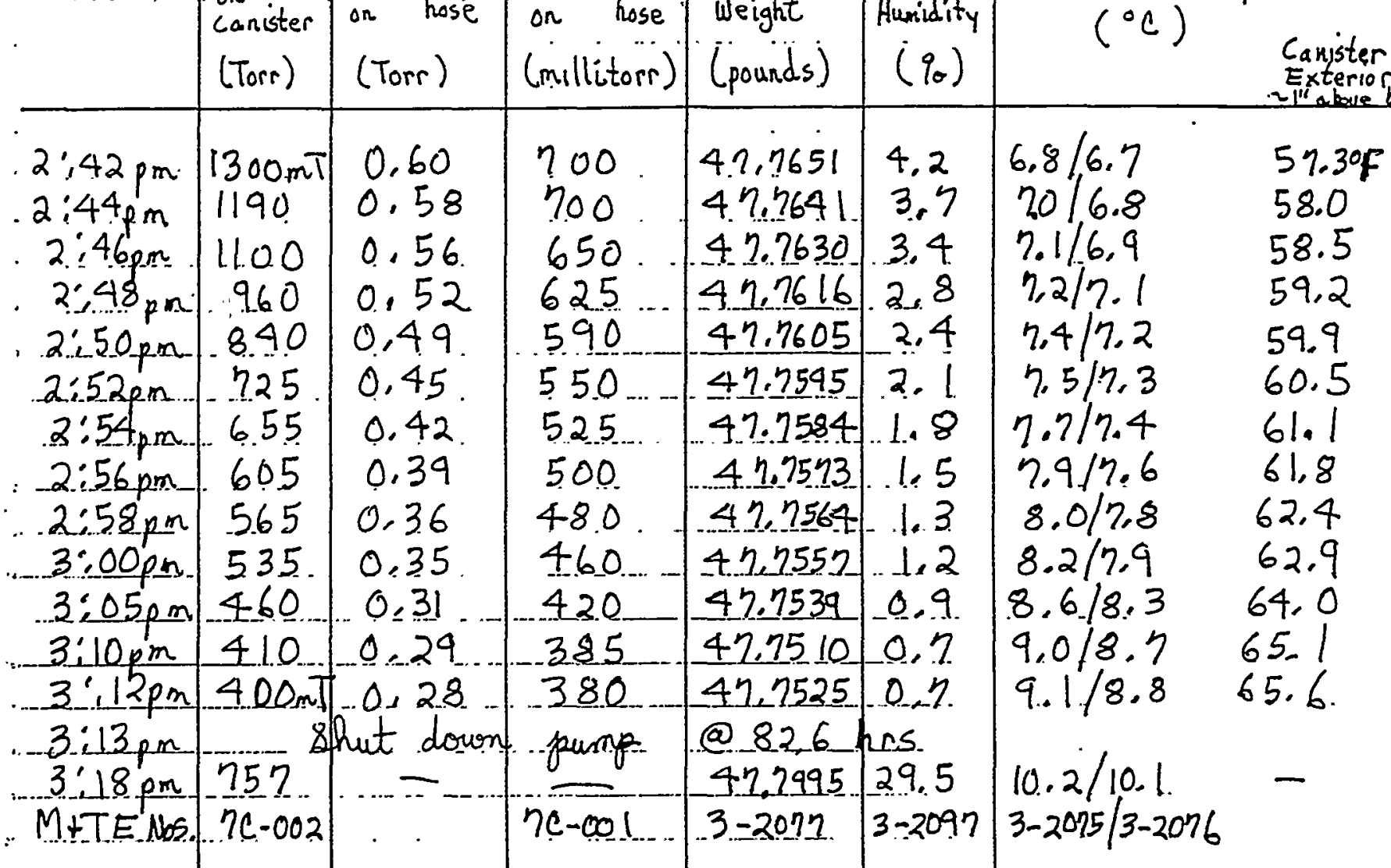

Remove 297 m $(0.6$ fint $)$ of $\mathrm{H}_{2} \mathrm{O}$ in 6.5 hours with so

SNF anface temperstifre drupped v210 duning drying -

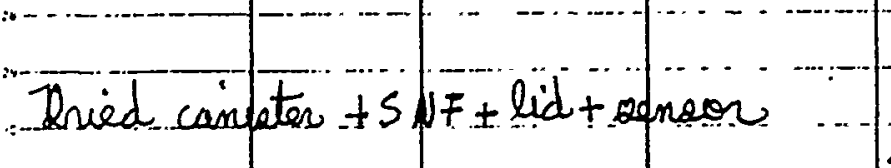

46.9755 46.9753

46.9752

46.975 .6

46.9754

46.9750
46.9753 lbs avg 
Procedure FP- 721

$\therefore \quad$ Canister +5NF+297m.l

$\mathrm{H}_{2} \mathrm{O}$ with no Heat Input corn.... Large $8 / 25 / 97$

4

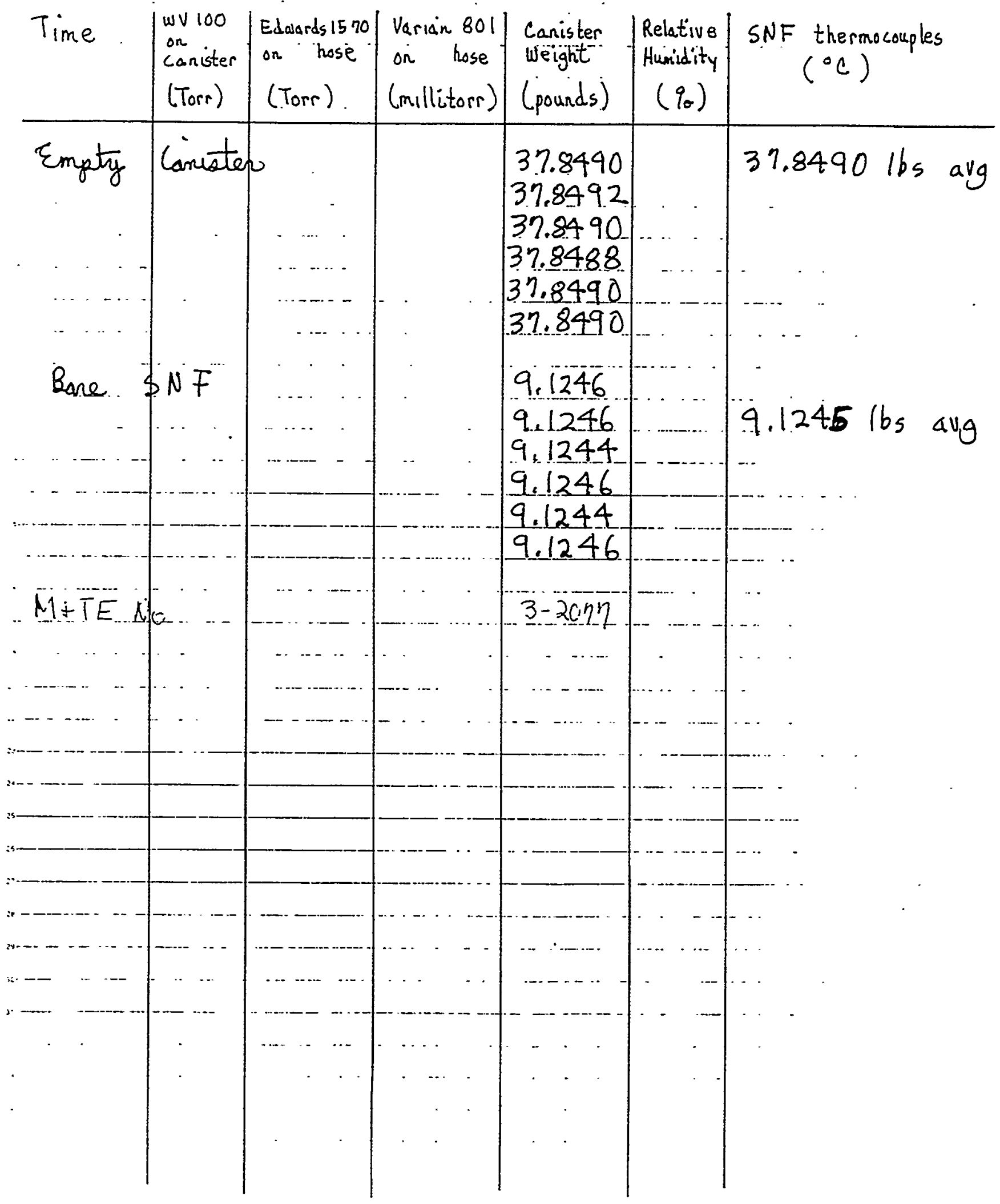




\section{WESTINGHOUSE SAVANNAH RIVER CO. Report WSRC-TR-97-00269}

\section{DISTRIBUTION \\ SAVANNAH RIVER SITE}

I. B. New, 704-C (w/o appendices)

G. H. Clare, 704-C (w/o appendices)

M. W. Barlow, 704-C (w/o appendices)

C. E. Anderson, DOE-SR, 704-K (w/o appendices)

S. Wood, 773-A (w/o appendices)

G. T. Wright, 773-A (w/o appendices)

C. R. Wolfe, 773-A (w/o appendices)

J. D. Cohen, 773-A (w/o appendices)

T. L. Capeletti, 773-41A (w/o appendices)

W. A. Condon, 705-K (w/o appendices)

E. R. Conatser, 704-C (w/o appendices)

M. E. Dupont, 707-C (w/o appendices)

S. W: O'Rear, 707-C (w/o appendices)

J. R. McEntire, Jr., -707-C (w/o appendices)

R. J. Skwarek, 704-C (w/o appendices)

D. C. Wood, 704-C (w/o appendices)

S. D. Burke, 707-C (w/o appendices)

S. R. Smith, 707-C (w/o appendices)

B. D. Clark, 707-C (w/o appendices)

J. C. Guy, 707-C (w/o appendices)

S. L. Tibrea, 773-A (w/o appendices)

M. A. Kyle, Jr., 723-A (w/o appendices)

J. B. Jenkins, 723-A (w/o appendices)

R. P. Addis, 773-A (w/o appendices).

J. Brotherton, 730-2B (w/o appendices)

N. C. Iyer, 773-A (w/o appendices)

M. R. Louthan, Jr., 773-A (w/o appendices)

H. B. Peacock, Jr, 773-A (w/o appendices)

P. S. Lam, 773-41A (w/o appendices)

C. Holding-Smith, $773-42 \mathrm{~A}$ (w/o appendices)

S. Lee, 773-42A (w/o appendices)

N. K. Gupta, 773-42A (w/o appendices)

J. F. Zino, 730-B (w/o appendices)
J. R. Murphy 707-C

W. B. Epling, Jr., 705-K.

R. R. Reichel, 244-H

D. G. Blanchard, 105-L

W. S. Large, 707-C

D. J. Pak, 773-A

P. J. French, 723-A

R. F. Eakle, Jr., 723-A

K. Chen, 773-A

S. J. Nathan, 730-2B

W. F Ayres, 773-41A

R. L. Sindelar, 773-41A

Records, 773-51A 